استراتيجية مقترحة لإدارة عمليات الأمن المعلوماتي بمدارس التعليم

$$
\text { الثانوي الصناعي بـ ج·م·•ع. }
$$

إعداد: د. ولاء السيد عبد الله السيد صقر

\title{
"ملخص البحث"
}

يساعد التخزين الآمن للمعلومات والبيانات المدارس على استعادة قدراتها بسهولة ويسر ، وخاصةً بعد الازمات التي قد تمر بها المؤسسات التعليمية، إذ أن التخزين الآمن للبيانات والمعلومات يتيح لمتخذي القرار استرجاع البيانات والمعلومات اللازمة لاستعادة النظام حيث تظل بيانات أعضاء هيئة التدري، والطلاب، والنتائج النهائية للطلاب، وسجلات ميزانية المدرسة، وامكاناتها من معامل وأجهزة، وتقارير أداء الإداريين والمعلمين، وعقود الشراكة بين المدارس وغيرها من الهيئات،

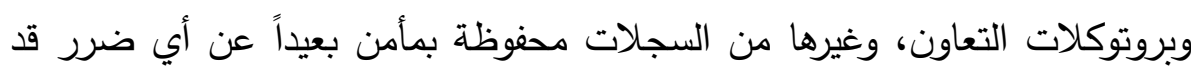
تكون الأزمة قد تسبيت فيه.

وتعتبر المدارس الثانوية الصناعية من أكثر المؤسسات التعليمية تعرضاً للأزمات، وذلك نظراً لأنشطتها وطبيعتها التي تتبع من تعاملها مع أدوات، وأجهزة

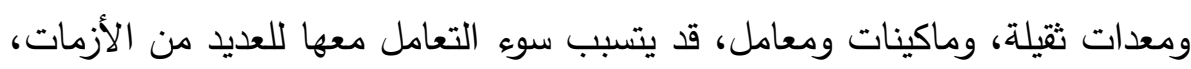
والتي إن لم يتم التنبه لها تتحول إلى كوارث قد تهدد قدرة المدرسة على استمرارية نشاطها، ومن ثم كان هناك بد من الاهتمام بالحفاظ على قواعد بيانات هذا النوع من المؤسسات التعليمية، ومن ثم إدارة عمليات الأمن المعلوماتي بها لسهولة تحقيق نظام معلومات متكامل تستطيع المدرسة الثانوية الصناعية الاعتماد عليه وقت الحاجة. ويشير مصطلح إدارة الأمن المعلوماتي إلى ذلك الإطار من العمل الذي يتضمن عدد من العمليات الإدارية التي من شأنها الحفاظ على أمن المعلومات بالمؤسسة، ومن تلك العمليات تعزيز أمن المعلومات، والحفاظ عليها، وإدارتها، وتنفيذها، الأمر الذي يتطلب بناء السياسات، وصياغة المعايير، والخطط، والإجراءات اللازمة للحفاظ على المعلومات لحين الحاجة إليها. وتتمثل حدود إدارة عمليات الأمن المعلوماتي التي قام البحث بالتعامل معها في عدة عمليات إدارية هي التخطيط، والإتصال، وتدريب العاملين، والتقويم. 
وهدف البحث إلى التوصل إلى استراتيجية مقترحة لإدارة عمليات الأمن

المعلوماتي بالمدارس الثانوية الصناعية بجمهورية مصر العربية، واستخدم البحث أسلوب التحليل الرباعي SWOT Analysis، وفي سبيل تحقيق ذلك تم تطبيق استمارة التحليل الرباعي على عدد من الخبراء التربويين للمساهمة في بناء الاستراتيجية المنشودة. 
إستر ليجية مقترحة لإدارة عمليات الأمن المعلوماتي في مدارس التعليم

الثانوي الصناعي في جمهورية مصر العربية

د. ولاء السيد عبد الله السيد صقر (1)

$$
\text { مقدمة: القسم الأول ـ الإطار العام للبحث: }
$$

يشهد العالم اليوم ثورة تكنولوجية هائلة، انعكست آثارها على مناحي الحياة كافة، ومنها التعليم، الذي يعتبر مرآة المجتمع، وقد سببت تلك الثورة العديد من لون التغيرات بالمؤسسات التعليمية، ومنها المدارس؛ إذ اتجهت الإدارات المدرسية إلى هراه بناء قواعد بيانات وبنوك معلومات ومواقع إلكترونية لها للإعلان عن خدماتها، وتخزين سجلاتها بطريقة آمنة، يسهل استرجاعها عند الحاجة؛ الأمر الذي يساعدها على سرعة اتخاذ القرارات المرتبطة بتطويرها وتحسين خدماتها. كما يساعد التخزين الآمن للمعلومات والبيانات المدارس على استعادة قدراتها بسهولة ويسر، خاصةً بعد الأزمات والكوارث التي قد تمر بها المؤسسات التعليمية، إذ أن التخزين الآمن للبيانات والمعلومات يتيح لمتخذي القرار استرجاع البيانات

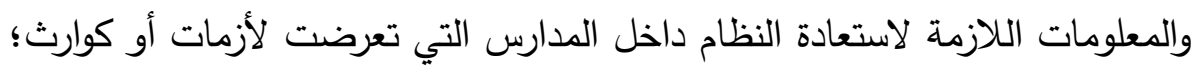
حيث تظل بيانات أعضاء هيئة التدريس، والطلاب، ونتائج الطلاب، وسجلات ميزانية لهابل

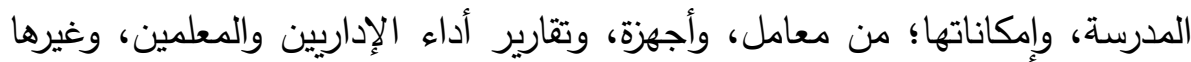
من السجلات، محفوظة بمأمن، بعيدًا عن أي ضرر قد ونكون ونعارير الأزمة أو الكارثة سبيًا

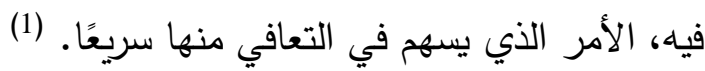

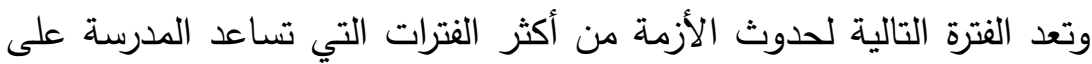
التغلب على السلبيات التي تسببت فيها الأزمة أو الكارثة، وهي بمثابة فترة النقاهة التي يقضيها المريض بعد تعرضه لمرض ما، وتتطلب العديد من الإجراءات والخطوات والممارسات الإدارية التي تساعد المدرسة على استرجاع نشاطها، واستعادة

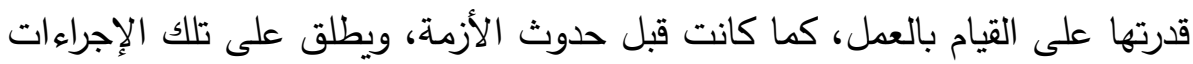
والخطوات والممارسات الإدارية، إدارة التعافي Recovery Management، والتي

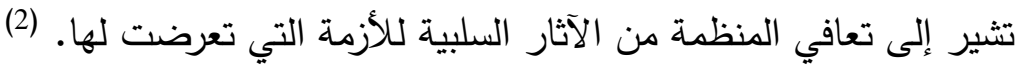

(1) مدرس التربية المقارنة والإدارة التعليمية، كلية التربية ـ جامعة عين شمس. 
وتعتبر المدارس الثانوية الصناعية من أكثر المؤسسات التعليمية تعرضًا

للأزمات، وذلك نظرًا لأنشطتها وطبيعتها التي تتبع من تعاملها مع أدوات وأجهزة

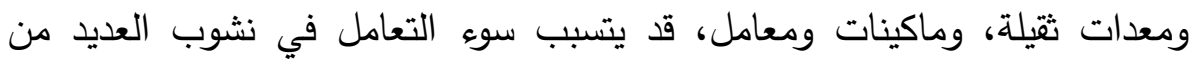

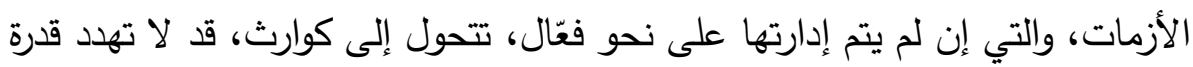

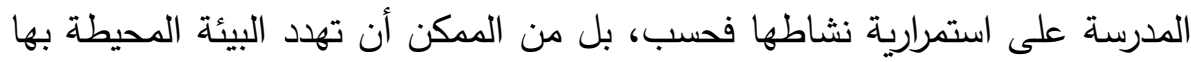
أيضًا، ومن ثم كان هناك ضرورة لتصميم وبناء قواعد بيانات بهذه المدرسة تتيح للفئات المختلفة من الإدارين والمعلمين، استرجاع البيانات والمعلومات أثناء فترة تعافي المؤسسة التعليمية من الأزمة أو الكارثة التي مرت بها. وقد قامت وزارة التربية والتعليم، والتعليم الفني، باستكمال التجهيزات وصيانة

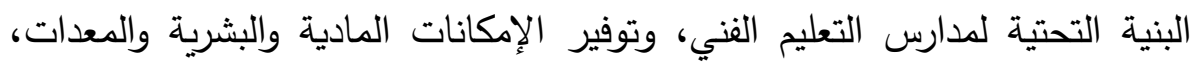
والآلات والخامات اللازمة لدعم العملية التعليمية بها (3)، كما قامت الونئه الوزارة بإمداد

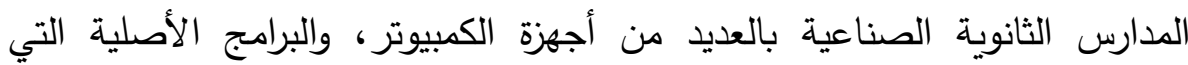
تساعدها على إنشاء قواعد البيانات اللازمة للحفاظ على بيانات أعضاء هيئة التدريس، والإداريين، والطلاب، والإمكانات المادية للمدرسة من أجهزة وميزانية؛ فقد وفرت الوزارة للمدارس الثانوية الصناعية أجهزة كمبيوتر بمكاتب الإداريين، وشئون والإن الطلاب، وشئون العاملين، ومدير المدرسة، وبكل قسم من الأقسام المدرسية، الإداين، بالإضافة إلى إتاحة خدمة الإنترنت في المدرسة، وعمل شبكة داخلية بين أقسام المدرسة، وكذا شبكة تربط المدارس بعضها البعض لتسهيل التواصل وتبادل الخبرة (4)، الأمر الذي يتيح لها التجهيزات التي تمكنها من الحفاظ على معلوماتها واسترجاعها في الوقت الملائم، ومن ثم استعادة نشاطها بسرعة في حالة حدوث الأزمات.

وفي إطار مبادرة تطوير التعليم المصرية الثاملة، قامت الوزارة بالتعاون مع وزارة الاتصالات بتطبيق مشروع "تطوير التعليم الفني باستخدام تكنولوجيا المعلومات والاتصالات"، ويتمثل الغرض من هذا المشروع في الارتقاء بالتعليم الفني والتدريب

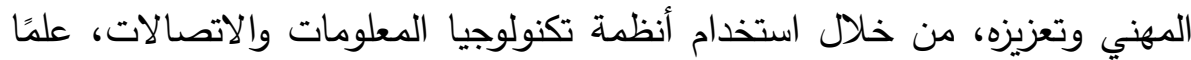
بأن فئات المستقيدين المستهدفة تتمثل في المعلمين والطلاب في المدارس الصناعية، فضلًا عن المجتمع الأكبر المحيط بهذه المدارس. وخلال المشروع، تم تحديث 10 
مدارس مهنية متقدمة في نواحي البنية التحتية لتكنولوجيا المعلومات والاتصالات

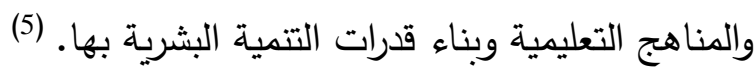

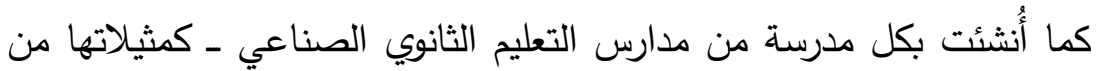

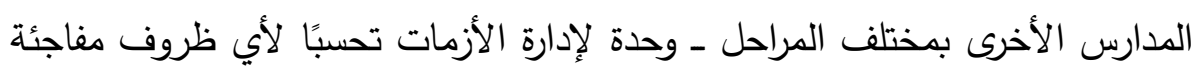

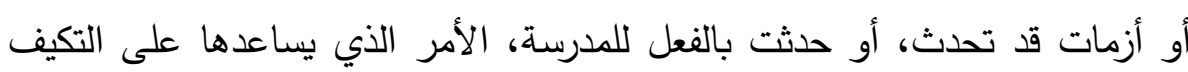

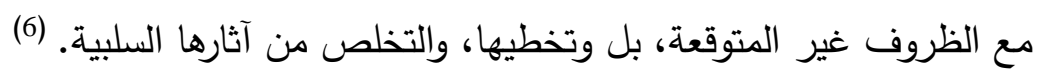
مثكلة البحث:

على الرغم من الجهود التي قامت بها الهيئات المسئولة في مجال التعليم الثانوي الصناعي للتغلب على الأزمات والتعافي منها، والحفاظ على البيانات

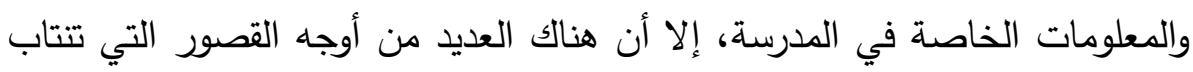

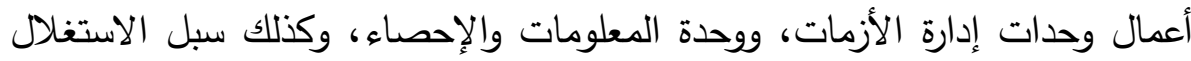

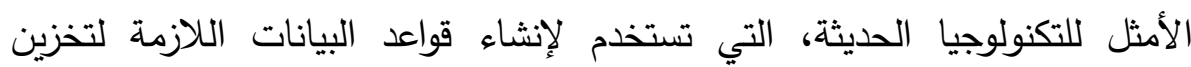

المعلومات والحفاظ عليها، واسترجاعها عند الحاجة إليها، وفيما يلي إيجاز لها:

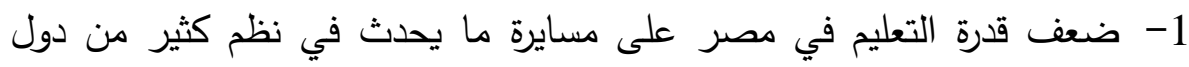

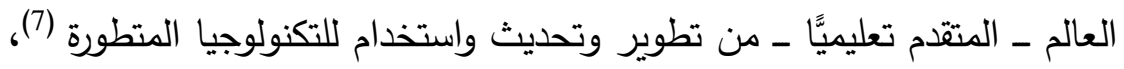
ومن ثم ضعف قدرة المدارس الثانوية الصناعية على استخدام تلك التكنولوجيا بشكل عام، واستخدامها في الحفاظ على أمنها المعلوماتي بشكل خاص.

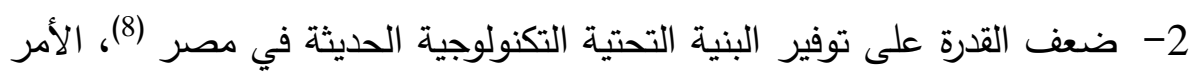

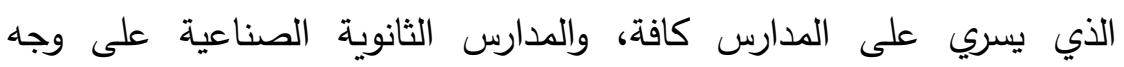
الخصوص، الأمر الذي أدى إلى افتقار المدارس الثانوية الصناعية للبنية التحتية الملائمة التي تسهم في الحفاظ على الأمن المعلوماتي للددرسة، واسترجاع تلك المعلومات وقت الحاجة إليها. 3- محدودية استغلال الإمكانات التي تتيحها تكنولوجيا المعلومات؛ فاستخدامات

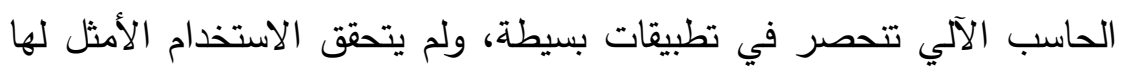
في معظم القطاعات. (9) 4- نقص عدد المتخصصين في مجالات المعلوماتية وعشوائية خبراتهم، وخلفياتهم العلمية. (10) 
5- ضعف المعلومات اللازمة للتعامل مع الأزمة قبل وبعد حدوثها لدى مديري المدارس الثانوية الصناعية، بالإضافة إلى ضعف اهتمامهم بتحديث قاعدة البيانات والمعلومات لاستخدامها وقت حدوث الأزمة أو بعدها. (11) 6- ل ال تسمح إدارة المدرسة الثانوية الفنية للعاملين بالمشاركة في التخطيط المدرسي، إذ إنها لا تطرح المشكلات المدرسية على الثبكة الداخلية للحاسبات الآلية (12)، مما يوضح غياب دور العاملين في التخطيط للحفاظ على الأمن المعلوماتي في المدارس الثانويـة الصناعية، على الرغم من إنها الفئة الأقرب قربًا من الواقع وإدراكًا لمشكلاته. ويمكن تحديد مشكلة البحث في السؤال الرئيس التالي: كيف يمكن التوصل إلى إستراتيجية مقترحة لإدارة عمليات أمن المعلومات في المدارس الثانوية الصناعية في جمهورية مصر العربية؟ إنها ويتفرع من السؤال الرئيس السابق، الأسئلة الفرعية التالية: 1- ما الأسس النظرية لإدارة عمليات الأمن المعلوماتي في المدرسة الثانوية الصناعية من منظور الأدبيات الإدارية المعاصرة؟ الإده 2- ما جوانب القوة والضعف المرتبطة بإدارة عمليات الأمن المعلوماتي في المدارس الثانوية الصناعية في جمهورية مصر العربية؟ 3- ما الفرص والتهديدات المرتبطة بإدارة عمليات الأمن المعلوماتي في المدارس الثانوية الصناعية في جمهورية مصر العربية؟ 4- ما الإستراتيجية المقترحة لإدارة عمليات الأمن المعلوماتي في المدارس الثانوية

الصناعية في جمهورية مصر العربية؟ أهداف البحث: تتمثل أهداف البحث فيما يلي: الهي: 1- الوقوف على الأسس النظرية لإدارة عمليات الأمن المعلوماتي في المدارس الثانويـة الصناعية في الأدبيات الإدارية المعاصرة. 2- التعرف على جوانب القوة والضعف المرتبطة في إدارة عمليات الأمن المعلوماتي في المدارس الثانوية الصناعية في جمهورية مصر العربية. 
3- التعرف على الفرص والتهديدات المرتبطة في إدارة عمليات الأمن المعلوماتي

في المدارس الثانوية الصناعية في جمهورية مصر العربية.

4- التوصل إلى إستراتيجية مقترحة لإدارة عمليات الأمن المعلوماتي في المدارس

الثانوية الصناعية في جمهورية مصر العربية.

$$
\text { أهمية البحث: }
$$

تتبع أهمية البحث من كونها ترتبط في المدرسة الثانوية الصناعية التي تقع في بؤرة تركيز المسئولين عن التعليم بصفة عامة، لما لها من دور هام في النهوض بالاقتصاد المصري. كما أن هذا البحث يركز على قضية هامة وهي قضية الأمن المعلوماتي، تلك القضية التي تتواكب مع اهتمام الدولة بالتكنولوجيا، واستثمارها وتوظيفها في كافة قطاعات الدولة، ومن بينها قطاع التعليم. مصطاح البحث: تتحدد المصطلحات الأساسية للبحث فيما يلي:

1. التعليم الثانوي الصناعي Industrial Secondary Education: هو جميع أنواع التعليم المتعلق بالصناعة، بما في ذلك الفنون الصناعية وتعليم المهن الصناعية على كل المستويات. (13) 2. الأمن المعلوماتي Information Security: هو حماية المعلومات وأنظمة المعلومات من الدخول العشوائي (غير (غنائ المراقب)، أو الاستخدام غير المرشد، أو الكثف عن تلك المعلومات لغير المعنيين،

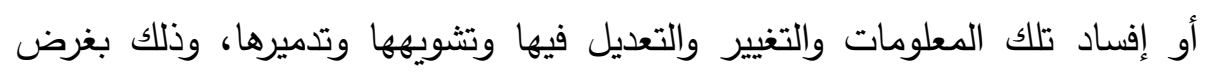
الحفاظ على ثقة المستخدمين في المنظمة، وسلامة المنظمة، وقدرتها على إفادة الآخرين. (14) كما أنه يستخدم للتعبير عن العملية التي تضمن الحفاظ على المعلومات الخاصة بأي منظمة أو مشروع، وحمايتها من السطو أو التعديل أو التغيير بدون إذن، أو الاستخدام غير المصرح به، الأمر الذي يسهم في استمرارية ثقة المستفيدين في المنظمة، وسلامتها، والقدرة على استرجاع تلك المعلومات عند حاجة المنظمة إليها. (15) 


\section{3. إدارة الأمن المعلوماتي Information Security Management:}

هي إطار من العمل يتضمن عددًا من العمليات الإدارية التي من شأنها الحفاظ على أمن المعلومات بالمؤسسة، ومن تلك العمليات تعزيز أمن المعلومات، والحفاظ عليها، وإدارتها، وتتفيذها. الأمر الذي يتطلب بناء السياسات، وصنياغة المعايير والخطط، والإجراءات اللازمة للحفاظ على المعلومات لحين الحاجة إليها.

كما عرفت بأنها "تلك المدخل الفعّال لإدارة أمن المعلومات باستمرار وبفاعلية،

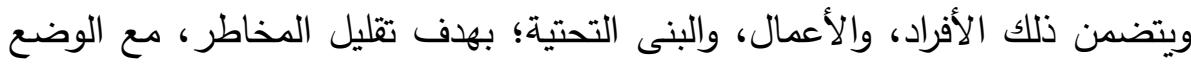

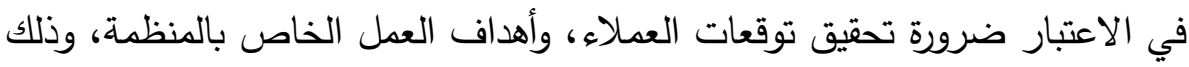

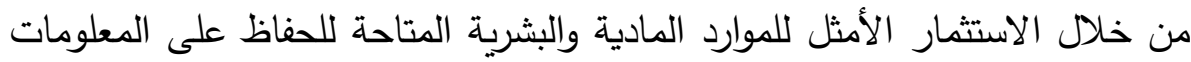
واسترجاعها وقت الحاجة، ومن ثم حماية المنظمة من المخاطر والأزمات التي قد الد تتعرض لها". (17)

وهي كذلك "التخطيط والتطبيق للبنى والعمليات التي تساعد على الترابط والتوازن بين إستراتيجية الأمن المعلوماتي وبين أهداف العمل، والقوانين المطبقة،

$$
\text { والمعايير التي تحكم المنظمة". (18) }
$$

وبناءً على ما سبق، يتضح أن إدارة الأمن المعلوماتي تتلخص فيما يلي:

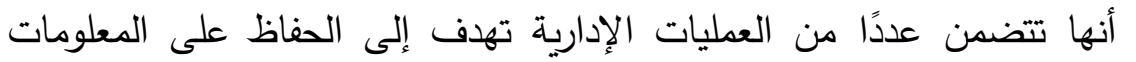

$$
\text { الموجودة في المدرسة. }
$$

• أنها لكي تقوم بدورها وتحقق أهدافها يلزمها عدد من المتطلبات؛ كبناء

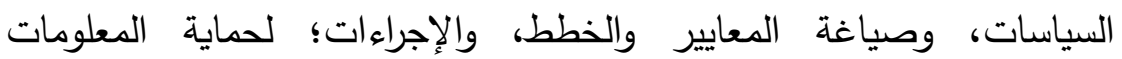

$$
\text { واسترجاعها وقت الحاجة. }
$$

أنها مدخل يقوم على الاستمرارية وتحقيق الفاعلية، من خلال الاستخدام الأمثل وفتل للموارد المادية والبشرية المتاحة. أنها مدخل شامل يتضمن الأفراد، والأعمال، والبنى التحتية.

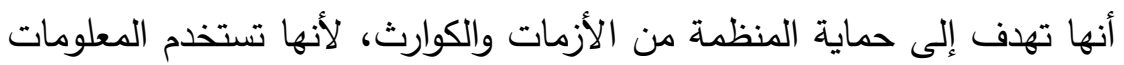

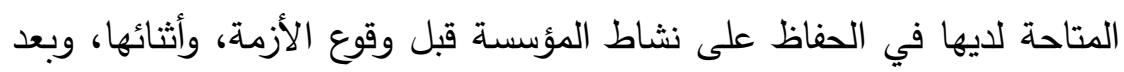
انتهائها. 
ومما سبق يمكن استخلاص التعريف الإجرائي التالي لإدارة الأمن المعلوماتي، وهي: "ذلك المدخل الثامل والفعال الذي يهدف إلى الاستغلال الأمثل

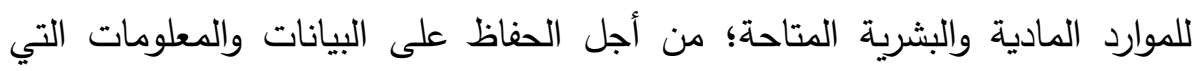
تمتلكها المنظمة؛ لاسترجاعها وقت الحاجة إليها. خاصة في وقت الأزمات والكوارث، المارئ

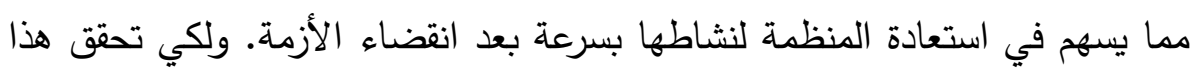

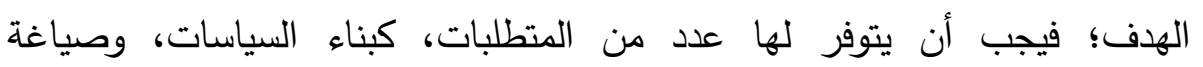
المعايير ، والخطط، والإجراءات؛ لحماية المعلومات واسترجاعها وقت الحاجة إليها".

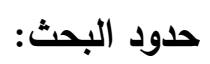
يقتصر البحث على ما يلي:

أولاً - بالنسبة للمرحلة الدراسية، ونمط المدرسة: لئية

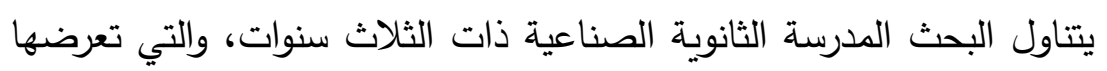
طبيعة العمل فيها للعديد من الأزمات، نظرًا لما تقوم به من تصميم وتخطيط

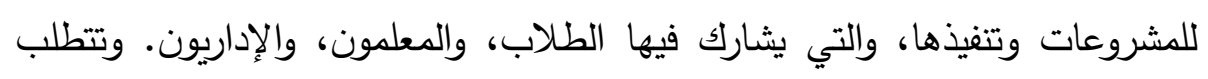

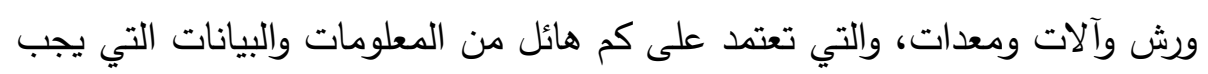

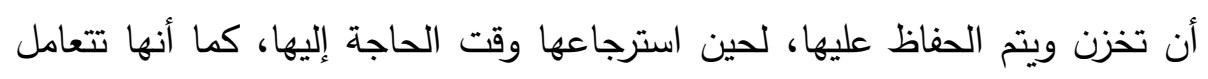
مع طلاب في سن الطفولة، إذ إنها متخرجون حديثًا من الحلقة الثانية من التعليم

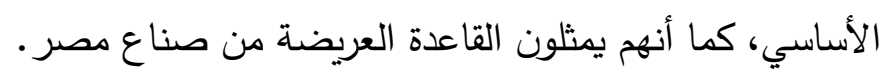
ثانيًا ــ بالنسبة لإدارة عمليات الأمن المعلوماتي: لاعني

يقتصر البحث الحالي على دراسة العمليات التالية: التخطيط لإدارة الأمن المعلوماتي في المدرسة الثانوية الصناعية، والاتصال، وتدريب العاملين على الحفاظ

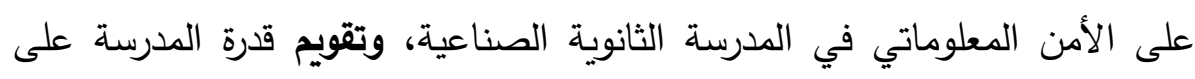
الحفاظ على الأمن المعلوماتي لها، وذلك لقرب تلك العمليات من الأمن المعلوماتي؛

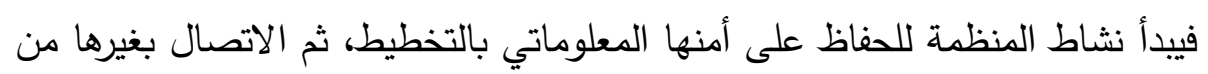

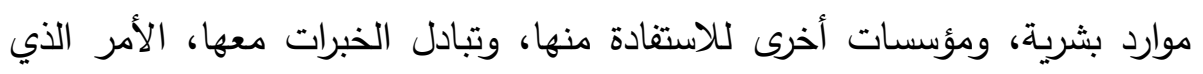

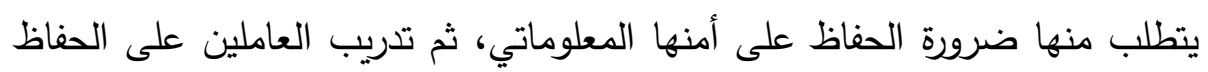
على الأمن المعلوماتي، ثم أخيرًا الوقوف على نقاط القوة والضعف في أداء الماء المدرسة

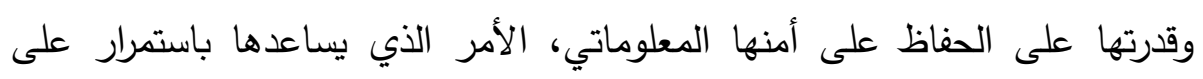


الحفاظ على قدرتها على التعافي من الأزمات التي قد تصيبها، بوصفها من أكثر البيئات التعليمية تعرضًا للأزمات.

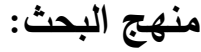

يسير البحث في خطواته وفقًا لخطوات أسلوب SWOT Analysis، الذي يهتم بالاحتمالات المستقبلية لكل من الجوانب الإيجابية والسلبية داخل المنظمة وخارجها، ويعتمد هذا الأسلوب على المعرفة التامة بالوضع الحالي والاتجاهات الحالية، ويساعد في إعداد الخطط والقرارات الإستراتيجية للمنظمة، وتتمثل العناصر الأساسية للتحليل البيئي فيما يلي: ولئه مؤشرات عن البيئة الداخلية للمنظمة: وتشمل تحديد جوانب القوة (S) Strengths، وجوانب الضعف Weaknesses (W)، القائمة بالمنظمة. مؤشرات عن البيئة الخارجية للمنظمة: ويقصد بها القوى والعوامل الخارجية

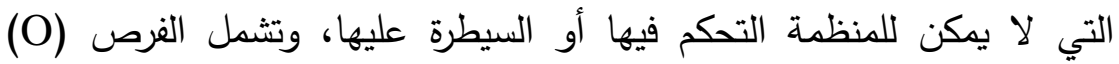
هhreats (T) Opportunities هذه المؤشرات الاتجاهات المستقبلية في مجال عمل المنظمة، والعوامل الاقتصادية، ومصادر التمويل، والخصائص الديمغرافية للمنظمة، والتشريعات، والأحداث المحلية والقومية، والدولية.

وينتج عن تحليل جوانب القوة والضعف الداخلية، والفرص والتهديدات الخارجية، الوصول إلى هدف نهائي، يتمثل في التوصل لإستراتيجية مقترحة

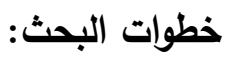
بناء على الخطوات النظرية السالفة، يسير البحث وفقًا للخطوات الإجرائية

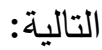
الخطوة الأولى: الإطار العام، ويشمل المقدمة، والمشكلة، والأهداف، والأهمية، والحدود، والمنهج المستخدم، وخطوات البحث. الخطوة الثانية: إدارة عمليات الأمن المعلوماتي في المدرسة الثانوية الصناعية

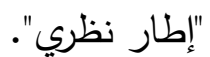


• الخطوة الثالثة: واقع إدارة عمليات الأمن المعلوماتي في المدرسة الثانوية الصناعية بـ ج· م. ع، والتي يتم فيها تحديد جوانب القوة والضعف في البيئة الاخلية، والفرص والتهديدات بالبيئة الخارجية. الخطوة الرابعة: تصميم جدول التحليل الرباعي للخروج بعدة إستراتيجيات لإدارة

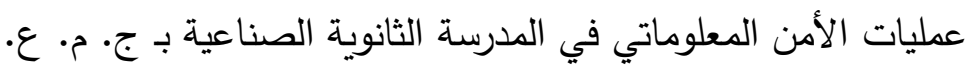

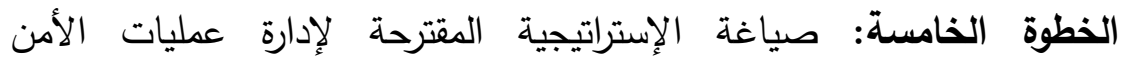

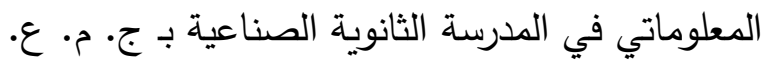
القسم الثاني ـ إدارة عمليات الأمن المعلوماتي في المدرسة الثانوية الصناعية، "إطار نظري": يتتاول البحث في هذا القسم بالتحليل الإطار النظري عن الأمن المعلوماتي في المدرسة الثانوية الصناعية، وذلك وفقًا للمحاور التالية: أولًا: الأمن المعلوماتي في المدرسة الثانوية الصناعية. ثانيًا: إدارة عمليات الأمن المعلوماتي في المدرسة الثانوية الصناعية. وفيما يلي تفاصيل ذلك:

أولًا ــ الأمن المعلوماتي في المدرسة الثانوية الصناعية: تعتمد المدارس بشكل عام على الاحتفاظ بما لديها من معلومات في قواعد الدئ

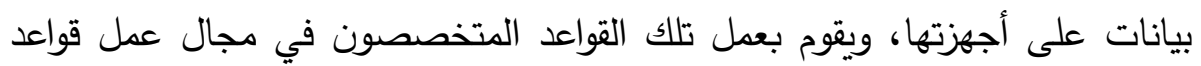
البيانات، وتتنوع قواعد البيانات بين قواعد خاصة ببيانات الطلاب، وأعضاء هيئة لئية التدريس، وميزانية المدرسة، وإمكاناتها المادية والبشرية، وكل ما تمتلكه المدرسة، أو

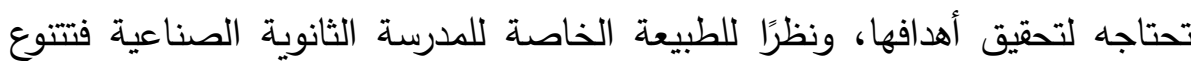
قواعد البيانات الموجودة بها، نظرًا لطبيعتها في الإنتاج، وإعداد الميزانيات، وإعداد دراسات الجدوى، وغيرها من الأمور التي ترتبط بالطبيعة الإنتاجية لتلك المؤسسات.

وتهدف المدرسة الثانوية الصناعية إلى تحقيق ما يلي: الاهورئ (20)

تقديم المعرفة التي تمكن الطلاب من فهم الدور الذي تقوم به التكنولوجيا المتطورة في مجال الصناعة، وتأثيرها على المجتمع والبيئة المحيطة.

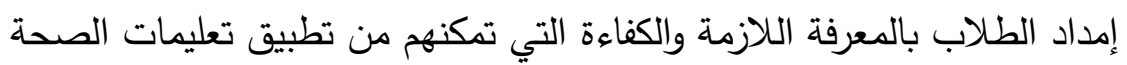
والسلامة والأمن الصناعي، وإدارة المخاطر بشكل عملي. 
• تمكين الطلاب من امتلاك المعرفة والكفاءة في تصميم المنتجات، وعمل

$$
\text { المشروعات العملية. }
$$

وبالنظر إلى هذه المدرسة تتضح الطبيعة الخاصة لها؛ فهي تسعى للقيام بمشروعات، وتسعى إلى تمكين الطلاب من مهارات إدارة المخاطر، نظرًا للاقتناع

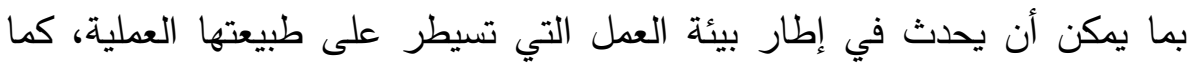
تسعى إلى تصميم المنتجات؛ الأمر الذي يتطلب كمَّا من المعلومات تحسبًا للظروف التي قد تحدث للمدرسة أثناء محاولتها لتحقيق تلك الأهداف.

1. أهداف الحفاظ على الأمن المعلوماتي في المدارس الثانوية الصناعية:

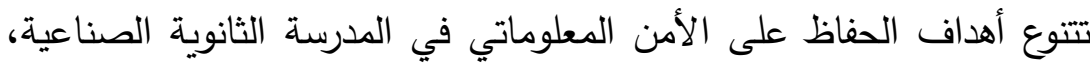
ومن تلك الأهداف ما يلي: (21)

الحفاظ على المعلومات الموجودة في المدرسة من الاستخدام غير الآمن.

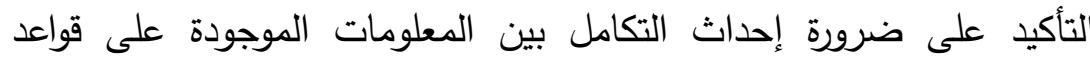

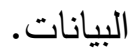

سهولة استرجاع المعلومات وقت الحاجة إليها. ضمان استمرارية العمل من خلال الحفاظ على المعلومات التي يتطلبها إنجاز

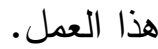
تدريب جميع أعضاء المجتمع المدرسي على حماية بيانات ومعلومات المدرسة بما يضمن سريتها، وسهولة استرجاعها وقت الحاجة. وكما سبقت الإشارة، يعتبر الحفاظ على الأمن المعلوماتي وسيلة لغاية أكبر

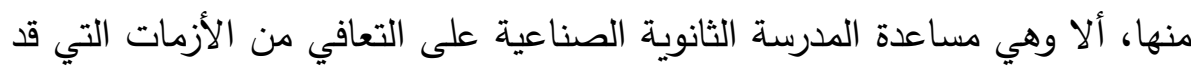

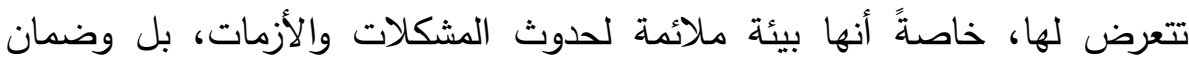

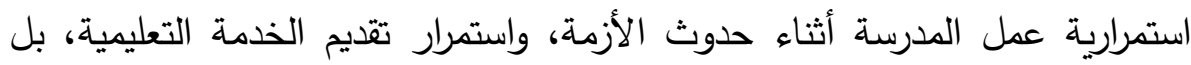
وأيضًا استمرار إنتاجية المدرسة، خاصةً أن طبيعة عمل تلك المدرسة تركز بالدرجة والثة

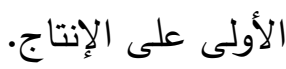


2. الأجهزة المستخدمة للحفاظ على الأمن المعلوماتي في المدرسة الثانوية

الصناعية:

تتنوع الأجهزة المستخدمة للحفاظ على الأمن المعلوماتي في المدرسة، فلا

يستقيم الحفاظ على الأمن المعلوماتي دون وجود مثل تلك الأجهزة، ومنها: (22)

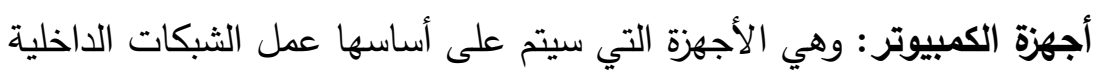
بين الأقسام المختلفة في المدرسة، والثبكات التي تربط المدرسة بما خارجها، سواء بالمجتمع الخارجي، أو على المستوى الدولي، والتي تتمثل في علاقة المدرسة بالمدارس الأخرى على مستوى العالم، ووفقًا لتلك المهمة ينبغي أن الن التئي

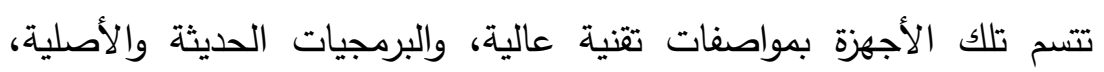
وأيضًا تكون مزودة ببرامج مضادة للفيروسات لحماية الأجهزة من الاختراق قدر الإمكان، مع الحرص على تحديث تلك البرامج باستمرار .

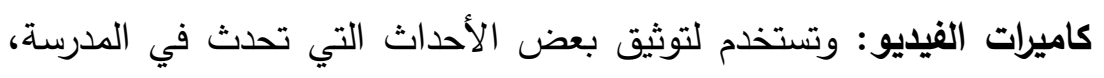

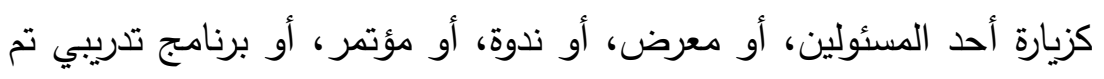

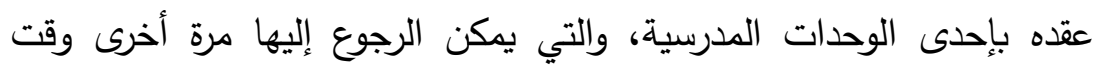
الحاجة للاستفادة بخبرات المدرسة السابقة في مواقف مشابهة.

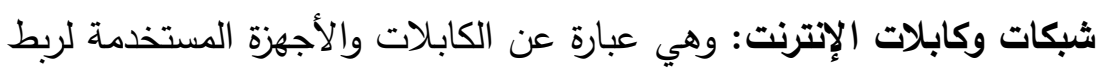

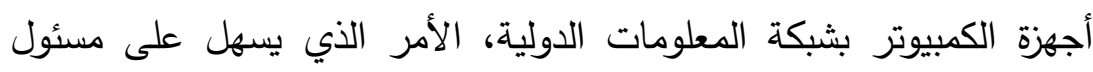

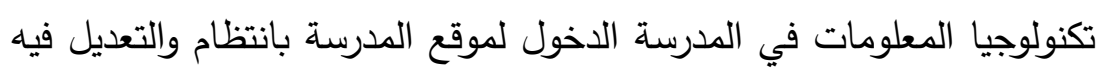

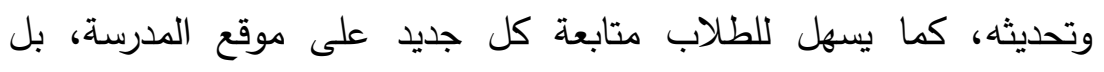
واستخدام هذا التواصل الدولي في التعرف على خبرات مدارس أخرى، وتبادل الخبرة معهم في مجال التخصص. كابلات الثبكات الداخلية: وهي الكابلات المستخدمة لربط الوحدات والمكاتب الموجودة في المدرسة ببعضها البعض؛ بهدف تسهيل التواصل بينهم، والسرعة في إنجاز العمل، بل وتبادل المعلومات بينهم كلما اقتضت الحاجة لذلك. وبالنظر إلى ما سبق، يتضح أن هناك بنية تحتية يجب أن تتوافر لتحقيق

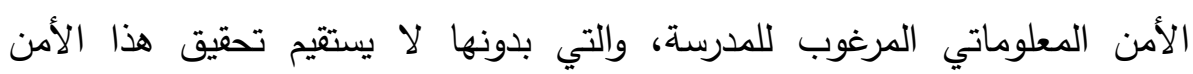


المعلوماتي، ومن ثم على إدارة المدرسة الثانوية الصناعية توفير تلك الأجهزة

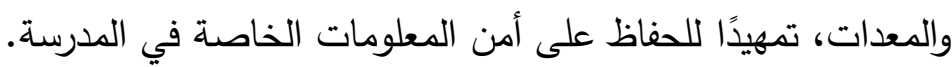

3. متطلبات الحفاظ على الأمن المعلوماتي في المدارس الثانوية الصناعية: هناك عدة متطلبات يجب أن تتوافر لتحقيق الأمن المعلوماتي في المدرسة،

$$
\text { ومن تلك المتطلبات ما يلي: (23) }
$$

الموارد البشرية المدربة على استخدام وسائل التكنولوجيا المختلفة.

برامج تدريبية للموارد البشرية للتعرف على كل جديد في مجال الحفاظ على لـى

$$
\text { المعلومات واستردادها. }
$$

كتيبات إرشادية توضح للجميع أهمية الحفاظ على الأمن المعلوماتي في المدرسة توزع على مسئولي الوحدات المختلفة.

إدارة إلكترونية واعية بأهمية الحفاظ على دقة المعلومات وسريتها. تغيير كلمة السر الخاصة بالأجهزة والموقع الإلكتروني من آن لآخر .

تصنيف المعلومات الموجودة في المدرسة وفقًا لطبيعتها والهدف منها. ومما هو جدير بالذكر أن الأجهزة لا تعتبر هي المتطلب الوحيد للحفاظ على لئل

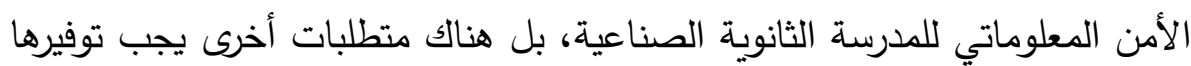
لتحقيق الأمن المعلوماتي المطلوب، الأمر الذي يتطلب في المقام الأول إدارة واعية بتلك المتطلبات لتوفيرها في المدرسة، حتى يمكن تأدية مهمة الحفاظ على الأمن المعلوماتي بفاعلية عالية.

4. آليات الحفاظ على الأمن المعلوماتي في المدارس الثانوية الصناعية: يعتبر الحفاظ على بيانات المدرسة الثانوية الصناعية واستخدامها على نحو المن جيد من أهم أدوات الوصول إلى جودة أداء المدرسة، واستمرارية أعمالها في وقت حدوث الأزمات والطوارئ، ويتطلب الحفاظ على الأمن المعلوماتي في المدرسة المداء الثانوية الصناعية تبني مجموعة من الآليات المحددة، والتي يمكن إجمالها فيما يلي: • توفير البنية التحتية ذات الكفاءة العالية لتدعيم الاستخدام الآمن لتكنولوجيا

\section{المعلومات:}

لعل الحفاظ على أمن المعلومات لا يقتصر فقط على توفير الأجهزة

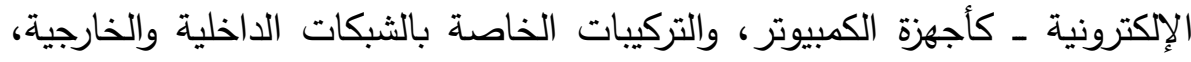


وأطباق الستالايت، وأجهزة الفيديو، والتليفزيون، وإنما يتطلب أيضًا الكفاءة العالية لتلك

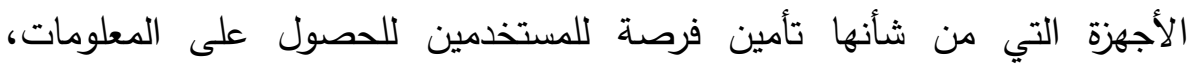

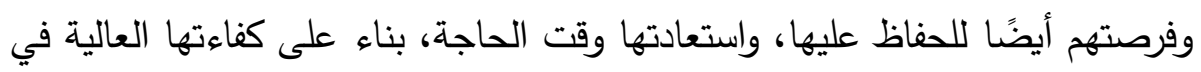
الاحتفاظ بالمعلومات وحمايتها من الدخلاء. (24) وبالنظر إلى الطبيعة الخاصة للمدرسة الثانوية الصناعية، يلاحظ أن بها عدداً ليس بالقليل من المعلومات التي يجب الحفاظ عليها، كالميزانية، والمشروعات التي ينجزها الطلاب، والإيرادات، والمصروفات، وقواعد البيانات الخاصة بالطلاب،

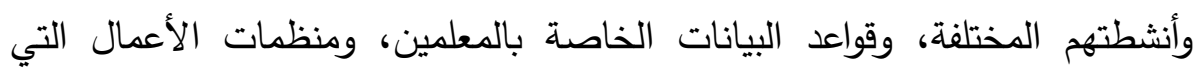
بإمكانها الاستفادة من منتجات تلك المدارس، واتفاقيات الثراكة بين المدارس الثانوية

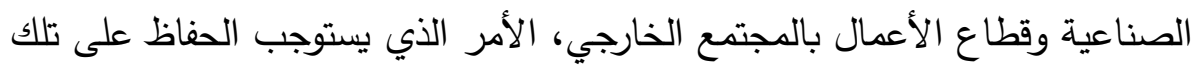

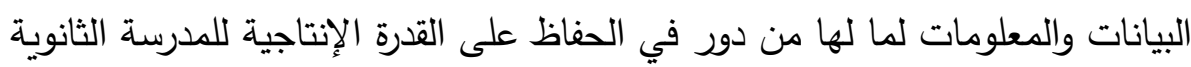
الصناعية، بالثكل الذي يحافظ على أدائها التعليمي، وقدرتها الإنتاجية. إثراك الطلاب في الحفاظ على الأمن المعلوماتي في المدرسة:

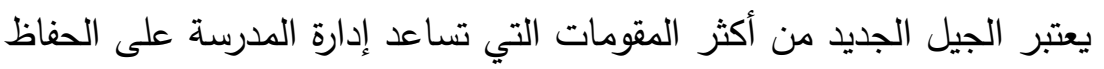
على أمنها المعلوماتي، وذلك بالاستعانة بهم وبخبراتهم في التعامل مع الأجهزة الإلكترونية الحديثة، ومواقع التواصل الاجتماعي، التي يتبنون من خلالها كافة

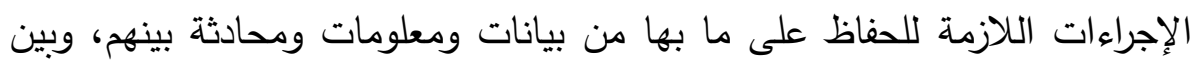
زملائهج، والتي من الممكن أن يكون لها وزنها، ويمكن الاستعانة بها في مساعدة المدرسة على تأمين معلوماتها، الأمر الذي يشعرهم بأهمية ما يقومون به من من أعمال

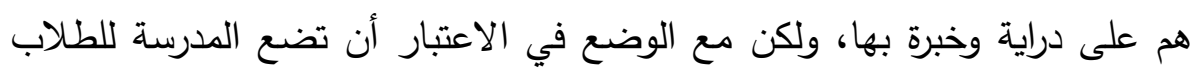
القواعد والقوانين التي يعملون في إطارها. (25)

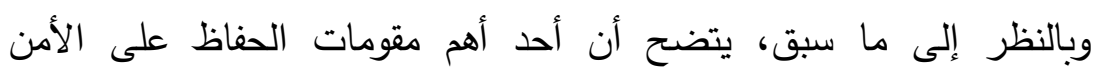

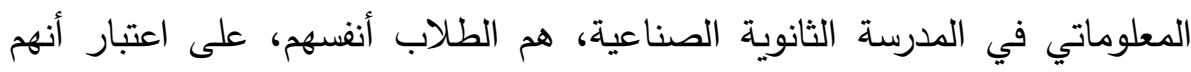
المخرج الأساسي للمدرسة، كما أنهم في مرحلة عمرية تتميز بالتحدي، والرغبة في

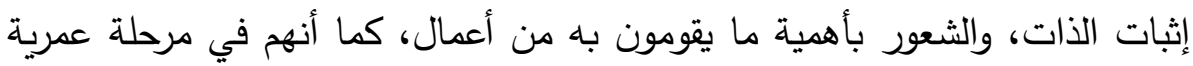

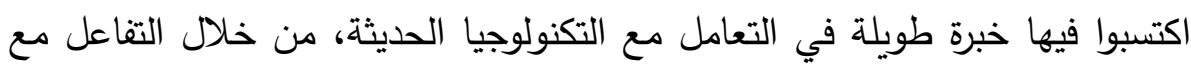

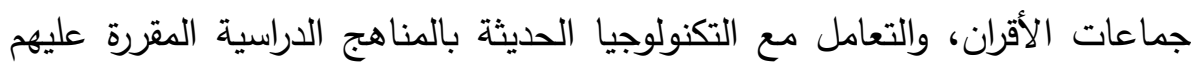


منذ بدء التحاقهم بالمدرسة، وحتى وصولهم إلى المدرسة الثانوية، الأمر الذي انعكس

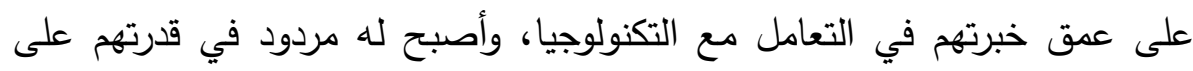
تقديم الحلول والمقترحات والتوصيات في الحفاظ على الأمن المعلوماتي لما تمتلكه المدرسة الثانوية الصناعية من معلومات يجب الحفاظ عليها، لضمان استمرار تقديم

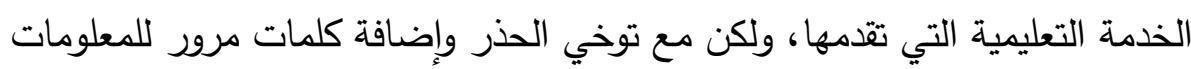

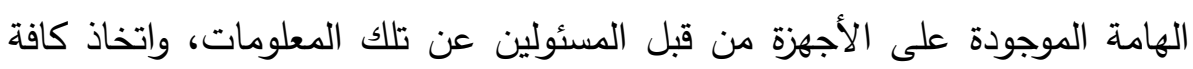

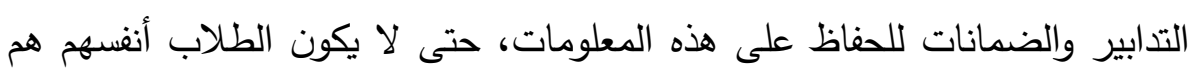
السبب الأساسي وراء اختراق المعلومات الهامة للمدرسة.

كما يمكن إضافة الآليات التالية: (26)

الحفاظ على أمن البربد الإكتروني الخاص باليات المدرسة:

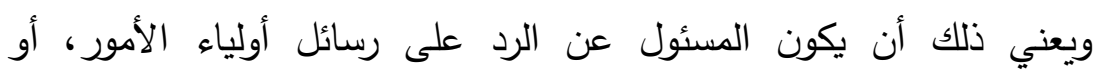

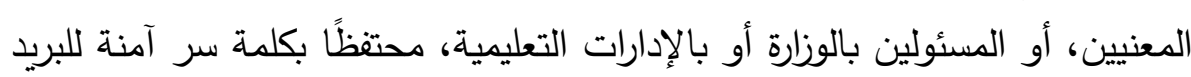

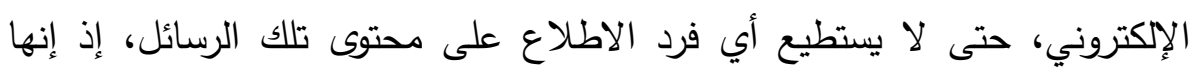

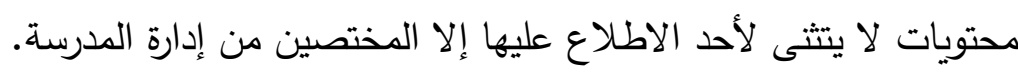
ومن ثم يجب أن يكون ذلك الثخص هو شخص واحد، بحيث لا يمكن لأحد

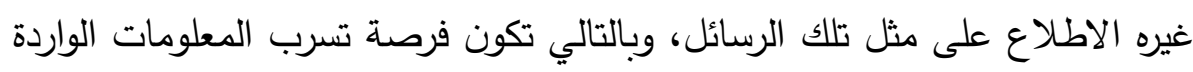
بتلك الرسائل ضئيلة، إن لم تكن معدومة، ويكون دوره محصورًا في نقل محتويات

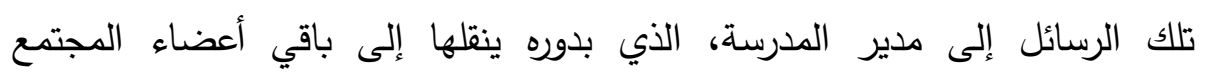
المدرسي، كل فيما يخصده، وما يفيد إنجازه للعمل.

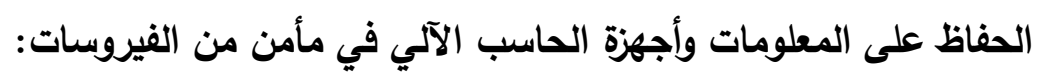

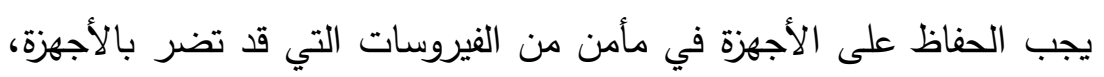

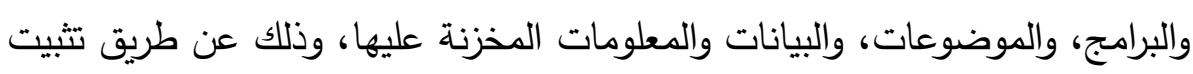
برامج أصلية لمقاومة الفيروسات؛ حتى يسهل تحديثها باستمرار، فيكون الجهاز

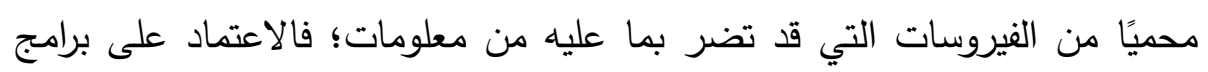

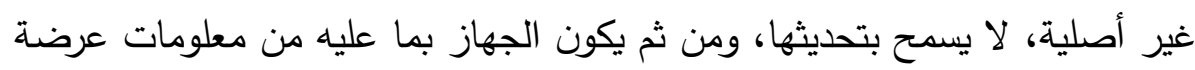

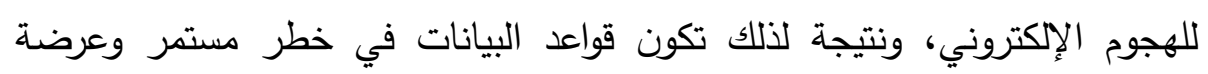
للضياع أو التلف أو السرقة. 


\section{الحفاظ على الموقع الإكتروني الخاص بالمدرسة من الاختراق:}

يستخدم موقع المدرسة للإعلان عنها، وعن منتجاتها، وقدراتها، ورؤيتها، ورسالتها قبل أي شيء، ولا يجب أن يكون لأي شخص حق الدخول على موقى موقع المدرسة والتعديل عليه غير الشخص المسئول عن تقديم المعلومات للمستفيدين من الخدمة التي تقدمها المدرسة، كما أنه المسئول عن صدق المعلومات المعروضة لزائري الموقع. وبالتالي تضمن إدارة المدرسة أكبر قدر ممكن من مصداقية المعلومات المعروضة عن المدرسة، والتي تصل إلى المستثيدين من خدماتها كافة. • وضع كلمة مرور آمنة لأجهزة الكمبيوتر الموجودة في المدرسة: تحتوي أجهزة الكمبيوتر الموجودة في المدرسة على بيانات ومعلومات تتسم لاهره بالسرية، ولا يجب أن يتمكن أي فرد من غير المسئولين من الدخول على الكمبيوتر ،

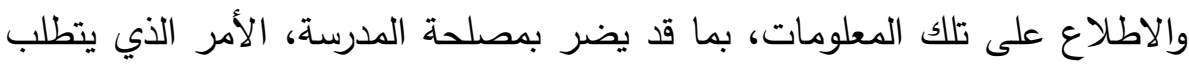
من كل موظف يستخدم جهاز كمبيوتر في مجال عمله، أن يقوم بعمل كلمة مرور

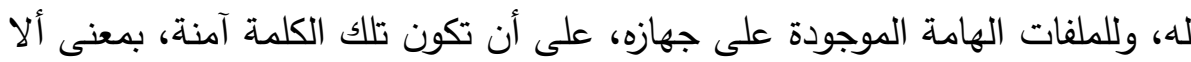

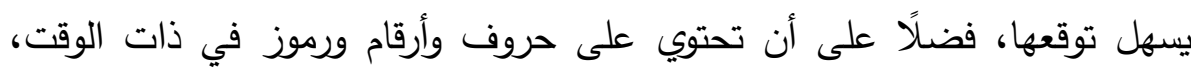

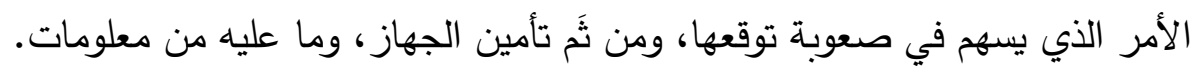

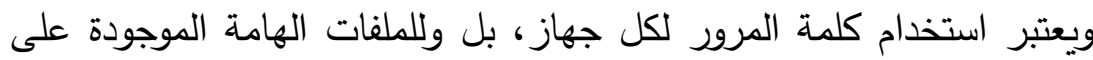
الأجهزة ـ خاصةً وإن كان لجهاز الكمبيوتر الواحد أكثر من مستخدم ـ من أكثر ولثر

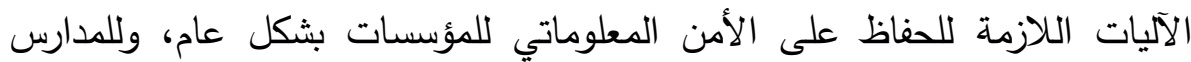
بشكل خاص، وللمدرسة الثانوية الصناعية بشكل أكثر خصوصية، لما لكل مؤسسة ـ

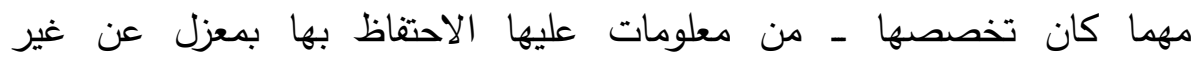
المتخصصين من العاملين بها؛ لأنهم أصحاب التخصص، وأصحاب الحق في في الحسن استخدام تلك المعلومات في عملهم داخل المؤسسات والمدارس، ولا يحق لغيرهم استخدامها، أو الاطلاع عليها، ومن ثم يجب على الموظف عند صياغة كلمة مرور أن يتحرى فيها كل عناصر الدقة، والأمان، حتى لا يسهل توقعها من الآخرين، بما

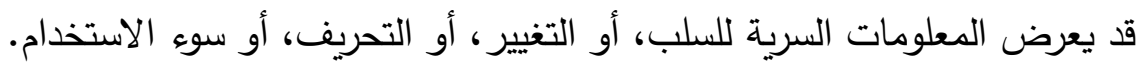




\section{اختيار المواقع الآمنة للاستفادة منها:}

تحتاج المدرسة والمسئولون بها إلى الدخول على مواقع إلكترونية من آن آن النهارهان لآخر؛ بهدف الاطلاع على خبرات مدارس أخرى، والاستفادة منها، وتناقل الخبرات بينها؛ بغرض التطوير والتحسين. وهذا الأمر يفرض على المسئولين عن أداء تلك الك

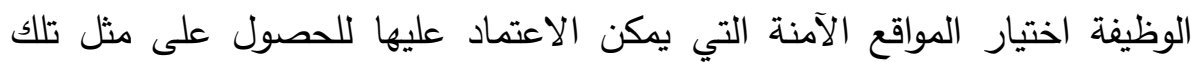

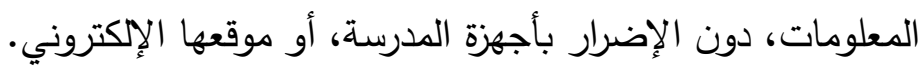
ولعل الاعتماد على مواقع لها سمعتها، مثل المواقع الرسمية للمدارس الثانوية

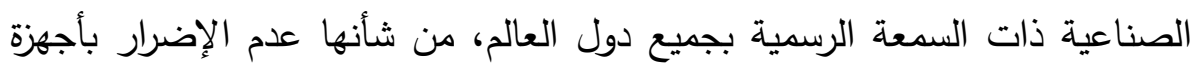

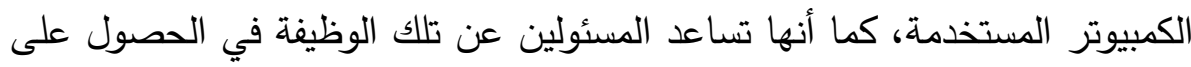
معلومات ذات مصداقية عالية، مما يسهل عملية تبادل الخبرة بين المدارس الثانوية الصناعية بأنحاء العالم كافة.

الحفاظ على نسخ من قواعد البيانات الموجودة في المدرسة على وسائط تخزين خارجية: من الضروري تخزين قواعد بيانات المدرسة على وسائط تخزين خارجية، تحسبًا لحدوث أي مشكلة قد تتسبب في فقدان أي قاعدة بيانات خاصة بالمدرسة، وندانة

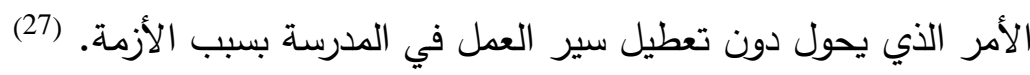

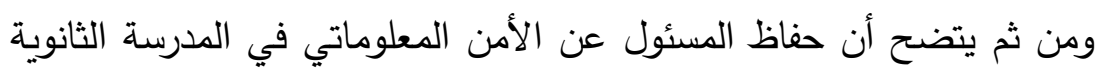
الصناعية، على نسخ احتياطية للمعلومات الموجودة في المدرسة كافة، على أقراص الصن صلبة، أو أقراص مدمجة، وكذلك الهاردات الخارجية والفلاشات والأسطوانات وغيرها،

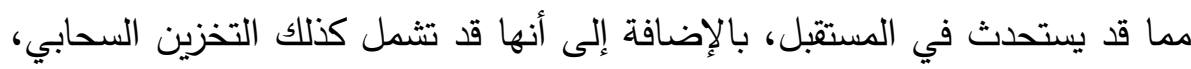

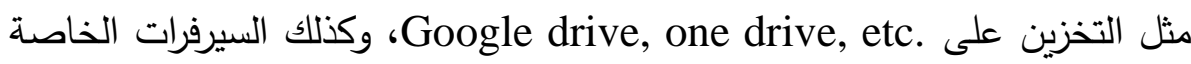
بالتخزين، التي من شأنها الحفاظ على تلك المعلومات وقت الحاجة، واستعادتها عند حدوث أي ظروف في الددرسة، تستلزم استعادتها مرة أخرى، وخاصةً في بيئة مدرسية محفوفة بالمخاطر، مثل بيئة المدرسة الثانوية الصناعية. وبناء على ما سبق عرضه من آليات من شأنها الحفاظ على الأمن

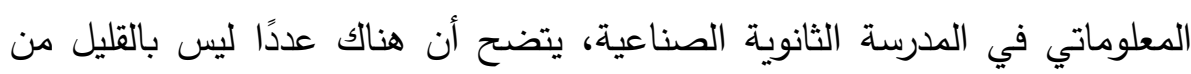
تلك السياسات، التي من السهل ـ على المدارس كافة بشكل عام، والمدارس الثانوية 
الصناعية بشكل خاص ـ تبنيها، ذلك أن البيانات، والمعلومات بالمؤسسات التعليمية

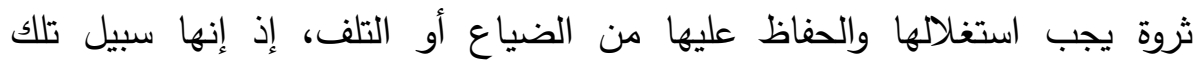
المؤسسات للنهوض، في حالة حدوث أي ظروف طارئة قد تضر بها، أو تحول دون القيام بوظائفها المعتادة، وكذلك الحال بالنسبة للمدارس الثانوية الصناعية؛ حيث إنها أكثر عرضة للمخاطر التي قد تحول دون استمرارية نشاطها، فتكون البيانات والمعلومات آنذاك هي سبيلها لاستعادة هذا النشاط بنفس المستوى الذي كانت عليه. 5. دورة حياة الأمن المعلوماتي في المدرسة الثانوية الصناعية:

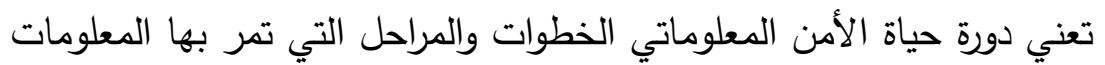
من بداية استخدامها، وحتى الاستفادة منها بالثكل الذي يحافظ عليها في صورتها،

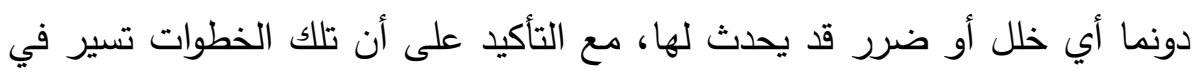
شكل دائري ومستمر ، أي أنها عملية غير منتهية.

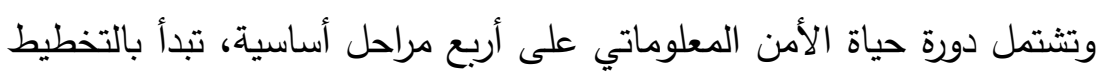

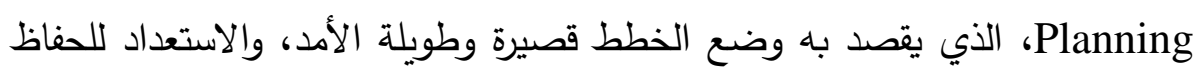
على الأمن المعلوماتي للمنظمة ضد أي خطر قد يؤثر سلبًا عليه، ويطلق على ولى

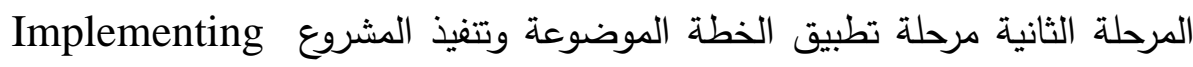
the Plan and Carrying out the Project الموضوعة في المرحلة السابقة، أما المرحلة الثالثة فتسمى بمرحلة مراجعة الأداء ومراقبة تحقيق الأهداف Performance Review and Monitoring the Achievement of Objectives في المحافظة على أمنها المعلوماتي، أي أن المعلومات محفوظة بطريقة فعالة، وأنها

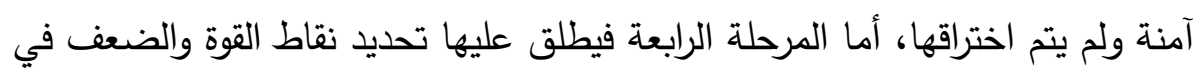
الخطة:Eliminating Discovered Flows and Improvements، والتي تتضح من خلال التنفيذ، وذلك للاستفادة منها عند وضع الخطط الأخرى، وإذا ثبت أن هناك العديد من نقاط الضعف في الخطة الموضوعة، فيجب العودة إلى مرحلة وضع الخطة، وإجراء مزيد من التعديلات على الخطة التي تم بناؤها في تلك المرحلة للتقليل من نقاط الضعف والوصول إلى خطة عالية الجودة، وبناء عليه قام العالم ديمنج Deming، بتصميم هذه المراحل في نموذج أسماه نموذج دورة حياة الأمن 
المعلوماتي Lifecycle Information Security Model، والذي اختصره إلى

أربع كلمات أساسية بإمكانها تمثيل المراحل السابقة، وهي: خطط Plan، وافعل Do، وراجع Check، ونفذ Act، وأطلق عليه نموذج PDCA، ويمكن تمثيل دورة حياة

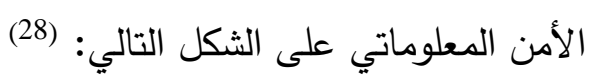

شكل رقم (1) دورة حياة الأمن المعلوماتي

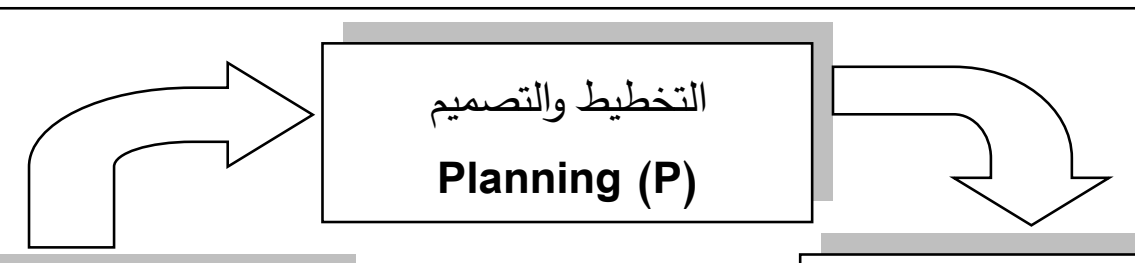

تطبيق مزيد من التحسينات

Improvement- Act $(\mathrm{A})$

التطبيق

Implementation -Do (D)

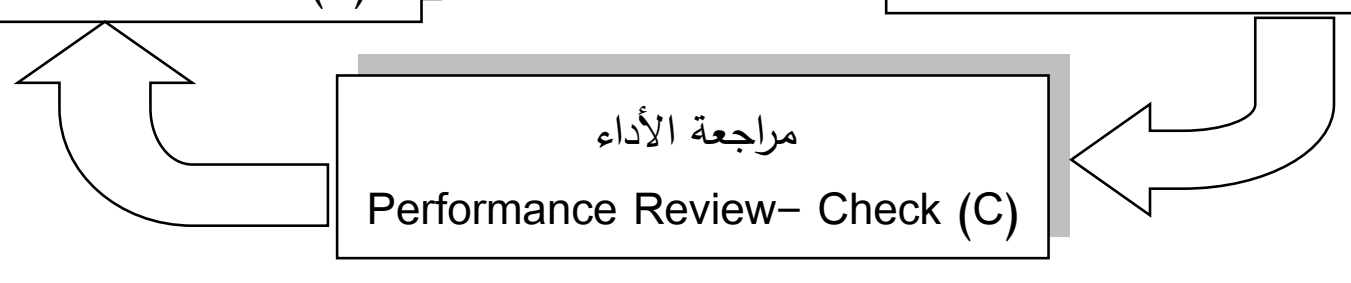

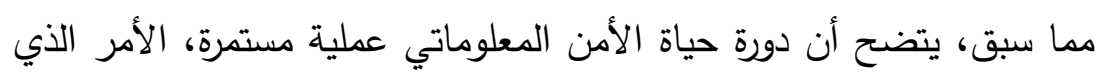

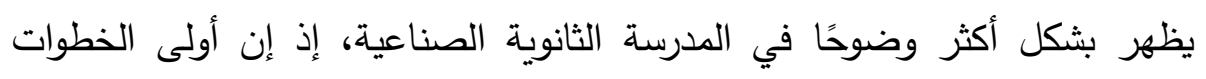

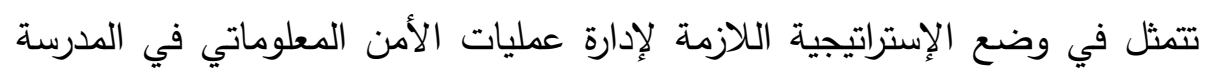

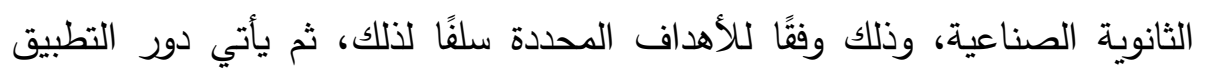

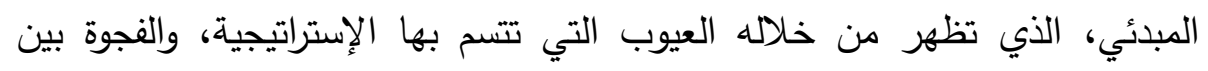
الأهداف المحددة والإنجازات التي تم تحقيقها، ومن خلال مراجعة نقاط القوة

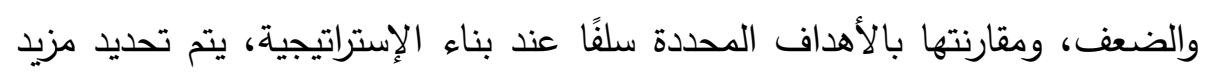

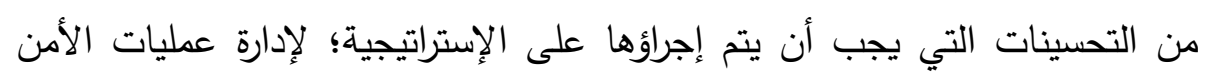

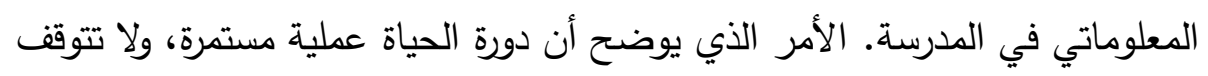

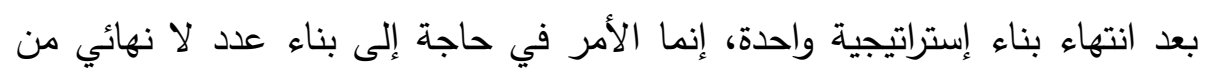
الإستراتيجيات لإدارة عمليات الأمن المعلوماتي في المدرسة الثانوية الصناعية. 
6. دور الإدارة المدرسية في إدارة عمليات الأمن المعلوماتي في المدرسة الثانوية

الصناعية:

لإدارة المنظمات دور لا يمكن إغفاله في إدارة عمليات الأمن المعلوماتي بها، ومن ثم يقوم مدير المنظمة بعدد من الأدوار للحفاظ على الأمن المعلوماتي بمنظمته، الأدانه

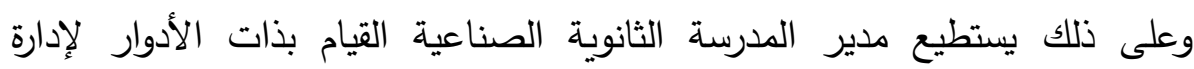
عمليات الأمن المعلوماتي بمدرسته، ومن تلك الأدوار ما يلي: (29)

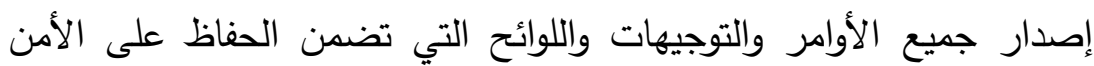
المعلوماتي بالمنظمة على مستوى التتفيذ.

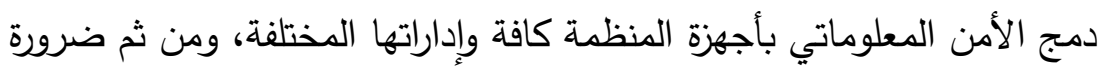
تدريب الموظفين على التمكن من مهارات التعامل معها.

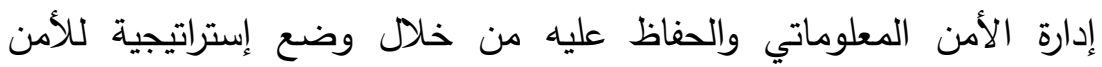
المعلوماتي، وتحديد أهداف الحفاظ على المعلومات بالمنظمة، ويجب أن أن يوافق إفى عليها الموظفون بالمنظمة، بالإضافة إلى استثمار التجارب التي واجه فيها

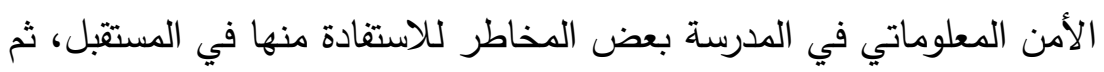
وضع الإجراءات التحصينية المختلفة التي تحافظ على الوضع الحالي للمعلومات الموجودة بالمنظمة، ثم إتاحة الموارد والمصادر اللازمة للحفاظ

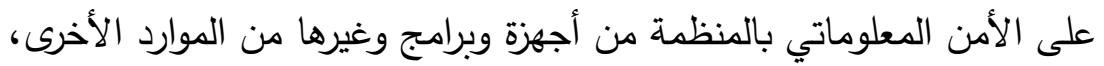

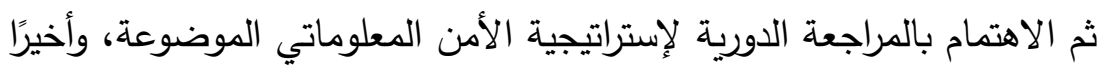

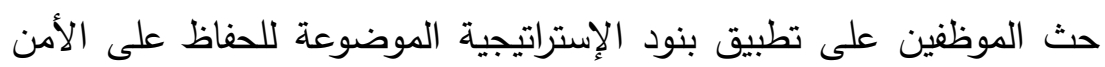
المعلوماتي للمنظمة بشكل فعلي. تحديد الأهداف التي تم تحقيقها بالفعل ومقارنتها بالأهداف المحددة سلفًا لتحديد نقاط القوة والضعف في الأداء. بناء على ما سبق، ثمة أدوار لمدير المدرسة الثانوية الصناعية عليه القيام بها لهاه للحفاظ على الأمن المعلوماتي بها، منها إصدار بعض تلثه اللوائح التي تلزم العاملين

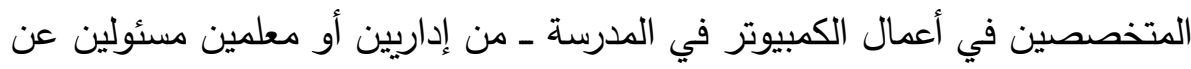

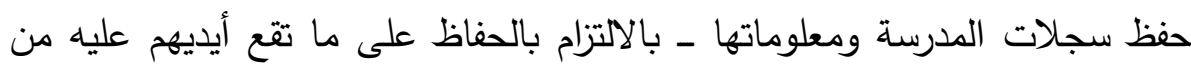
معلومات، وتوقيع العقاب عليهم في حال تقصيرهم، كما أن مدير المدرسة الثانوية 
الصناعية عليه أن يزود جميع الإدارات لديه بالأجهزة الإككترونية لتخزين المعلومات

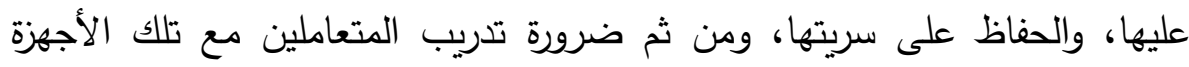
للتمكن من مهارات استخدامها، وتخزين أكبر قدر ممكن من البيانات والمعلومات عليها، ثم عليه إعداد تقارير دورية عن المخاطر التي تعرض لها نظام الأمن

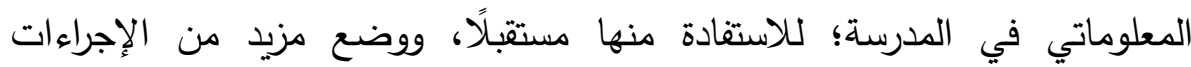

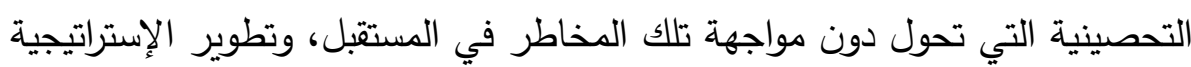

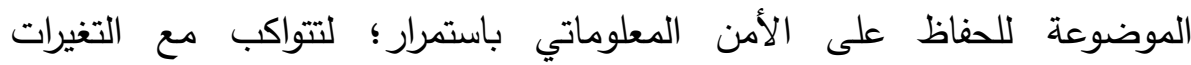

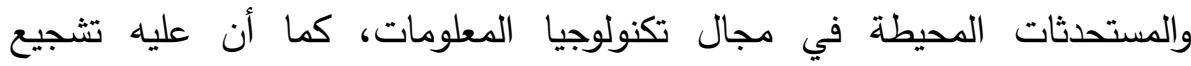
المسئولين عن أمن المعلومات في المدرسة على الحفاظ على المعلومات التي لديهم

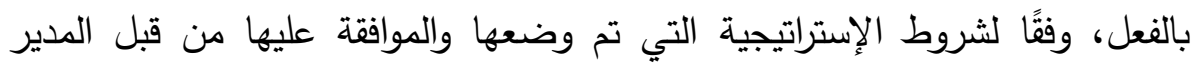

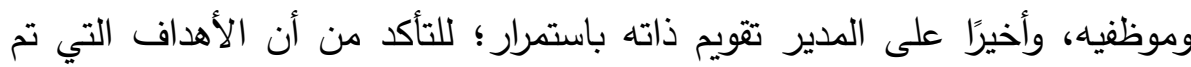

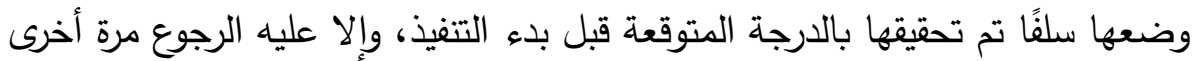

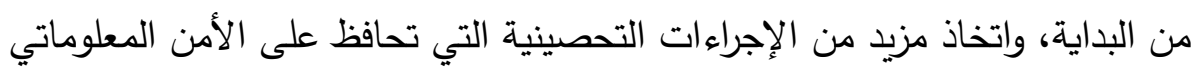
للمدرسة الثانوية الصناعية.

ويقوم مدير المدرسة أيضًا بتشكيل فريق الأمن المعلوماتي في المدرسة ـ والذي يطلق عليه فريق حارسي البيانات Data Guardians ـ من موظفي وحدة تكنولوجيا المعلومات في المدرسة IT Unit، ولكل منهم مجموعة من المسئوليات والأدوار •

\section{7. فريق الأمن المعلوماتي:}

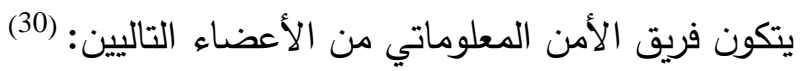

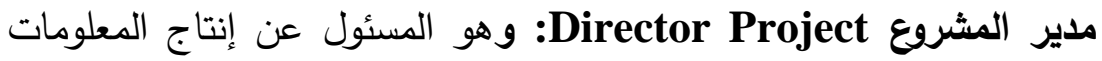
الخاصة ببحث أو بعمل علمي يقوم به أعضاء الفريق المدرسي، المسئول عن البيانات أو المعلومات، وذلك بالتعاون بينه وبين أعضاء المجتمع المدرسي بعيه المشتركين في هذا البحث، بالإضافة إلى تقديم المشورة لهم عند الحاجة، وتسهيل انتقال المعلومات بين أعضاء الفريق لإنجاز المهمة البحثية، وعليه

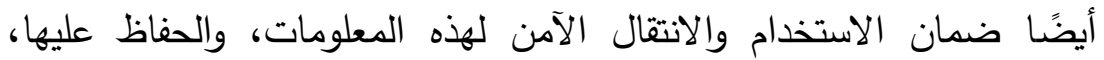
فيتولى حق إصدار كلمات المرور وتغييرها عندما يستدعي الأمر ذلك، وإدارة 
المعلومات نفسها عن طريق التحكم في الدخول لمواقع المعلومات، والاحتفاظ بنسخ احتياطية لها، واسترجاعها وقت الحاجة إليها.

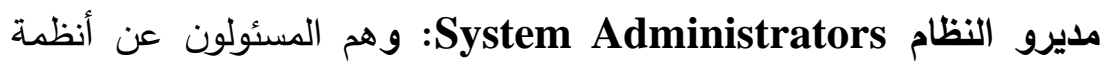
المعلومات بالمنظمة، مثل: التمويل، والتسجيل، والموارد البشرية، بما في ذلك

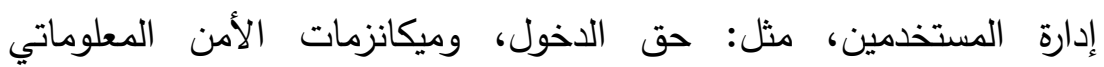
المستخدمة، وإدارة المعلومات نفسها عن طريق التحكم في الدخول لمواقع المعلومات، والاحتفاظ بنسخ احتياطية لها، واسترجاعها وقت الحاجة إليها. رؤساء القسم Heads of Department: وهم المسئولون عن توثيق ودعم أمن المعلومات، التي من الممكن أن تشتمل على وثائق المدرسة، وعقود

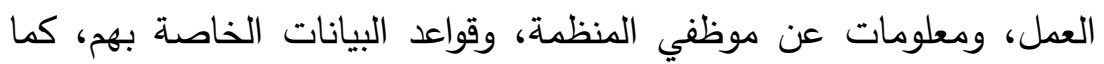
أنها قد تشتمل على قواعد البيانات الخاصة بالعاملين بتلك المنظمة. فريق خدمات المعلومات Information Service Staff: وهو فريق فرعي منبثق عن الفريق الأساسي (فريق أمن المعلومات)، وهم المسئولون عن

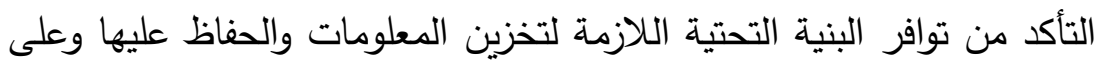
سلامتها، والتأكيد على التوافق بين المتطلبات التي يتطلبها الأمن المعلوماتي داخل المنظمات والإمكانات المادية الموجودة بالمنظمة لمساعدتها على أداء

مهامها.

8. الآثار السلبية لاخترلق الأمن المعلوماتي في المدرسة الثانوية الصناعية: تواجه المدرسة العديد من الآثار السلبية في حال تم اختراق معلوماتها، ومن الإن

تلك الآثار ما يلي: (31)

فشل النظام المعلوماتي، أو فساد وإفساد المعلومات.

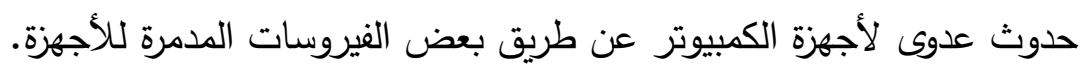

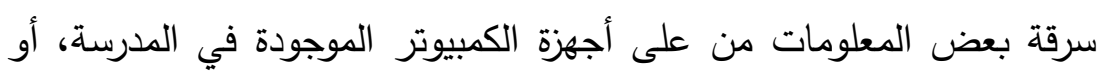

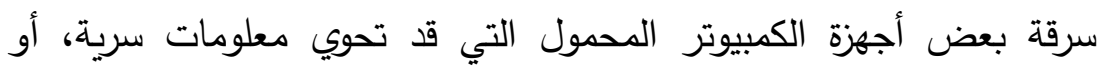
شخصية.

سوء استخدام بعض الموظفين للأجهزة والتي قد تتلفها، نتيجة نقص خبراتهم في التعامل مع الأجهزة المتاحة لهم للتعامل معها. 
اختراق المواقع الإككترونية للمدرسة، وتعديل ما عليها من معلومات، الأمر الذي ينتج عنه إضافة معلومات غير حقيقية، ومضللة للمستفيدين من الموقع

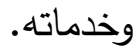

دمار قواعد البيانات الموجودة في المدرسة، سواء ما تخص الطلاب أو المعلمين، أو أي إمكانات في المدرسة؛ مما يؤثر سلبًا على صنع القرارات

$$
\text { واتخاذها في الوقت المناسب. المبان. }
$$

وبالنظر إلى الآثار السلبية سالفة الذكر ، يتضح أن تلك الآثار تتحول جميعها

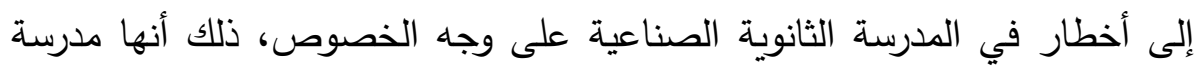
غير تقليدية، قد تحدث بها العديد من الأخطار والحوادث غير المتوقعة، نظرًا لطبيعة الطئة الدراسة والعمل بها؛ فهناك المعامل، والورش، ويتعامل الطلاب فيها مع الأجهزة، والمعدات الثقيلة، ويطلب منهم القيام بصيانة الأجهزة، وإنتاج منتجات، وتسويقها، ولتهان

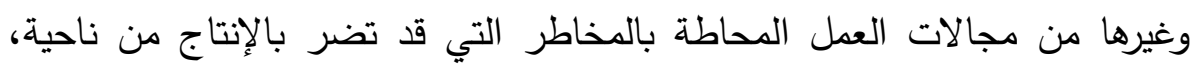

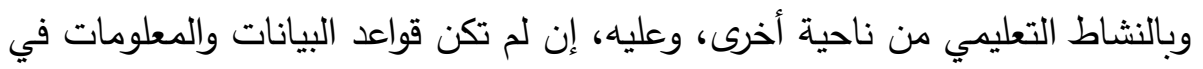

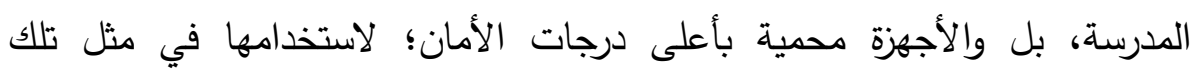
الظروف الطارئة، فإن المشكلات تتحول إلى أزمات يصعب التعامل معها؛ إذ تتحول داعل

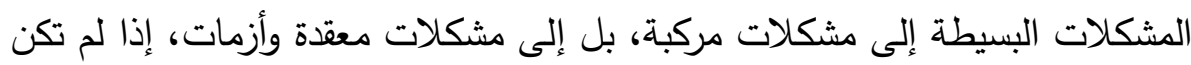

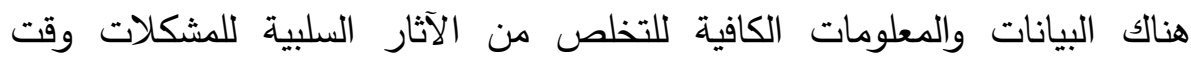

$$
\text { ظهورها. }
$$

9 9. أبعاد الأمن المعلوماتي في المدرسة الثانوية الصناعية:

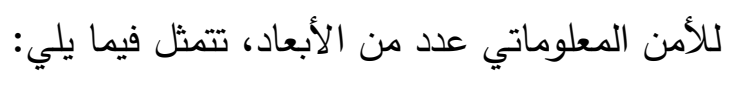

\section{هeople Dimension البعد البشري:}

يمثل العاملون البعد الأكثر أهمية من أبعاد الأمن المعلوماتي، لما لهم من

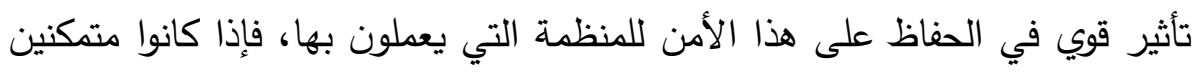

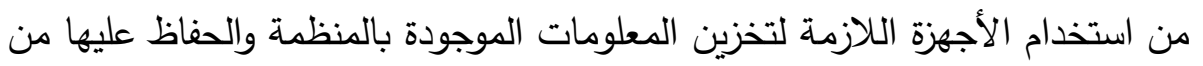
الاختراق، فإن ذلك يؤدي إلى وجود نظام فعال للأمن المعلوماتي في المدرسة، أما

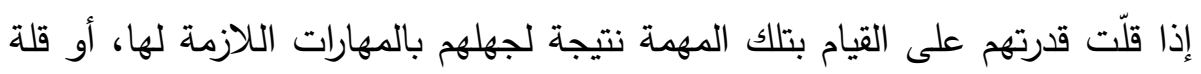
تدريبهم عليها، فإن ذلك يهدد أمن المعلومات بمنظمتهم، الأمر الذي يحولهم إلى بلى بلى بلى 
أعداء للمنظمة، كما أن ضعف إدراك العاملين بأهمية الدور الذي يقومون به للحفاظ

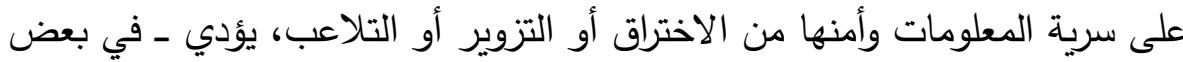

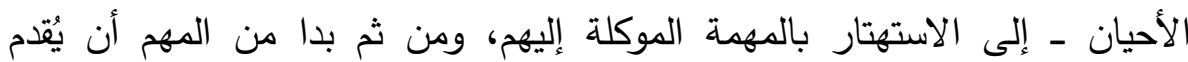
للعاملين بالمنظمات عدد من البرامج التدريبية التي توضح لهم أهمية الدور الذي لهي

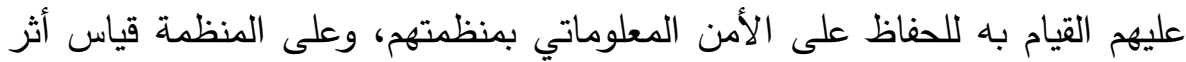

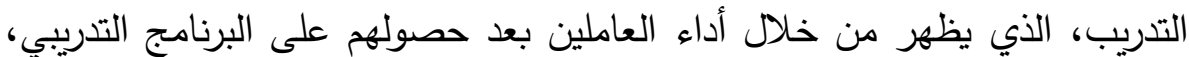
كما يجب أن تركز تلك البرامج التدريبية على ما يلي: (32) - تغيير الطريقة التي يفكر بها العاملون حين يعملون في مجال الأمن

المعلوماتي بشأن أهمية المهام التي يقومون بها. - - قياس أثر تدريب العاملين في أماكن عملهم. - - تقديم برامج تدريبية تتمي الثقافة الداعمة لأهمية الحفاظ على الأمن المعلوماتي لماتي للامنظمة، الأمر الذي يساعد العاملين على القيام بعملهم بناء على قناعة تامة لاميه لاهيه بأن الحفاظ على الأمن المعلوماتي يسهم في تحقيق النجاح لها.

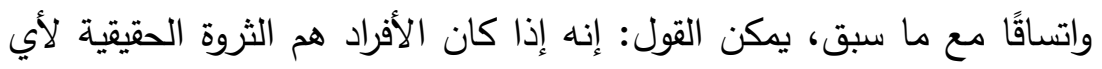

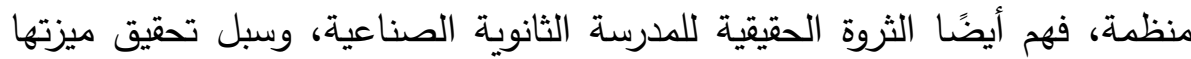
التتافسية، ولذا فمن المهم أن تولي المنظمات التعليمية عناية فائقة بتدريبهم وتأهيلهم لكي يمتلكوا الكفاءات والجدارات التي تمكنهم من الحفاظ على الأمن المعلوماتي

$$
\text { لمدارسهم. }
$$

\section{•}

يمثل بعد السياسة أحد الأبعاد الهامة للأمن المعلوماتي، ويشير إلى جميع

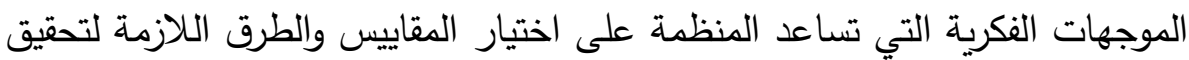
الأمن المعلوماتي ومنع التهديدات، ولذا يعتبر بعد السياسة هو المحدد للطرق والأساليب التي تساعد المنظمة على الحفاظ على أمنها المعلوماتي. (33)

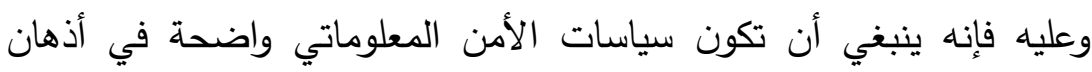
العاملين، ويجب أن يكون لديهم وعي بها، ويجب أن تكون نتائجها قابلة للقياس؛

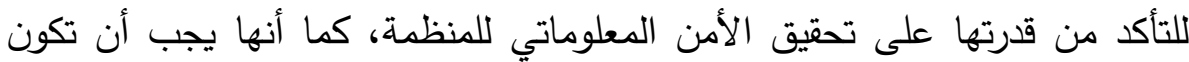
قابلة للتحقيق، ومن ثم فإن السياسات الواضحة من شأنها تحديد المسئوليات 
والواجبات التي على الموظفين القيام بها لتحقيق الأمن المعلوماتي المنشود للمنظمة، الأمر الذي يساعد الموظفين على طاعة Compliance الأوامر، وتتفيذ المسئوليات الموكلة إليهم في هذا الثأن. (34) بناء على ما سبق، يرتبط البعد السياسي بسياسات الحفاظ على الأمن

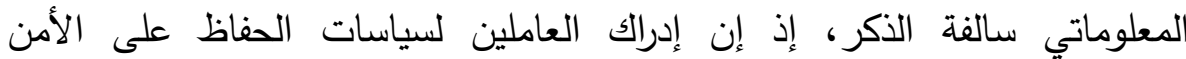

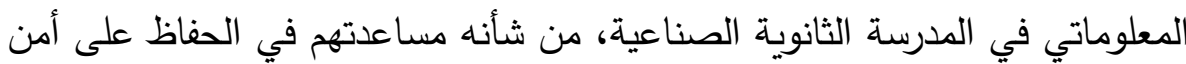
المدرسة، إذ يجعلهم هذا الإدراك واعين، بل ملتزمين باختيار السياسة الملائمة للحفاظ على الأمن المعلوماتي بمدرستهم.

\section{البعد التكنولوجي: Technological Dimension}

هو البعد الذي يركز على الموارد المادية التي تساعد على تخزين المعلومات

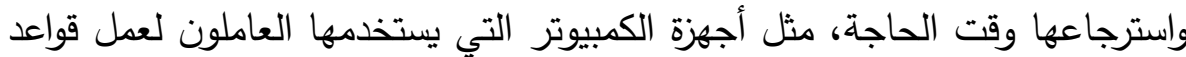
البيانات، وإدارتها، وكيفية الاستخدام الآمن للمعلومات والبيانات من شبكة الإنترنت.

كما يعد هذا البعد من حتميات الحفاظ على الأمن المعلوماتي في المدرسة الثانوية الصناعية؛ فالحفاظ على المعلومات في حاجة إلى أجهزة يتم تخزين

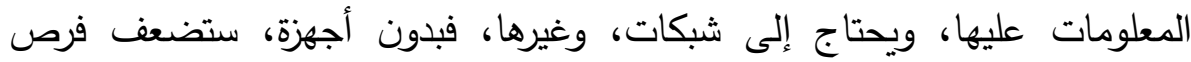
الحفاظ على البيانات والمعلومات؛ فالمعلومات الورقية أقل أمنًا من المعلومات المخزنة على الأجهزة، إذ إنها تكون أكثر عرضة للإفساد، والتلف، والسطو،

$$
\text { والتزوير ، وغيرها من المخاطر الأخرى. }
$$

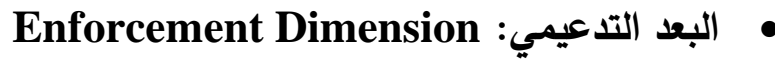

هو البعد الذي يركز على قدرة العاملين على فهم السياسات المستخدمة للحفاظ

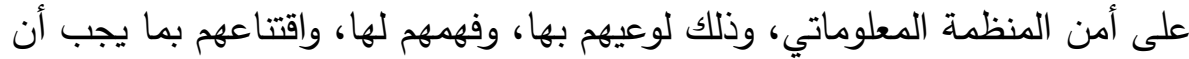

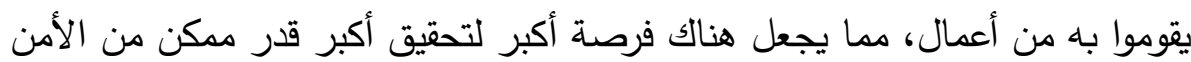
المعلوماتي للمنظمة، كما يؤدي إلى دعم قدرة المؤسسة على الحفاظ على أمنها

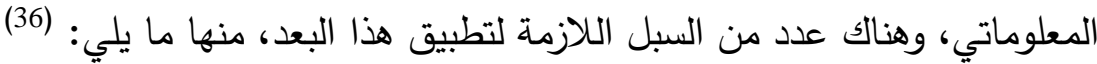
أ- التحكم في بيئة العمل Monitoring Work Environment التحكم في بيئة العمل من أهم العناصر اللازمة لتحقيق البعد التدعيمي 
بالمنظمات، إذ إن تأمين بيئة العمل، والأجهزة، وشبكات الاتصال،

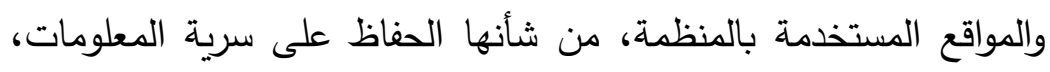

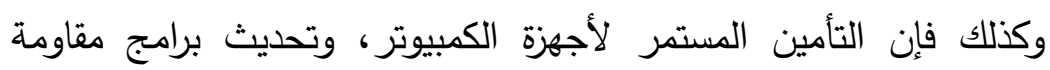

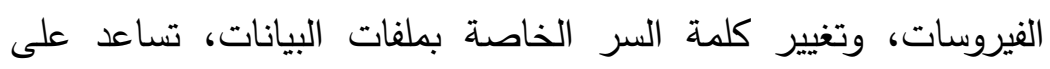
الحفاظ على البيانات والمعلومات الهامة التي تخص المنظمة.

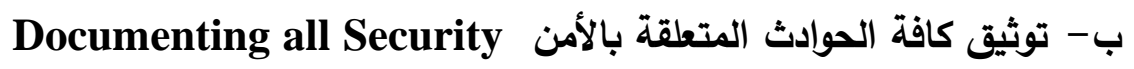

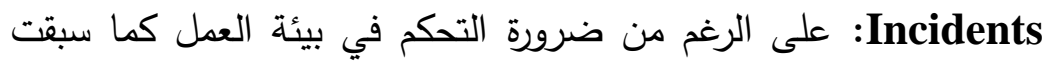

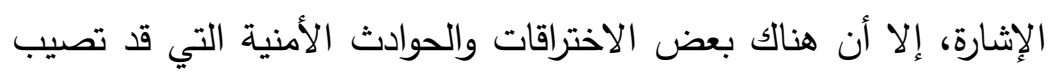

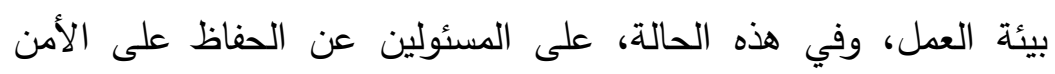
المعلوماتي توثيق تلك الحوادث كافة، ذاكرين الممارسات التي تم القيام بها للتعامل مع تلك الحوادث؛ للاستفادة منها في مواقف مشابهة، ولتفادي الأخطاء التي أدت إلى تلك المشكلات، التي أدت إلى الاختراق الأمني.

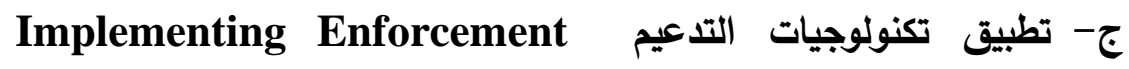

Technologies

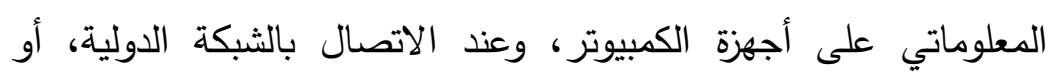

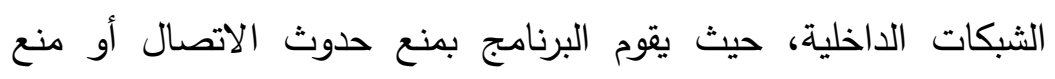

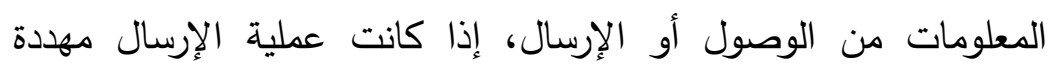

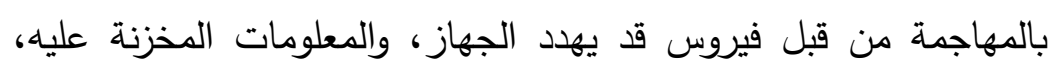
ومن ثم فإن الشركات المسئولة عن إصدار تلك البرمجيات، وتحديثها، تسهم بشكل كبير في تطبيق تكنولوجيات التدعيم والحفاظ على أمن المعلومات الخاصة بالمنظمة من الاختراق أو التلف، والانتقال من مجرد

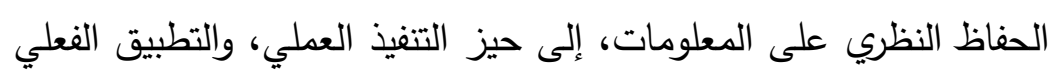
للحفاظ على أمن المنظمة المعلوماتي.

\section{البعد المؤسسي Organizational Dimension:}

للبعد المؤسسي أهمية لا يمكن إغفالها في الحفاظ على الأمن المعلوماتي

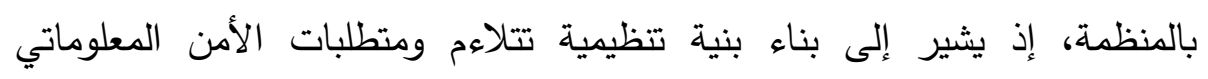

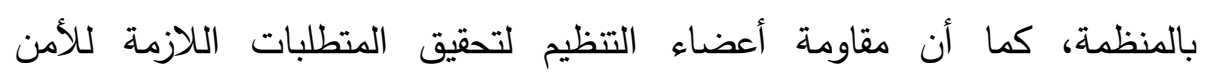


المعلوماتي، قد يعد أحد أهم العوامل التي تسهم في إحداث الصراع بين رغبة المنظمة في الحفاظ على أمنها المعلوماتي، وبين مقاومة الموظفين للقيام بالمهام التي تساعدهم على الحفاظ على أمن منظمتهم المعلوماتي، وعليه، من المفترض أن يكون بالمنظمة هيكل إداري مسئول عن التبه للمشكلات التي قد تهدد أمنها المعلوماتي، وكتابة تقرير عنها، ومحاولة مواجهتها قبل أن تتسلل إلى قواعد البيانات الخاصة بالمنظمة، مما يترتب عليه التحديد الدقيق للمسئوليات والواجبات التي على كل موظف متخصص في مجال تكنولوجيا المعلومات في المدرسة القيام بها، بالإضافة إلى عقد اتفاقيات خارجية مع الثركات المسئولة عن تقديم البرمجيات الخاصة بالحفاظ على الأمن المعلوماتي، بوصفها المسئولة عن توفير البرمجيات الأصلية للمنظمة لمساعدتها في الحفاظ على أمنها المعلوماتي، كما يشتمل هذا البعد على العمليات التي على مدير المنظمة والعاملين القيام بها؛ للحفاظ على الأمن المعلوماتي بها، بداية من التخطيط لمواجهة أي اختراقات أمنية قبل حدوثها، مرورًا بعمليات التظظيم، والتمويل، والاتصال، والرقابة، والتقويم... إلخ، الأمر الذي يسهم في

الاستعداد لتلك الخروقات والتعامل معها حال حدوثها. (37) ويتضح مما سبق، أن وجود مثل هذه البنية التظيمية يساعد المنظمة على التعافي من الأزمات التي من الممكن أن تحدث لها نتيجة للخروقات التي قد تحدث في نظامها الأمني، والتي ينتج عنها تسرب للمعلومات، وانهيار لقواعد البيانات الموجودة لديها.

وإن كان الأمن المعلوماتي آلية لإدارة التعافي بالمنظمات بشكل عام، فهو آلية هامة جدَّا داخل المدرسة الثانوية الصناعية على وجه الخصوص؛ وذلك لما للمدرسة الثانوية الصناعية من معلومات وبيانات تخص بنيتها، ومشاريعها، وميزانياتها، وإنتاجها، ودراسات الجدوى الخاصة بها، وغيرها من المعلومات السرية التي في حاجة إلى أن تُحفظ من الدخلاء؛ لأنها من الممكن أن تستغل لتعافي المدرسة الثانوية الصناعية من الأزمات التي قد تتعرض لها، وما أكثر تلك الأزمات؛ نظرًا لطبيعة المدرسة الثانوية الصناعية المحفوفة بالمخاطر، والذي يرجع إلى مجالات عملها المختلفة، المرتبطة باحتياجات السوق، وإرضاء العملاء، والحفاظ على أمن 
الطلاب، والحفاظ على الأمن المعلوماتي لقواعد البيانات في المدرسة، وغيرها من

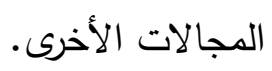

ثانيًا ــ إدارة عمليات الأمن المعلوماتي في المدرسة الثانوية الصناعية: تتحدد عمليات الأمن المعلوماتي في المدرسة الثانوية الصناعية، فيما يلي:

\section{1. التخطيط للأمن المعلوماتي في المدرسة الثانوية الصناعية:}

تتبع أهمية عملية التخطيط من كونها العملية الأولى التي تبنى عليها باقي

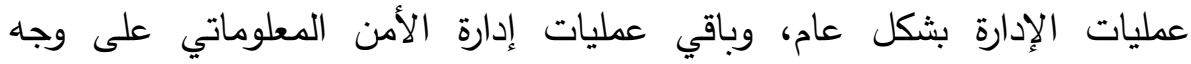
الخصوص، ويبدأ التخطيط للأمن المعلوماتي برفع وعي العاملين بأهمية هذا الأمر ،

ومن ثم يتم القيام بما يلي لرفع الوعي بالدرجة المطلوبة: (38)

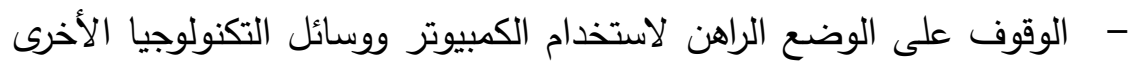
بالمنظمة. - فهم ما الذي يريد أن يتدرب عليه الموظفون بالفعل. -

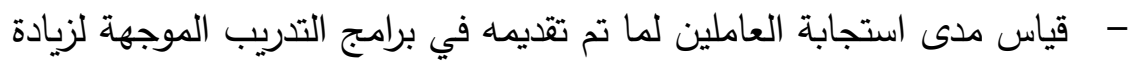
وعيهم بالأمن المعلوماتي. - فحص السبل المختلفة التي ستلاقي استحسانًا لدى جمهور العاملين العاملين للحصول على التهيئة المناسبة للاقتناع بضرورة الحفاظ على الأمن المعلوماتي. - التوصل إلى مزيد من الداعمين والحلفاء الذين من شأنهم المساهمة في

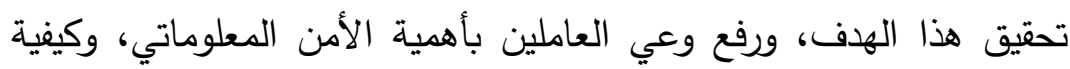
الحفاظ عليه. مما سبق، يتضح أن التهيئة هي أولى خطوات التخطيط للحفاظ على الأمن المعلوماتي، وبالنسبة للمدرسة الثانوية الصناعية، فإن تهيئة الموظفين والإداريين المسئولين عن التعامل مع المعلومات والحفاظ عليها، يعد من أسس الاهتمام بالحفاظ

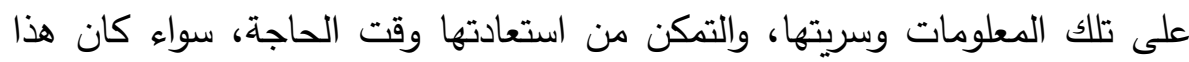

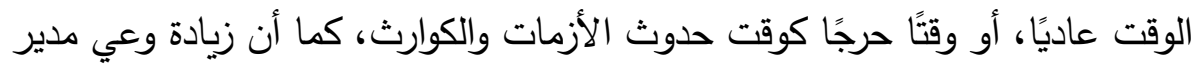
المدرسة بهذا الأمر يجعله قادرًا على استخدام المعلومات المتاحة لديه لتعافي المدرسة من الآثار السلبية للأزمات التي تعرضت لهادر لها. لهات 


\section{وتتحدد خطوات التخطيط للأمن المعلوماتي في: (39)}

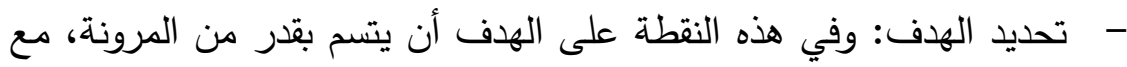

$$
\text { التحديد الدقيق والوضوح والبساطة. }
$$

- تطبيق الخطة الموضوعة: وهنا على المسئولين القيام بتطبيق الخطة

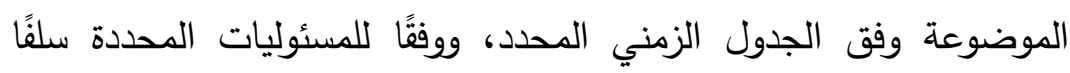

للأفراد القائمين بالتنفيذ.

- وضع معايير للحكم على مدى نجاح الخطة التي تم تتفيذها.

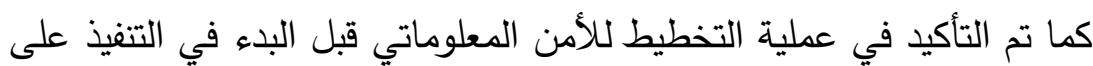

ما يلي: (40)

تحديد السلطة: بمعني تحديد الأفراد القادرين على اتخاذ القرارات التي

تخص الحفاظ على الأمن المعلوماتي، وسبل الحفاظ على المعلومات أيضًا. المحاسبية: بما يسهم في الحفاظ على تنفيذ الخطط الإستراتيجية للأمن

المعلوماتي في ضوء أهدافها، وبالتالي تحقيق الأهداف المرجوة.

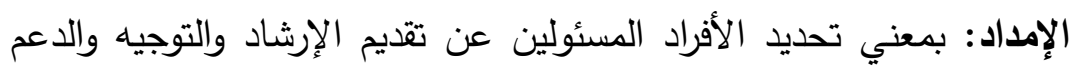

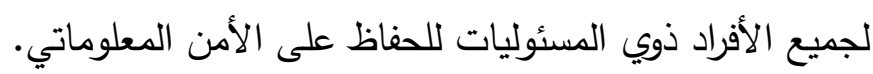

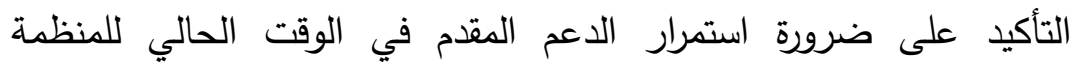

$$
\text { والعاملين فيها لتحقيق الأمن المعلوماتي. }
$$

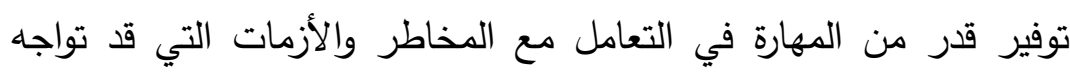

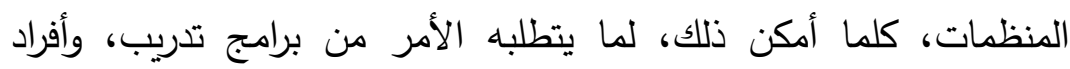

$$
\text { مؤهلين... إلخ. }
$$

وفي عملية التخطيط، يجب وضع عدة خطط لضمان استمرارية العمل في حالة حدوث ما يهدد الأمن المعلوماتي بالمنظمة، الأمر الذي يوضح ضرورة فئحة توقع ما

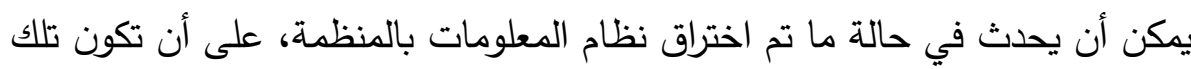

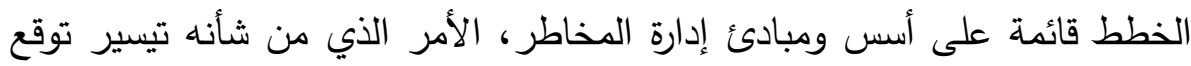
التهديدات التي قد تصيب المعلومات الموجودة بالمنظمة، كما يجب أن تتسق الخطط الموضوعة لاستمرارية الأعمال مع طبيعة عمل المنظمة، ثم يجب بعد ذلك اختبار الخطط الموضوعة لضمان نجاح تلك الخطط، والتأكد من صلاحيتها، واستعدادها 
للتعامل مع المواقف الطارئة، وذلك قبل حدوث الأزمة، وأخيرًا تصنيف المخاطر التي

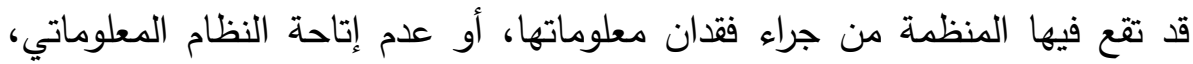
وفقًا للوقت الذي لا تتاح فيه المعلومات للمستقيدين منها، وذلك وفقًا للتصنيف التالي:

\begin{tabular}{|c|c|c|}
\hline الوصف & زمن فقدان القدرة على & درجة الخطر \\
\hline 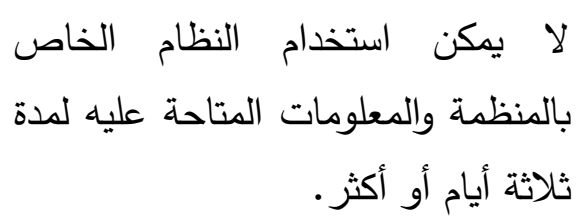 & ثلاثة أيام أو أكثر & عالية \\
\hline لإلى يمكن استخدام النظام من 8 ساعات & من 8 ساعات وحتى 24 & متوسطة \\
\hline لا يمكن استخدام النظام كدد أقصى 8 ساعات. & أقل من 8 ساعات & منخفضة \\
\hline
\end{tabular}

مما سبق، يتضح أن عملية التخطيط للأمن المعلوماتي تشتمل على الاهتمام

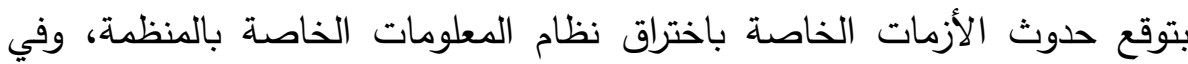
حالة المدرسة الثانوية الصناعية، تتضح أهمية تلك الخطوة، خاصةً وأن تلك البيئة مليئة بالمشكلات التي قد تتحول إلى أزمات قد تضر بالأمن المعلوماتي للمدرسة المدانه

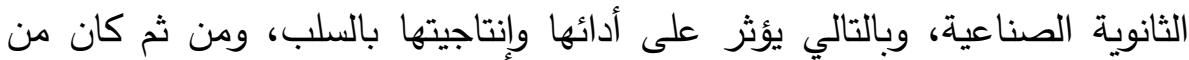
اللازم بناء خطة لضمان استمرارية العمل أثناء حدوث مثل تلك الأزمات.

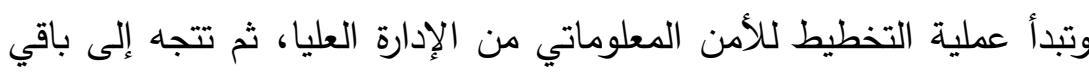
أعضاء المنظمة في شكل هيراركي رأسي، ومن ثم تمر تلك العملية بأربع مراحل

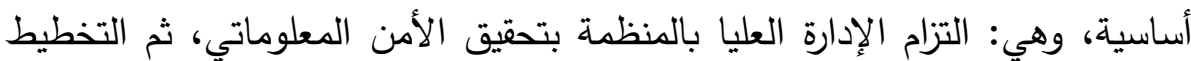

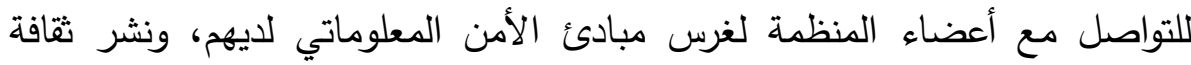

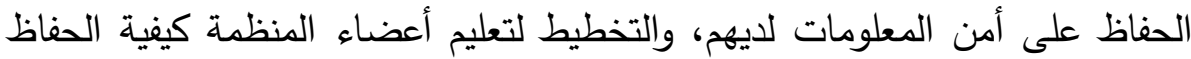
على أمن المعلومات، ثم التخطيط لضمان التزام العاملين بالمنظمة للحفاظ على الأمن المعلوماتي. (42) 
بناء على ما سبق، يتضح أن عملية التخطيط للأمن المعلوماتي في المدرسة

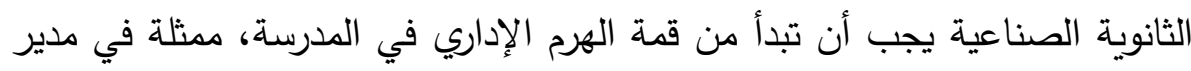

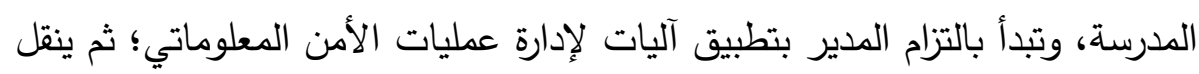

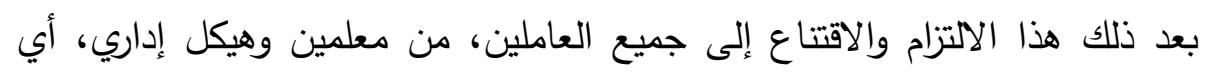

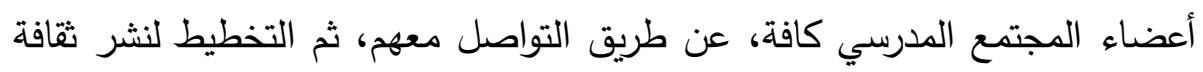

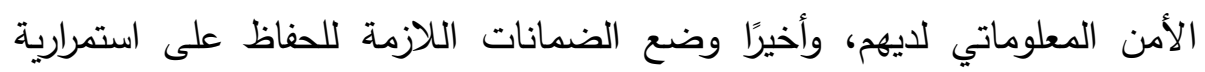
حفاظهم على الأمن المعلوماتي في المدرسة، ويمكن تمثيل تلك الأولويات على الهي

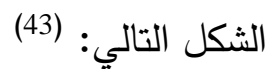

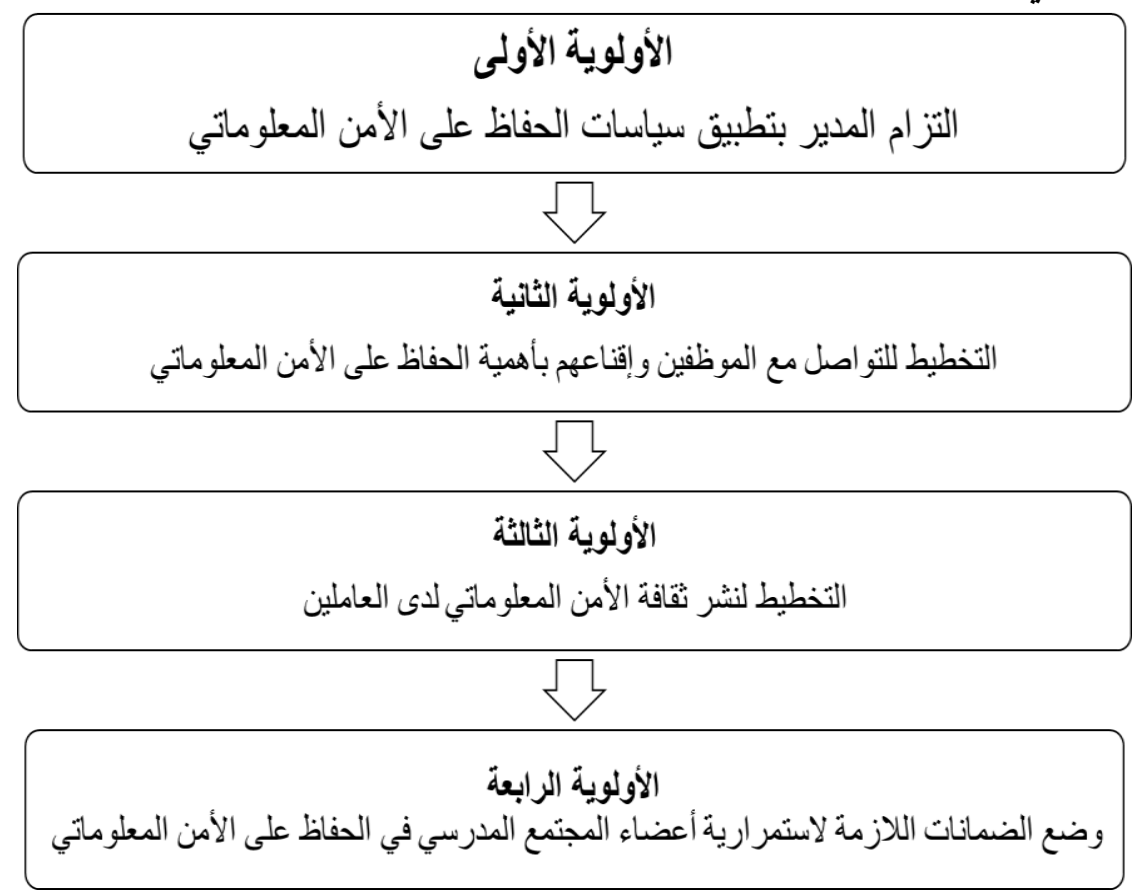

شكل رقم (2) أولويات مرتبطة بمهام المدير فيما يتعلق بالتخطيط للأمن المعلوماتي في المدرسة الثانوية الصناعية

ويتم تعزيز تلك الأولويات بعدد من المتطلبات التي تساعد في الانتقال السلس

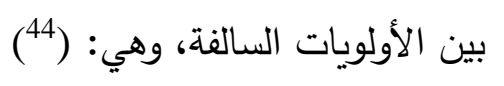

• الوعي الملائم من قبل الموظفين بأهمية نظم المعلومات وكيفية الحفاظ عليها.

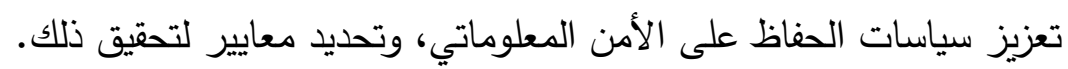

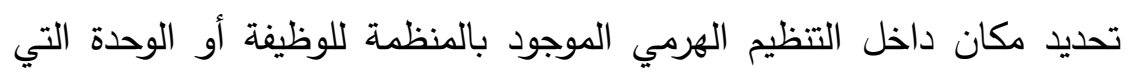

سيتم من خلالها الحفاظ على الأمن المعلوماتي. 
• تحديد مصادر تمويل واضحة للحفاظ على الأمن المعلوماتي في الددرسة، وتوضيح ذلك في خطة عمل محددة وواضحة.

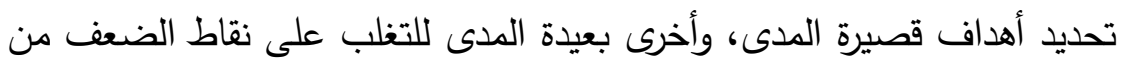
ناحية، ومن ناحية أخرى الحفاظ على الأمن المعلوماتي بالمنظمات.

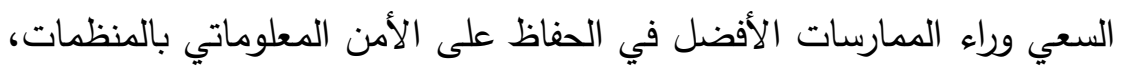
وذلك لتبادل الخبرات والاستفادة من الآخر .

ويتضح مما سبق، أن التخطيط للأمن المعلوماتي في المدرسة الثانوية الصناعية يتطلب تحديدًا دقيقًا للهدف المراد تحقيقه، الذي يتمثل في هذا السياق في الحفاظ على المعلومات الهامة الموجودة في المدرسة، مثل قواعد البيانات المتوفرة عن الطلاب، والمعلمين، والموظفين، والأجهزة، والورش، والمنتجات التي تستطيع المدرسة إنتاجها، بالإضافة إلى الميزانية، وجهات التعاون والمشاركة بين المدرسة ولهات

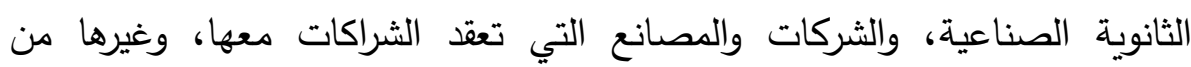

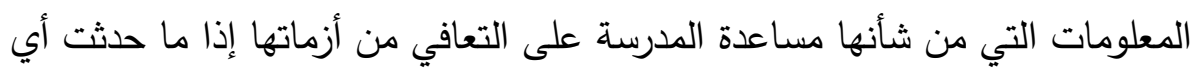

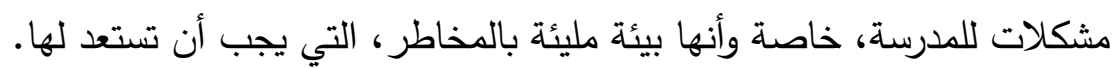

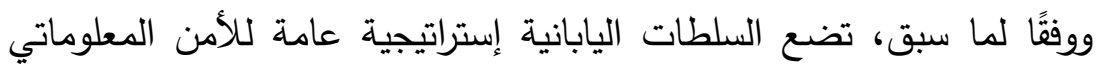
بمؤسساتها كافة، ومنها المؤسسات التعليمية، والمدارس الثانوية الفنية بها، وتتضمن تلك الإستراتيجية خطة للأمن المعلوماتي، وذلك وفقًا للخطوات التالية: (45) تحديد الهاف من وراء وضع الخطة اللازمة لإدارة الأمن المعلوماتي.

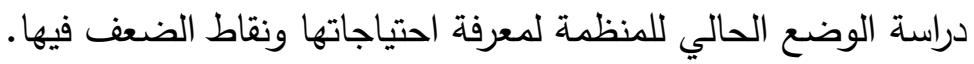
وضع الخطة اللازمة لإدارة الأمن المعلوماتي. تطبيق الخطة الموضوعة والاستعداد لتعديلها إذا اقتضت الضعند الضرورة. وضع معايير للحكم على الخطة الموضوعة وتعديلها في المستقبل لتعديل

\section{الخطط الجديدة.}

تعديل الخطط المستقبلية وفق المعايير الموضوعة استعدادًا للمستقبل. يتضح مما سبق، أن السلطات اليابانية تتبع خطوات محددة لوضع خطة

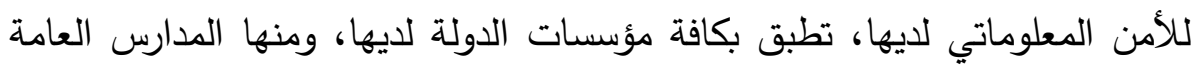

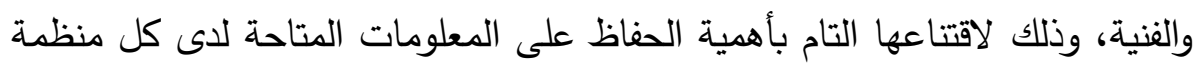


وفق طبيعتها، خاصة أن التعليم الفني بها يمثل حجر الزاوية في بناء الاقتصاد الياباني.

وعليه يتضح أن التخطيط هو أول العمليات الإدارية اللازمة للحفاظ على

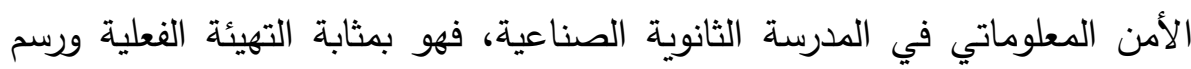
الخطوط المستقبلية التي ستسير عليها المدرسة من أجل تحقيق غايتها في الحفاظ

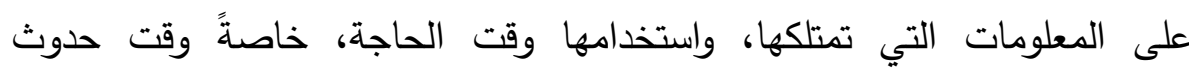
الأزمات، أو بعد الانتهاء منها، استعدادًا لاستعادة النشاط مرة أخرى.

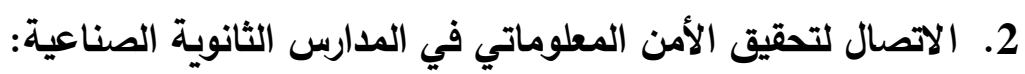
تعتبر عملية الاتصال Communication إحدى العمليات الهامة بالمنظمات

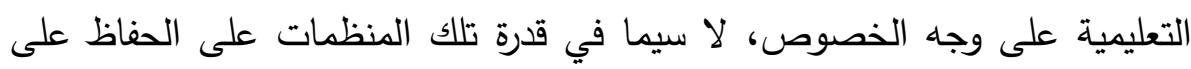
أمنها المعلوماتي، وخاصةً عند الاستعداد للمواقف الطارئة التي قد تواجه الائه المدارس

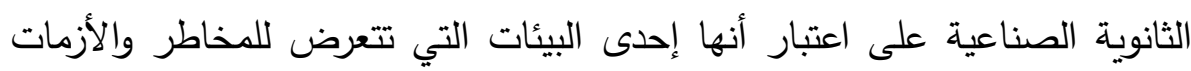

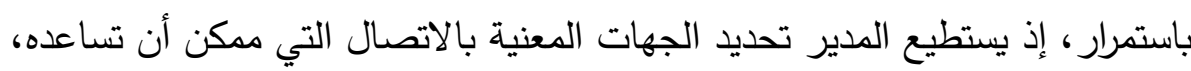

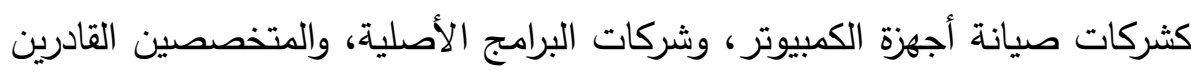

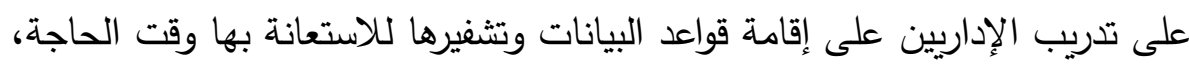

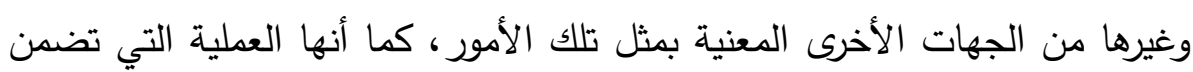
دخول المستفيدين على موقع المدرسة والحصول على المعلومات المتاح لهم الدخول

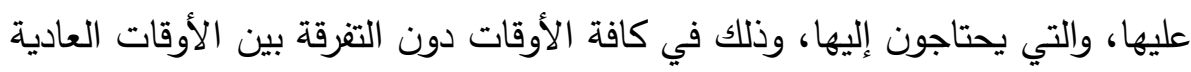

$$
\text { ووقت الأزمات. }
$$

كما تتضمن عملية الاتصال، قدرة المدرسة الثانوية الصناعية على الاتصال

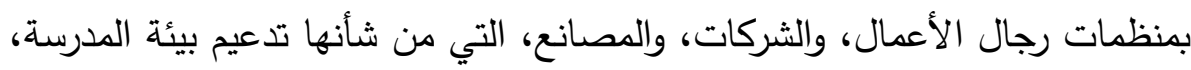

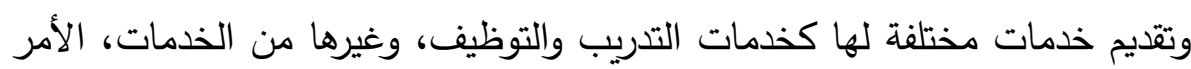
الذي يتطلب قواعد بيانات واسعة النطاق، ودقيقة، ومحدثة؛ لاستخدامها وقت حدوث

$$
\text { الأزمات، أو حتى في الأوقات العادية. }
$$

وهناك عدة خطوات يجب الاهتمام بها عند الاتصال بالجهات المعنية للحفاظ

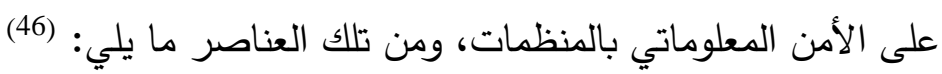


الحفاظ على القدرة على الاتصال عبر الثبكات التي تمتلكها المنظمة Network Security

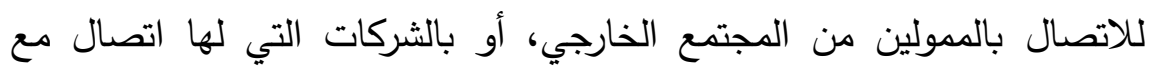
المنظمة. مراجعة عناصر الأمان المتوفرة بالمنظمة للحفاظ على أمنها المعلوماتي باستمرار، وذلك لتحديثها، وتطبيق أفضلها للمنظمة. • مراقبة انتقال المعلومات التي تخص المنظمة، من خلال قنوات الاتصال الشرعية

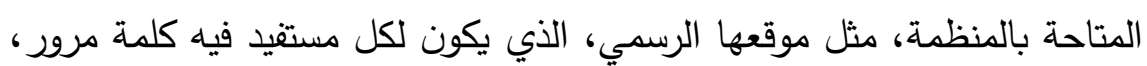
يستطيع من خلالها الحصول على ما يشاء من المعلومات.

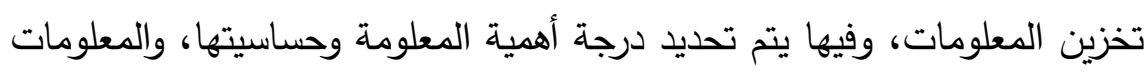

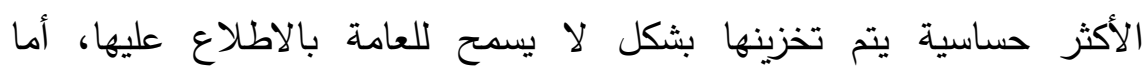

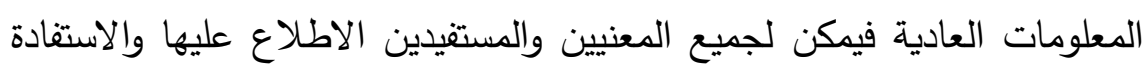
منها. درجة التشفير Encryption، يرتبط ذلك العنصر بما سبقه، إذ ترتفع درجة

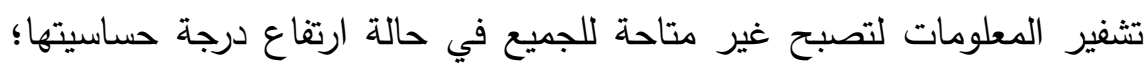

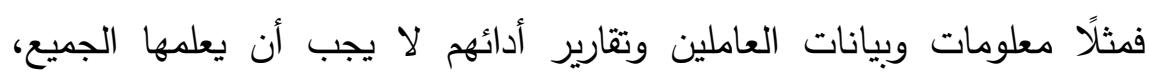
وغيرها من المعلومات التي لها ذات الطابع. الحفاظ على بيانات ومعلومات المنظمة من الفيروسات باستخدام البرامج الأصلية والحديثة. الاحتفاظ ببيانات ومعلومات المنظمة الهامة وذات الحساسية العالية في أماكن

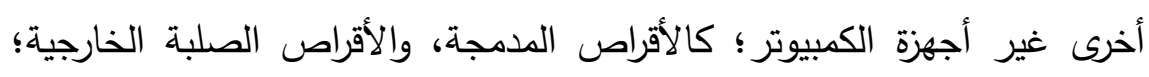
لحمايتها من أعمال القرصنة الإكترونية.

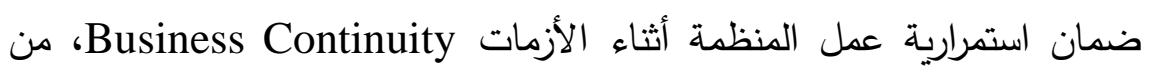
خلال استمرارية الاتصال مع العملاء وطمأنتهم عن جودة الخدمة والمنتجات، واستمرارية حصولهم على الامتيازات التي كانوا يحصلون عليها قبل حدوث الأزمة، ولكن بشرط إعلامهم بالمخاطر التي حدثت بالمنظمة، وبالإجراءات 
المتبعة لاستعادة النشاط والتعافي من الأزمة، وذلك لتحقيق الإدارة الثفافة

ومصارحة العملاء بما يحدث داخل المنظمة دون تعتيم على الحقائق.

وبالنظر لخطوات الاتصال السالفة، يتضح أنها ضرورية للحفاظ على أمن

المعلومات في المدرسة، سواء كانت بيانات ومعلومات عن الميزانية، وأعضاء هيئة التدري، وتقارير الأداء الخاصة بهج، والممولين الخارجيين، وجماعات الشراكة الخارجية، والشركات والمصانع المتضامنة مع المدارس، وتفاصيل الاتفاقيات المبرمة بينهم، وغيرها من المعلومات التي يجب الحفاظ عليها من الضياع أو القرصنة، وعليه يجب مراعاة توافر العناصر السالفة كافة عند التعامل مع البيانات والمعلومات الخاصة في المدرسة الثانوية الصناعية؛؛ لضمان قدرتها على تقديم الخدمات المتتوعة التي تقدمها للمستفيدين منها. وتعتبر قواعد البيانات المتوفرة عن الهيئات والجهات والشركات اللازم الاتصال بها وقت حدوث الأزمات أو بعد حدوثها، من أهم السبل التي تساعد المدرسة الثانوية الصناعية على تعافيها من تلك الأزمات واستعادة نشاطها مرة أخرى، ولعل تتوع وتعدد وسائل الاتصال المستخدمة في المدرسة الثانوية الصناعية وقت الأزمات أو بعدها تمهيدًا لاستعادة النشاط من أهم الأساليب التي تسهم في سرعة استعادة هذا النشاط، فهناك أجهزة الهاتف، وهناك الإنتركوم، الذي يجعل أجزاء المدرسة مرتبطة ببعضها البعض، وهناك أجهزة الكمبيوتر، والبريد الإلكتروني، وأجهزة الفاكس، ويعد هذا التوع أو التعدد من أشكال الأمن التي يجب على المدرسة توفيرها لذاتها؛ بحيث إذا حدث عطل في إحداها، أصبح الآخر متاحًا، الأمر الذي يسهم في عدم انقطاع المدرسة وانعزالها عن العالم الخارجي في وقت الأزمات، مما يمكنها من الاستعانة بمن يعينونها على تجاوز الأزمة التي تمر بها من المتخصصين. (47) كما يجب على المدرسة أن تضع لنفسها ما يسمى بثجرة الاتصالات Communication Tree

$$
\text { بالتواصل معها وقت حدوث الأزمة. (48) }
$$

بالإضافة إلى ما سبق، لا يمكن للمدرسة الثانويـة الصناعية استخدام وسائل الاتصال السالفة، أو إنشاء شجرة الاتصالات، إلا إذا كانت تمتلك قاعدة بيانات جاهزة للاستخدام وقت حدوث الأزمة، على ألّا يصيب تلك القاعدة أي شكل من 
أشكال الضرر نتيجة للأزمة التي تتعرض لها المدرسة، ومن ثم تتضح أهمية الحفاظ على أمن المعلومات في المدرسة الثانوية الصناعية، إذ إنها السبيل للتخلص من تلك الأزمات، عن طريق الاستعانة بعدد من الخبراء والمختصين من المجتمع الخارجي للمساهمة في التخلص من الآثار السلبية للأزمات، بل وتهديد قدرة المدرسة على تقديم خدماتها التعليمية للطلاب.

كما على المدرسة تعيين متحدث رسمي عنها وقت حدوث الأزمة، وهو الشخص الذي تتوافر لليه المعلومات المصرح للآخرين الحصول عليها أثناء الأوقات الحرجة، كما يتاح له الاتصال بجهات الاتصال الأخرى التي بوسعها المساعدة، ومن ثم تكون من سلطاته تقديم صورة كاملة لتلك الجهات عن الوضع الراهن للمدرسة، وذلك بناء على معلومات صحيحة وواضحة يشتقها من قواعد البيانات الموجودة في المدرسة لاستخدامها في هذه الأوقات، وذلك ليكون لديهم القدرة على تحديد الاحتياجات والمساعدات التي يستطيعون تقديمها للمدرسة. (49) ومما هو جدير بالذكر أن المدارس الفنية ـ بشكل عام - بولاية ماساتثوستس الأمريكية، تقدم نموذجًا حيَّا للاتصال بغيرها من جهات الاتصال؛ حيث تحدد جهات الاتصال التي من الممكن الاستفادة منها، وتحتفظ لذاتها بقاعدة بيانات كاملة عن تلك الجهات وكيفية الاتصال بها، ومن تلك الجهات المدارس الفنية الصناعية التي تقع في منطقة واحدة، والمعاهد الفنية الصناعية العليا، ووسائل الإعلام؛ كالجرائد والمجلات وهيئات الإذاعة والتليزيون بالولاية، وبعض الثركات والمصانع المحيطة بالمدرسة، وبعض شركات الكمبيوتر • (50) وبناء على ما سبق، يمكن القول إن هناك تعددية في جهات الاتصال بين المدارس الثانوية الصناعية، فهناك الثركات المسئولة عن ترويج منتجات تلك المدارس، وهناك شركات الكمبيوتر المسئولة عن إمداد المدرسة بالبرامج الأصلية التي تحتاجها الأجهزة للحفاظ على الأمن المعلوماتي، كما أنها مسئولة عن الصيانة وقت حدوث الأزمات، وهناك أيضًا المدارس المحيطة، التي يمكن إمداد بعضها البعض بالخبرات التي مرت بها أثناء حدوث الأزمات، كما أن هنالك المعاهد العليا، التي يمكن أن تقدم برامج تدريب مختلفة لكل من العاملين، والمعلمين، والطلاب في مختلف الأمور المرتبطة بعمهم، الأمر الذي يتضح من خلاله أن المدرسة الثانوية 
الصناعية في حاجة ماسة لقاعدة بيانات عريضة عن أهم الجهات التي يمكنها

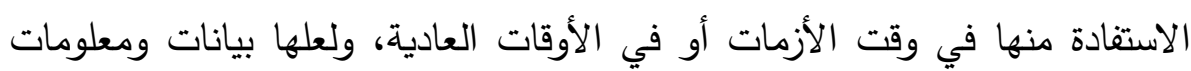
يجب أن تكون محفوظة بشكل سري، في يد المختصين والمعنيين فقط، لاستخدامها عندما تحتاج المدرسة إليها.

3. تدريب العاملين على إدارة الأمن المعلوماتي في المدرسة الثانوية الصناعية:

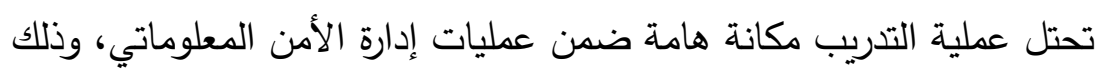

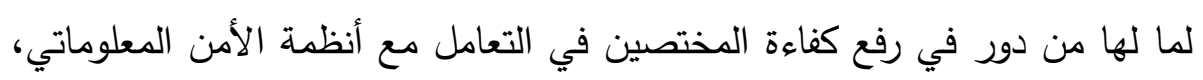

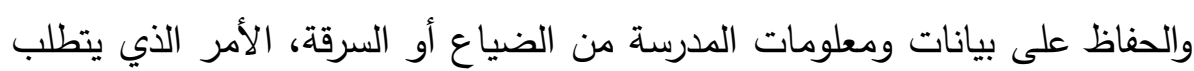

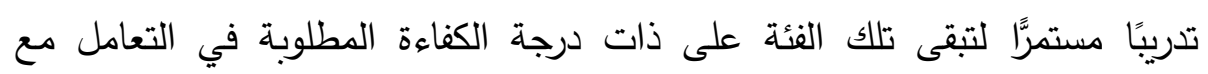
المعلومات، واستعادتها وقت الحاجة إليها، بل والوقوف على أحدث ما يمكن التوصل

$$
\text { إليه في مجال الأمن المعلوماتي، وتطبيقه في المدرسة. }
$$

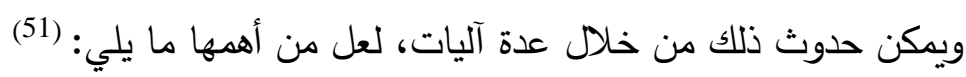

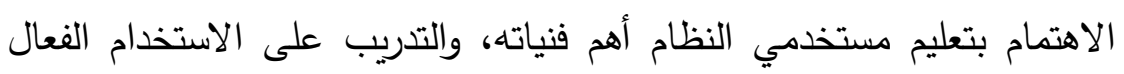

لذلك النظام.

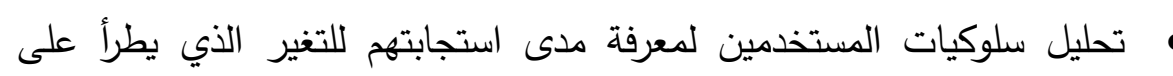

الأجهزة الإككترونية وأنظمة الأمن المعلوماتي لديهم.

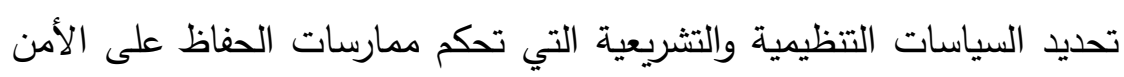

المعلوماتي للمنظمة.

تحديد أهم التهديدات التي تواجه الحفاظ على الأمن المعلوماتي بالمنظمات.

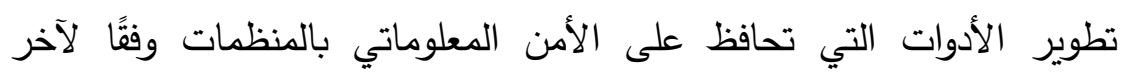
التطورات التي تحدث بأنظمة المعلومات بالعالم المحيط.

كما تقدم عدة مؤسسات دولية عددًا من البرامج لتتمية قدرات المتخصصين للحفاظ بالفال

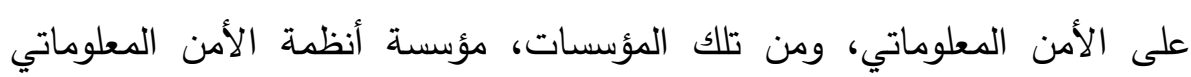
Information System Security Association(ISSA) ربحية، يتمثل هدفها الأساسي في إعداد وتدريب كل من يناط به الحفاظ على الأمن

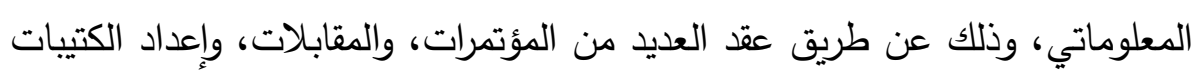

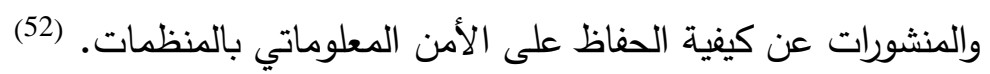


The وهناك أيضًا مؤسسة الرقابة والمراجعة على أنظمة المعلومات

،Information Systems Audit and Control Association (ISACA) وهي مؤسسة غير ربحية أيضًا، مهمتها الأساسية الرقابة والمراجعة على أنظمة

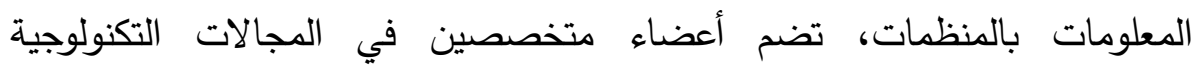
والإدارية، يقومون بدورهم بممارسات عن التمكن من تكنولوجيا المعلومات Information Technology (IT) داخل المنظمات للحفاظ على الأمن المعلوماتي في ضوء ما توصلت إليه من تقارير في أثناء المراجعة والتقييم، كما تقوم بنشر الأخلاقيات المرتبطة بالحفاظ على الأمن

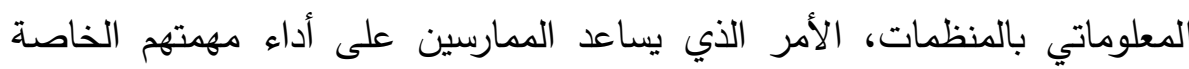

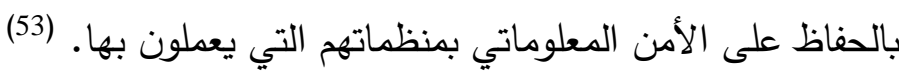

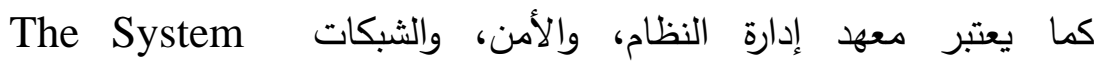
،Administration, Networking, and Security Institute (SANS) مؤسسة بحثية متخصصة، بعضوية عدد من المتخصصين في مجال الحفاظ على الأمن المعلوماتي، ويقدم بدوره عددًا من الثهادات العلمية للمتقدمين إليه، مثل شهادة عندية

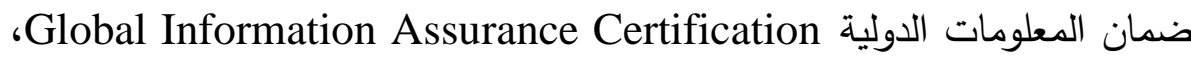
التي تهتم بضرورة تطبيق ما تم دراسته خلال فترة الدراسة بالمعهد على أرض الواقع،

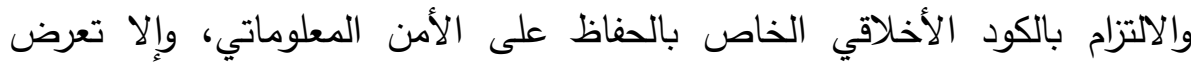

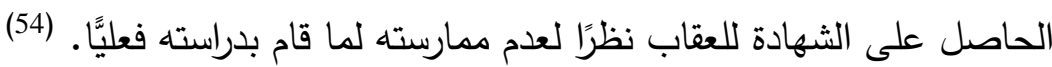
ويركز العمل بتلك المعاهد والمؤسسات على فكرة مؤداها التغير الدائم في الوظائف اللازمة للحفاظ على نظام الأمن المعلوماتي بالمنظمة، ومن تلك الوظائف التي يجب الانتباه لها وتدريب الموظفين عليها تصميم البرامج التي تحتاج المنظمة إليها، وتحديد المتطلبات وفقًا لطبيعة عمل المنظمة، وإنشاء نظام متكامل لتشفير المعلومات الموجودة بالمنظمة للحفاظ عليها، وتنزيل البرامج الجديدة والأصلية، والاحتفاظ بالمعلومات لحين الحاجة إليها دون أن يخترقها أحد الدخلاء وبدون إذن بـن لئن من المسئولين عن النظام. (55)

وبناء على ما سبق، يتضح أن برامج التدريب، تركز على التحديث والتجديد

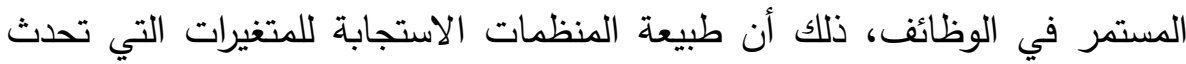


بالمجتمع الخارجي، وإذا كانت التكنولوجيا الحديثة هي أكثر المتغيرات بروزًا في الآونة الأخيرة، فإن التدريب على التمكن من مهارات التعامل معها، والتمكن منها

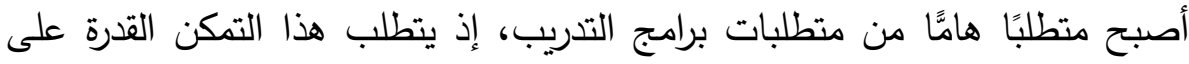

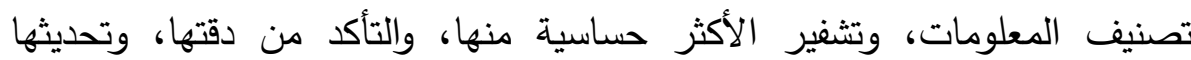
باستمرار -

كما تختلف مستويات التدريب الخاصة برفع وعي الموظفين عن الأمن المعلوماتي، وفقًا لمستوى عمق المفاهيم المقدمة بتلك البرامج، وذلك وفقًا أيضًا للمهام المطلوبة البه من كل فئة من فئات الموظفين، ويمكن تحديد ذلك، من خلال النظر للشكل التالي:

شكل رقم (3) درجة عمق التدريب الذي يركز على أهمية الأمن المعلوماتي بالمنظمة

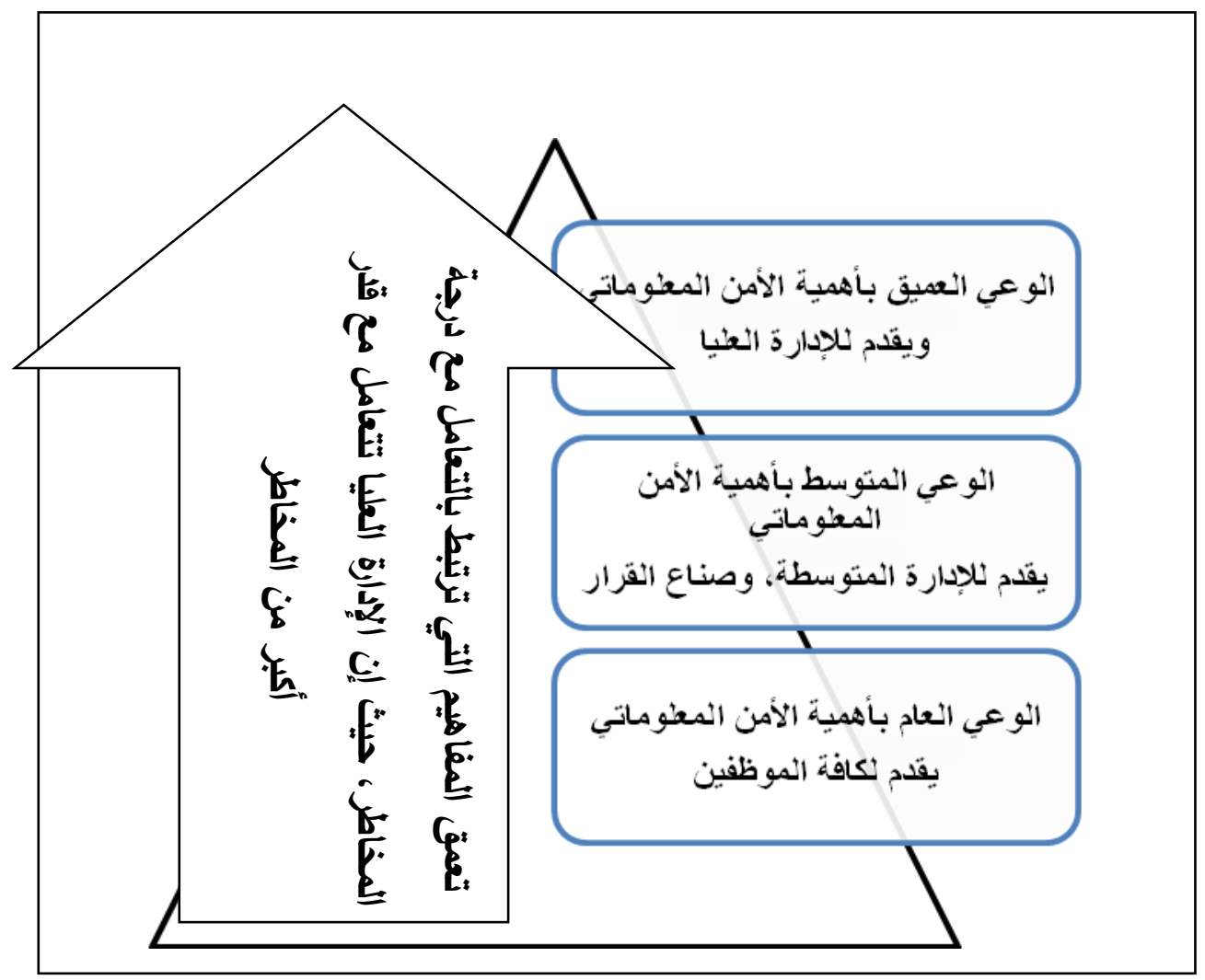

مما سبق، يتضح أن هناك ثلاثة مستويات يجب أن تركز عليها برامج التدريب المقدمة إلى المسئولين التربويين في المدارس الثانوية الصناعية؛ حيث يجب انب أن تركز 
البرامج المقدمة إلى جميع الإداريين والموظفين المسئولين عن الحفاظ على الأمن

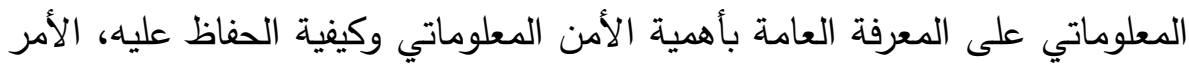

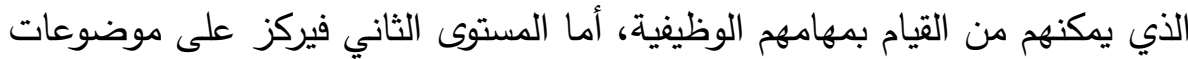

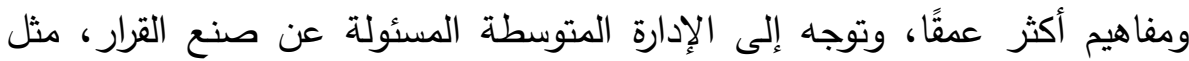
مدير المدرسة والوكلاء، وأخيرًا البرامج المقدمة إلى الإدارة العليا، الخاصة بهاء بالوزارة،

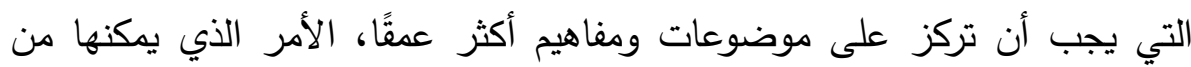
اتخاذ القرارات العليا، بناء على المعلومات الموجودة في المدارس والإدارات

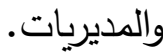

كما على برامج التدريب أن تهتم بتقديم مبادئ الأمن المعلوماتي للعاملين

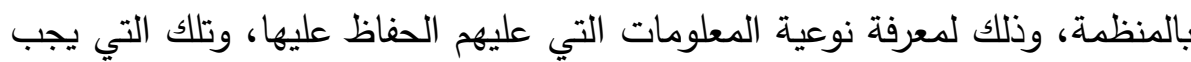
نشرها للفئات المستفيدة من عمل المنظمات، وتلك المبادئ هي: (57) - التكامل Integrity: وهو المبدأ الذي يعني قدرة العاملين على إحداث الربط والتكامل بين المعلومات التي تمتلكها المنظمة، والتي عن طريقها يمكن إمداد المستفيدين بمعلومات كاملة ذات دلالة ومعنى. - درجة حساسية المعلومات Confidentiality: وتعني قدرة العاملين على دلى دلى دماته معرفة المعلومات التي لا يجب أن تعلن للمستفيدين، لأنها تعتبر أسرار لها، ونها، تخص سياستها الداخلية التي لا يجب على أي فرد الاطلاع عليها. - الإخاحة Availability: وتعني قدرة العاملين على معرفة المعلومات التي لي لئي يجب إتاحتها للمستقيدين عن المنظمة، ومن ثم الاستفادة منها. ويلاحظ مما سبق، أن هناك ضرورة ملحة لتدريب العاملين بوجه عام، والإداريين في المدارس الثانوية الصناعية بشكل خاص، على تلك المبادي؛؛ للتثرقة بين نوعية المعلومات التي يجب الحفاظ عليها، والمعلومات التي عليهم نشرها من

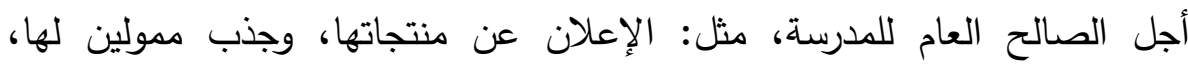
والتسويق لخدماتها، بل وإحداث التكامل بين المعلومات لخلق فرص التسويق لخدمات المدرسة الثانوية الصناعية، وفي ذات الوقت الحفاظ على المعلومات التي لا يمكن لتصن

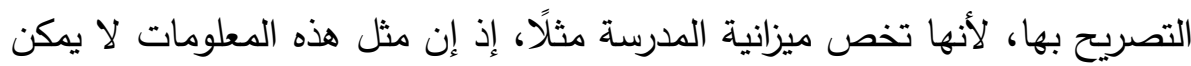
التصريح بها. 
وتهدف برامج التدريب للحفاظ على الأمن المعلوماتي إلى تحقيق عدد من

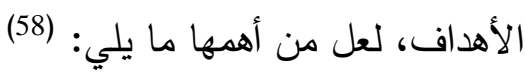

الفهم التام والتأقلم مع إجراءات وسياسات الحفاظ على الأمن المعلوماتي

بالمنظمة.

التمكن من القواعد التي يجب اتباعها عند حدوث أي اختراق للأمن المعلوماتي

بالمنظمة.

التعاون مع إدارة المنظمة للحفاظ على أمنها المعلوماتي ومقابلة الاحتياجات

التدريبية للموظفين الذين يعملون بها.

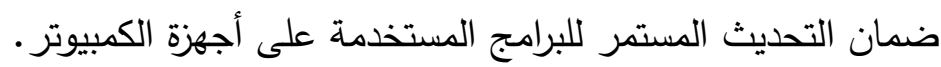

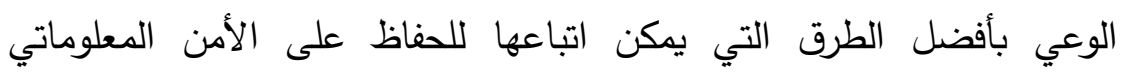

بالمنظمة التي يعملون بها.

كما لا يمكن أن نغفل دور برامج التدريب في تتمية المهارات اللازمة للتعامل مع الحواسيب، والبرامج المضادة للفيروسات، وبناء قواعد البيانات، وتشفير

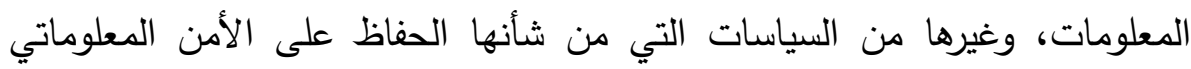

بالمنظمة. (59)

بناء على ما سبق، يتضح أنه لا يمكن إغفال تمكين العاملين في مجال الإدارة

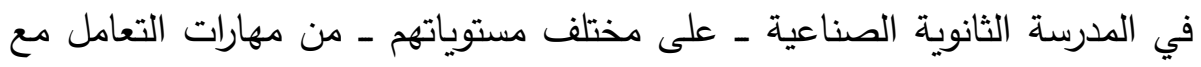

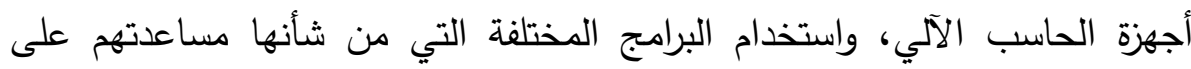

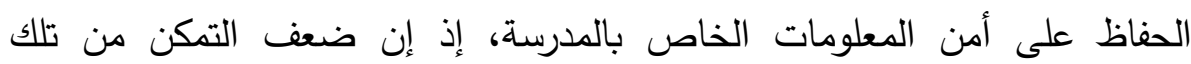
المهارات، يعوق تحقيق الغاية القصوى من وراء التمكن منها، ألا وهي الحفاظ على إلى إنى الأمن المعلوماتي المرغوب، وبالتالي مساعدة المدرسة الثانوية الصناعية على تعافيها من الأزمات واستعادة نشاطها سريعًا بما يحقق رضات المعابل المستفيدين.

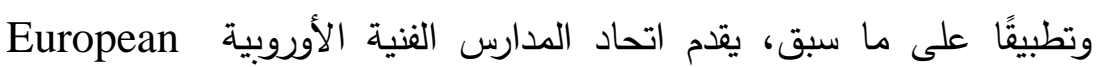

Technical School Union

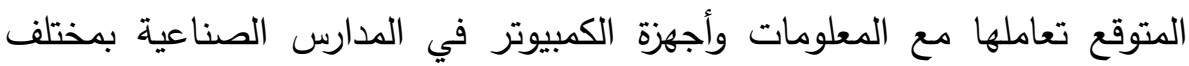
أنحاء القارة الأوروبية، بدءًا من مدير المدرسة، وحتى المعلمين، والعاملين والإداريين

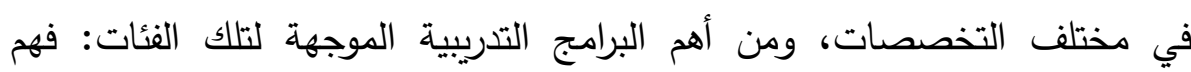


السياق الإستراتيجي لإدارة عمليات الأمن المعلوماتي، وترجمة إستراتيجية الأمن

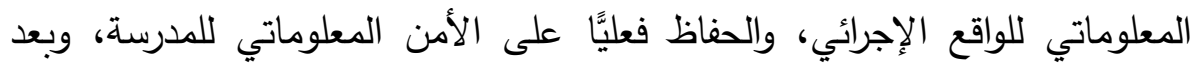
الانتهاء من تلك البرامج التدريبية يتوقع من المشاركين بتلك البرامج أن يتمكنوا من الن

المهارات التالية: (60)

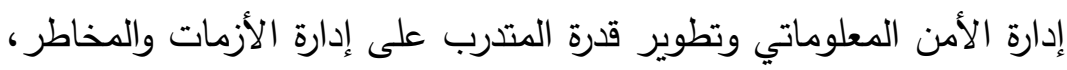

وامتلاك السياسات الملائمة لاحتياجات المدرسة.

إنثاء نظام للأمن المعلوماتي، وعمليات إدارة المخاطر •

الوعي بأهية الحفاظ على الأمن المعلوماتي، وتحديد المقاييس الدارة اللازمة

للحكم على مستوى الأمن المعلوماتي في المدرسة.

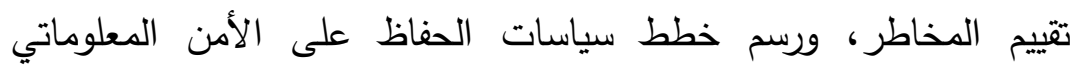

ل ل لمدرسة.

التسيق بين فرق العمل المختلفة وتوزيع مهام العمل؛ حيث إن لكل فرد

مهمة في الحفاظ على الأمن المعلوماتي للمدرسة.

4. تقويم الأمن المعلوماتي في المدرسة الثانوية الصناعية:

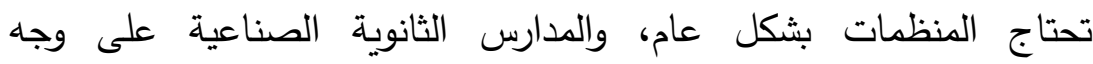

الخصوص لنظام تقويم يؤكد قدرة المدرسة على الحفاظ على أمنها المعلوماتي، ويتم ذلك عن طريق عدة طرق؛ كالاستبيانات، والمقابلات، وملاحظة التقارير الرسمية،

$$
\text { وغيرها من الأساليب الأخرى. (61) }
$$

ويعتبر نظام ISO27001، أهم الأنظمة المتبعة بالمنظمات للتأكد من قدرة

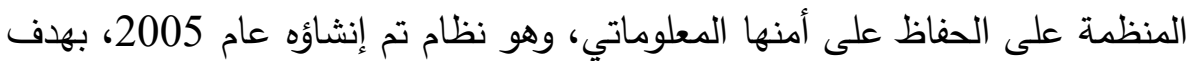

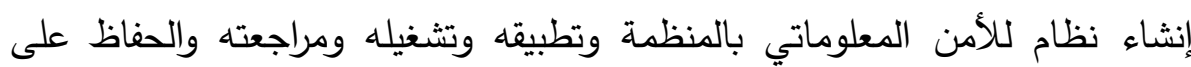
إدارته، كما يشتمل هذا النظام على وضع التحسينات اللازمة لتطوير هذا النظام

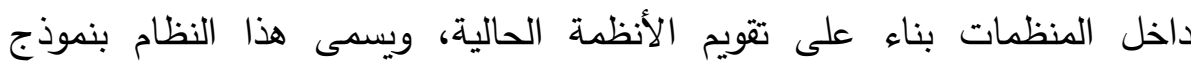
PDCA Model وتشير الـ D إلى Do، وتشير الـ C إلى Check، وأخيرًا تشير الـ A Act إلى Act

وذلك كما هو مبين بالشكل التالي: (62) 


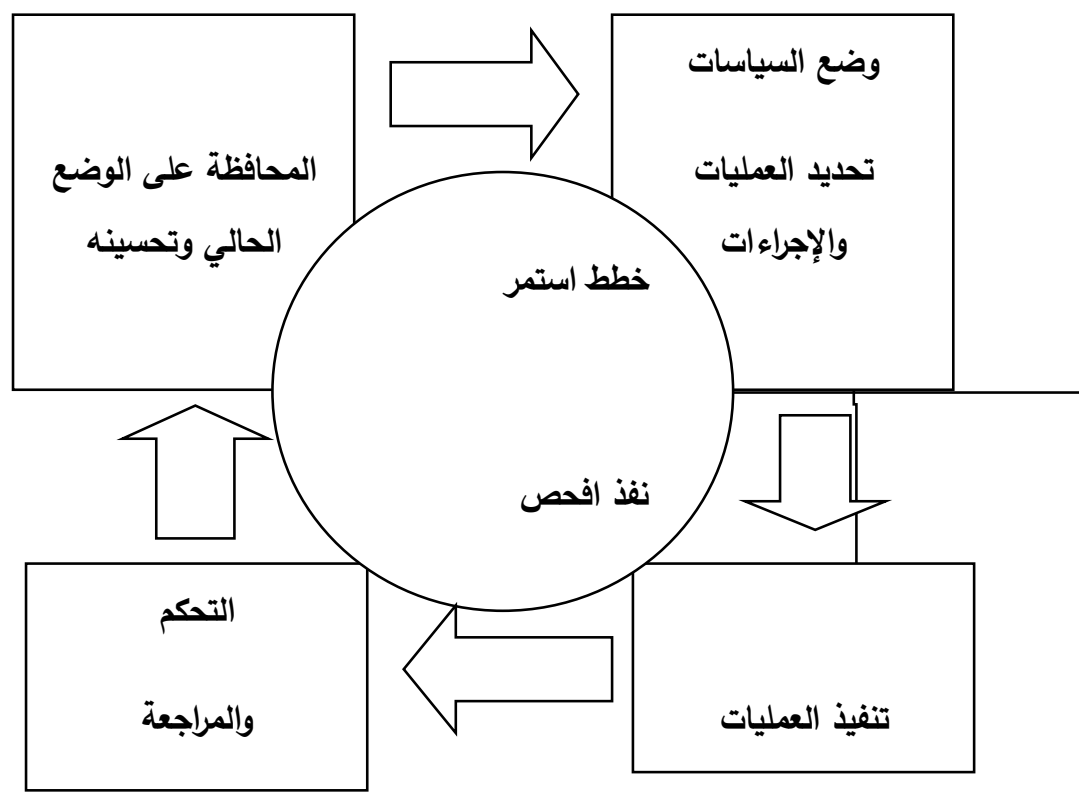

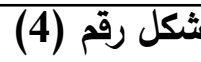

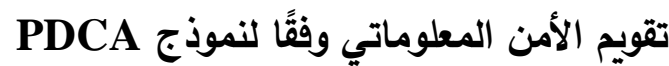

يعتبر هذا النموذج أحد نماذج تقويم قدرة المنظمة على الحفاظ على أمنها المعلوماتي، وتحسين الإجراءات التي تتبعها للحفاظ عليه في المستقبل، ولتستطيع المدرسة الثانوية الصناعية تقويم قدرتها على الحفاظ على أمنها المعلوماتي عليها أن إنهاء

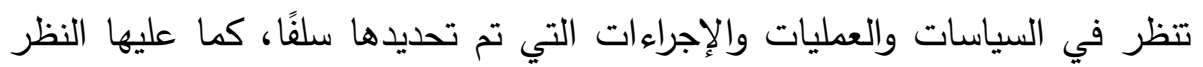
في الطريقة التي نفذت بها العمليات، الأمر الذي سيمكنها من المراجعة، والتقويم، ثم التحسين، وتبني مزيد من الإجراءات التي ستضمن مزيدًا من الحفاظ على الأمن

$$
\text { المعلوماتي لها. }
$$

ويركز هذا النظام على ضرورة اتباع عدة خطوات لتحقيق عملية التقويم

والتأكد من حفاظ المنظمة على أمنها المعلوماتي، وتلك الخطوات هي: (63)

الحصول على دعم الإدارة العليا Upper Management Support: تعني هذه الخطوة إيمان الإدارة العليا بالمنظمة، والتزامها بالحفاظ على الأمن

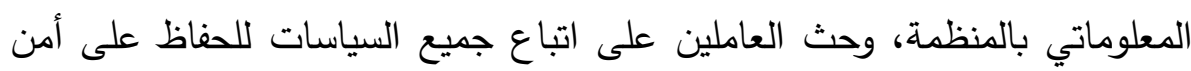

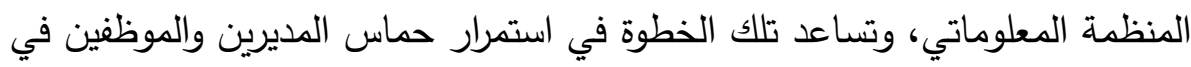


الحفاظ على الأمن المعلوماتي، فالأمن المعلوماتي عملية تبدأ من المدير، وتتتهي إليه؛ فهو الذي يمتلك أساسيات الحفاظ على الأمن المعلوماتي بالمنظمة التي يرأسها.

\section{• مefine Security Perimeter مضوح الحدود الفاصلة للأمن}

لعل من الأولويات الهامة لهذا النظام التقويمي وضع المحيط الذي يتم الحفاظ على الأمن فيه، أي الحدود الفاصلة التي يمكن للأمن المعلوماتي أن يعمل فيها، بمعنى تحديد نمط المنظمة، أو نوعها، وبالتالي تحديد نوعية المعلومات التي يتم الحفاظ عليها وعلى سريتها.

Create Information Security وضع سياسة للأهن المعلوماتي

\section{:Policy}

من الممكن أن تأخذ سياسات الأمن المعلوماتي أكثر من شكل، ويمكن أن توضع في شكل وثيقة واحدة، أو أكثر من وثيقة توجه لعدد من الأفراد، أو توضع في شكل عدد من المعايير التي يجب أن يلتزم بها الأفراد، كما أنها قد تشتمل على الأهداف التي من الممكن أن تتحقق من وراء الحفاظ على الأمن المعلوماتي بالمنظمة.

Create Information Security إنشاء نظام إدارة الأمن المعلوماتي

\section{:Management System}

يقوم هذا النظام التقويمي على النظر في إجراءات إنشاء نظام الأمن المعلوماتي بالمنظمة، بالإضافة إلى إجراءات التطبيق، والتعزيز أيضًا، الأمر الذي يساعد على تحسين الإستراتيجيات، ووضع الإجراءات الجديدة لوضع أنظمة إدارة الأمن المعلوماتي، وبناء الفرق، وتحديد مزيد من الإجراءات اللازمة للحفاظ على الأمن المعلوماتي.

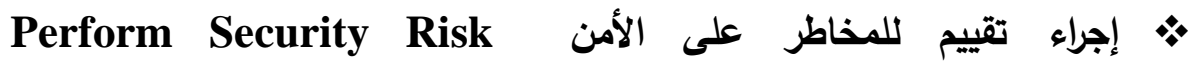

\section{:Assessment}

في هذه الخطوة يتم توقع جميع المخاطر التي من الممكن أن تهدد الأمن المعلوماتي للمنظمة، وذلك للاستعداد لها، وتتضمن تلك الخطوة الخطوات الفرعية 
تحديد الأسس والأصول التي تتضمنها عملية الحفاظ على الأمن

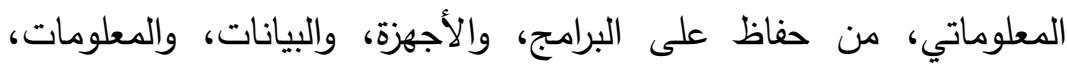

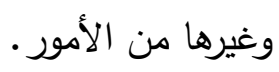

تحديد التهديدات المتوقعة لهذه الأسس والأصورل.

تحديد نقاط الضعف المتوقعة بهذه الأسس والأصول، والتي تحول دون

تحقيقها.

تحديد احتمالية التفاعل بين التهديدات المتوقعة، ونقاط الضعف المتوقعة،

$$
\text { والتي قد تحول دون تحقيق الأهداف أيضًا. }
$$

حساب نسبة الضرر التي قد تصيب المنظمة من جراء عدم الحفاظ على لهى الأمن المعلوماتي للمنظمة.

حساب درجة الخطر التي قد تصيب المنظمة من جراء عدم الحفاظ على الى أمنها المعلوماتي.

\section{Implementing and Selecting تنفيذ الخطة واختيار أنماط الرقابة}

\section{:Control}

يتم في هذه الخطوة مراقبة إجراءات التطبيق التي تتم بالمنظمات للحفاظ على

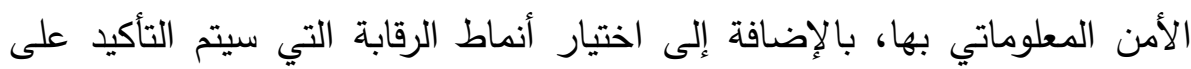

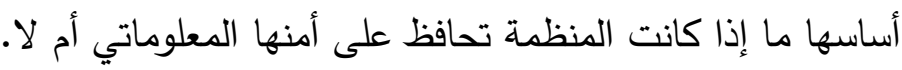

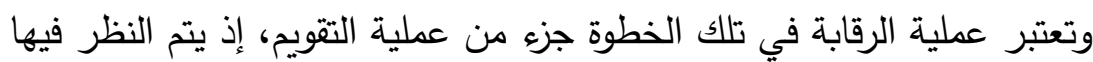

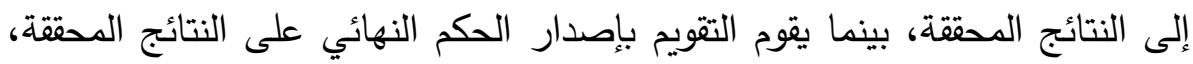

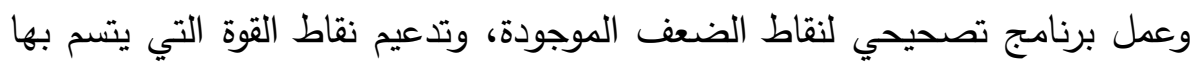

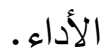

وبناء على الخطوات السابقة، تستطيع المنظمة استرجاع المعلومات وقت الحاجة إليها، خاصةً وقت الأزمات والكوارث، وبالتالي تضمن استمرارية العمل وقت التصاء

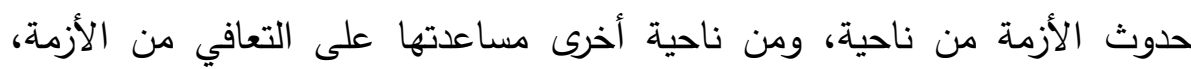
واسترجاع مكانتها بسرعة، الأمر الذي يساعدها على نيلى زيادة إنتاجيتها، وزيادة ثقة عملائها فيها. 
كما يوجد نظام ISO 17799 وهو نموذج آخر لمراقبة قدرة المنظمات على الحفاظ على أمنها المعلوماتي، وقدرتها على استخدام تلك المعلومات في استعادة نشاطها بعد حدوث الأزمات، ويركز هذا النموذج على ضرورة توافر عدد من العناصر للحكم على قدرة المنظمات على الحفاظ على أمنها المعلوماتي، وتتمثل تلك

العناصر فيما يلي: (64)

وجود سياسات مختلفة للحفاظ على الأمن المعلوماتي بالمنظمة. توافر قدر من الأمن المؤسساتي للمنظمة، والذي يشير إلى قدرة المنظمة ــ من خلال إمكاناتها المختلفة ـ على الحفاظ على المعلومات الموجودة بها، وذلك عن طريق توفر عدد من الآليات للحفاظ على الأمن المعلوماتي بها، والتي كلما ازدادت وتتوعت دلّ ذلك على قدرة المنظمة على الحفاظ على الأمن المعلوماتي

الأمن البشري، الذي يشير إلى تأمين قدرة العامل البشري على استخدام جميع الأجهزة الخاصة بالحفاظ على الأمن المعلوماتي للمنظمة، وتدربهم باستمرار للحفاظ على قدراتهم في هذا الصدد. قدرة المنظمة على التواصل مع غيرها من المنظمات الأخرى للمساهمة في التخلص من الأزمات التي قد تواجهها، بالإضافة إلى قدرتها على تبادل المعلومات مع تلك الجهات. قدرة المنظمة على مراقبة دخول الآخرين للمعلومات الخاصة بها، والحفاظ على المعلومات ذات الحساسية العالية، التي لا يمكن لأي فرد الدخول إليها، إلا المتخصصين من داخل الإدارة فقط. قدرة المنظمة على الاستمرار في تقديم خدماتها للمستفيدين أثناء حدوث الأزمات. قدرة المنظمة على تطوير نظامها باستمرار وابتكار أنظمة جديدة للحفاظ على أمنها المعلوماتي. وبناء على ما سبق، يتضح أن هناك نماذج متعددة لتقويم إدارة الأمن المعلوماتي، تللك النماذج تهدف في مجملها إلى التأكد من قدرة المنظمات بشكل عام، والمدارس الثانوية الصناعية على وجه الخصوص - بوصفها أحد أنماط المنظمات ـ 
على الحفاظ على أمنها المعلوماتي، بل وتطوير تلك القدرة باستمرار، وتحديثها، من أجل مساعدتها على استعادة نشاطها بعد حدوث الأزمة، وتعافيها من آثار الأزمة

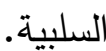

ووضعت ولاية أوهيايو مجموعة من المعايير التي يمكن للمدارس الثانوية الفنية تقويم قدرتها للحفاظ على الأمن المعلوماتي لديها، ومن تلك المعايير ما يلي:

توافر بيانات ومعلومات لدى المدرسة عن جهات التسويق، وصيانة الأجهزة، واحتياجات سوق العمل، وأولياء الأمور، وجميع الجهات التي يمكن أن تثيد

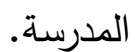

توافر قيادة واعية بالأدوار الأساسية اللازمة للحفاظ على الأمن المعلوماتي في

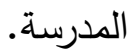
توافر وسائل وقنوات اتصال بين المدرسة والجهات المعنية للاستفادة من تلك الجهات وقت الحاجة، كالاتصال بالشركات للتدريب وصيانة الأجهزة، والاتصال بأولياء الأمور لإببلاغهم عن الوضع الحالي للمدرسة، أو الجهات التي يمكن تسويق منتجات المدرسة عن طريقها أو إليها. توافر فريق مسئول عن الحفاظ على أمن المعلومات في المدرسة؛ بحيث يكون إنهات

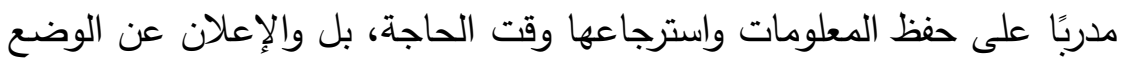
الراهن للمدرسة، خاصةً وقت الأزمات. توافر مجموعة من القواعد المعلنة التي يعلمها جميع العاملين في المدرسة عن العقوبات التي تفرض على مخترقي قواعد البيانات والمعلومات. توافر الأجهزة والبنية التحتية والبرمجيات الحديثة والأصلية اللازمة لتخزين

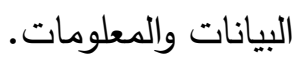
تحديد المخاطر المتوقعة التي قد تصيب المدرسة، ووضع الخطط اللازمة لالتغلب عليها. توافر الاحتياجات اللازمة لعمل شبكات داخلية وخارجية في المدرسة؛ لتسهيل

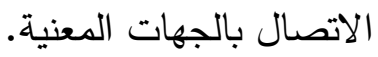


توفر أنظمة محددة لتشفير المعلومات ذات الحساسية العالية، والتي يجب أن يتعامل معها فقط المتخصصون من داخل المدرسة.

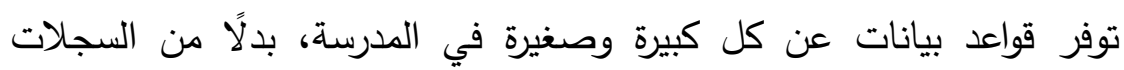

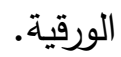
وبالنظر إلى تلك الخطوات يتضح، أن هناك اتساقًا بينها وبين نظامي التقويم المعروضين سالفًا، أي نموذج PDCA، ونظام 17799 ISO، أي أن تلك الخطوات جمعت بين النظامين للتأكد من قدرة المدرسة الثانوية الصناعية على الحفاظ على الأمن المعلوماتي بها. القسم الثالث ـ واقع إدارة عمليات الأمن المعلوماتي في المدرسة الثانوية الصناعية في مصر: يقدم هذا الجزء من البحث نظرة شمولية لواقع الأمن المعلوماتي في المدرسة

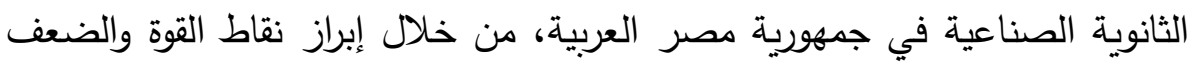
في المدرسة الثانوية الصناعية والفرص والتهديدات بالمجتمع المحيط؛ من أجل إدارة عمليات الأمن المعلوماتي للمدرسة، وفيما يلي تقصيلًا لتلك الخطوة، والتي تتناول توضيحًا لواقع المدرسة الثانوية الصناعية في جمهورية مصر العربية، من حيث فلسفتها وأهدافها وإداراتها وممارسات مديريها، وذلك من خلال الدراسات التي أُجريت في هذا الصدد، وفيما يلي تفصيل لذلك الواقع: تنطلق الرؤية المستقبلية لسياسة التعليم قبل الجامعي، من منطلق أساسي، ألا

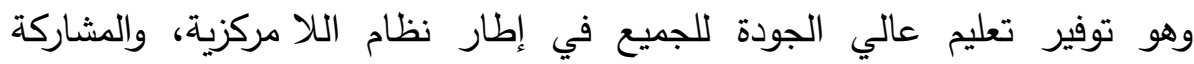
المجتمعية، وعلى قدرة القيادات في التعامل مع المتغيرات الحديثة بكفاءة، والتخطيط الإستراتيجي الجيد، والتفكير المتأمل، وذلك حتى يكون للقادة دور في التئي التغيير

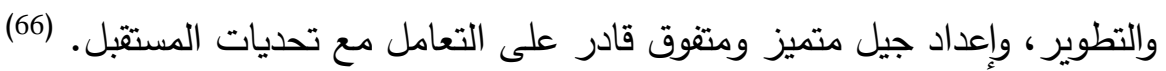
ويهدف التعليم قبل الجامعي إلى تكوين الدارس تكوينًا ثقافيًّا وعلميَّا وقوميًّا؛ بقصد إعداد الإنسان المصري المؤمن بربه ووطنه وبقيم الخير والحق والإنسانية،

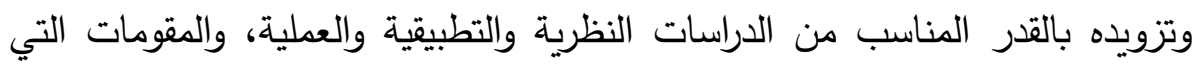
تحقق إنسانيته وكرامته، وقدرته على تحقيق ذاته، والإسهام بكفاءة في عمليات وأنشطة الإنتاج والخدمات، من أجل تتمية المجتمع، وتحقيق رخائه وتقدمها. 
والتعليم قبل الجامعي حق لجميع المواطنين في مدارس الدولة بالمجان، ومن

هذا المنطلق تم إنشاء مدارس التعليم الفني بنوعياته، وذلك لإعداد فئة "الفني" في

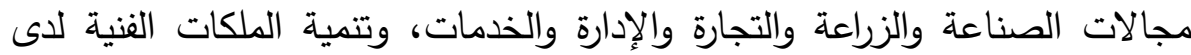
الدارسين، ويتم القبول في نوعيات التعليم الثانوي الفني بعد الحصول على شهادة

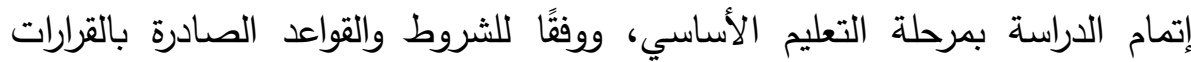
الوزارية المنظمة للنواحي التعليمية، وقد تم إنشاء المدارس الفنية بمواصفات فنية

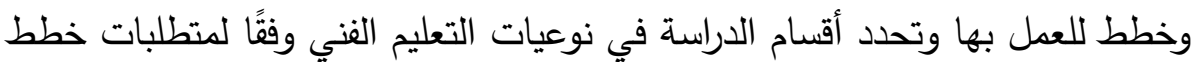

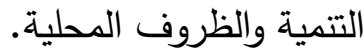

كما أن المدارس الفنية تقوم بمشروعات إنتاجية ذات صلة بتخصصها ولخدمة

البيئة والمجتمع داخل كل محافظة، وقد صدر قانون التعليم رقم 139 لسنة 1981 المعدل بالقانون رقم (233) لسنة 1988 ومن خلاله صدرت القرارات الوزارية المنظمة للنواحي التعليمية. (67) بلون

ومن ثم تقوم فلسفة التعليم الثانوي في مصر على تتمية الموارد البشرية المدربة والواعية، القادرة على استيعاب التكنولوجيا، وأصولها، وطرق استثمارها، وتكييفها لحاجات التتمية الاقتصادية، ومواجهة تحديات المستقبل، ومتطلبات سوق العمل، من خلال ما يلي: (68)

العمل على الوفاء بالحاجات التعليمية للمتعمين، وتطوير المهن والوظائف بما يتفق مع خصائص مرحلة المراهقة.

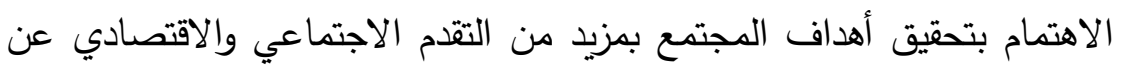
طريق تنمية طاقات الفرد، ومشاركته الإيجابية في تحقيق الأهداف. تهيئة الطلاب للعمل المفيد والربط بين أغراض التربية المدرسية، والأغراض

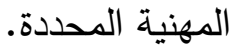
الاهتمام بالكثف عن ميول الطلاب وقدراتهم واستعداداتهم، وتوجيه هذه الميول

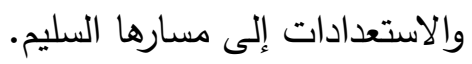
إمداد الطلاب بالمهارات الأساسية والمعلومات والمفاهيم العلمية والفنية التي هـاتي تمكنهم من احتراف المهنة، ومساعدتهم على الاستمرار في التقدم فيها. 
بناء على ما سبق، يتضح أن المدرسة الثانوية الصناعية، كجزء من المدرسة الثانوية الفنية، تسعى إلى بناء اقتصاد متقدم قائم على العلم والمعرفة، وقائم أيضًا على مهارات الطلاب الخريجين القادرين على تقديم منتجات عالية الجودة، تكون قادرة على منافسة مثيلاتها من المنتجات الأخرى على مستوى العالم. ويمكن استتباط نوعيات مختلفة من البيانات والمعلومات التي يجب الحفاظ عليها، وإدارتها، بشكل يسهر في استعادتها وقت الحاجة في الددرسة الثانوية الصناعية، ومن تلك النوعيات:

بيانات أعضاء هيئة التدريس والإداريين والعاملين في المدرسة، بما فيها بياناتهم الشخصية، وتقارير أدائه، وسنوات خبرتهم، والبرامج التدريبية التي حصلوا عليها. بيانات الطلاب المقيدين في المدرسة وأولياء أمورهم. ميزانية المدرسة، والموارد المادية المتاحة لها لتنفيذ خططها الحالية والمستقبلية. المعلومات التي تقدمها المدرسة لزائري صفحتها الرسمية على الإنترنت.

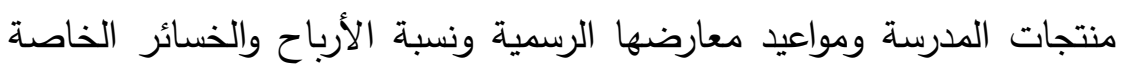
بكل مشروع. المعلومات التي تجلبها المدرسة عن الممارسات الأفضل لدى مثيلاتها من المدارس الأخرى لتحقيق الإنتاجية الأعلى والمنافسة. معلومات عن احتياجات سوق العمل من المهارات والإمكانات المختلفة. معلومات عن أهم المصانع والثركات المحيطة، التي يمكن أن تقدم للموظفين أو المعلمين أو الطلاب برامج تدريبية تربط الدراسة النظرية بالدراسة التطبيقية.

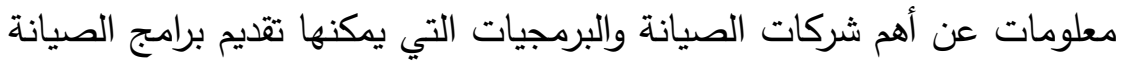
والبرامج الأصلية للمدرسة، وبالتالي الاستعانة بها بسهولة وقت الحتردات الحاجة. يتضح مما سبق، أن المعلومات الموجودة في المدرسة تتراوح في درجة أهميتها بين المعلومات التي تحتاج إلى قدر من السرية فتحتاج إلى تشفير، كالميزانية،

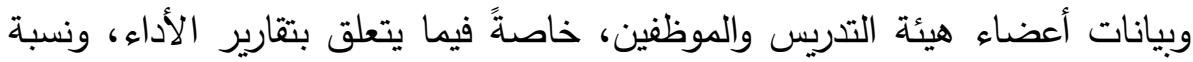
الأرباح والخسائر ، والمشروعات المستقبلية التي تتوى المدرسة القيام بها، والممارسات الأفضل لاى المدارس الأخرى، والبيانات العادية التي تتاح على موقع المدرسة، لوكية 
وتستخدم في تسويق منتجاتها؛ كمواعيد المعارض السنوية، ونوعية المنتجات المقدمة فيها، وغيرها من المعلومات الأخرى.

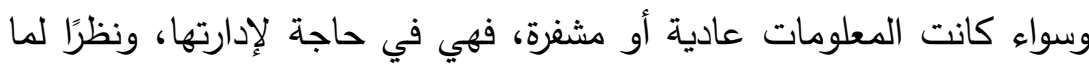

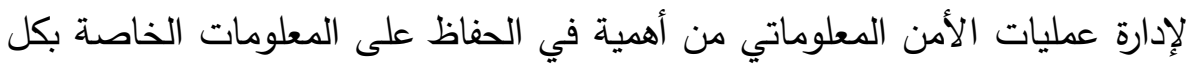

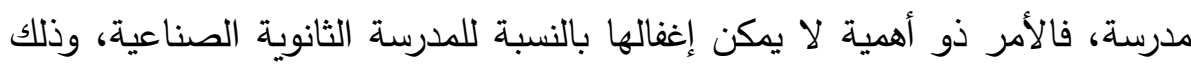

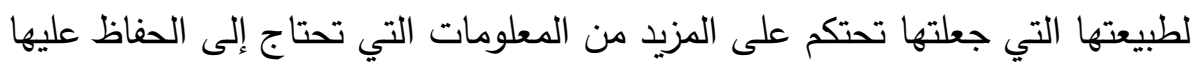
من الضياع أو السرقة مقارنةً بأنماط المدارس الأخرى.

وفي السطور القليلة القادمة يقوم البحث ـ وففًا لمنهجيته ـ بتحليل البيئة

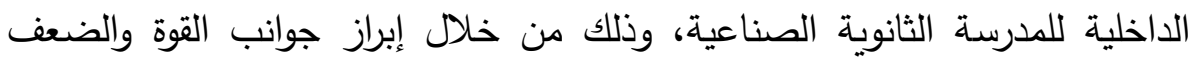

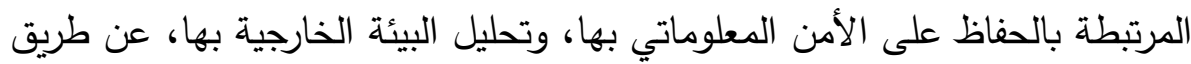
إبراز الفرص والتهديدات المرتبطة بالحفاظ على الأمن المعلوماتي في المدرسة

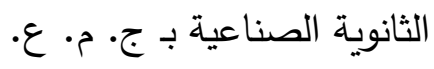

أولًا ــ نقاط القوة المرتبطة بإدارة عمليات الأمن المعلوماتي في المدرسة الثانوية

الصناعية (Strengths (S)

يتعرض هذا الجزء من البحث للجهود التي قامت بها الوزارة لمساعدة العاملين في المدرسة الثانوية الصناعية ـ وعلى رأسهم مدير المدرسة ـ على الحفاظ على هنى الأمن المعلوماتي للمدرسة، ومن ثم تهدف الخطة الإستراتيجية للتعليم قبل الجامعي فيما يخص التعليم الفني - إلى إتاحة التجهيزات وتكنولوجيا التعليم بما يتناسب مع إنسئ نوعية التعليم الفني وعدد الطلاب وفق معايير معدة لذلك، بالإضافة إلى استكمال التجهيزات والبنية التحتية اللازمة للمدارس، وتوفير البنية التحتية والإمكانات المادية والبشرية، والآلات والعدد والخامات والبرامج التدريبية لتفعيل العملية التعليمية في

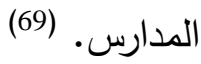

وفي إطار مبادرة تطوير التعليم المصرية الثاملة، يتمثل الغرض من مشروع تطوير التعليم الفني باستخدام تكنولوجيا المعلومات والاتصالات، في الارتقاء بالتعليم

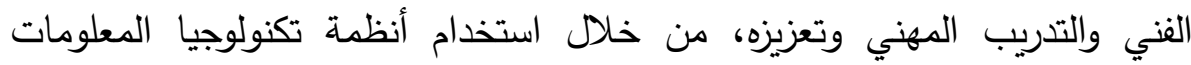

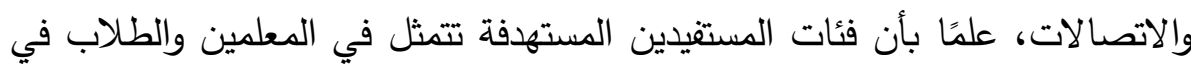
المدارس الصناعية، فضلًا عن المجتمع الأكبر المحيط بهذه المدارس. وخلال 
المشروع، تم تحديث 10 مدارس مهنية متقدمة في نواحي البنية التحتية لتكنولوجيا

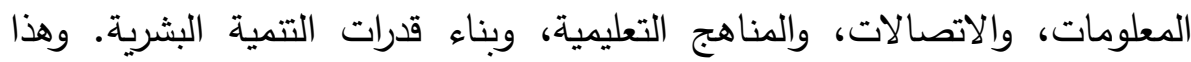
المشروع شراكة بين وزارة الاتصالات وتكنولوجيا المعلومات والبرنامج الإنمائي للأمم ولاه المتحدة. (70) ( )

كما استحدثت وزارة التربية والتعليم بعض الوحدات المدرسية داخل المدارس

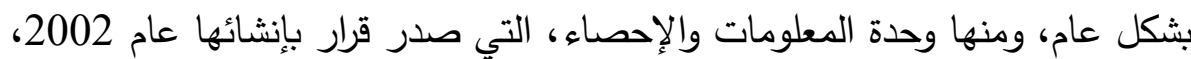
بموجب القرار الوزاري رقم 99، الذي نصت مادته الأولى على أن يتم إنشاء وحدة تسمى وحدة المعلومات والإحصاء بجميع المدارس بالمراحل الدراسية كافة، وتتثكل على النحو التالي: (71)

$$
\text { • أحد الوكلاء في المدرسة (ويكون مشرفًا على الوحدة). }
$$

أحد العاملين في المدرسة ممن يجيدون استخدام الحاسب الآلي من غير العاملين

$$
\text { بالتدريس. }
$$

عدد من العاملين والسكرتارية.

ويتراوح عدد العاملين بالوحدة من 2 ـ 5 أفراد، وذلك حسب حجم حمث المدرسة،

$$
\text { وتكون الوحدة تحت الإشراف المباشر لمدير المدرسة. }
$$

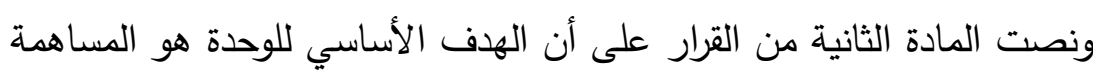
في تحقيق نظام معلومات شامل ومتكامل، يلبي متطلبات المستويات الإدارية

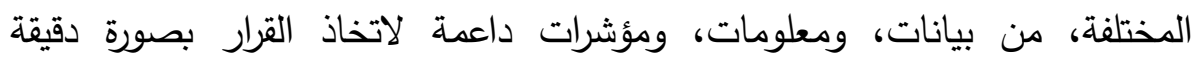

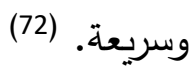

أما عن اختصاصات الوحدة فقد حددها القرار في مادته الثالثة وفقًا لما يلي:

• تجهيز وتدقيق إدخال البيانات اللازمة لنظام المعلومات. تسجيل كل ما يطرأ من تغيير على بيانات التلاميذ والعاملين في المدرسة فورًا، وبكل دقة. - مبك.

• التأكد من صحة البيانات ودقتها، ومطابقتها للواقع باستمرار • توفير المعلومات لكل المستويات وتداولها وفق التعليمات. الحفاظ على أمن البيانات وسريتها. 
• القيام بالإجراءات الفنية الخاصة بعمل نسخ الحفظ وخلافه.

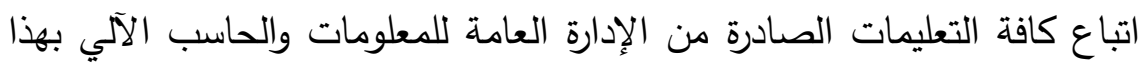

الشأن.

كما استحدثت وزارة التربية والتعليم وحدة مدرسية جديدة في المدرسة الثانوية الفنية، أطلق عليها وحدة معلومات سوق العمل، وأنشئت بهدف دراسة البيانات الخاصة بسوق العمل وتحليلها، للوصول إلى نتائج تتيح فرص تعليم أفضل وسهولة

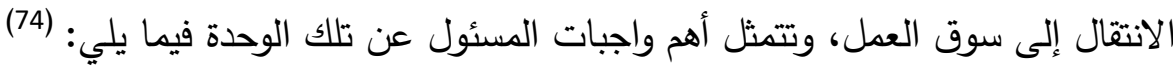
• قيادة قسم معلومات سوق العمل بالوحدة المدرسية. • الاشتراك مع أعضاء الوحدة في وضع الخطة السنوية للقسم والوحدة. التعاون مع مسئول التوظيف في إنشاء قاعدة بيانات عن سوق العمل في نطاق

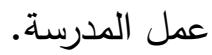
تحليل البيانات الخاصة بسوق العمل وتقديم المقترحات لمدير الوحدة المدرسية، ومسئول معلومات سوق العمل بالوحدة الفرعية.

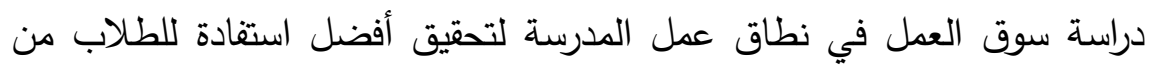
البرامج التدريبية. بناء علاقات عمل جيدة مع أصحاب الأعمال للوقوف على احتياجاتهم ومحاولة تلبيتها. إمداد قسم التدريب بنتائج دراسة سوق العمل وتحليله، حتى تتيح للطلاب برامج تكميلية وتحويلية لمواكبة متطلبات سوق العمل. تحديد المهارات والمعارف والقدرات المطلوبة لخريجي المدارس بناءً على معلومات سوق العمل، وذلك لتسهيل انتقال الطلاب إلى سوق العمل. رفع بيانات سوق العمل للوحدة الفرعية بالمديرية، حتى تقوم برسم الخريطة

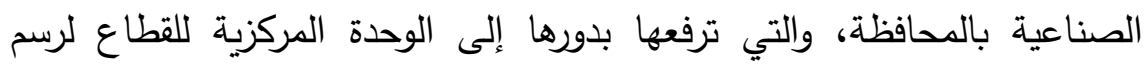
الخريطة الصناعية على المستوى القومي. كما حددت وزارة التربية والتعليم مسئوليات العاملين عن بعض الوحدات المدرسية المسئولة عن المعلومات الموجودة في المدرسة، كوحدة التوظيف في لئي المدرسة الثانوية الفنية، وهي وحدة مسئولة عن تيسير الانتقال إلى سوق العمل، والتي 
أنشئت بقرار وزاري رقم 283 بتاريخ 2014/6/26، وتهتم بتمكين طلاب وخريجي التعليم الفني من الانتقال لسوق العمل، من خلال مساعدتهم على اتخاذ القرارات

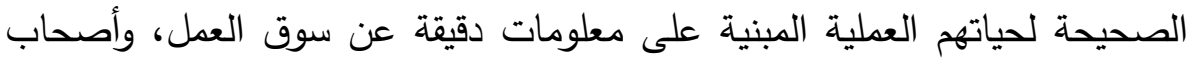

العمل. وتتمثل الواجبات الأساسية لمسئول تلك الوحدة فيما يلي: (75) توطيد العلاقة مع أصحاب الأعمال والمجتمع المحيط. توفير أكبر قدر من المعلومات عن فرص العمل المتاحة للطلاب وخريجي

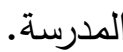
• توفير معلومات عن أماكن التدريب المتاحة لخريجي المدرسة. •المساهمة الفعالة مع مسئول قسم دراسات سوق العمل في تبادل المعلومات

$$
\text { وضمان صحتها. }
$$

توفير البيانات والمعلومات المتاحة لدى القسم بقاعدة البيانات لباقي أقسام

$$
\text { الوحدة. }
$$

يضاف إلى ما سبق تحديد وزارة التربية والتعليم - بموجب القرار الوزاري رقم

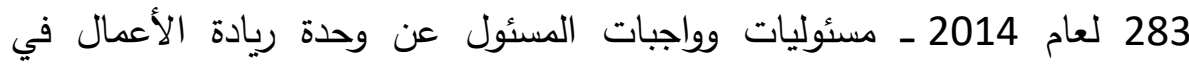
المدرسة الثانوية الفنية، وذلك لتيسير الانتقال لسوق العمل أيضًا، ومن مسئولياته ما

• العمل على وضع خطة للمشاريع الصغيرة لخريجي التعليم الفني. يعتبر بمثابة المرجع الرئيس لتقديم معلومات ريادة الأعمال في المدرسة.

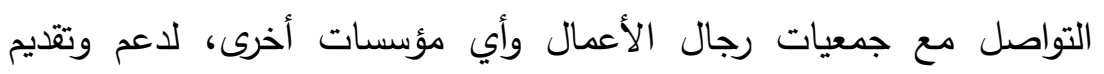
خدمات وبرامج ريادة الأعمال المتكاملة والفعالة لطلاب التعليم الفني. • إدارة برامج ريادة الأعمال داخل المدرسة وتقييمها والإشراف عليها. •التعاون مع مدارس التعليم الفني داخل المحافظة لتقديم خدمات ريادة الأعمال

$$
\text { للطلاب والخريجين. }
$$

يضاف إلى ما سبق اهتمام وزارة التربية والتعليم بتحديد الوصف الوظيفي

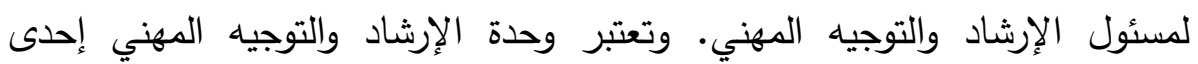
الوحدات المستحدثة في المدارس الثانوية الفنية بوجه عام، وهي المسئولة أيضًا عن إلنا تيسير الانتقال إلى سوق العمل، وذلك من خلال مساعدة الطلاب على اتخاذ قرارات 
صحيحة لحياتهم العملية، والمبنية على معلومات دقيقة عن سوق العمل، وذلك عن طريق مساعدة الطلاب على التخطيط الوظيفي لحياتهم العملية حسب قدراتهم ومهاراتهم، واحتياجات سوق العمل، وتتمثل الواجبات الأساسية لمسئول تلك الوحدة

فيما يلي: (77)

•التعاون مع قيادات التعليم الفني من أجل تنفيذ برامج الإرشاد والتوجيه المهني

$$
\text { في المدرسة. }
$$

الإشراف على تدريبات توجيه وتقييم برامج التوجيه والإرشاد التي يتم تقديمها

$$
\text { في المدرسة. }
$$

•تقديم خدمة الإرشاد والتوجيه المهني لطلاب المدرسة.

التعاون مع مسئول قسم معلومات العمل لضمان تقديم معلومات صحيحة

$$
\text { للخريجين عن احتياجات سوق العمل. }
$$

وبالنظر إلى القرارات الوزارية سالفة الذكر، يتضحت أن أن جميع الوحدات المدرسية

المستحدثة في المدرسة الثانوية الصناعية ركزت على ما يلي:

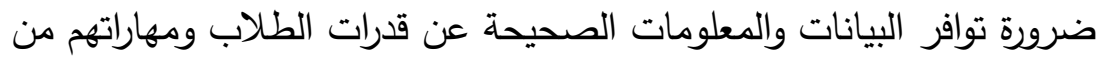

$$
\text { ناحية، ومتطلبات سوق العمل من ناحية أخرى. }
$$

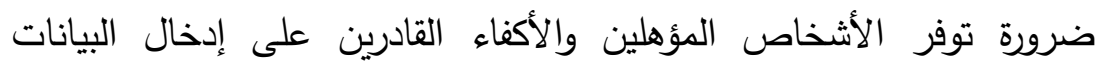

$$
\text { والمعلومات واستدعائها وقت الحاجة. }
$$

ضرورة توفر قاعدة بيانات عن أصحاب العمل ورجال الأعمال لما لهم من وفن وفاتهات

$$
\text { دور في توظيف الخريجين وتدريب الطلاب. }
$$

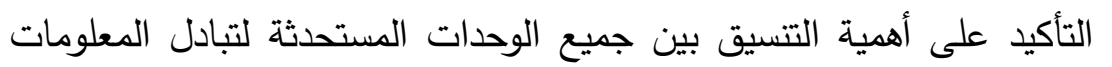

$$
\text { اللازمة لإرشاد الطلاب والخريجين وتوجيههم. }
$$

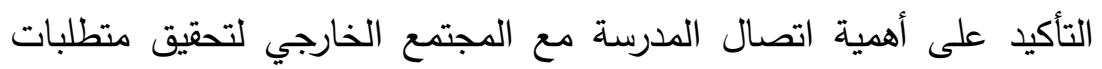

$$
\text { المجتمع. }
$$

الاهتمام بالتعاون والتتسيق بين الوحدات من أجل عمل خطة شاملة للتوظيف

$$
\text { والوفاء بمتطلبات سوق العمل. }
$$

الاهتمام بعمل قواعد بيانات عن المشروعات الصغيرة التي يمكن للطلاب

$$
\text { والخريجين القيام بها، ومن ثم تسهيل فرص العمل المتاحة لهم. }
$$


بناء على ما سبق، يتضح أن تواجد جميع الوحدات المدرسية سالفة الذكر في

المدرسة الثانوية الفنية، يمثل نقاط قوة لا يجب الاستهانة بها للمدرسة الثانوية الفنية بثكل عام، والمدرسة الثانوية الصناعية على وجه الخصوص، ذلك أنها بمثابة البوابة التي ينطلق من خلالها الطلاب إلى سوق العمل بناء على معلومات صحيحة ودقيقة، تقوم المدرسة بجمعها وتخزينها حتى وقت الحاجة إليها، الأمر الذي إن غاب، أصبحت الأمور تتسم بالعشوائية، بما إنها لا تقوم على معلومات وقواعد بيانات مدققة

وسليمة.

وبالتكامل بين ما سبق والعمليات المختارة لإدارة الأمن المعلوماتي في المدرسة

الثانوية الصناعية في جمهورية مصر العربية، يمكن تلخيص أهم نقاط القوة في المدرسة في وجود جهود لا يستهان بها للتخطيط للأمن المعلوماتي في المدرسة الثانوية الصناعية، وذلك من خلال الوحدات المدرسية المستحدثة، التي تساعد ـ من خلال قدرتها واختصاصها في الحفاظ على البيانات والمعلومات ـ على الحفاظ على أمن المعلومات في المدرسة، تمهيدًا لاتخاذ القرار الرشيد.

ثانيًا ـ جوانب الضعف المرتبطة بإدارة عمليات الأمن المعلوماتي في المدرسة الثانوية

الصناعية (Weaknesses (W)

تعاني المدرسة الثانوية الفنية بشكل عام، والمدرسة الثانوية الصناعية على وجه الخصوص، من عدد من جوانب الضعف، لا سيما في قدرتها على الحفاظ على

الأمن المعلوماتي، ومن جوانب الضعف المرتبطة بهذا السياق ما يلي: (78) • ضعف مشاركة أصحاب المصلحة والمستفيدين الحقيقيين من مخرجات التعليم والتدريب في المدرسة، وهو ما يظهر في صياغة مواصفات المهن المختلفة، والتوصيف الوظيفي للعاملين، ووضع المناهج والبرامج الدراسية، والاشتراك في عمليات المتابعة والتقويم. عدم وجود آلية محددة ومدروسة لتمويل عمليات التدريب المختلفة، سواء للتدريب الأساسي، أو التدريب أثناء الخدمة، أو ما قبل الخدمة. ويمثل ما سبق، نظرة شاملة عن الوضع الحالي للعلاقة بين المدرسة الثانوية الصناعية، وجماعات المصالح والمستفيدين، سواء من رجال الأعمال، أو أصحاب الشركات، تلك الفئة التي من شأنها استيعاب كافة الخريجين من هذا النوع من 
المدارس، إذ يتضح أنهم من أكثر الفئات التي على المدرسة الثانوية الصناعية الاستفادة منها في وضع وتحديد مواصفات الخريج والمهارات التي يجب أن يتسموا لتصن بها ليتم استيعابهم في سوق العمل، ولعل الانفصال الواضح بين الددرسة، ورجال

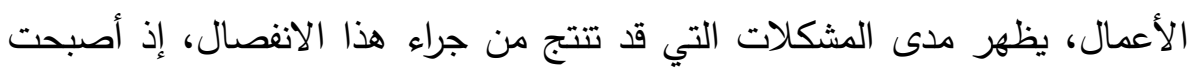

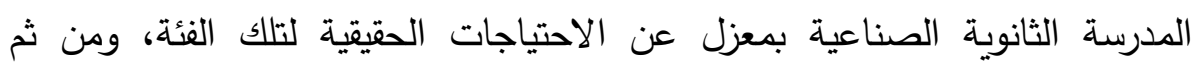
ضعفت المشاركة المنشودة.

كذلك يمكن إضافة نقاط الضعف التالية: (79) عدم اعتماد البرامج التدريبية على معرفة الاحتياجات التدريبية الفعلية، وبالتالي عدم إعداد برامج تدريبية قائمة على الاحتياجات الحقيقية للأفراد.

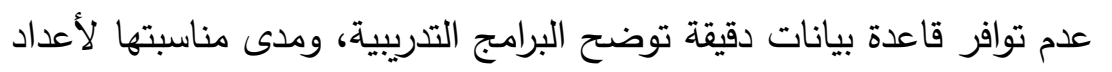
المستفيدين منها وأنواعها.

يضاف إلى ما سبق النقاط التالية: (80) انخفاض مستوى أداء الإدارة المدرسية على مستوى بعض مداط مدارس التعليم الفني، وضعف جهاز التوجيه، وقدرته على أداء مهامه.

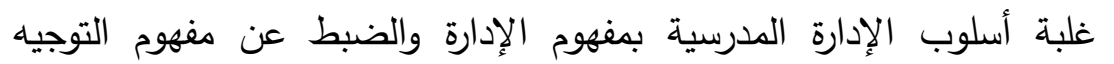

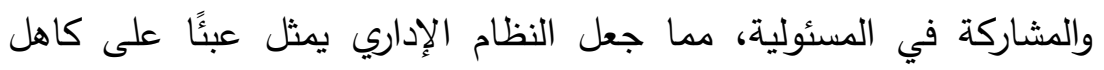

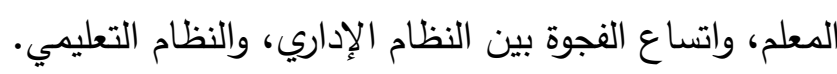
ق قلة وجود صف ثان من القيادات. ضعف قدرات معظم مديري التعليم الفني الصناعي.

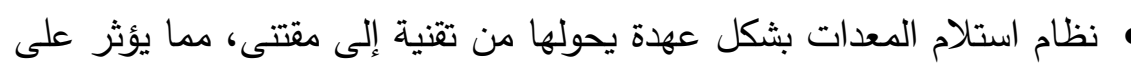
استخدامها بوصفها معدات يمكن أن تفسد أو تتلف من الاستخدام. ضيق مساحة بعض الأقسام والمعامل وقلة الخامات والأدوات.

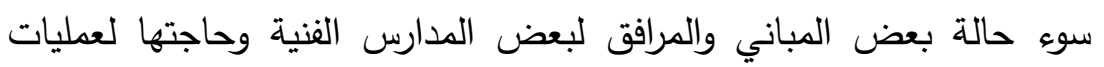
صيانة شاملة أو إحلال وتجديد. وجود بعض الآلات والمعدات والأدوات الفنية الخاصة بالعملية التعليمية والتدريبية التي تحتاج إلى إصلاح وصيانة، وقد يتعذر ذلك بسبب عدم وجود 
عقود صيانة لها، بالإضافة إلى عدم توافر قطع الغيار اللازمة لها، مما يجعلها معطلة دون الاستفادة منها. • عدم توفر الحماية الأمنية للمدارس الفنية لتأمين الآلات والماكينات والعدد

$$
\text { والبيانات والمعلومات من السرقة. }
$$

ضعف تسويق المنتجات لقلة عدد المعارض المتاحة.

بالنظر إلى نقاط الضعف السالفة يتضح أنها في المجمل تتلخص في ضعف

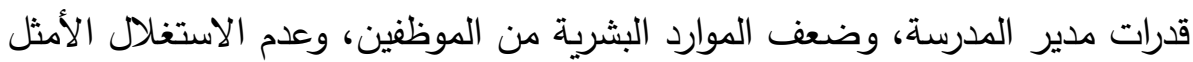
للموارد المادية، وسيطرة فكرة العهدة عليها. الأمر الذي يؤثر على عدم توفر قواعد بيانات عن احتياجات السوق من المنتجات، ومواصفات تلك المنتجات؛ مما يؤثر بالسلب على تسويقها، كما أن عدم توفر خطة صيانة متكاملة لصيانة الأجهزة يهدد

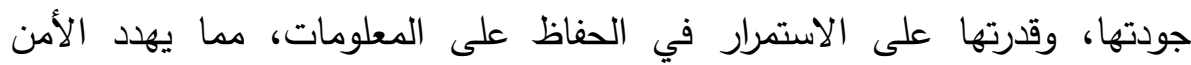

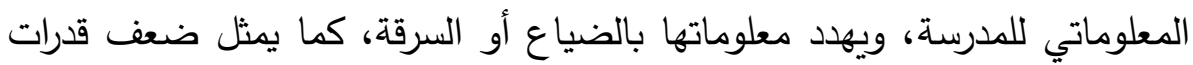
وكفاءات مديري المدرسة بشكل عام، ومسئولي الوحدات المستحدثة بشكل خاص،

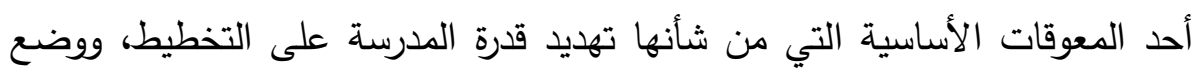

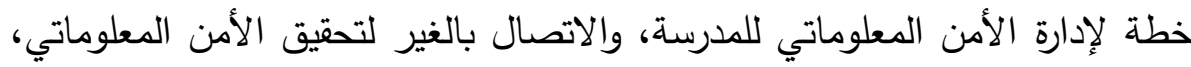

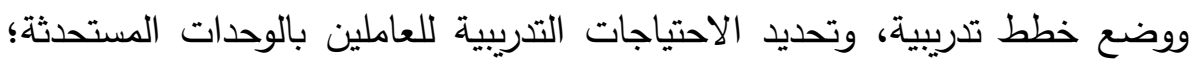
من أجل الحفاظ على الأمن المعلوماتي بها، وتقويم قدرة المدرسة على الحفاظ على بلى بلى لإلى

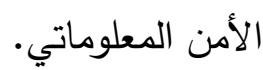

كما يمكن إضافة نقاط الضعف التالية: (81) ه قصور المعلومات الحقيقية عن سوق العمل.

ضعف البنية التحتية لشبكة المعلومات بمدارس التعليم الثانوي الصناعي. سوء مرافق التعليم الثانوي الصناعي والبنية الأساسية للاتصالات وتكنولوجيا

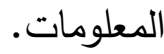

• محدودية التعاون بين المدارس الثانوية الفنية الصناعية والبيئة المحيطة. • عدم وجود قاعدة بيانات تخص التعليم الفني الصناعي. بالنظر إلى ما سبق، يتضح أن عدم وجود قاعدة بيانات تخص أهم البيانات والمعلومات التي تحتاج إليها المدرسة الثانوية الصناعية، مثل الجهات التي يمكنها 
الاستفادة منها؛ كالشركات والمصانع، ورجال الأعمال، والميزانية، والأرباح التي قد تجنيها من المشروعات التي تقوم بها، ومهارات الخريجين، وخطة التوظيف، والخطط والمشروعات المقترحة الصادرة عن وحدة ريادة الأعمال، وقواعد البيانات الخاصة بالاحتياجات التدريبية للمعلمين والعاملين والطلاب، وخطط التدريب المستقبلية لكافة وحتدات الفئات السالفة، وقواعد البيانات الخاصة باحتياجات سوق العمل، والمواصفات

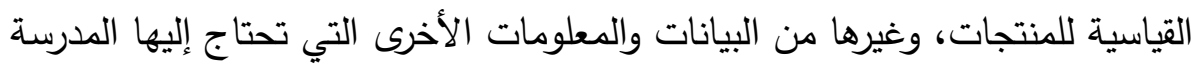
الثانوية الصناعية، سواء في الأوقات العادية، أو للتخلص من الأزمات والتعافي منها، واستعادة نشاط المدرسة بأسرع وقت ممكن. وبمقارنة الإطار النظري للبحث مع الواقع النظري للمدرسة الثانوية الصناعية

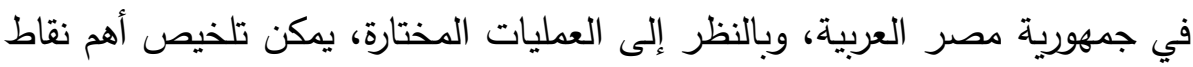
الضعف في تلك العمليات فيما يلي: ضعف قدرة المدرسة الثانوية الصناعية على التخطيط للحفاظ على أمنها

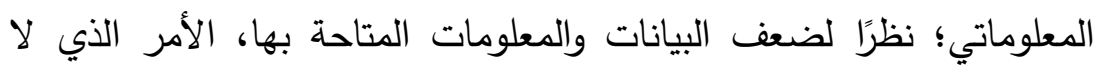

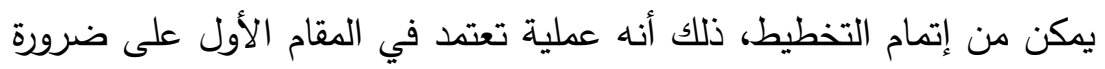
توافر البيانات والمعلومات الدقيقة والحديثة. ضعف قدرة المدرسة الثانوية الصناعية على التخطيط والتدريب للعاملين والمديرين على الحفاظ على الأمن المعلوماتي، لعدم توافر بيانات ومعلومات دقيقة عن البرامج التدريبية، ومدى جودتها، ومدى استفادة المستقيدين منها.

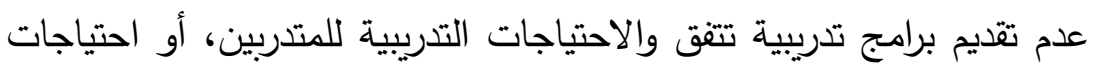
الوظائف الجديدة التي ظهرت نتيجة للوحدات المدرسية المستحدثة. ضعف فرص الاتصال بين المدرسة الثانوية الصناعية والبيئة المحيطة، وضعف مهارات التواصل لاى القائمين على إدارة هذه الددارس والعاملين فيها، مما يؤثر على قدرة المدرسة في تحديد الجهات التي يمكنها الاتصال بها عند الحاجة للحفاظ على الأمن المعلوماتي.

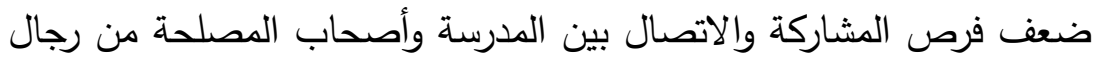
الأعمال أو أصحاب المشروعات من القادرين على تقديم خدمات للمدرسة من شأنها تحسين مستواها، وتحسن مخرجاتها. 
• عدم وجود خطط تقويمية للمدرسة تستطيع عن طريقها تحديد ما إذا كانت قادرة أو غير قادرة على الحفاظ على أمنها المعلوماتي بناء على نماذج أو مؤشرات فعلية تكون بمثابة الحكم على جودة الأداء. ثالثًا ــ الفرص المرتبطة بإدارة عمليات الأمن المعلوماتي في المدرسة الثانوية

الصناعية (O) (Opportunities

يقدم هذا الجزء من البحث الفرص التي يمكن للمدرسة الثانوية الصناعية في جمهورية مصر العربية استغلالها للتغلب على نقاط الضعف، واستثمار نقاط القوة، فيما يخص الحفاظ على الأمن المعلوماتي بها، ويمكن عرض تلك الفرص فيما يلي: قامت وزارة التربية والتعليم بالتعاون مع وزارة الاتصالات بعمل الشبكة الداخلية للمدارس لربط جميع أجهزة الحاسب بشبكة واحدة وربطها بالثبكة المعلوماتية الدولية،

$$
\text { كما تم توريد وتشغيل ما يلي: (82) }
$$

- عدد (2) معمل حاسب آلي بواقع (16) جهاز لكل معمل. - عدد (6) جهاز حاسب، بواقع (2) للمكتبة، (1) لمدير المدرسة، (1) لشئون الطلاب، (1) لشئون العاملين، (1) للعيادة المدرسية. - عدد (1) جهاز لكل قسم من أقسام المدرسة. - عدد (2) فصل مطور لكل مدرسة من المدارس المختارة، ويشمل الفصل

$$
\text { المطور (عارض ضوئي + لاب توب). }
$$

- عدد (1) كاميرا ديجيتال، عدد (4) طابعات ليزر ، و(1) ماسح ضوئي.

$$
\text { - إتاحة خدمة الإنترنت لعدد (7) مدارس. }
$$

- كما قامت وزارة الاتصالات وتكنولوجيا المعلومات بعمل مشروع قانون أمن

الفضاء المعلوماتي، والذي يشمل ثلاثة محاور أساسية، هي: (83)

حماية الفضاء المعلوماتي بجميع مشتملاته من أي تعدٍّ خارجي. التزام الجهات المختلفة ـ بمختلف تخصصاتها ـ بحماية ما يخصها من الفضاء المعلوماتي، وما يضمه من بيانات ومعلومات، وخاصةً الشخصية منها. إنشاء جهاز قومي للرقابة على جميع أعمال أمن المعلومات، ومنح تراخيص مزاولة أعمال الخبرة، والتخصص في هذا المجال. 
كما هدف هذا القانون إلى وضع القواعد اللازم على المتحكم في البيانات والمعلومات اتباعها لتأمين ما يخصها من الفضاء المعلوماتي، وما تحتويه من بيانات ونظم وبرامج وشبكات، وتحديد التزاماته، كما يهدف إلى مكافحة برامج اختراق نظم

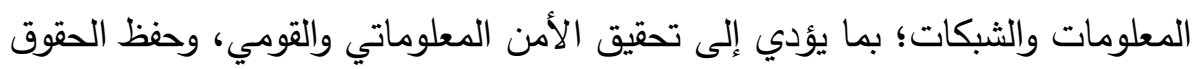

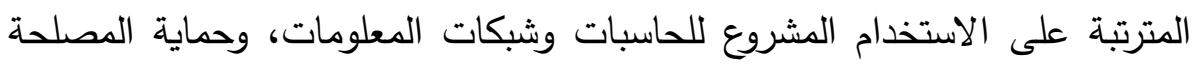

العامة. (84) - (84)

ويتلخص دور الجهاز القومي لأمن المعلومات في ترسيخ فكر وثقافة أمن المعلومات، وتحديد التزامات المتحكم في المعلومات، ووضع نظام لإدارة تشغيل

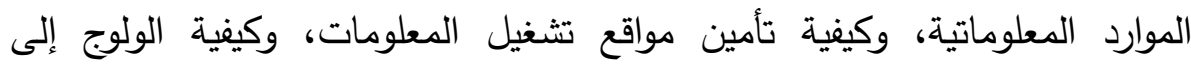

$$
\text { المعلومات والثبكات. (85) }
$$

كما وضعت منظمة اليونسكو عددًا من المؤشرات التي يمكن استخدامها للحكم على قدرة المؤسسات التعليمية في استخدام تكنولوجيا المعلومات، ومن تلك المؤشرات ما يلي: (86)

توافر برامج تدريبية تساعد العاملين بالمؤسسة التعليمية على استخدام أجهزة

$$
\text { الحاسب الآلي. }
$$

توافر فرص دورية لصيانة الأجهزة الموجودة في المدرسة. وجود شبكات للاتصال بالإنترنت داخل المدرسة. وجود معامل للكمبيوتر متاحة لاستخدام العاملين والمعلمين والطلاب. وجود برامج أصلية تستخدم للحفاظ على المعلومات الموجودة في المدرسة. كما أعدت وزارة التربية والتعليم ـ من خلال قطاع التعليم الفني بها ــ قواعد بيانات مختلفة، تمهيدًا لعقد مؤتمرها التقني الأول والثاني، من أجل ربط التعليم الفني

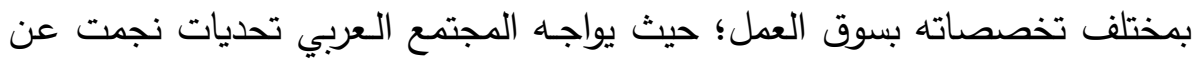

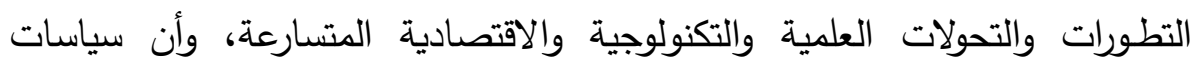
التعليم بوجه عام، والتعليم الفني بوجه خاص، قد تكون الوسيلة التي يجب أن ولنيه يعتمد

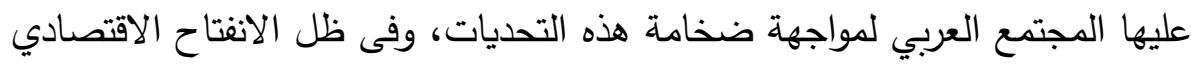

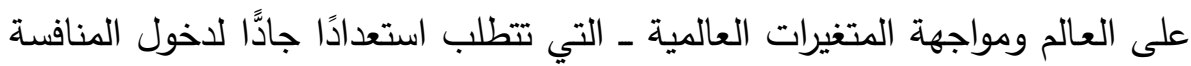
الضارية في السوق الدولية ـ كـان لا بد للتعليم الفني أن يتحمل مسئولية رفع 
إنتاجية المـواطن، عن طريق؛ التدريب والتأهيل المستمر ، والارتفاع بقدراته التتافسية؛

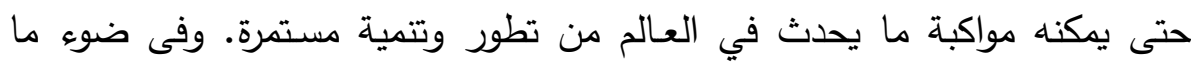
أحدثته ثورة المعلومات في هذا العصر من تطور ، أصبح كل من العلم والتكنولوجيا

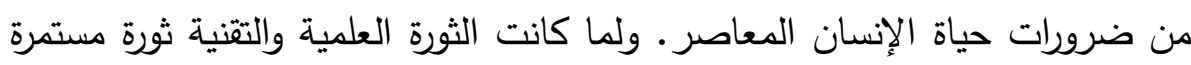
يزداد تأثيرها في الحياة، فإن ذلك تطلب أن تكون هناك وقفة تقويمية لسياسة التعليم ونظامه ومحتواه؛ لمواجهة هذا التغير السريع، وتتمية قدرة الإنسان على المعرفة واكتساب المهارات.

وقد تعددت محاور المؤتمر التقني الأول لتتناول خبرات الاتحاد الأوروبي في

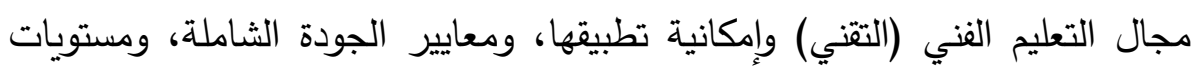

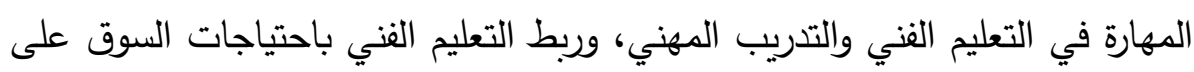

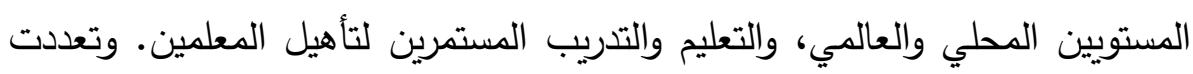

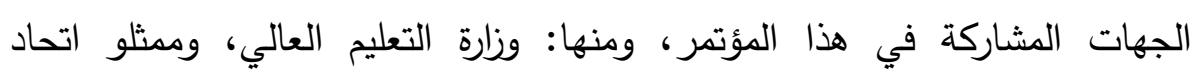
الصناعات والغرف التجارية، ومخططو وواضعو سياسات تطوير التعليم والتدريب،

والمستثمرون، وأصحاب الأعمال، والمراكز البحثية القومية. (87) وبالنظر إلى ما سبق، يتضح أن تنظيم مثل هذا المؤتمر يتطلب من كل

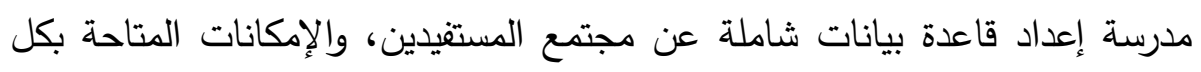
مدرسة، والاحتياجات اللازمة، والثركات، والمؤسسات التي يمكنها المساهمة في

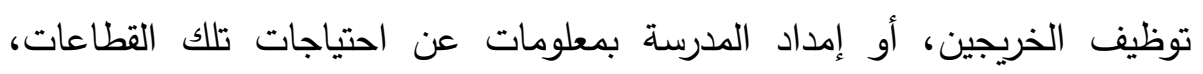
وبالتالي ربط المدرسة باحتياجات المجتمع المحيط وسوق العمل. ولم تتوقف جهود الوزارة عند هذا الحد؛ حيث عقدات المبات المؤتمر التقني الثاني، استكمالًا للمجهودات التي قام بها المؤتمر التقني الأول؛ حيث هدف المؤتمر إلى الى

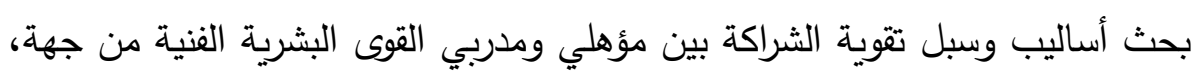
ومشغلي تلك القوى من جهة أخرى، وذلك لتطوير التعليم الفني والتدريب المهني بما

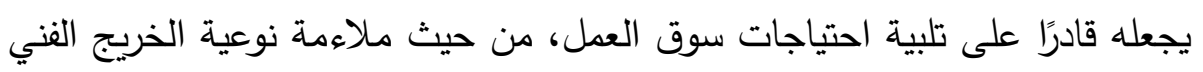
وكفاءته، لمتطلبات التقنيات الحديثة المستخدمة في مجالي الإنتاج والخدمات، حتى لتى لئه يمكن دعم أنشطة الإنتاج والخدمات باحتياجاتها من القوى الفنية المدربة، لتمكينها

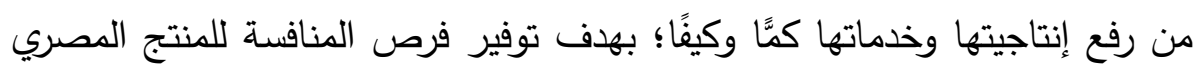


في السوقين المحلي والدولي، بما ينعكس إيجابًا على الاقتصاد القومي، وزيادة فرص العمل لخريجي التعليم الفني والتدريب المهني عن طريق تزويدهم بما يتطلبه سوق العمل المحلي من مهارات وقدرات. (88) ومن المعلوم أنه لا يمكن تتظيم مثل تلك المؤتمرات، إلا بناء على وجود قواعد

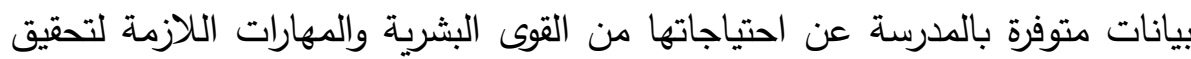
المنافسة المطلوبة، وكذا المهارات اللازمة لتمكين الدارسين من تلك المهاريات. كما يمكن إضافة عدد من الفرص التي تظهر من خلال الأهداف الإستراتيجية

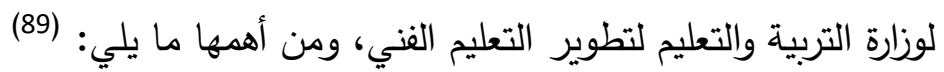

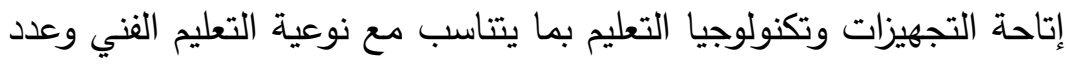
الطلاب وفق معايير معدة لذلك. ربط التعليم الفني بمؤسسات الإنتاج والخدمات في البيئة المحيطة لتدريب الطلاب في هذه المؤسسات الإنتاجية. التعاون مع الثركات وأصحاب الأعمال من أجل تطوير التعليم الفني

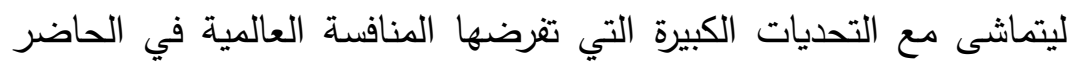
والمستقبل، وكذلك من أجل إمداد أصحاب الأعمال بخريجين ذوي مهارة ومؤهلات يتطلبها سوق العمل. بالنظر للتوجهات سالفة الذكر، يتضح أنها تركز على ضرولى لمرة إتاحة

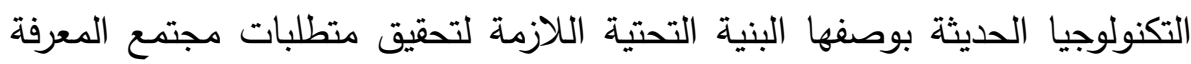
من ناحية، وبوصفها السبيل الذي لا بد منه لتحقيق الأمن المعلوماتي المنشود للمعلومات التي يجب على المدرسة الثانوية الصناعية الحفاظ عليها من ناحية أخرى، لأل التهنه كما ركزت تلك التوجهات على ضرورة إحداث التعاون مع رجال الأعمال. الأمر الذي يؤكد على الاهتمام بالاتصال مع أعضاء المجتمع المحلي لإمدادهم باحتياجاتهم

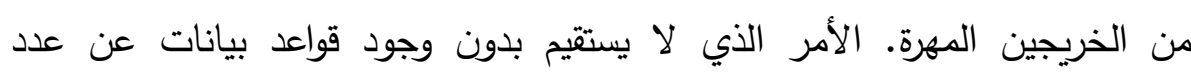

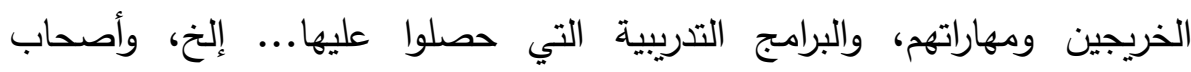
الأعمال، وتخصصاتهم، والدعم المحتمل منهم... وهكذا. وجدير بالذكر في هذا السياق، أن هناك بعض من جهود النه الشراكة المجتمعية

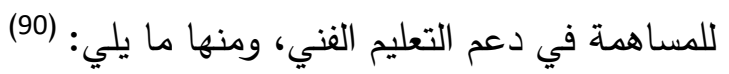


التعاون دع وزارة الإعلام لتخريج العمالة الفنية الددربة في مجال

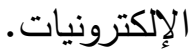

التعاون مع وزارة البترول لتخريج العمالة الفنية المدربة في مجال تكنولوجيا البترول.

توقيع اتفاقية مع مؤسسة مصر الخير ؛ تهدف إلى تأهيل خريجي المدارس

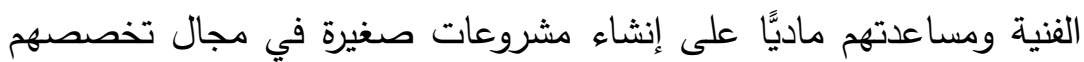
الدراسي وإدارتها، وتحسين كفاءة الإدارة المدرسية والتوجيه الفني والمعلمين

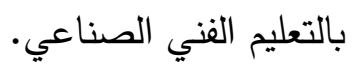

توقيع اتفاقية تعاون مع كلية الهندسة بجامعة قناة السويس؛ لتدريب المعلمين والطلاب والموجهين في المحافظات الداخلة في النطاق الإقليمي لجامعة قناة السويس. التعاون مع الهيئة القومية للاتصالات السلكية واللا سلكية؛ لتخريج العمالة الفنية المدربة في المجالات التالية (سنترالات إلكترونية ـ تراسل ـ فني اتصالات شبكات ـ فني اتصالات قوى كهربية ـ تكييف ـ حاسبات).

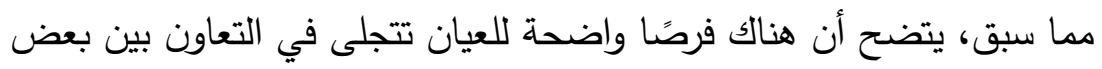

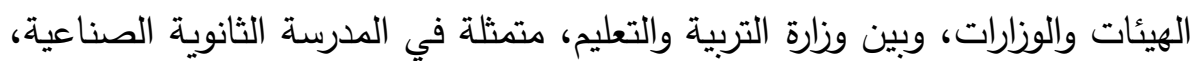
الأمر الذي لا يمكن إتمامه بالثكل الصحيح إلا من خلال توافر بيانات صحيحة ولتهات ودقيقة، ومخزنة بشكل سليم، بأجهزة مقاومة للسطو والتلف، عن تللك الهيئات

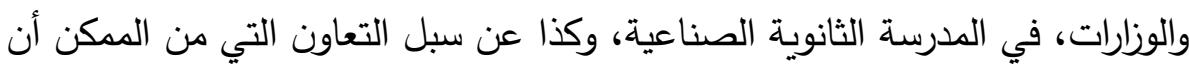
تتم بين الجانبين، خاصةً أن ذلك التعاون يفرز متخصصين في في مجالات متعددة. كما تضمنت الخطة الإستراتيجية القومية سبل تطوير التعليم الفني في جمهورية مصر العربية، ومن أهم تلك السبل ما يلي: (91) استكمال التجهيزات وصيانة البنية التحتية لمدارس التعليم الفني.

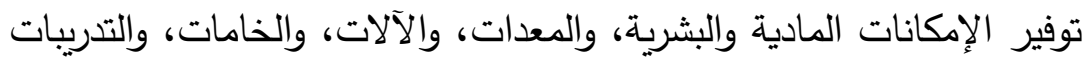
اللازمة لتفعيل العملية التعليمية في المدارس. 
تحويل مدارس التعليم الفني إلى تعليم قائم على التعليم والتدريب المزدوج، في إطار مدرسة في كل مصنع، مع إصدار القواعد المنظمة للتعاون بين إدارة

$$
\text { المدرسة والمؤسسات الإنتاجية. }
$$

وبالنظر إلى ما سبق، يتضح أنه إذا تم استكمال البنية التحتية اللازمة

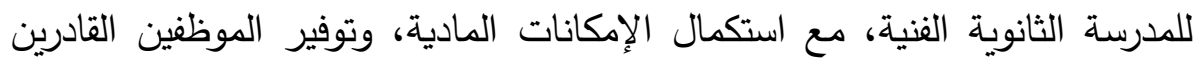
على استخدام الموارد المادية بالثكل الصحيح، فإن ذلك يكون بمثابة الفرصة التي لإني

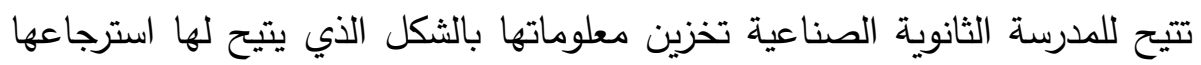
واستعادتها وقت الحاجة إليها.

كما يعتبر مركز التطوير التكنولوجي ـ الذي تم إنشاؤه لإدخال التكنولوجيا

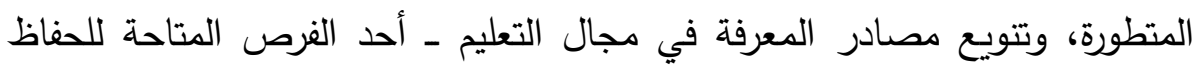
على الأمن المعلوماتي في المدرسة الثانوية الصناعية؛ حيث يوجد 27 مركزًا فرعيًّا للتطوير التكنولوجي، بمعدل مركز بكل مديرية تعليمية. ويعتبر المركز بمثابة الفرصة لإحداث فرص التدريب على المهام الجديدة التي يمكن أن توكل إلى مسئولي الوحدات المستحدثة، لتدريبهم على القيام بالمهام الجديدة.

كما يوجد مركز المعلومات الفنية للتعليم الصناعي والتدريب، الذي أُنشئ بشبرا عام 1998، وكان هدف إنشائه تدريب معلمي التعليم الفني الصناعي في تخصصات السيارات وغيرها. (93) ويمكن استغلال وجود مثل هذا المركز في تدريب العاملين المسئولين عن

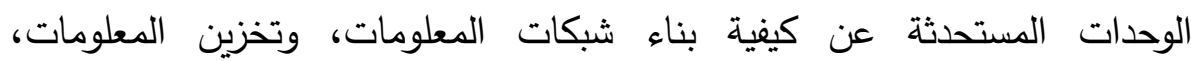

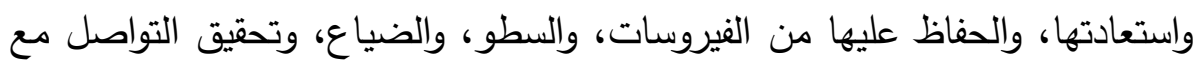
الغير من خلالها، أي باختصار استغلال تلك المعلومات الاستغلال الأمثل، بناء على الحفاظ عليها في المقام الأول. كما تولى المعهد القومي للاتصالات بالتسيق مع وزيق وزارة الاتصالات والمعلومات ووزارة التربية والتعليم ـ منذ عام 2002 ـ الإشراف على البرنامج القومي الخاص بالتدريب المتخصص في مجال تكنولوجيا المعلومات والاتصالات، وقد تم تتفيذ الدورات التدريبية من خلال مجموعة من الشركات العالمية من أجل تدريب 
متخصصين في مجال تكنولوجيا المعلومات، بواقع 5000 متخصص سنويًّا في

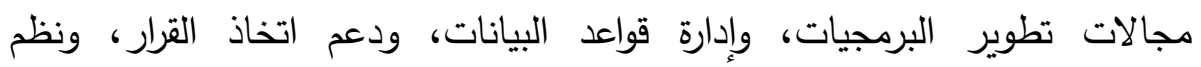

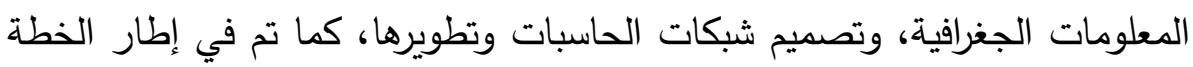
القومية للاتصالات تدريب حوالي 2000 متدرب على أساسيات تكنولوجيا المعلومات

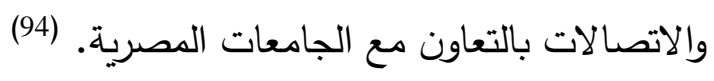

ولعل استغلال المدرسة الثانوية الصناعية للفرص الموجودة بالبيئة الخارجية المحيطة في المدرسة الثانوية الصناعية، يعد بمثابة طوق النجاة التي على المدرسة التمسك بها؛ للتغلب على نقاط ضعفها، ومواجهة ما يواجهها من تهديدات. وبالنظر إلى ما سبق، يمكن تلخيص أهم الفرص المتاحة بالبيئة الخارجية

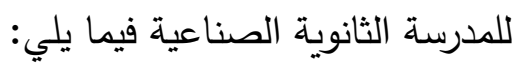

وجود بعض الفرص التي تهيئ للمدرسة الثانوية الصناعية التخطيط للحفاظ

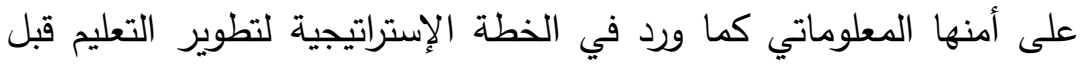
الجامعي، عن طريق استكمال البنية التحتية، والأجهزة اللازمة للحفاظ على الإنى

$$
\text { البيانات والمعلومات الموجودة في المدرسة. }
$$

تشريع عدد من القوانين، مثل قانون الحفاظ على الفضاء المعلوماتي كنوع من فئن

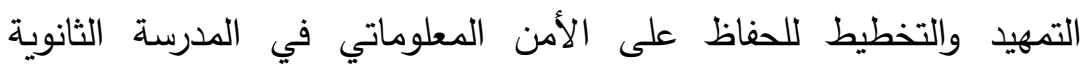
الصناعية على غرار مثيلاتها من المؤسسات الأخرى. تحقيق قدر من الاتصال والتنسيق بين عدد من الوزارات لتقديم تدريب لتوسيطات

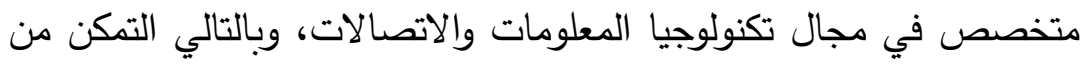

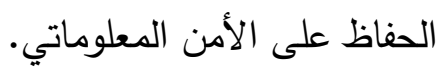
توفير مؤشرات قدمتها اليونسكو يمكن الحكم بها على قدرة المدرسة الثانوية الصناعية على الحفاظ على الأمن المعلوماتي بها.

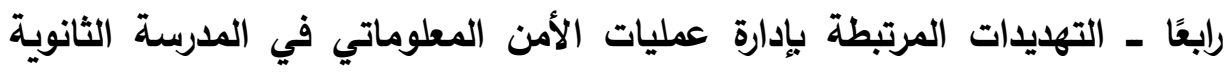
Threats (T) الصناعية: تتمثل أهم التهديدات المرتبطة بحفاظ المدرسة الثانوية الصناعية على أمنها المعلوماتي فيما يلي: (95) 
لا توجد قواعد بيانات صحيحة وموثقة تحدد احتياجات سوق العمل من المهن

والتخصصات المختلفة بالتعليم الفني.

ضعف فاعلية تطوير التعليم الفني؛ إذ إن آليات سوق العمل تتغير وتتطور بسرعة تفوق تطور إمكانات ومخرجات التعليم الفني، مما أدى إلى التباين

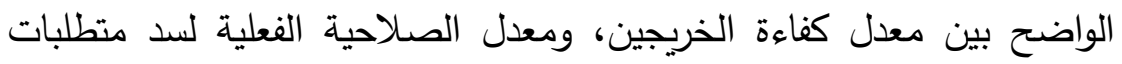

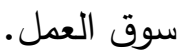
عدم وجود دراسات واقعية ومتكاملة لحالة ومتطلبات أسواق العمل العربية من العمالة المؤهلة والماهرة، سواء على المدى القربب أو المدى البعيد.

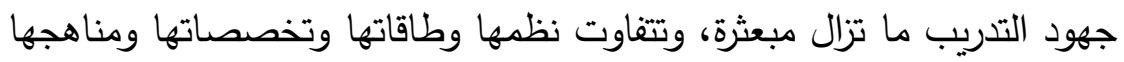

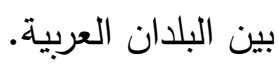

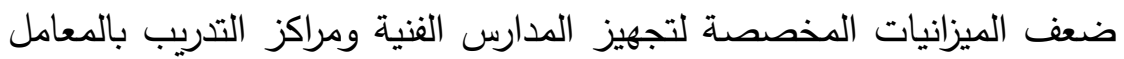
والمعدات اللازمة التي تخدم المناهج والبرامج، بما يحقق متطلبات سوق العمل، ويساير التطور التكنولوجي. عزوف القطاع الخاص عن تقديم فرص تدريب كافية للدارسين للتدريب العملي

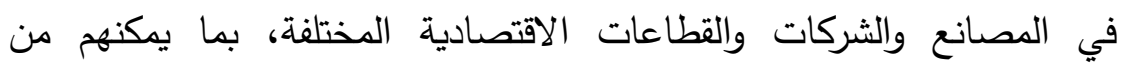
اكتساب مهارات وجدارات فعلية على أرض الواقع وإكسابهم ثقافة العمل ولتهاعل

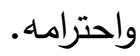
افتقار العديد من برامج التدريب بالتعليم الفني إلى وثاقة الصلة باحتياجات سوق العمل، ومتطلبات عصر التكنولوجيا الحديثة. يضاف إلى ما سبق، نقاط الضعف التالية: (96) - - قلة الموارد، وعدم الاتساق مع متطلبات سوق العمل. - وجود عدد من المهن المستحدثة التي لا تجد من يشغلها.

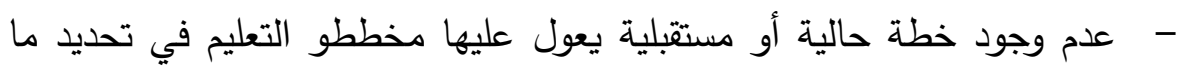
هو مطلوب من مهن وتخصصات في سوق العمل من جهة، مع عدم وجود

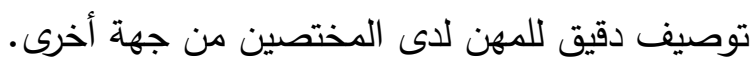
مما سبق الإشارة إليه في تلك الدراسة، يتضح أن ضعف المئن الموارد، سواء كانت

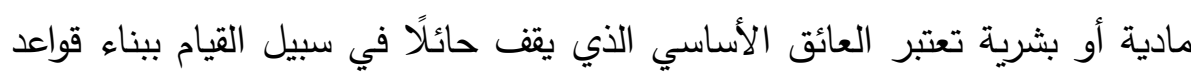


البيانات، وبالتالي تضيع البيانات الهامة، ويصعب استرجاعها وقت الحاجة، فلا تستطيع المدرسة اتخاذ القرارات اللازمة لمواجهة الأزمات أو التعافي منها، أو

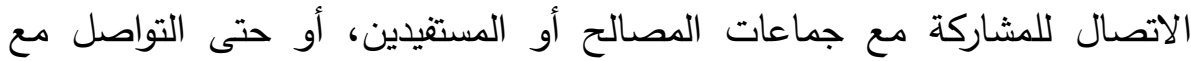
المدارس الأخرى لتبادل الخبرة، بدون توافر الموارد المطلوبة، بل ومع استحداث

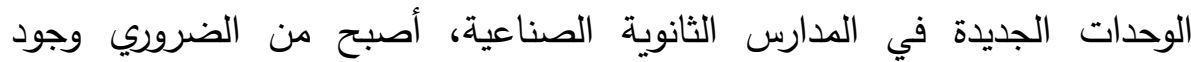
متخصصين لشغل وظائف المسئولين عن تلك الوحدات، على أن يكونوا مؤهلين للقيام بالمهام الموكلة إليهم، الأمر الذي يسهم في وجود خطط محددة ومدروسة تسهم

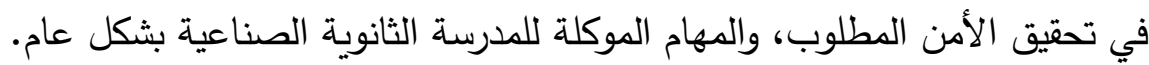

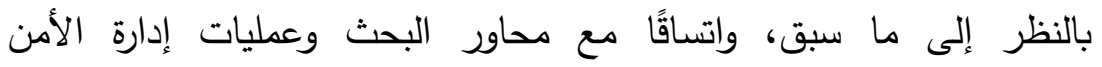
المعلوماتي المختارة، والإطار النظري للبحث، والتهديدات سالفة الذكر ، يمكن تلخيص أهم التهديدات الموجودة بالبيئة الخارجية للمدرسة الثانوية الصناعية فيما يلي: لإنيات غياب التخطيط للأمن المعلوماتي على مستوى المديريات التعليمية، بل على مستوى الوزارة ككل، ويرجع ذلك إلى ضعف قواعد البيانات المتوفرة عن المدارس بالوزارة والمديريات، الأمر الذي يستحيل معه القيام بتخطيط سليم تحسبًا للظروف المستقبلية. غياب الخطط المستقبلية التي عن طريقها تحدد الوزارة والمديريات والإدارات التعليمية المهن المتاحة بسوق العمل الخارجي فيما يخص تخصصات خريجي التعليم الثانوي الصناعي. ضعف القدرة على الاتصال بين الجهات المعنية بتحقيق الأمن المعلوماتي للمدارس الثانوية الصناعية، كثركات الصيانة والبرامج الأصلية، وجهات التدريب، ووزارة التربية والتعليم، والمديريات التعليمية، والإدارات، نظرًا لعدم وجود قاعدة بيانات تحدد الجهات اللازم الاتصال بها عند الحاجة، وإن وجدت فلا تكون دقيقة، ولا يتم تحديثها. • ضعف مستوى البرامج التدريبية المقدمة للمسئولين عن الحفاظ عن الأمن المعلوماتي في المدرسة من ناحية، والبرامج المقدمة لمديري المدارس الثانوية

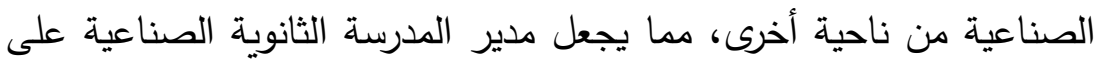


غير دراية بأهمية الحفاظ على الأمن المعلوماتي في المدرسة، وكيفية الحفاظ عليه.

غياب البرامج التقويمية التي تساعد المدرسة على تحديد مستواها وقدرتها على الحفاظ على الأمن المعلوماتي بها، مما ينعكس على عدم وجود خطة تقويمية

$$
\text { لأداء المدرسة في هذا الصدد. }
$$

القسم الرابع ـ تصميم جدول التحليل الرباعي للخروج بإستراتيجيات لإدارة عمليات الأمن المعلوماتي في المدرسة الثانويـة الصناعية في مصر: في ضوء ما أسفرت عنه الدراسة النظرية لواقع الحفاظ على الأمن المعلوماتي في المدرسة الثانوية الفنية الصناعية في جمهورية مصر العربية من عناصر قوة وضعف بالبيئة الداخلية للمدرسة، وفرص وتهديدات بالبيئة الخارجية لها، يمكن تصميم جدول التحليل الرباعي، والذي يمثل مصفوفة (Matrix) لتجميع تلك العناصر الأربعة للتحليل البيئي، والمزاوجة بينها؛ للخروج بمجموعة من الإستراتيجيات التي تساعد في صياغة إستراتيجية مقترحة لإدارة عمليات الأمن المعلوماتي في المدرسة الثانوية الفنية الصناعية في جمهورية مصر العربية، ويتضح ذلك من خلال الجدول التالي: جدول رقم (2) التحليل الرباعي لعناصر البيئة الداخلية والخارجية للمدرسة الثانويـة الصناعية

\begin{tabular}{|c|c|c|}
\hline \multicolumn{2}{|c|}{ تحليل البيئة الداخلية } & \\
\hline عناصر الضعف (Weaknesses) & عناصر القوة (Strengths) & \\
\hline 1. ضعف مشاركة أصحاب & 1. تهدف الخطة الإستراتيجية & \\
\hline المصلحة والمستفيدين & للتعليم قبل الجامعي ـ فيما & \\
\hline الحقيقيين من مخرجات & يخص التعليم الفني ـ إلى & \\
\hline التعليم والتدريب في المدرسة، & إتاحة التجهيزات وتكنولوجيا & تحليل \\
\hline في صياغة مواصفات المهن & التعليم بما يتتاسب مع نوعية & البيئة \\
\hline المختلفة، والتوصيف الوظيفي & التعليم الفني وعدد الطلاب، & 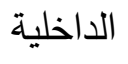 \\
\hline للعاملين، ووضع المناهج & وفق معايير معدة لذلك، & \\
\hline والبرامج الدراسية، والاشتراك & بالإضافة إلى استكمال & \\
\hline
\end{tabular}




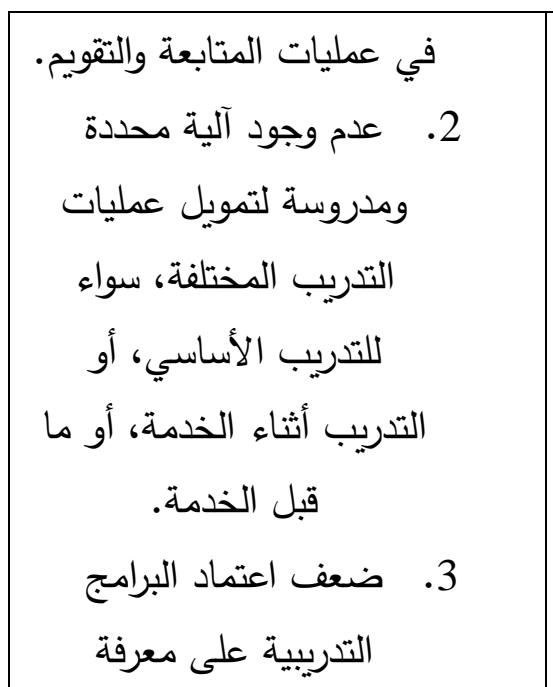

الاحتياجات التدربيية الفعلية،

وبالتالي ضعف إعداد برامج

تدريبية قائمة على

الاحتياجات الحقيقية للأفراد.

4. عدم توافر قاعدة بيانات دقيقة

توضح البرامج التدريبية

ومدى تواصلها، وأعداد

المستفيدين منها وأنواعها.

5. انخفاض مستوى أداء الإدارة

المدرسية في بعض مدارس

التعليم الفني، وضعف جهاز

$$
\text { التوجيه. }
$$

6. غلبة أسلوب الإدارة المدرسية بمفهوم الإدارة والضبط على مفهوم التوجيه والمشاركة في المسئولية، مما جعل النظام الإداري يمثل عبئًا على كاهل المعلم، واتساع الفجوة بين
التجهيزات والبنية التحتية

اللازمة للمدارس، وتوفير البنية

التحتية والإمكانات المادية

والبشرية، والآلات والعدد،

والخامات، والبرامج التدريبية،

لتفعيل العملية التعليمية في

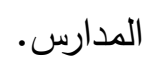

2. وجود بعض الوحدات المدرسية

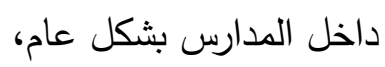

ومنها وحدة المعلومات

$$
\text { والإحصاء. }
$$

3. وجود وحدة مدرسية جديدة في

المدرسة الثانوية الفنية، أطلق

عليها وحدة معلومات سوق

$$
\text { العمل. }
$$

4. التحديد الدقيق لمسئوليات

العاملين في بعض الوحدات

المدرسية المسئولة عن

المعلومات الموجودة في

المدرسة كوحدة التوظيف في

المدرسة الثانوية الفنية.

5. يضاف إلى ما سبق تحديد

واجبات المسئول عن وحدة

ريادة الأعمال في المدرسة

الثانوية الفنية.

6. التحديد الدقيق للوصف

الوظيفي لمسئول الإرشاد 


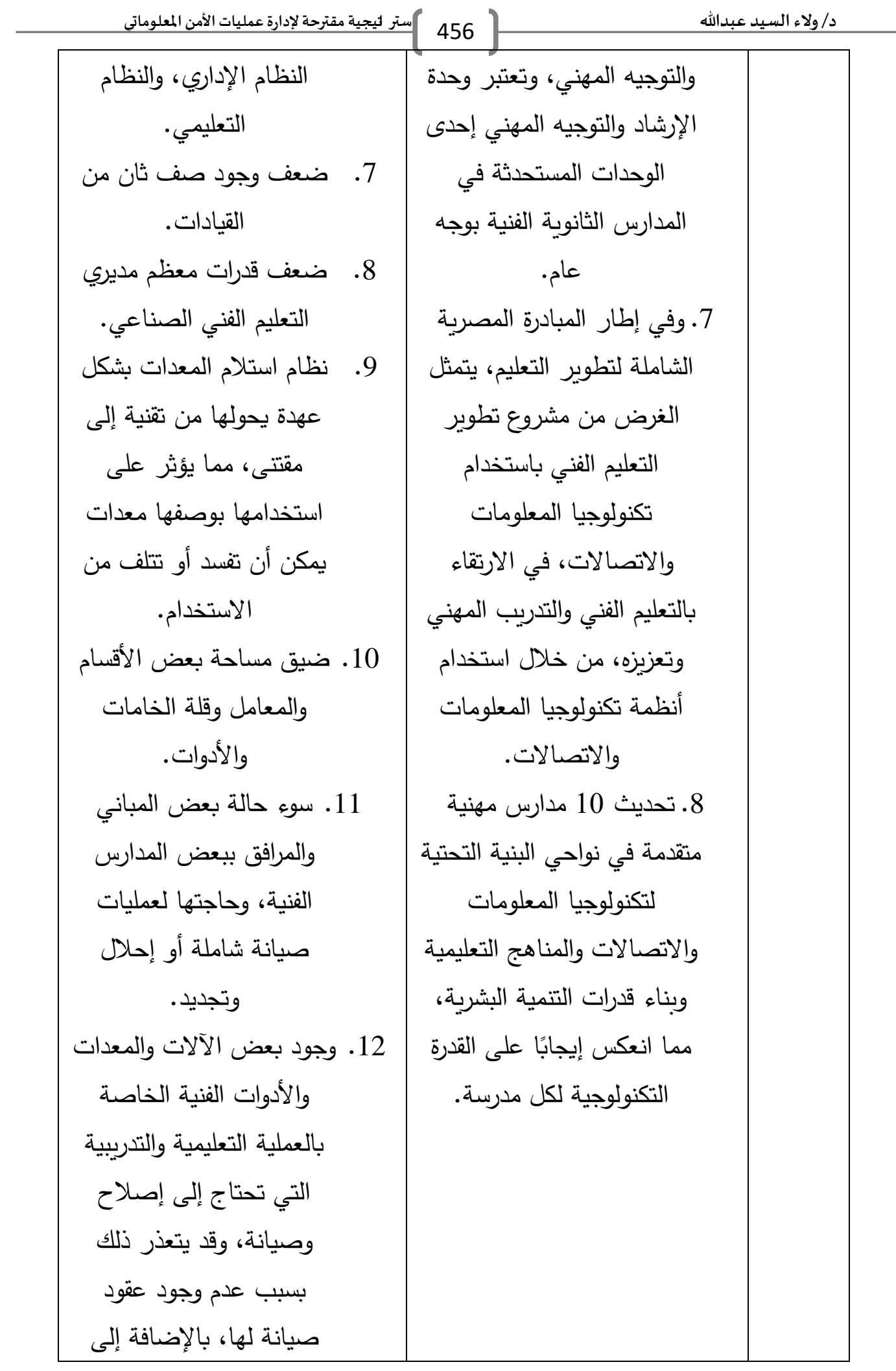


عدم توافر قطع الغيار

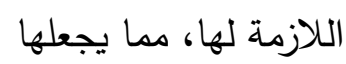

معطلة دون الاستفادة منها.

13. عدم توفر الحماية الأمنية

للمدارس الفنية لتأمين الآلات

والماكينات والعدد والبيانات

والمعلومات من السرقة.

14. ضعف تسويق المنتجات لقلة

عدد المعارض المتاحة.

15. قصور الاستفادة من الموارد

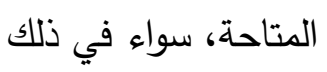
البشرية، والمادية.

16. قصور المعلومات الحقيقية

عن سوق العمل.

17. ضعف البنية التحتية لشبكة

المعلومات بمدارس التعليم

الثانوي الصناعي.

18. سوء مرافق التعليم الثانوي

الصناعي والبنية الأساسية

للاتصالات وتكنولوجيا

المعلومات.

19. محدودية التعاون بين

المدارس الثانوية الفنية

الصناعية والبيئة المحيطة.

20. عدم وجود قاعدة بيانات

تخص التعليم الفني

الصناعي. 
التهايدات (Threats)

1. لا توجد قواعد بيانات صحيحة وموثقة تحدد احتياجات سوق العمل من المهن والتخصصات

المختلفة بالتعليم الفني.

2. ضعف فاعلية تطوير التعليم

الفني، إذ إن آليات سوق العمل تتغير وتتطور بسرعة تفوق

تطور إمكانات ومخرجات التعليم الفني؛ مما أدى إلى التباين الواضح بين معدل كفاءة الخريجين، ومعدل الصلاحية الفعلية لسد متطلبات سوق

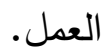

3. عدم وجود دراسات واقعية

ومتكاملة لحالة ومتطلبات

أسواق العمل العربية من العمالة المؤهلة والماهرة، سواء على المدى القريب أو المدى البعيد. 4. جهود التدريب ما تزال مبعثرة، وتتفاوت نظمها وطاقاتها وتخصصاتها ومناهجها بين البلدان العربية.

5. ضعف الميزانيات المخصصة لتجهيز المدارس الفنية ومراكز التدريب بالمعامل والمعدات اللازمة التي تخدم المناهج
تحليل الفرص (Opportunities)

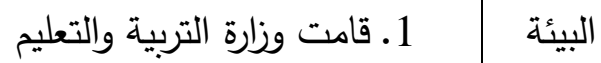
الخارجية بالتعاون مع وزارة الاتصالات بعمل الشبكة الداخلية للمدارس؛ لربط جميع أجهزة الحاسب الب الهب بشبكة واحدة وربطها بالثبكة المعلوماتية الدولية. 2. قامت وزارة الاتصالات وتكنولوجيا المعلومات بعمل مشروع قانون أمن الفضاء المعلوماتي.

3. إنشاء جهاز قومي للرقابة على جميع أعمال أمن المعلومات، ومنح تراخيص مزاولة أعمال الخبرة في هذا المجال.

4. كما وضعت منظمة اليونسكو عددًا من المؤشرات التي يمكن استخدامها للحكم على قدرة المؤسسات التعليمية في استخدام تكنولوجيا المعلومات. 5. أعدت وزارة التربية والتعليم ـ من خلال قطاع التعليم الفني بها ـ قواعد بيانات مختلفة، تمهيدًا لعقد مؤتمرها التقني الأول والثاني من أجل ربط التعليم الفني - بمختلف تخصصاته ـ بسوق العمل. 


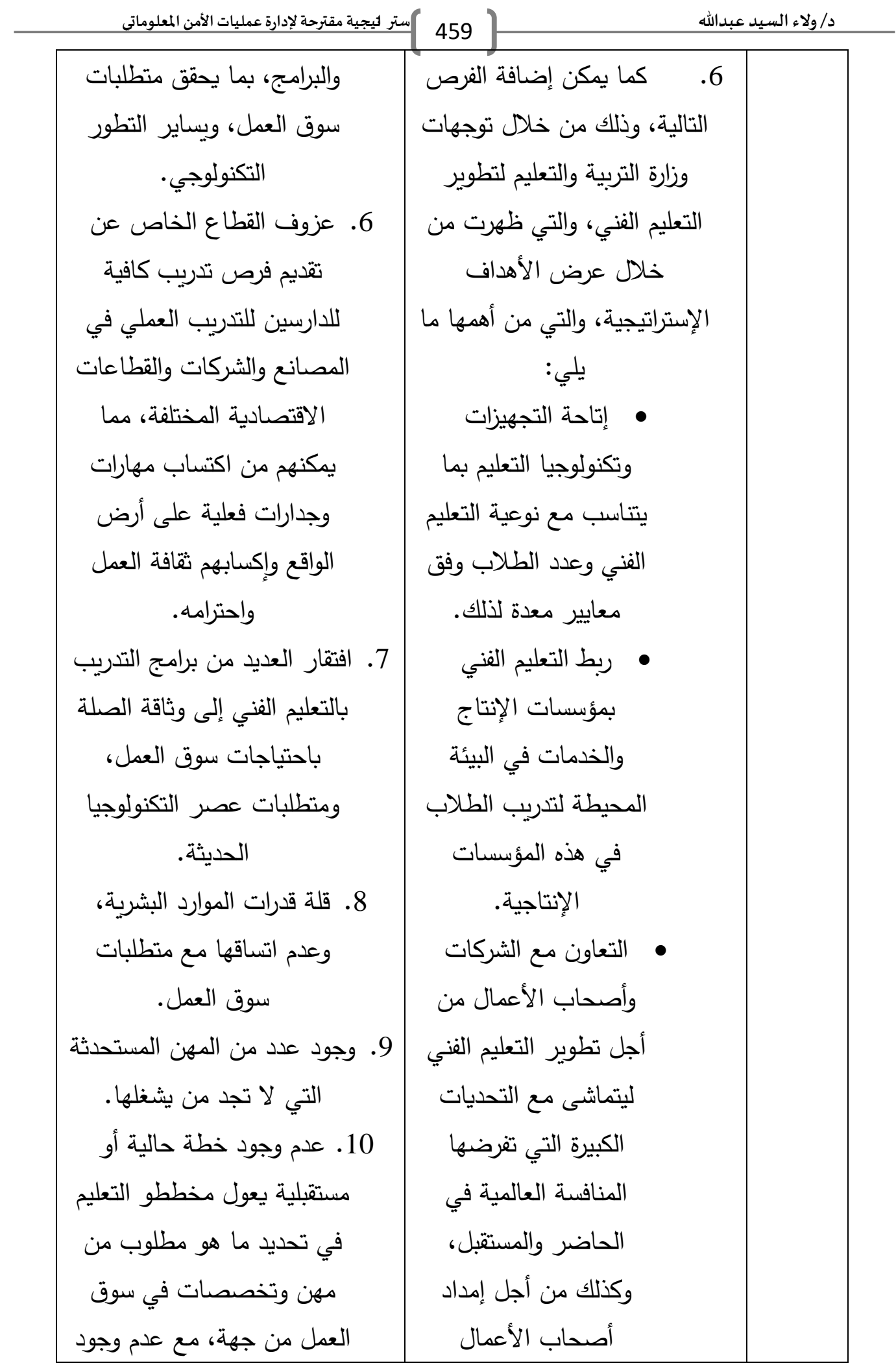




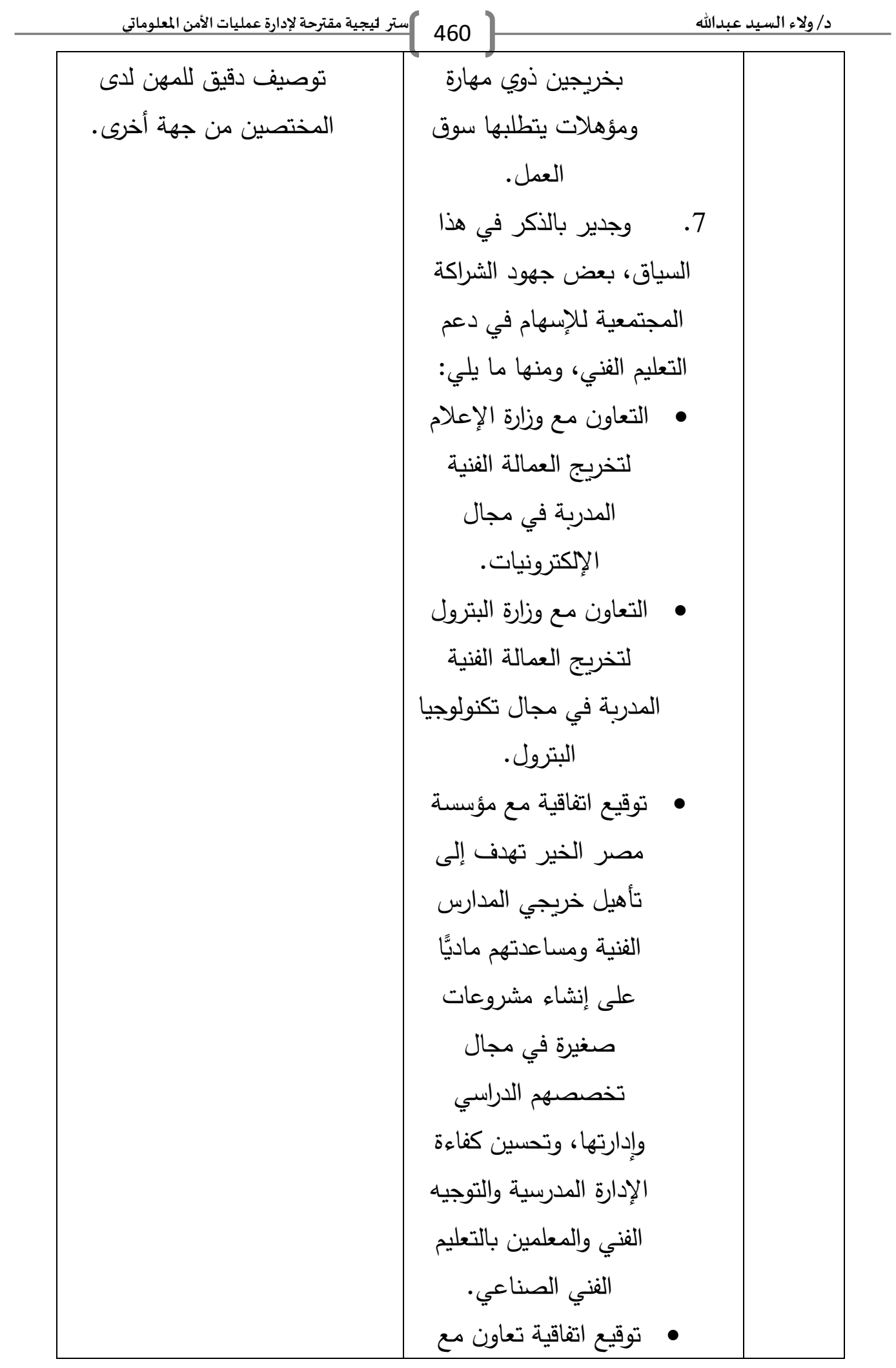




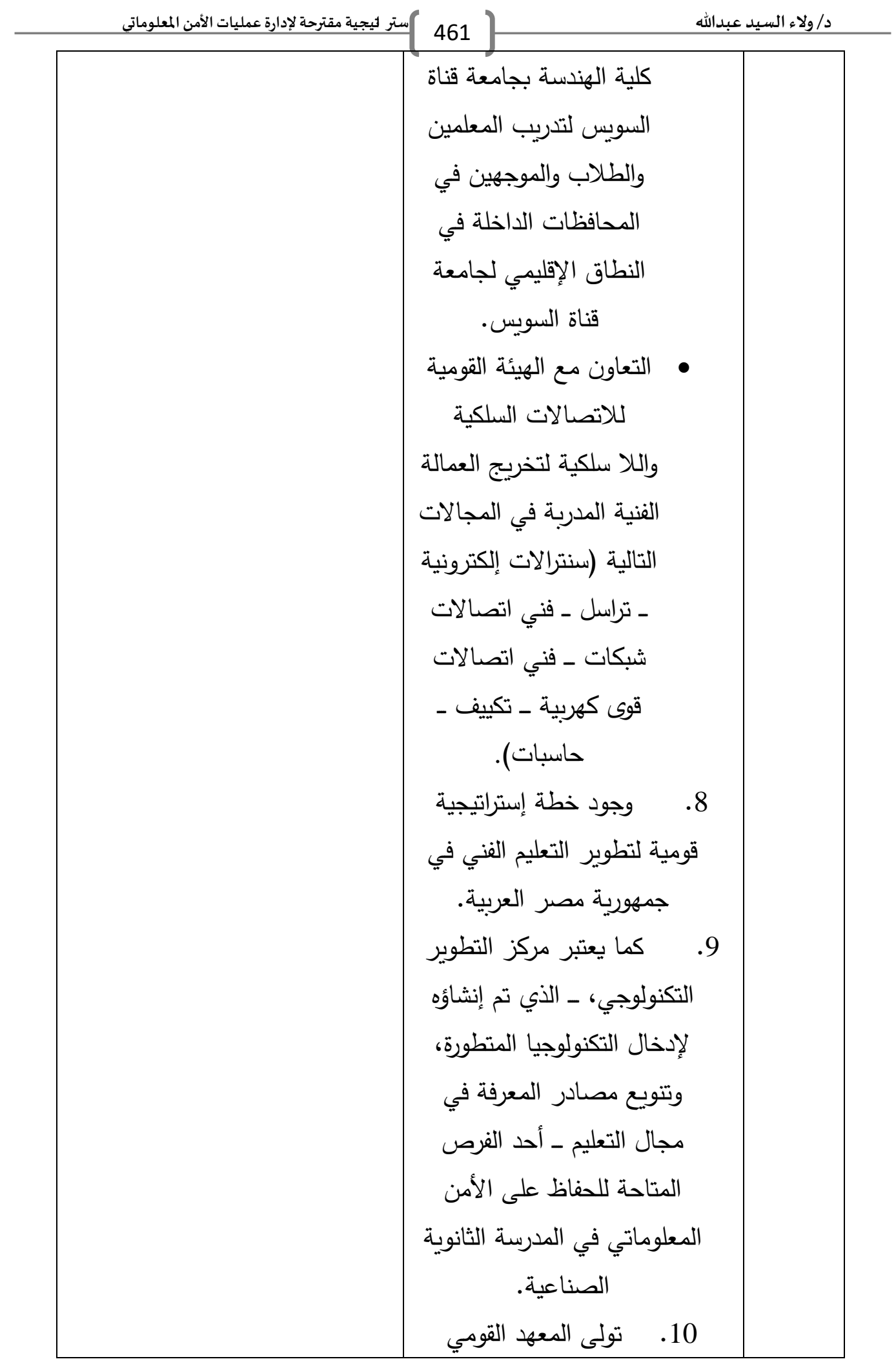




\begin{tabular}{|c|c|c|}
\hline \multirow[t]{2}{*}{ كستر ليجية مقترحة لإدارة عمليات الأمن المملوماتي } & 462 & د/ولاء السيد \\
\hline & 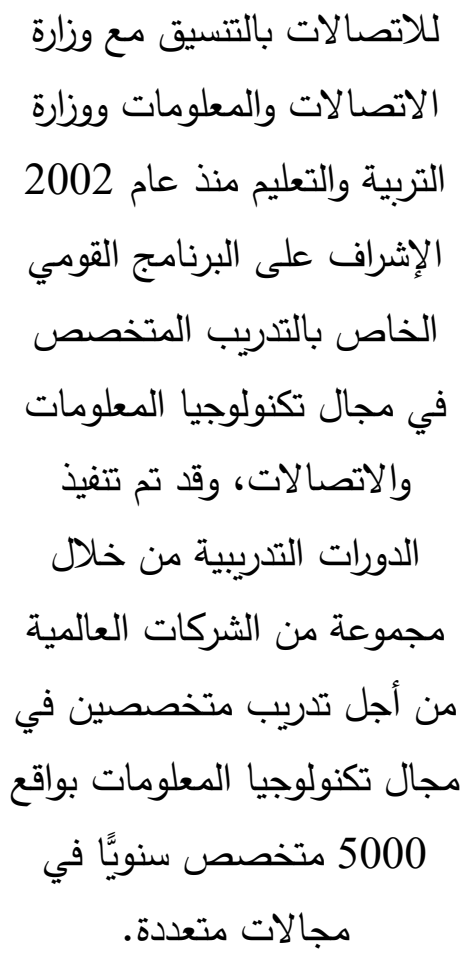 & \\
\hline
\end{tabular}

وقد تضمن تحليل البيئة الداخلية للمدرسة الثانوية الصناعية في جمهورية مصر العربية، والبيئة الخارجية المحيطة بها تطبيق استمارة التحليل الإستراتيجي على عدد من الخبراء في مجال التعليم الفني الصناعي؛ لاستطلاع آرائهم حول عبارات الاستمارة، وتحليل البيئة الداخلية والخارجية، وتضمنت العينة في مجملها (25) فردًا؛ منهم (4) أساتذة جامعات، (4) من المسئولين عن التعليم الفني الصناعي بمديرية التربية والتعليم بالقاهرة، و(8) من الأساتذة العاملين بشعبة التعليم الفني بالمركز القومي للبحوث التربوية والتنمية، و(7) من الأساتذة العاملين بقطاع التعليم الفني التابع لوزارة التربية والتعليم، و(2) من العاملين بالإدارة العامة لمركز تطوير التعليم

$$
\text { الفني، وتضمنت الاستمارة ما يلي: لوراكئ }
$$

1- محور نقاط القوة، ويشمل ما يوجد في المدرسة الثانوية الصناعية ويؤثر فيها إيجابيَّا، ومحور جوانب الضعف، ويشمل ما يوجد في المدرسة الثانوية الصناعية ويؤثر سلبًا على قدرتها على الحفاظ على أمنها المعلوماتي. 
2- محور الفرص التي يمكن الاستفادة منها، ومحور التهديدات التي يجب التعامل

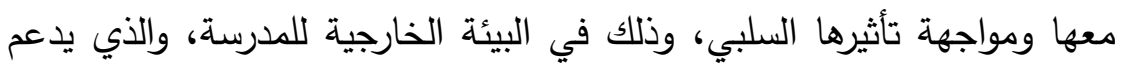

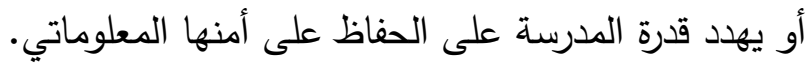
3- مدى التأثير، ويعبر عن درجة تأثير العنصر على عمليات إدارة الأمن

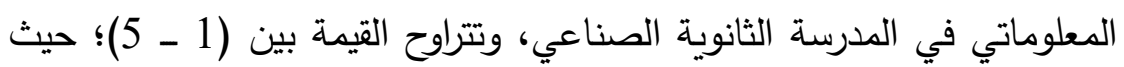
تمثل (5) الأثر الأعلى، و(1) تبين مستوى التأثير الأضعف. 4- احتمالية الحدوث (بالنسبة للفرص والتهديدات)، ويعبر عن ولاتل مدى إمكانية الحدوث، وتتراوح القيمة بين (1 ـ 10)؛ حيث تمثل (10) الاحتمالية الأعلى للحدوث، والدرجة (1) الاحتمالية الأقل للحدوث. 5- درجة التواجد (بالنسبة لنقاط القوة والضعف)، وتتراوح القيمة من (1 ـ 10)؛ حيث تمثل الدرجة (10) درجة التواجد، بينما تعبر الدرجة (1) عن الدرجة الأقل لمتواجد. التحليل الإحصائي: 1- متوسط الوزن النسبي لجوانب القوة والضعف = (متوسط مدى التأثير × متوسط درجة التواجد) 2- متوسط الوزن النسبي للفرص والتهديدات = (متوسط مدى التأثير × متوسط احتمالية الحدوث)

3- تم الاعتماد في التحليل الإحصائي للاستجابات على المتوسط الحسابي (لمدى

التأثير، واحتمال الحدوث، ودرجة التواجد) وفق المعادلة التالية: (97) مجموع درجات الاستجابات عدد أفراد العينة

وتم ترتيب العبارات تتازليَّا وفق متوسط الوزن النسبي، كما سيتضح فيما يلي: أولًا ـ تحليل عناصر البيئة الداخلية:

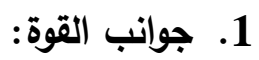
جدول رقم (3) جدول الأوزان النسبية لعناصر القوة 


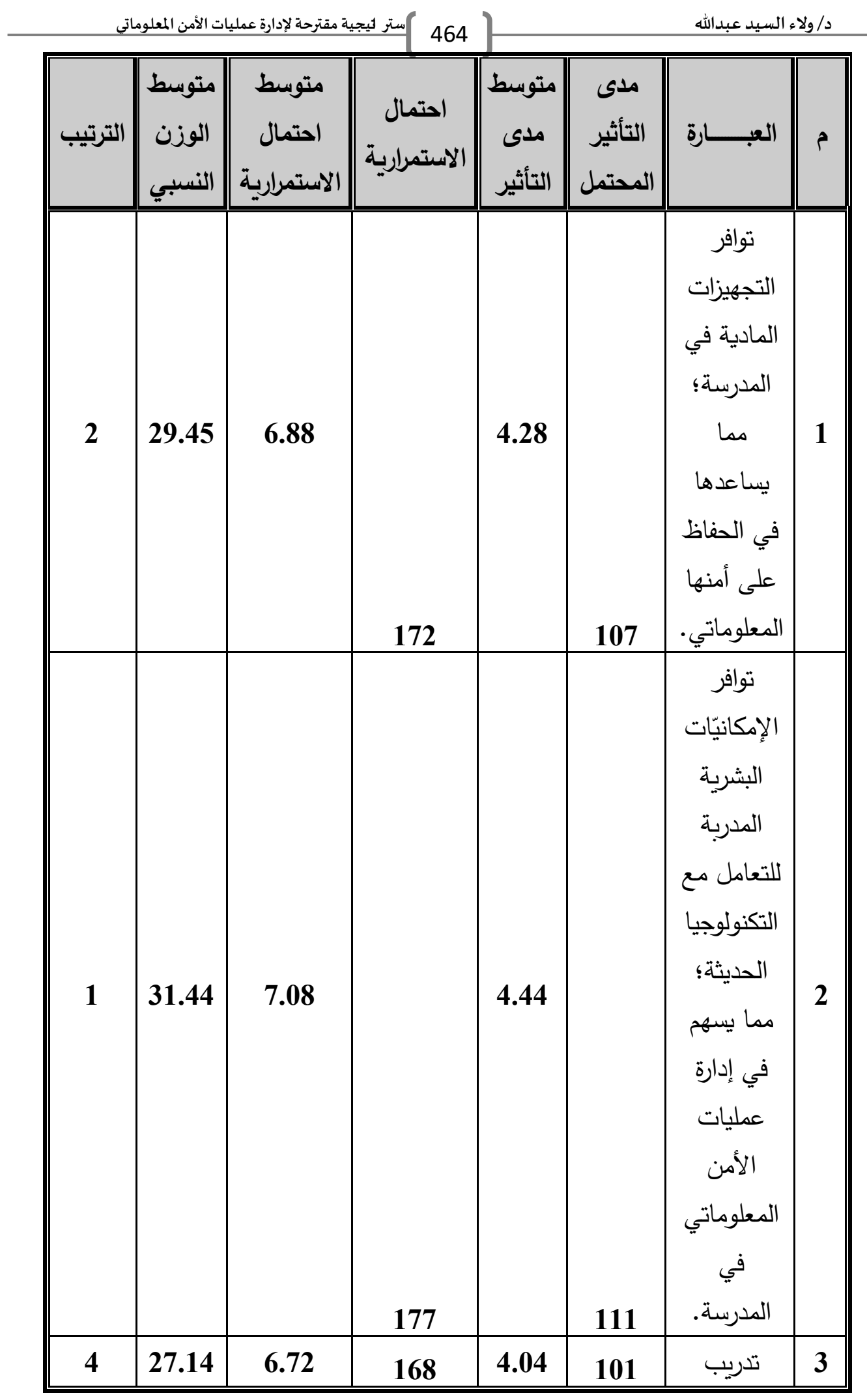

العدد الثاني عشر - مارس 2017 


\begin{tabular}{|c|c|c|c|c|c|c|c|}
\hline \multicolumn{4}{|c|}{465 كستر ليجية مقترحة لإدارة عمليات الأمن المعلوماتي } & \multicolumn{4}{|c|}{ د/ ولاء السيد عبدالله } \\
\hline 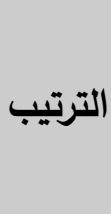 & الوتوسط & 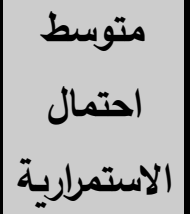 & الاستمرارية & متوسط & التأثثر & العبـــــــارة & b \\
\hline & & & & & & في المدرسة & \\
\hline 5 & 26.93 & 6.6 & 165 & 4.08 & 102 & للمعلومات & 4 \\
\hline 7 & 22.22 & 6.04 & 151 & 3.68 & 92 & ونوقاقات & 5 \\
\hline
\end{tabular}




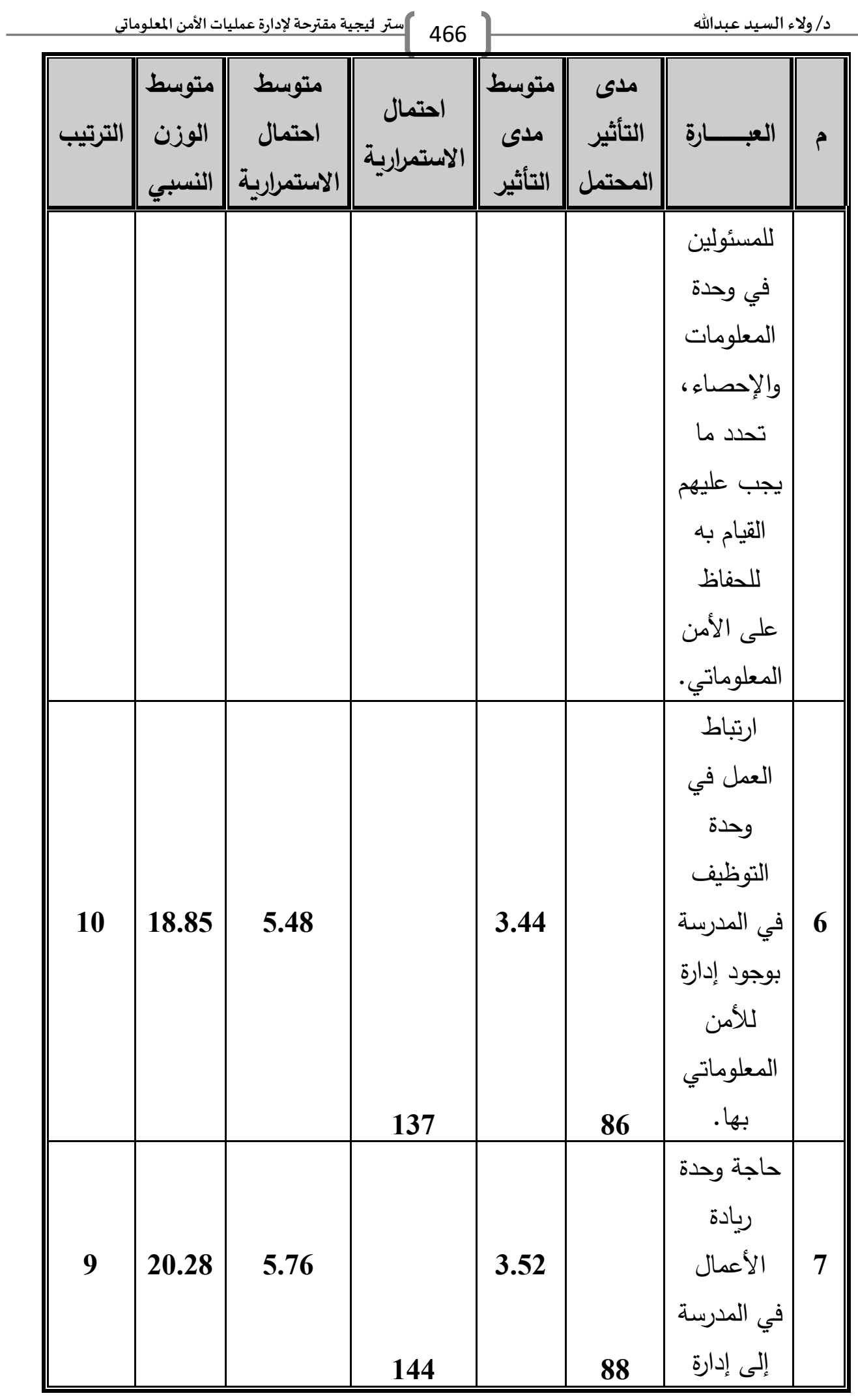




\begin{tabular}{|c|c|c|c|c|c|c|c|}
\hline \multicolumn{4}{|c|}{467 ـ كستر ليجية مقترحة لإدارة عمليات الأمن المعلوماتي } & \multicolumn{4}{|c|}{ د/ ولاء السيد عبدالله } \\
\hline الترتيب & الوزن النسبط & الاستمال & الاستمال & متوسط & التأثير & العبــــــارة & r \\
\hline & & & & & & المعلومن & \\
\hline 8 & 20.88 & 5.8 & 145 & 3.6 & 90 & الاجلة الإرشاد وحدة المهني & 8 \\
\hline 3 & 27.48 & 6.48 & 162 & 4.24 & 106 & 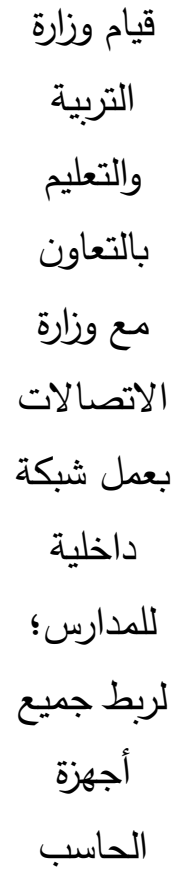 & 9 \\
\hline
\end{tabular}




\begin{tabular}{|c|c|c|c|c|c|c|c|}
\hline الترتيب & الوزن & 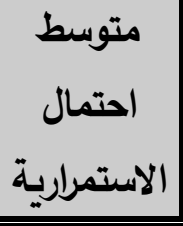 & الاستمال & متوسط & $\begin{array}{l}\text { المدىى } \\
\text { التأثير }\end{array}$ & العبــــــارة & p \\
\hline & & & & & & والبشة المعبكة & \\
\hline 6 & 23.97 & 6.24 & 156 & 3.84 & 96 & المالمدارس & 10 \\
\hline & 248.6 & \multicolumn{6}{|c|}{ مجموع متوسطات الوزن النسبي } \\
\hline
\end{tabular}

يتضح من الجدول السابق، أن جميع عناصر القوة التي وردت في الجدول لها تأثير كبير على إدارة عمليات الأمن المعلوماتي في المدرسة الثانوية الصناعية في إني جمهورية مصر العربية؛ حيث إن متوسط درجة التأثير لها أكبر من (2.5)، ومتوسط التيط

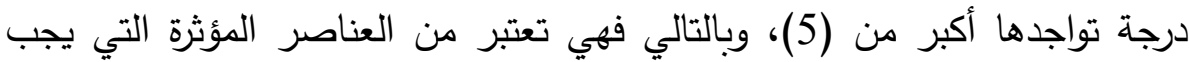
الاستفادة منها في بناء جدول التحليل الرباعي، ويرجع السبب في ذلك إلى توجهات الخطة الإستراتيجية للتعليم في مصر لإجراء المزيد من الإصلاحات في قطاعات

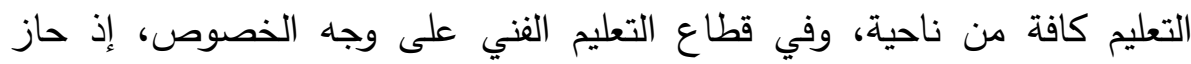
عنصر (تجهيز المدارس بوسائل التكنولوجيا الحديثة، والتدريب المستمر على ولى استخدام تلك التكنولوجيا) على النصيب الأكبر من توجهات الوزارة في الآونة الأخيرة، 
كما أن وجود عدد من الوحدات المستحدثة ـ كوحدة الإحصاء والمعلومات، والإششاد

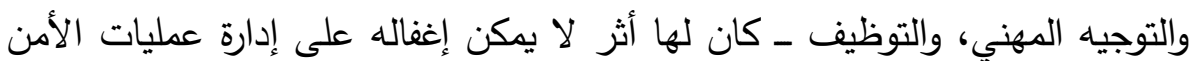

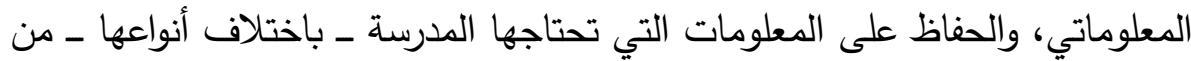

$$
\text { الضياع، واستعادتها وقت الحاجة إليها. }
$$

ويمكن للمدرسة الثانوية الصناعية أن تستفيد من تلك النقاط وتدعمها، من إنها.

خلال الاستمرار في تجهيز المدارس بالتجهيزات الملائمة، التي تستخدم لإدارة عمليات الأمن المعلوماتي في المدرسة الثانوية الصناعية، وإتاحة فرص أكثر في التدريب المتخصص على إدارة عمليات الأمن المعلوماتي في المدرسة للمدير، والإداريين المسئولين عن حفظ المعلومات، والاحتفاظ بها في مختلف الوحدات المدرسية، بالإضافة إلى ضرورة عقد المزيد من بروتوكولات التعاون بين وزارة التربية

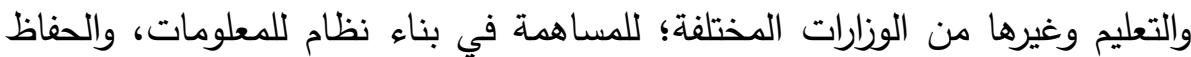

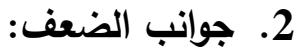

جدول رقم (4) جدول الأوزان النسبية لعناصر الضعف.

\begin{tabular}{|c|c|c|c|c|c|c|c|}
\hline 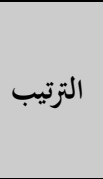 & الوزتوسط & الاستمال متمال & الاستمرارية & متوسط & المتأثير & العبـــارة & م \\
\hline 16 & 24.72 & 6.8 & 170 & 4.04 & 101 & انخفاض مستوى أداء العاملين بإدارة المدرسة. & 1 \\
\hline 5 & 28.56 & 7 & 175 & 4.08 & 102 & عملية التخطيط للأمن المعلوماتي في المدرسة & 2 \\
\hline 2 & 29.50 & 7.16 & 179 & 4.12 & 103 & 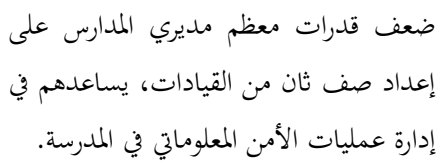 & 3 \\
\hline 9 & 26.72 & 6.68 & 167 & 4 & 100 & قلإدارة الأمن المعلوماتي في المدرسة. التكنولوجية المتنوعة اللازمة & 4 \\
\hline 17 & 24.64 & 6.16 & 154 & 4 & 100 & والمكان المحصاء في المدرسة غير مؤمن. لوحدة المعلومات & 5 \\
\hline 3 & 29.05 & 7.12 & 178 & 4.08 & 102 & 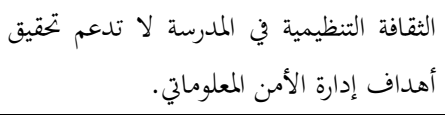 & 6 \\
\hline
\end{tabular}




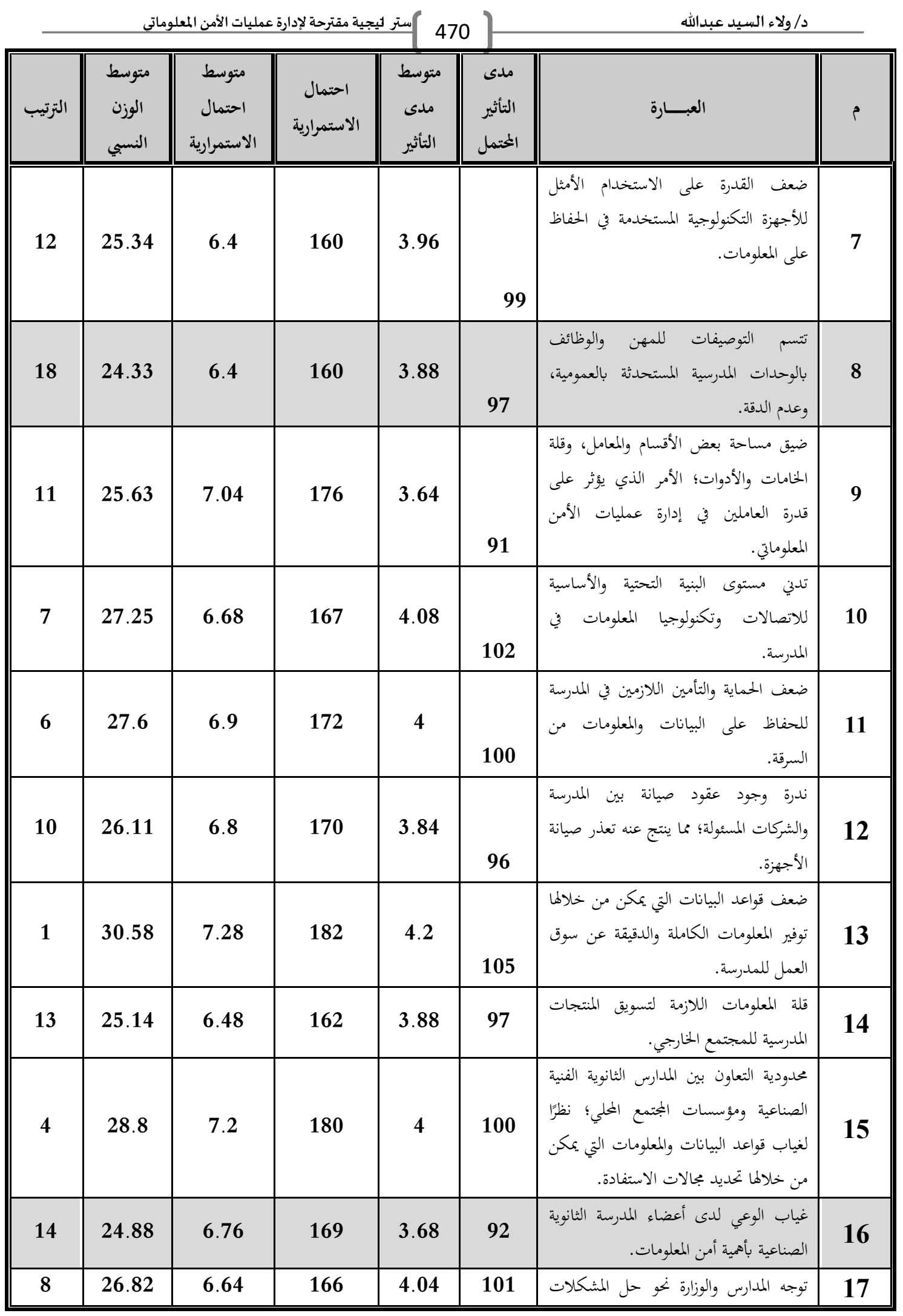




\begin{tabular}{|c|c|c|c|c|c|c|c|}
\hline \multicolumn{5}{|c|}{ ستر ليجية مقترحة لإدارة عمليات الأمن المعلوماتي } & \multicolumn{3}{|c|}{ د/ولاء السيد عبدالله } \\
\hline 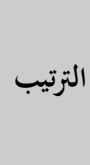 & الوزت النوسط & الاستمال المتمارية & الاستمرارية & متوسط & المتأثير & العبــــارة & b \\
\hline & & & & & & 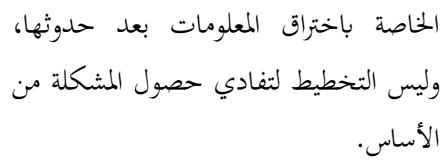 & \\
\hline 15 & 24.73 & 6.72 & 168 & 3.68 & 92 & اللا يتم تدريب العاملين في الوحدات المدرسية & 18 \\
\hline & & & & & & وسطات الوزن النسبي = 4. & \\
\hline
\end{tabular}

ويتضح من الجدول السابق أن جميع عناصر الضعف التي وردت في الجدول

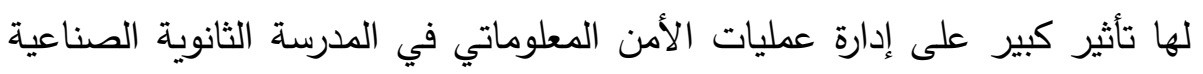

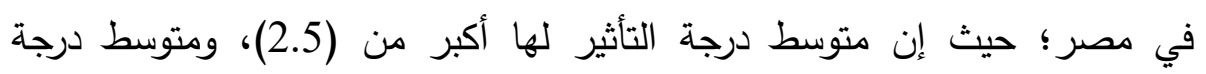

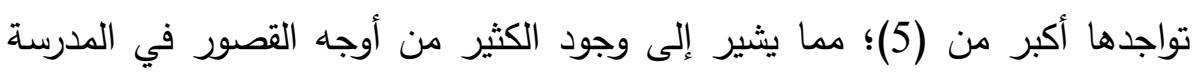
الثانوية الصناعية، والذي قد يحول بينها وبين تحقيق الأمن المعلوماتي المنشود،

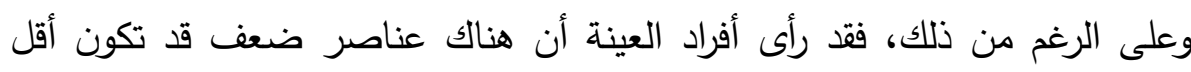

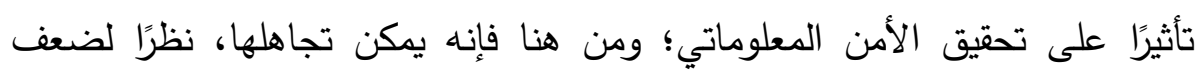
تأثيرها.

وعلى الرغم من ذلك هناك العديد من أوجه القصور في البيئة الداخلية للمدرسة الثانوية الصناعية التي قد تحول دون حفاظها على أمنها المعلوماتي، مدًّا

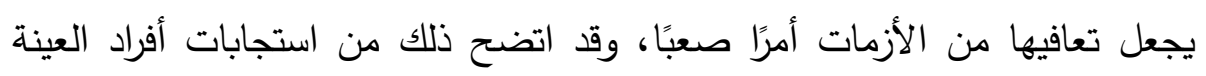

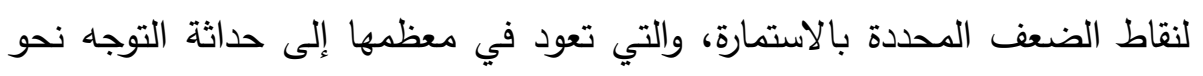

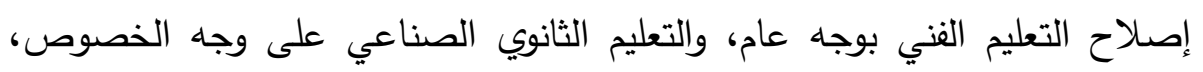

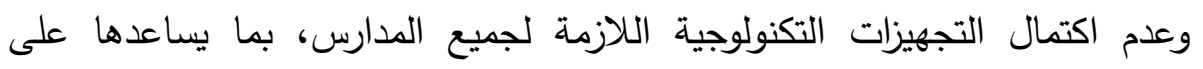
الحفاظ على أمنها المعلوماتي، وقلة وعي المديرين والإداريين بأهمية الاستعداد

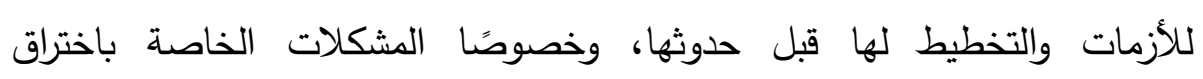

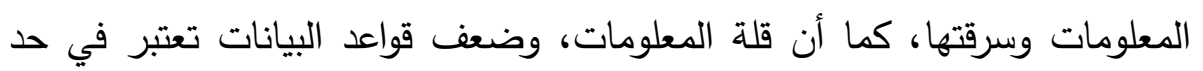

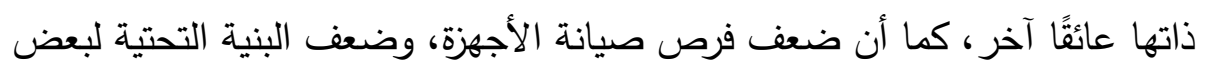
المدارس يمثل عائقًا آخر ؛ وقد يرجع ذلك إلى عدم امتلاك الهيئات المسئولة لخريطة 
زمنية يمكن عن طريقها تحديد موعد الانتهاء من تجهيز الددارس باحتياجاتها

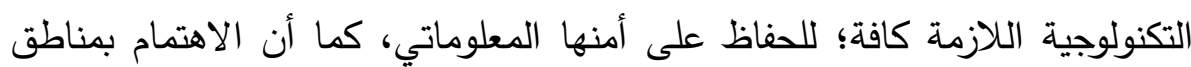
على حساب أخرى، قد يجعل من بعض المدارس الثانوية الصناعية بيئة ملائمة

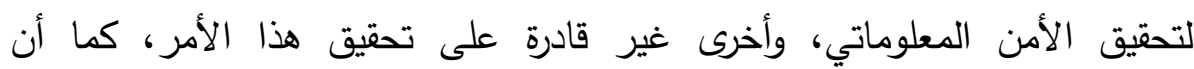
الانفصال، وعدم التسيق، ومحدودية الاتصال، وغياب الخطط التعاونية ـ التي تحدد ولئي

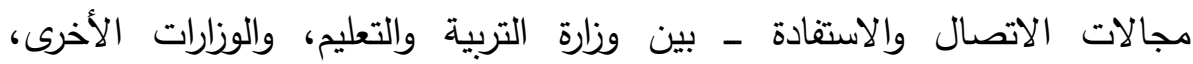

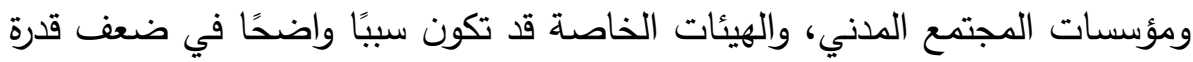
المدارس على إدارة عمليات الأمن المعلوماتي بها، كما أن المفهوم الخطأ لدى مدير

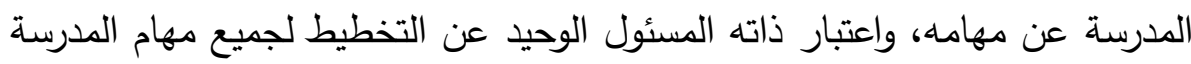

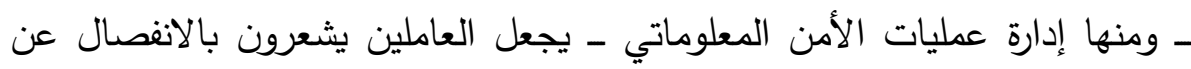
المدرسة، ولا يشعرون بدورهم داخلها، إلا في كونهم تقع عليهم مسئولية تتفيذ الأوامر .

3. تحليل التوازن بين جوانب القوة والضعف:

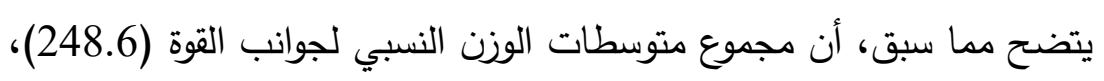

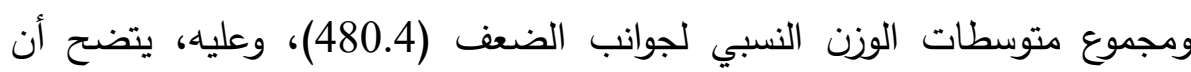
مجموع متوسطات الوزن النسبي لجوانب الضعف أكبر من مجموع متوسطات الوزن

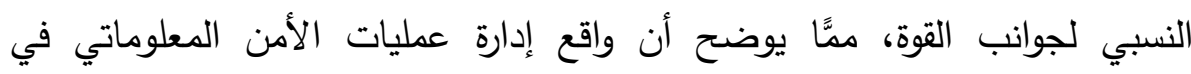

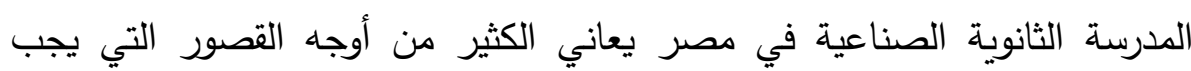

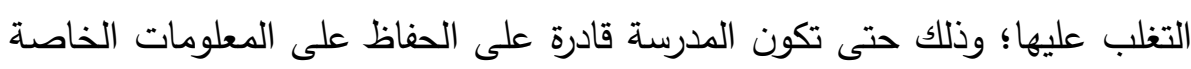
بها، واستعادتها وقت الحاجة إليها، وربما يرجع ذلك إلى ضعف الثى الإمكانات المادية،

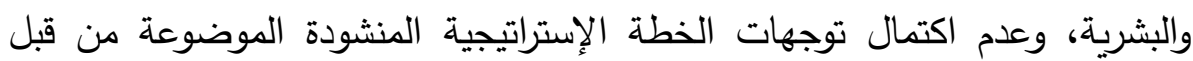

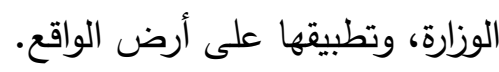




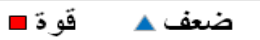

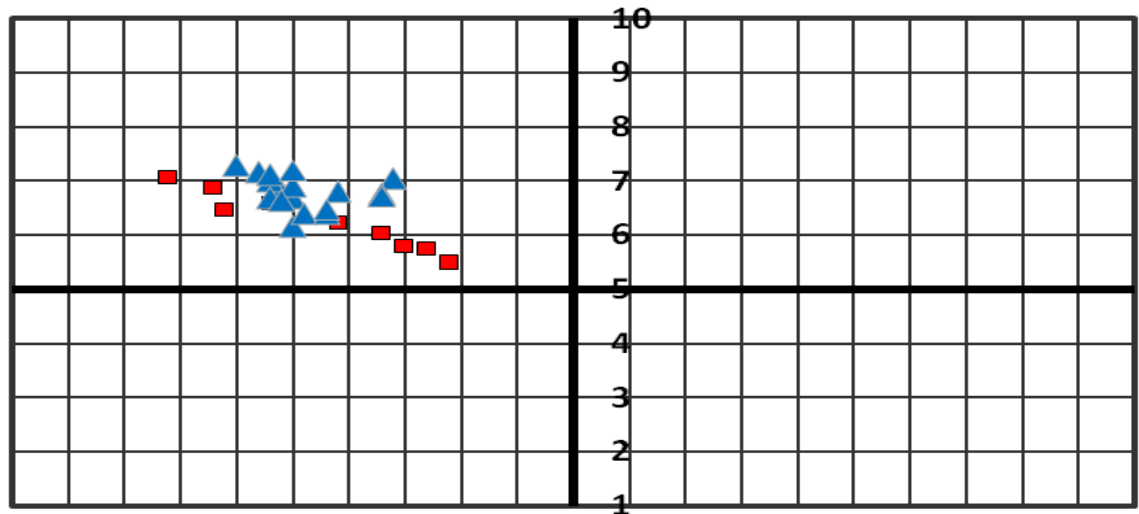

شكل رقم (5) موقع عناصر القوة والضعف وفق الوزن النسبي.

يتضح من الشكل السابق أن جميع عناصر القوة والضعف تقع في المربع

الرابع؛ مما يعني أن درجة تأثيرها كبير ، ودرجة استمراريتها عالية.

ويوضح الشكل التالي، مستوى التوازن بين عناصر القوة والضعف التي لها

تأثير على إدارة عمليات الأمن المعلوماتي في المدرسة الثانوية الصناعية في مصر، بحيث يمثل الاتجاه الأعلى نقاط القوة، والاتجاه الأدنى نقاط الضعف، كما هو موضح بالشكل التالي:

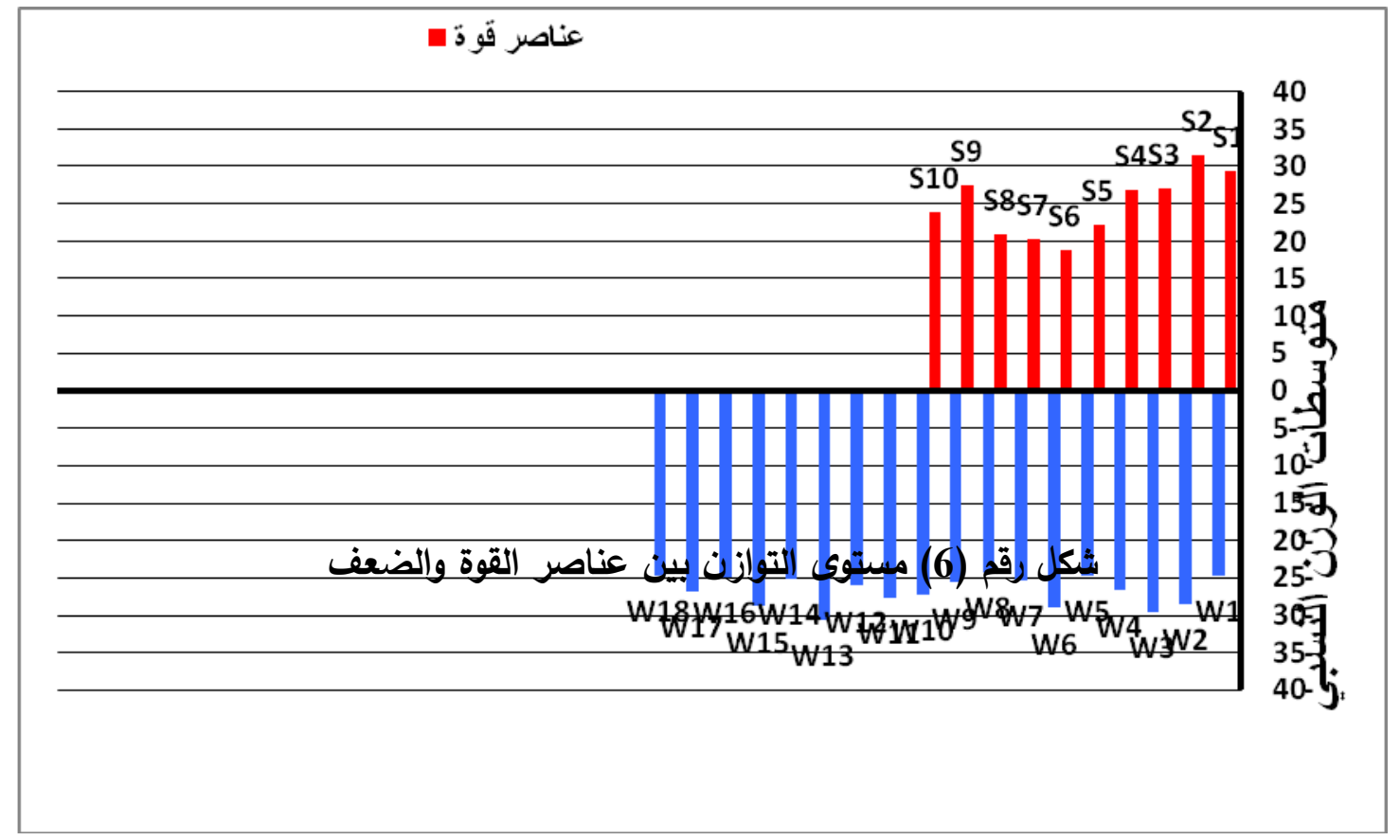


يتضح من الشكل السابق، أن عناصر الضعف التي تؤثر على إدارة عمليات

الأمن المعلوماتي في المدرسة الثانوية الصناعية أكثر من عناصر القوة التي تدعم

وجود إدارة فعالة للأمن المعلوماتي؛ مما يوضح أن نسبة تأثير عناصر الضعف

ودرجة تواجدها أكبر من نسبة تأثير عناصر القوة، ودرجة تواجدها.

ثانيًا: تحليل عناصر البيئة الخارجية:

1

جدول رقم (5) الأوزان النسبية للفرص

\begin{tabular}{|c|c|c|c|c|c|c|c|}
\hline الترتيب & النوسط & الحتوسط الحدول & الحتمال الحدوث & مدى التأثير & المتأثير & العبــــارة & م \\
\hline 12 & 25.66 & 6.48 & 162 & 3.96 & 99 & 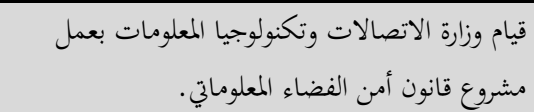 & 1 \\
\hline 5 & 29.17 & 6.88 & 172 & 4.24 & 106 & إنشاء الجهاز القومي للرقابة على جميع أعمال أمن & 2 \\
\hline 11 & 26.04 & 7 & 175 & 3.72 & 93 & 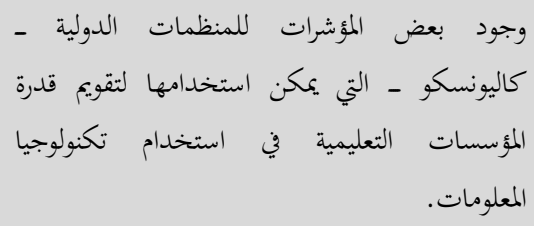 & 3 \\
\hline 8 & 27.79 & 6.88 & 172 & 4.04 & 101 & 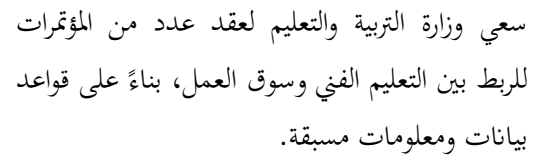 & 4 \\
\hline 4 & 30.61 & 7.36 & 184 & 4.16 & 104 & 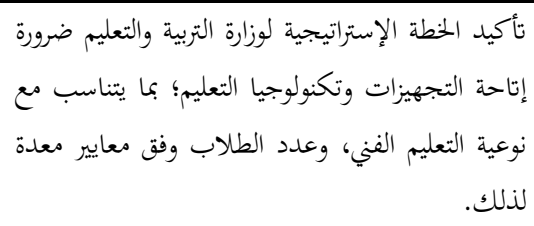 & 5 \\
\hline 3 & 31.50 & 7.36 & 184 & 4.28 & 107 & 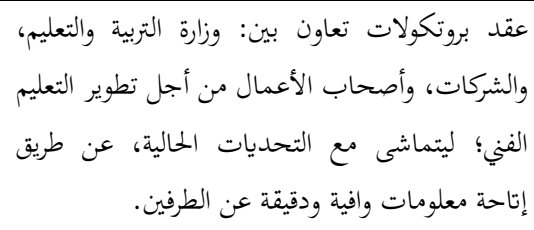 & 6 \\
\hline 13 & 22.27 & 6.12 & 153 & 3.64 & 91 & 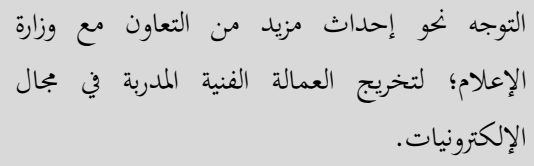 & 7 \\
\hline
\end{tabular}




\begin{tabular}{|c|c|c|c|c|c|c|c|}
\hline \multicolumn{5}{|c|}{ كتر ليجية مقترحة لإدارة عمليات الأمن المعلوماتي } & 175 & \multicolumn{2}{|l|}{ د دولاء السيد عبدالله } \\
\hline 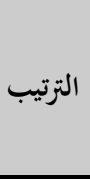 & الوزتون & متوسط احتمال & المتمال & مدى التأثير & التأثير & العبــــارة & b \\
\hline 10 & 27.47 & 7.08 & 177 & 3.88 & 97 & 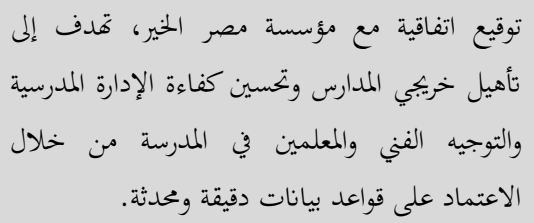 & 8 \\
\hline 7 & 28.23 & 6.92 & 173 & 4.08 & 102 & 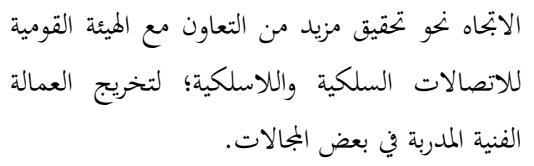 & 9 \\
\hline 1 & 39.6 & 10 & 265 & 3.96 & 99 & 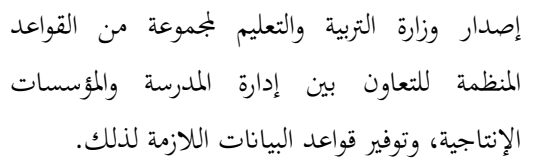 & 10 \\
\hline 6 & 28.32 & 7.08 & 177 & 4 & 100 & 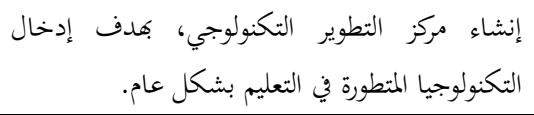 & 11 \\
\hline 9 & 27.52 & 6.88 & 172 & 4 & 100 & 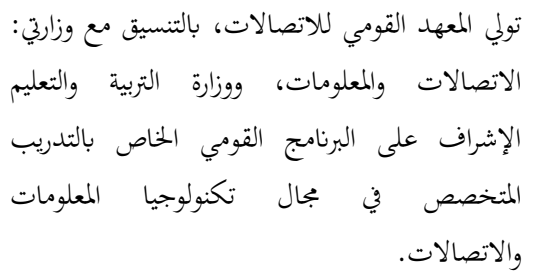 & 12 \\
\hline 2 & 32.1 & 7.16 & 179 & 4.48 & 112 & 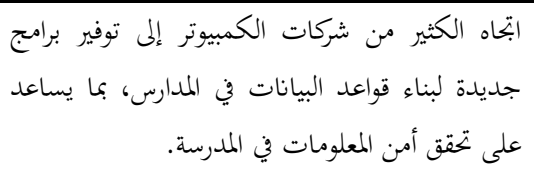 & 13 \\
\hline & 376.6 & & & & & توسطات الوزن النسبي & \\
\hline
\end{tabular}

يتضح من الجدول السابق أن جميع الفرص التي وردت في الجدول لها تأثير

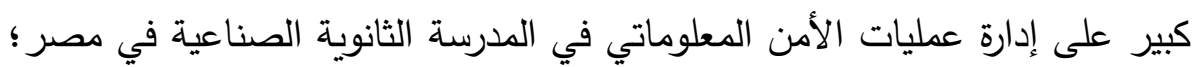
حيث إن متوسط درجة التأثير لها أكبر من (2.5)، ومتوسط احتمالية حدوثها أكبر من (5)، ممَّا يشير إلى توفر العديد من الفرص في البيئة الخارجية للمدرسة الثانوية

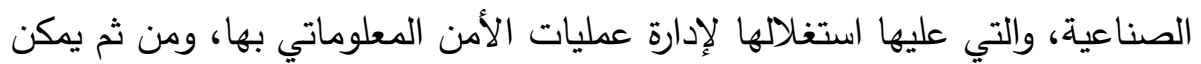
الاعتماد عليها في بناء جدول التحليل الرباعي الذي يحدد الإستراتيجيات التي يمكن أن تتبعها المدرسة الثانوية الصناعية، وربما يرجع ذلك إلى ما شهده قطاع التعليم الفني من توجهات متعددة نحو الإصلاح والتطوير، ومحاولات دائمة للتخلص من 
المشكلات التي تعوقه عن تحقيق أهدافه، إضافةً إلى التوجه نحو الاستفادة من الدول

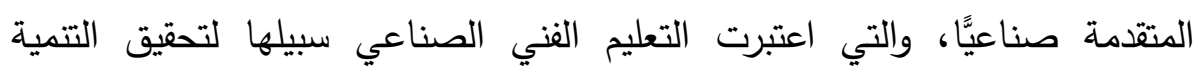
الصناعية المنشودة.

وتمثلت تلك الفرص في إنشاء الجهاز القومي للرقابة على جميع أعمال أمن المعلومات، ومنح تراخيص مزاولة أعمال الخبرة والتخصص في هذا المجال، وسعي

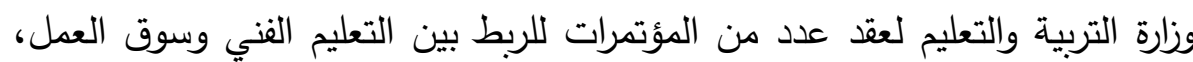
بناءً على قواعد بيانات ومعلومات مسبقة، وتأكيد الخطة الإستراتيجية لوزارة التربية

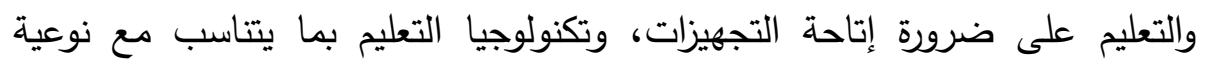
التعليم الفني وعدد الطلاب وفق معايير معدة لذلك، وإنشاء مركز التطوير التكنولوجي، بهدف إدخال التكنولوجيا المتطورة في التعليم بشكل عام، فقد رأى أفراد العينة أنها فرص يجب أن تستغلها المدرسة في سبيل تحقيق إدارة جيدة لأمنها المعلوماتي.

وعلى الرغم من وجود فرص من المككن أن تستغلها المدرسة الثانوية

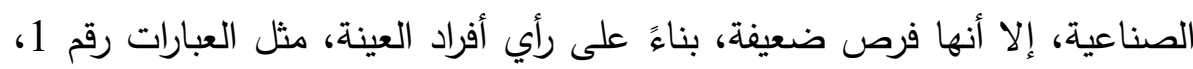

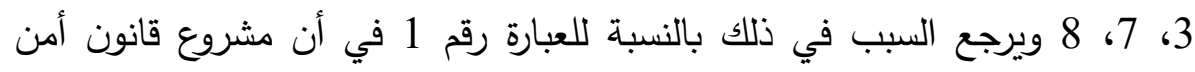
الفضاء المعلوماتي مازال مجرد مشروع لم يرتق إلى رحلة التطبيق إلى الآن، وعليه

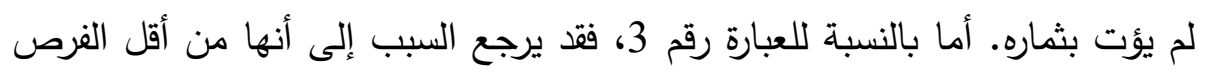

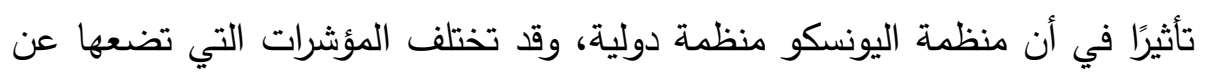
المؤشرات التي تحتاجها المدارس الثانوية الصناعية، باعتبارها مؤسسات تعليمية تختلف طبيعتها من دولة لأخرى، ومن ثَّمَ فهي في حاجة إلى مؤشرات محلية،

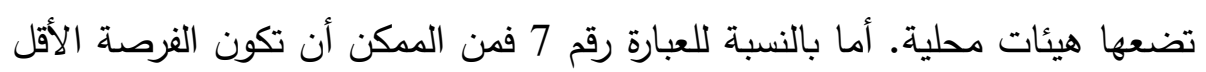

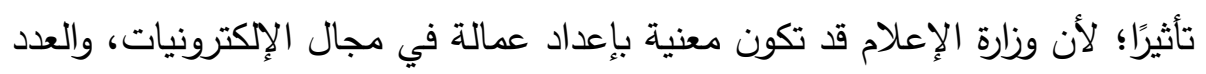

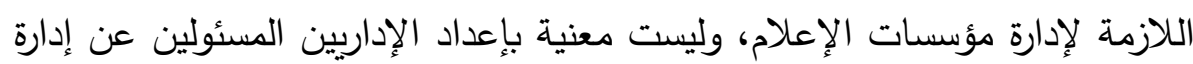

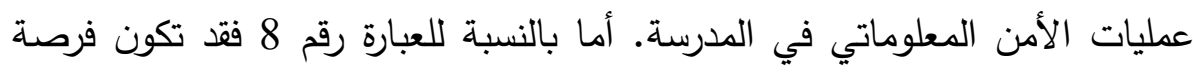

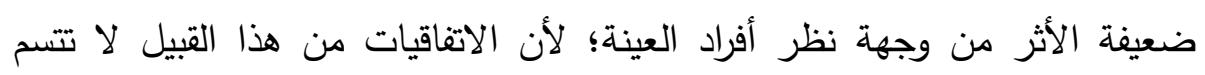
بالاستمرارية، وإنما تكون اتفاقية تتعلق بأفراد معينين ومن الممكن ألا تتكرر، وبالتالي لاني لإني 
لا تعمم الفرصة على المستفيدين منها كافة، وبالتالي يحصل البعض على فرصة

$$
\text { دون الآخرين. }
$$

وبناءً على ما سبق، يمكن تدعيم تلك الفرص وإجراء بعض التعديلات عليها

لتدعيمها، واستخدامها الاستخدام الأمثل لإدارة عمليات الأمن المعلوماتي في المدرسة

$$
\text { 2. الثانويـة الصناعية. }
$$

\begin{tabular}{|c|c|c|c|c|c|c|c|}
\hline الترتيب & الوزتون & الحتوسط & الحدوث احتمال & 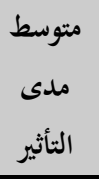 & المختمل & العبـــــارة & p \\
\hline 6 & 30.30 & 7.08 & 177 & 4.28 & 107 & والمؤمنة، والتي تحدد قواعد البيانات الصحيحة والموثقة & 1 \\
\hline 5 & 30.41 & 7.04 & 176 & 4.32 & 108 & لوياب المؤشرات والمعلومات عن التطورات السريعة & 2 \\
\hline 12 & 27.52 & 6.68 & 167 & 4.12 & 103 & قلة والمعلومات الدقيقة عن الدراسات التحليلية، والبحوث العلمية، & 3 \\
\hline 13 & 27.28 & 6.96 & 174 & 3.92 & 98 & 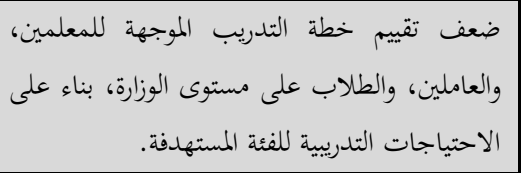 & 4 \\
\hline 4 & 30.91 & 7.36 & 184 & 4.2 & 105 & 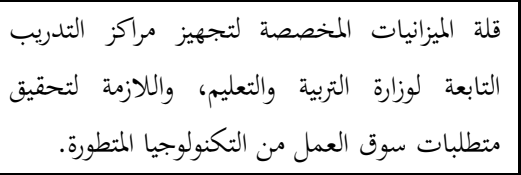 & 5 \\
\hline 9 & 29.88 & 7.2 & 180 & 4.04 & 101 & 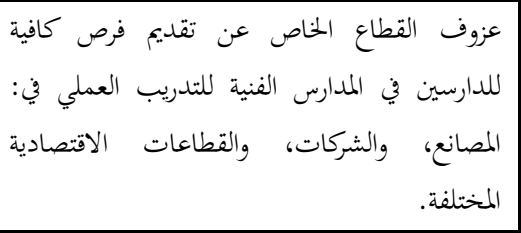 & 6 \\
\hline 10 & 28.8 & 7.2 & 180 & 4 & 100 & 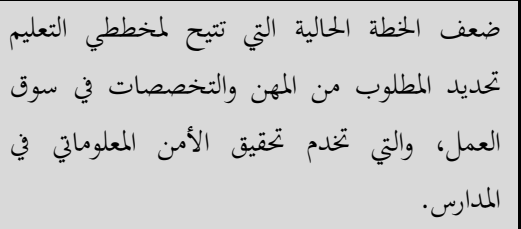 & 7 \\
\hline
\end{tabular}

جدول رقم (6) الأوزان النسبية للتهديدات 


\begin{tabular}{|c|c|c|c|c|c|c|c|}
\hline & \multicolumn{4}{|c|}{ كستر ليجية مقترحة لإدارة عمليات الأمن المعلوماتي } & \multicolumn{3}{|c|}{ د/ ولاء السيد عبدالله } \\
\hline الترتيب & النوزئ & الحتوسط & 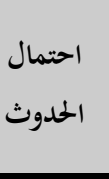 & متوسط & المختمل & العبـــارة & r \\
\hline 11 & 27.56 & 6.96 & 174 & 3.96 & 99 & 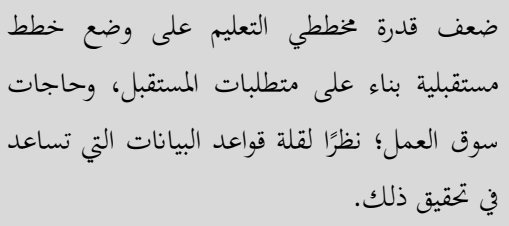 & 8 \\
\hline 1 & 33.38 & 7.8 & 195 & 4.28 & 107 & 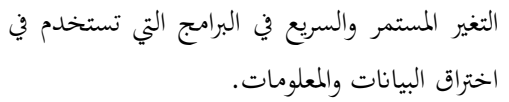 & 9 \\
\hline 7 & 30.21 & 7.48 & 187 & 4.04 & 101 & تلدني المنظومة القيمية في المجتمع؛ مما يمثل قتديدًا & 10 \\
\hline 3 & 31.61 & 7.6 & 190 & 4.16 & 104 & زالبيادة تكلفة برامج الحماية، وبرامج بناء قواعد & 11 \\
\hline 2 & 32.83 & 7.6 & 190 & 4.32 & 108 & وحساسيتها عند الوعي الكافي بكيفية التعامل مع المعلومات & 12 \\
\hline 8 & 30.07 & 7.16 & 179 & 4.2 & 105 & المعلومات بدءًا من التخطيط لبناء برنامج متكامل لأمن، وحتى المدرسة. & 13 \\
\hline & 90.76 & & & & النسبي & مجموع متوسطات ال & \\
\hline
\end{tabular}

ويتضح من الجدول السابق، أن جميع التهديدات السالفة لها تأثير كبير على

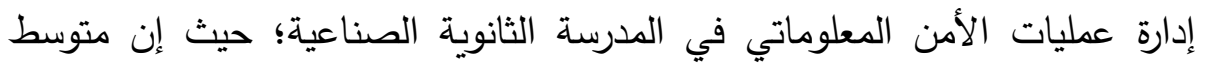
مدى التأثير لجميع العناصر أكبر من 2.5، ومتوسط احتمالية الحدوث لتلك العناصر أيضًا أكثر من (5)، ولكن هنالك بعض العناصر تمثل تهديدًا أقل على إدارة عمليات

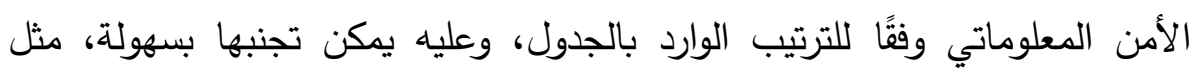

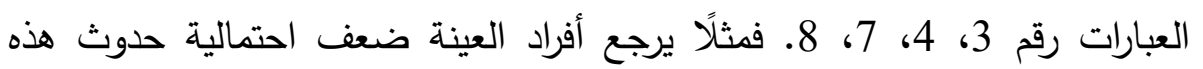

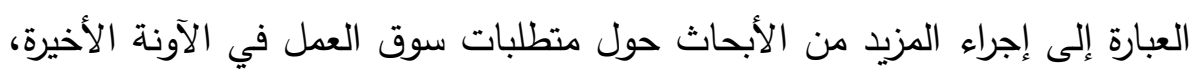

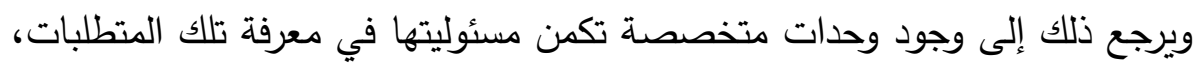
وإمداد سوق العمل بما يحتاجه من خريجين ذوي كفاءة ومتخصصين ومؤهلين للوفاء بتلك المتطلبات، كما أن خطط التدريب الموجهة للإداريين والعاملين في المدارس هن الثانوية الصناعية تعد بناءً على احتياجاتهم التدريبية سواء على مستوى المدرسة، أو لوريل

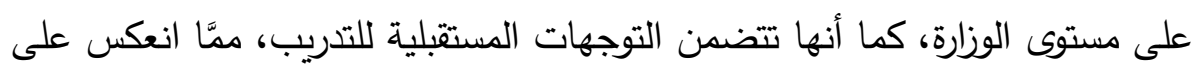


تدريب المسئولين في مجال التكنولوجيا على الحفاظ على الأمن المعلوماتي للمدرسة، الأمر الذي يوضح فرص التغيير والتطوير التي طرأت على برامج التدريب في الفترة

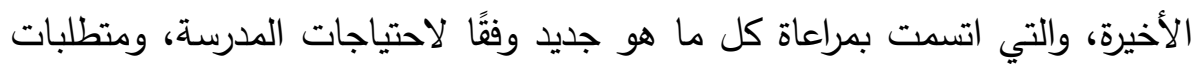

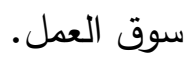

وعلى جانب آخر، يمثل التطور السريع في مجال البرمجيات ــ الخاصة بسهولة سرقة المعلومات والحصول عليها؛ حيث أصبحت هنالك برامج تكنولوجية حديثة من شأنها الحصول على المعلومات المشفرة والسرية، حتى وإن كانت

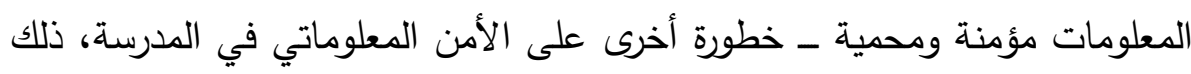
بالإضافة إلى قلة وعي العاملين بأهمية الحفاظ على سرية المعلومة؛ ممّا ولد سبيًا هامًا لنشر تلك المعلومات على الرغم من ضرورة إبقائها سرية، الأمر الذي يتطلب

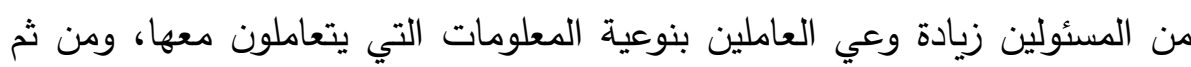
فعليهم تصنيفها، ومعرفة أكثرها حساسية، ومنع الأكثر حساسية من الانتشار ، ويتم

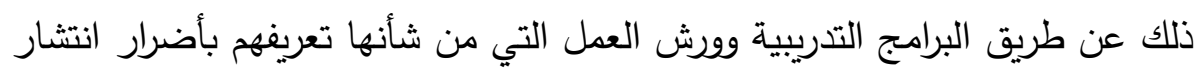

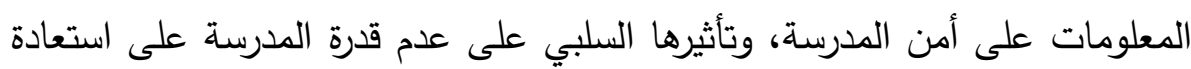

$$
\text { نشاطها بسهولة وقت الأزمات والكوارث. }
$$

يضاف إلى ما سبق، ارتفاع تكلفة البرامج التكنولوجية الحديثة المخصصة

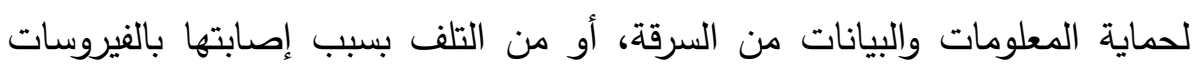
التي قد تودي بحياة جهاز الكمبيوتر ، وما يحتفظ به من بيانات ومعلومات. 3. تحليل التوازن بين الفرص والتهديدات:

يتضح من جدولي تحليل البيئة الخارجية للمدرسة الثانوية الصناعية (الفرص

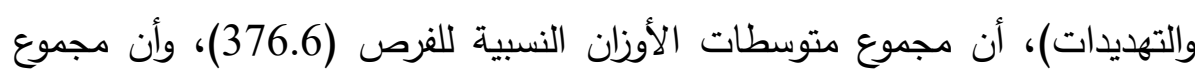

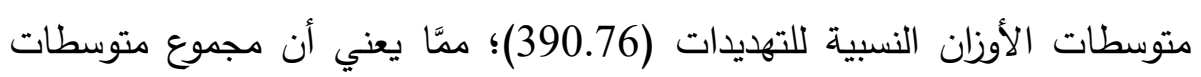

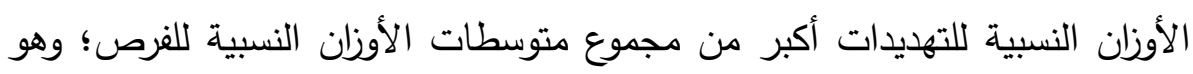

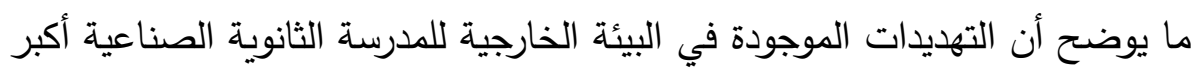
من الفرص المتاحة لها، وهذا يقلل من قدرتها على الاستفادة من الفرص، ويهدد

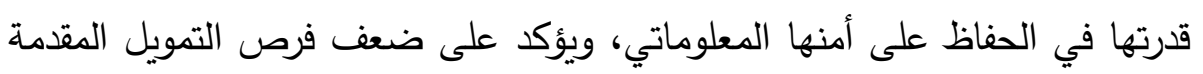
للمدارس لاستكمال تجهيزها بالبنية التحتية اللازمة للحفاظ على الأمن المعلوماتي 
بها، وكذلك ضعف اهتمام القطاع الخاص بتقديم برامج تدربيية للدارسين والعاملين في المدارس الثانوية الصناعية للحفاظ على الأمن المعلوماتي، ذلك أن الغالبية العظمى من الاهتمام ينصب على تقديم القطاع الخاص لخريجي التعليم الثانوي أو الدارسين فيه بعض البرامج التي تتعلق بتوظيفهم داخل الشركة والمصنع فحسب، دون أن يعود ذلك بالنفع على إدارة المدرسة.

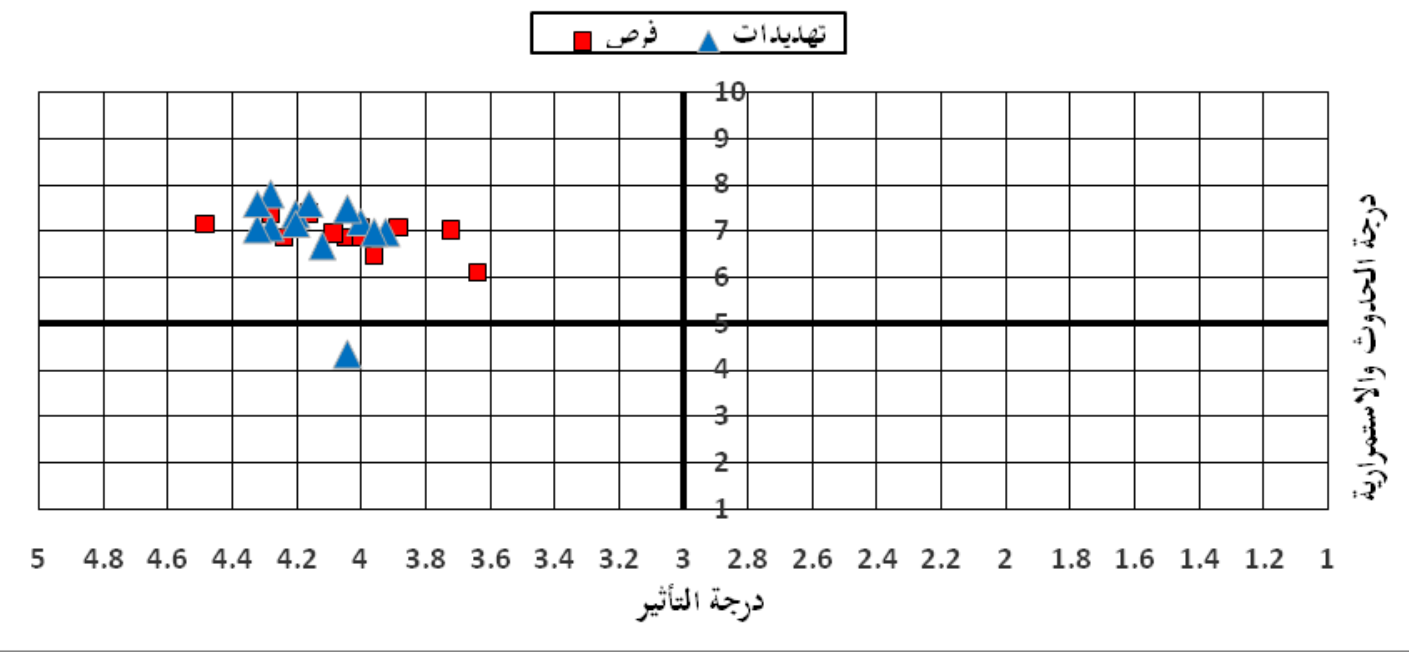

شكل رقم (7) موقع الفرص والتهديدات وفق الوزن النسبي يتضح من الثكل السابق أن جميع الفرص والتهديدات تقع في المربع الرابع، الذي يوضح أن درجة تأثيرها عالية، واحتمال استمراريتها كبير، فيما عدا العبارة رقم (6) في التهديدات، التي نصت على (عزوف القطاع الخاص عن تقديم فرص كافية للدارسين في المدارس الفنية للتدريب العملي في: المصانع، والثركات، والقطاعات الاقتصادية المختلفة)؛ حيث جاءت في الربع الثالث، وهي تعني أن درجة تأثيرها عالية، ولكن احتمالية استمراريتها ضعيفة. كما يمكن تمثيل مستوى التوازن بين الفرص والتهديدات التي تئثر على إدارة عمليات الأمن المعلوماتي في المدرسة الثانوية الصناعية في مصر، كما في الثكل التالي، بحيث يمثل الاتجاه الأعلى الفرص، والاتجاه الأسفل التهديدات: 


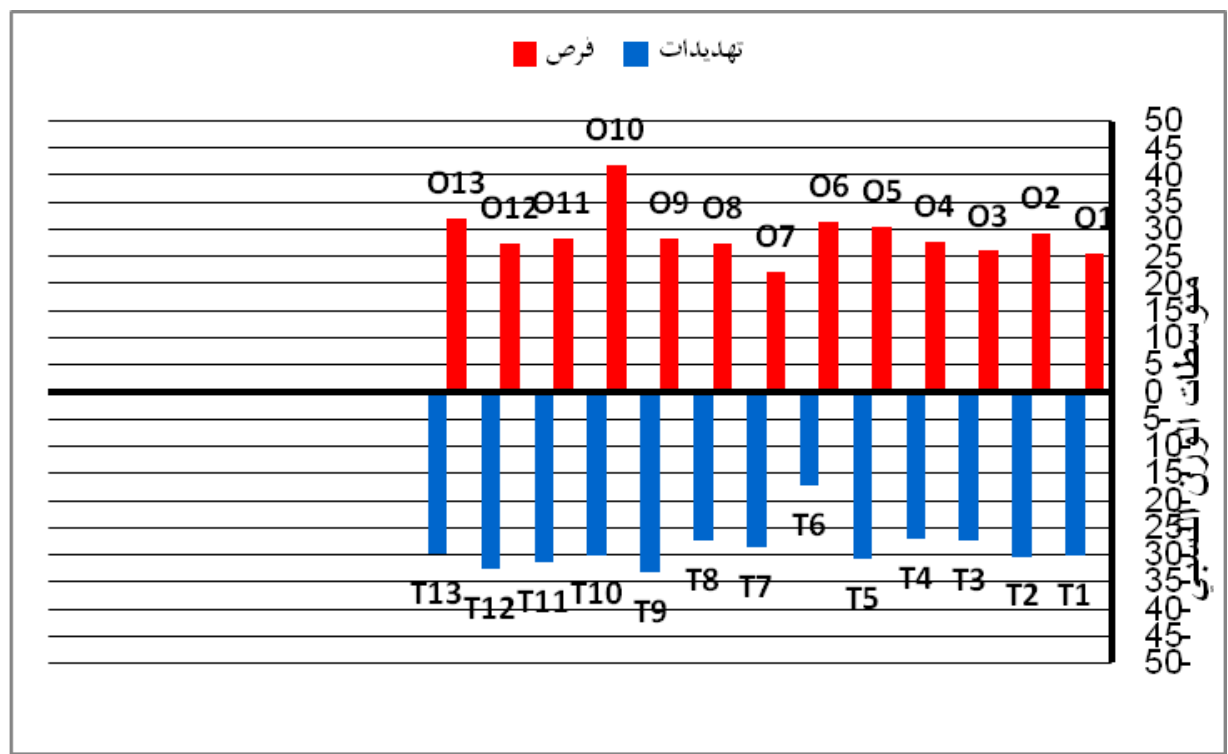

شكل رقم (8) مستوى التوازن بين الفرص والتهايدات

بالنظر إلى الثكل السابق، يتضح أن هناك تقاربًا بين الأوزان النسبية للفرص

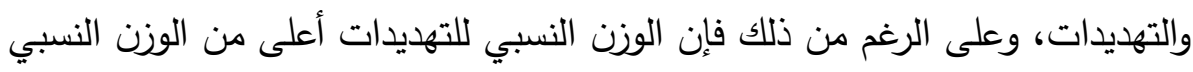

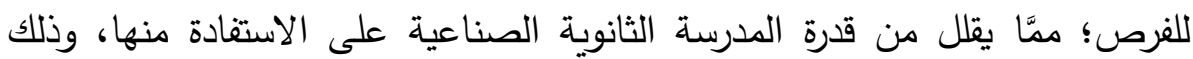
أيضًا في ضوء أن درجة كل من حدوث التهديدات، واستمرارية حدوثها عالية، وفي

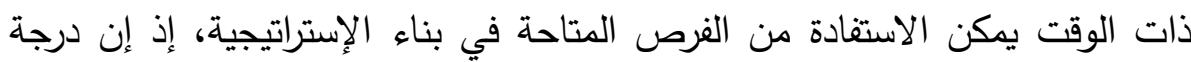
تأثيرها واستمرارية حدوثها عالية. ثالثًا ـ بناء مصفوفة التحليل الإستراتيجي SWOT Matrix يتضمن بناء مصفوفة التحليل الإستراتيجي الاعتماد على عناصر البيئة الداخلية: (القوة والضعف)، والبيئة الخارجية: (الغرص والتهديدات) الأكثر تأثيرًا على الإهن

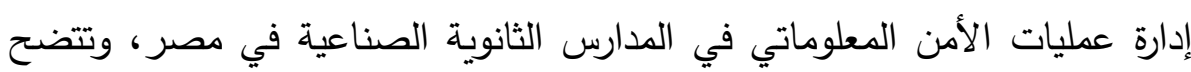
أبعاد هذه المصفوفة من خلال الجدول التالي:(98) جدول رقم (7) مصفوفة التحليل الرباعي.

\begin{tabular}{|c|c|c|}
\hline مرغوبة & غير مرغوبة & \\
\hline الفرص & التهديدات & لا يمكن السيطرة عليها \\
\hline عناصر القوة & عناصر الضعف & يمكن السيطرة عليها \\
\hline
\end{tabular}


يوضتح الجدول التالي التحليل الرباعي لعناصر البيئة الداخلية والخارجية، التي

تم التوصل إليها، وقد تم استبعاد الجوانب الأقل أهمية؛ لتجنب التشتيت عند وضع الإستراتيجيات البديلة كما يتضح فيما يلي:

جدول رقم (8) التحليل الرباعي لعناصر البيئة الاخلية والخارجية

\begin{tabular}{|c|c|c|}
\hline 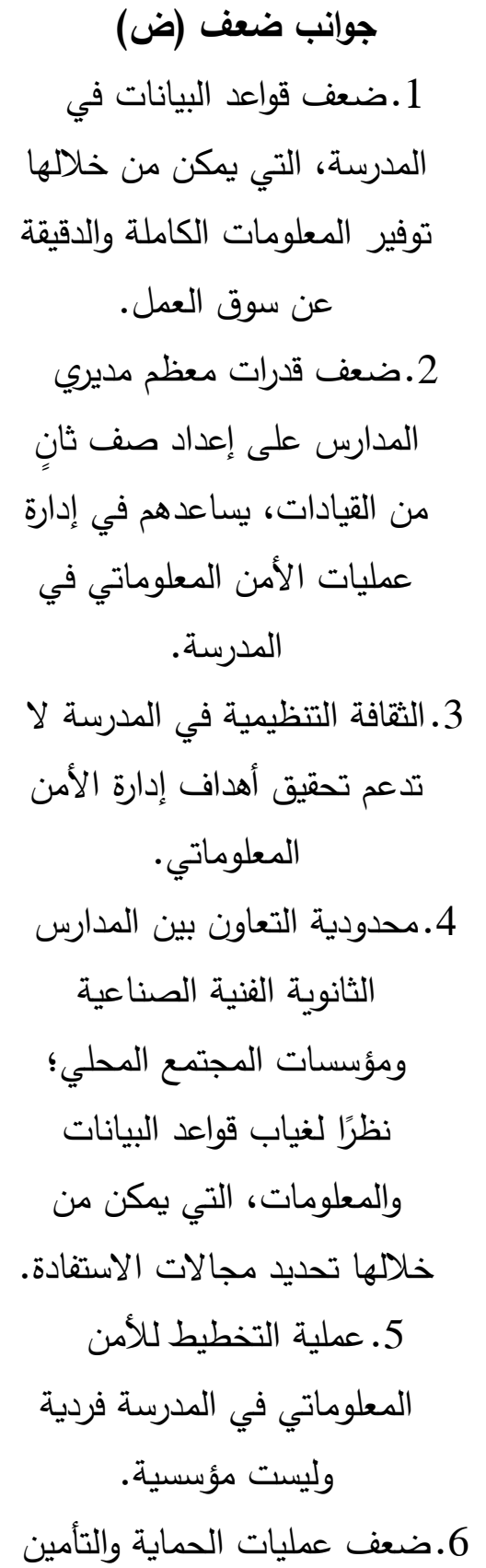 & 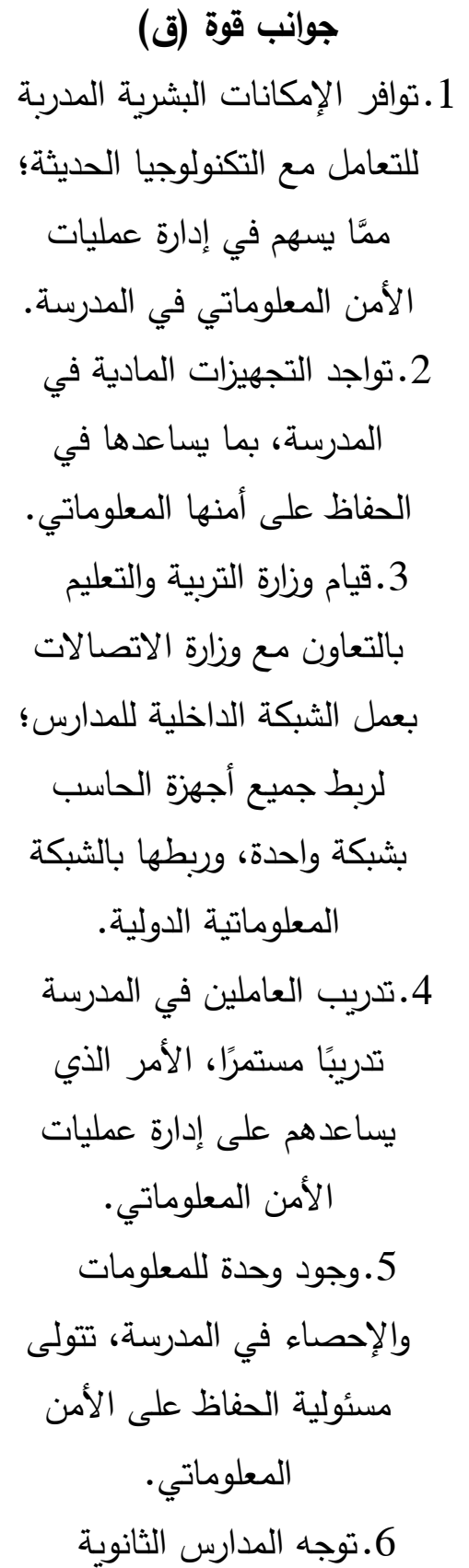 & البيئة الداخلية \\
\hline
\end{tabular}


ستر ليجية مقترحة لإدارة عمليات الأمن المعلوماتي

483

د/ولاء السيد عبدالله

في المدرسة للبيانات والمعلومات

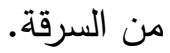

7.تدني حالة البنية التحتية

والأساسية للاتصالات وتكنولوجيا

المعلومات في المدرسة.

8.توجه المدارس والوزارة نحو حل

المشكلات الخاصة باختراق

المعلومات بعد حدوثها وليس

التخطيط لتفادي حصول المشكلة

من الأساس.

9.قلة توافر البرامج التكنولوجية

المتنوعة اللازمة لإدارة الأمن

المعلوماتي في المدرسة.

10. ندرة وجود عقود صيانة بين

المدرسة والثركات المسئولة؛

ممَّا ينتج عنه تعذر صيانة

$$
\text { الأجهزة. }
$$

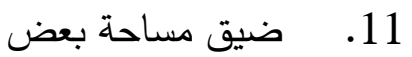

الأقسام والمعامل، وقلة الخامات

والأدوات، الأمر الذي يؤثر

على قدرة العاملين على إدارة

عمليات الأمن المعلوماتي.

12. ضعف القدرة على

الاستخدام الأمثل للأجهزة

التكنولوجية المستخدمة في

الحفاظ على المعلومات.

13. قلة المعلومات اللازمة
الصناعية للأخذ بنظام

المعلومات الإدارية.

7.وجود بطاقات توصيف وظيفي

للمسئولين في وحدة المعلومات

والإحصاء، تحدد ما يجب

البيئة الخارجية

الأمن المعلوماتي.

8.حاجة وحدة ريادة الأعمال في

المدرسة إلى إدارة للأمن

المعلوماتي بها.

9.حاجة وحدة الإرشاد والتوجيه

المهني في المدرسة إلى إدارة

لكأمن المعلوماتي بها.

العدد الثاني عشر - مارس 2017

مجلة الإدارة التربوية 


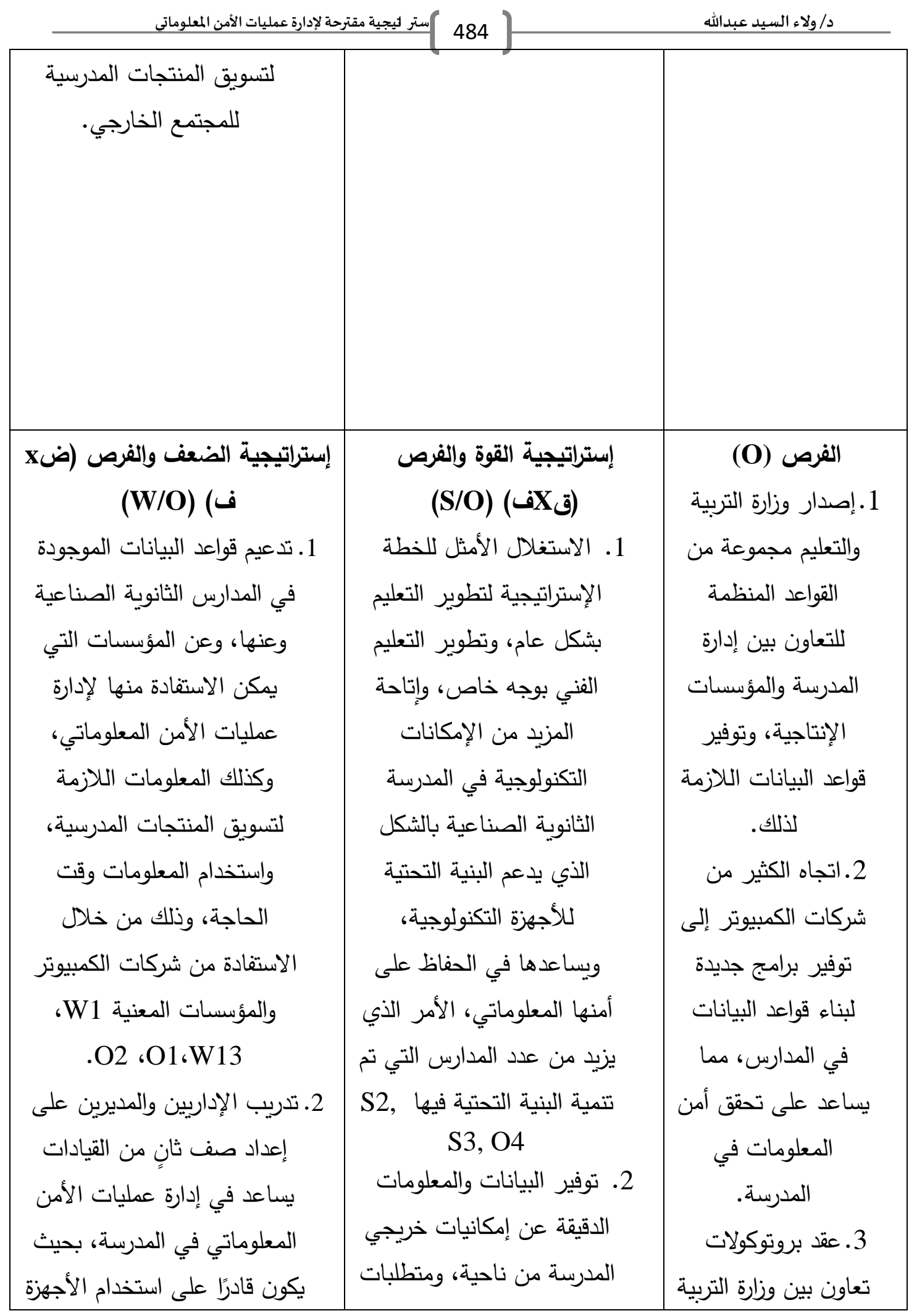




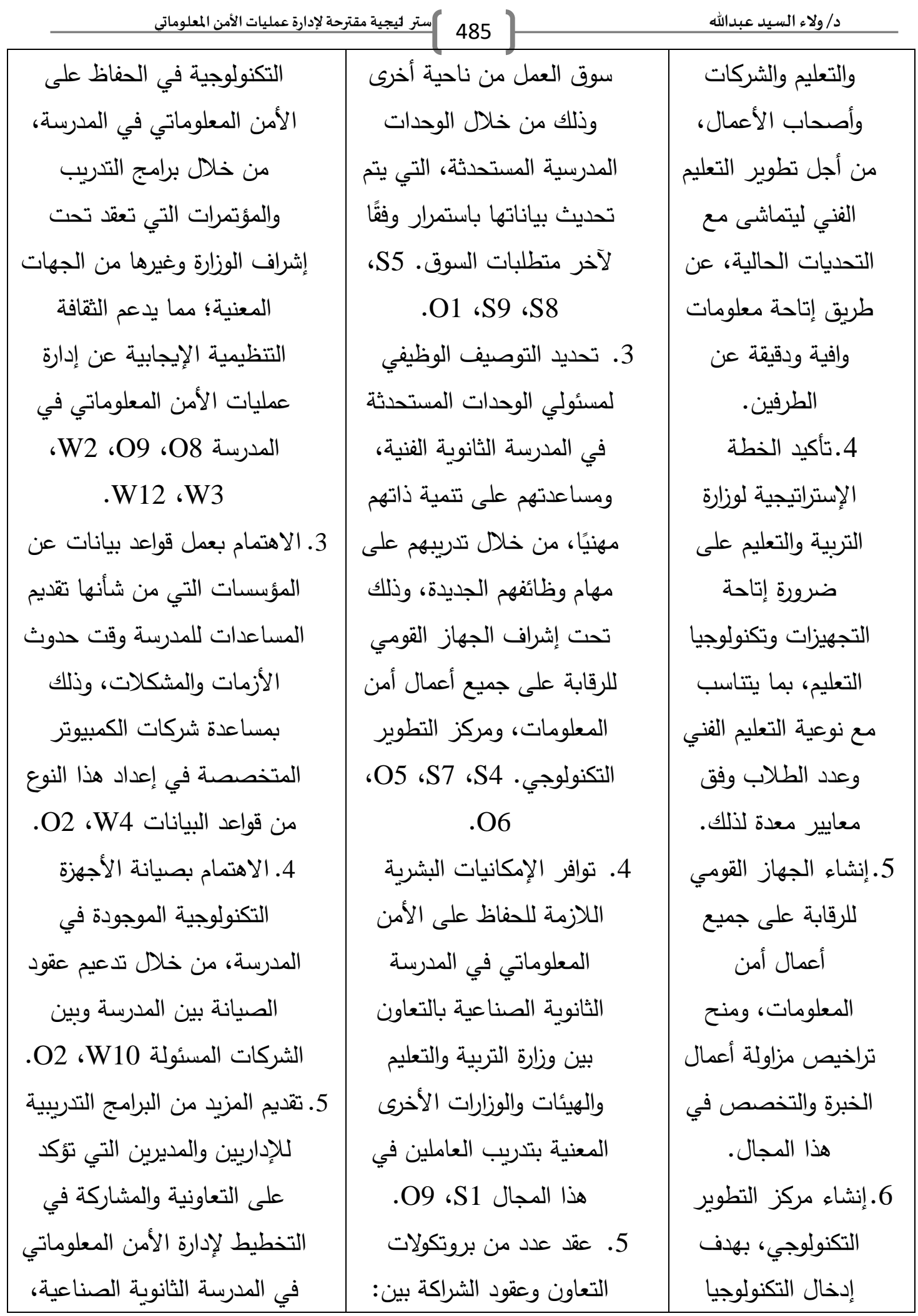




\begin{tabular}{|c|c|c|}
\hline إدارة عمليات الأمن المعلوماتي & ) 486 (ستر ليجية ه & د/ولاء السيد عبدالله \\
\hline 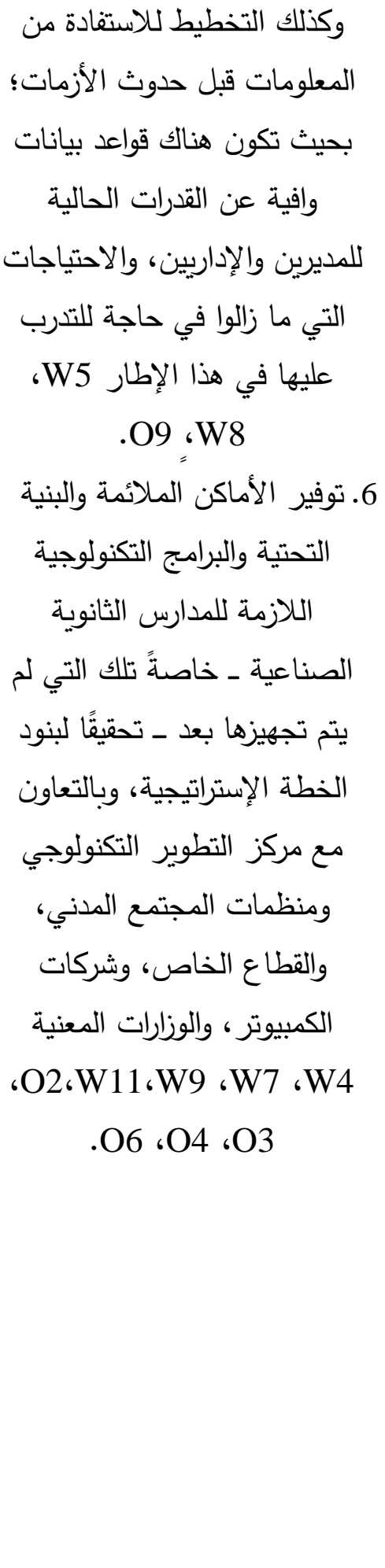 & 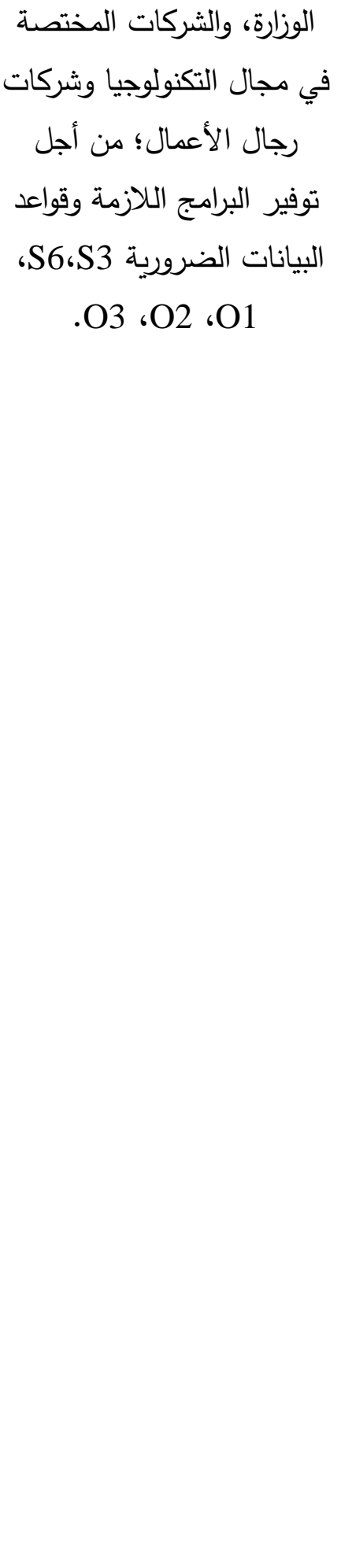 & 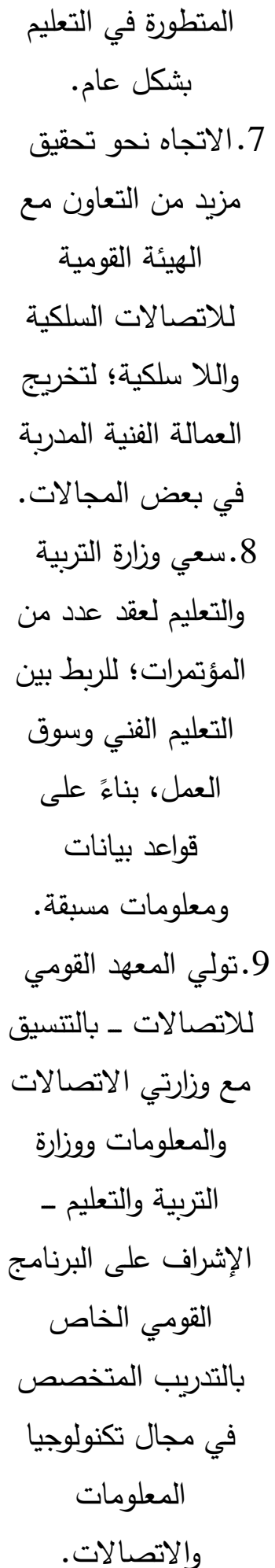 \\
\hline
\end{tabular}




\begin{tabular}{|c|c|c|}
\hline كستر ليجية مقترحة لإدارة عمليات الأمن المعلوماتي & ستر ليجية مق & د/ولاء السيد عبدالله \\
\hline $\begin{array}{c}\text { إستراتيجية الضعف والتهديدات } \\
\text { (W/T) }\end{array}$ & $\begin{array}{c}\text { إستراتيجة القوة والتهديدات } \\
\text { (S/T) }\end{array}$ & 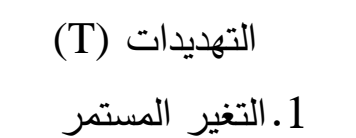 \\
\hline 1. تعزيز قدرة المديرين في المدارس & 1. الاهتمام بتوفير التجهيزات & والسريع في البرامج \\
\hline الثانوية الصناعية على إعداد & المادية والبرمجية للمدرسة & التي تستخدم في \\
\hline صف ثانٍ من القيادات للتخطيط & الثانوية الصناعية، بحيث يتم & اختراق البيانات \\
\hline لإدارة الأمن المعلوماتي في & توفير أجهزة أكثر أمنًا، وبرامج & والمعلومات. \\
\hline جماعي، على & جديدة؛ لمواكبة التغير السريـع & 2.ضعف الوعي الكافي \\
\hline مستوى المدرسة، والإدارة، & في البرامج المستخدمة & بكيفية التعامل مع \\
\hline والمديرية، والوزارة، وتدعيم الثقافة & لاختراق المعلومات، وذلك & المعلومات وحساسيتها \\
\hline لتي تعزز لدى & بتكلفة تتلاءم والإمكانات & عند استخدام الشبكات \\
\hline العاملين أهمية المعلومات، & المادية للمدرسة، من خلال & الاجتماعية المنتشرة \\
\hline وتعزيز وعيهم أيضًا بكيفية & عقود شراكة، ومن ثم التغلب & (مثل: فيس بوك، \\
\hline ، وتصنيفها وفقًا & عليها ومواجهتها، وبناء قواعد & وتويتر ونحوهما). \\
\hline لدرجة حساسيتها لضمان عدم & بيانات في المدارس عن: & 3.زيـادة تكلفة برامج \\
\hline تسربها W2، W3 ، W2 ،2 ، & قدرات المدرسة، واحتياجات & الحماية، وبرامج بناء \\
\hline. $\mathrm{T} 8$ & السوق، وغيرها دن البيانات & قواعد البيانات. \\
\hline 2. تدعيم البنية التحتية والبرمجية & والمعلومات؛ مما يساعد على & 4.قلة الميزانيات \\
\hline للمدرسة الثانوية الصناعية & تحقيق أمن المعلومات في & المخصصة لتجهيز \\
\hline لمواكبة التغير المستمر والسريح & المدرسة، وخاصةً في ظل & مراكز التدريب التابعة \\
\hline في البرامج التي تستخدم في & توجه المدرسة الثانوية & لوزارة التربية والتعليم \\
\hline اختراق البيانات والمعلومات، & الصناعية للأخذ بنظام & اللازمة لتحقيق \\
\hline ومن ثم تدعيم الحماية الأمنية & المعلومات الإدارية، والاهتمام & متطلبات سوق العمل \\
\hline للبيانات والمعلومات الخاصة في & بربط المدرسة بشبكة & من التكنولوجيا \\
\hline المدرسة، وذلك بالتعاون مع & المعلومات الدولية التي تمكنها & المتطورة. \\
\hline القطاع الخاص، ومنظمات & من تحديث برامجها والاتصال & 5. غياب المؤشرات \\
\hline المجتمع المدني، وشركات & بغيرها من المدارس للاستفادة & والمعلومات عن \\
\hline الكمبيوتر التي من شأنها تقديم & من خبراتها S2، S36، S6، & التطور المتسارع \\
\hline
\end{tabular}




\begin{tabular}{|c|c|c|}
\hline 488 كستر ليجية مقترحة لإدارة عمليات الأمن المعلوماتي & 4 488 ستر ليجية مقا & د دولاء السيد عبدالله \\
\hline البرامج اللازمة للمدرسة بأ & .T6 ،T3 ،T1 & ل لمتطلبات سوق \\
\hline مخفضة W4 ،W7 ، 'W6 & 2. الاهتمام بتدريب العاملين في & العمل، بما يفوق \\
\hline .T9 ،T3 ،T1 ،W9 & مجال تكنولوجيا المعلومات & تطور إمكانات \\
\hline 3.تصميم المزيد من قواعد البيانات & على الوعي بأهمية الحفاظ & ومخرجات التعليم \\
\hline التي تضم معلومات عن سوق & على المعلومات، وتصنيغها & الفني. \\
\hline العمل، والإمكانيات المادية & ومعرفة درجة حساسيتها، ومن & 6.ندرة وجود قواعد \\
\hline والبشرية للمدرسة، والهيئات التي & ثم عدم الإفصاح عن أي & البيانات الصحيحة \\
\hline يمكن للمدرسة الاستعانة بها وقت & معلومة قبل التأكد من درجة & والموثقة والمؤمنة التي \\
\hline الأزمات، على أن تكون مؤمنة، & حساسيتها أولاً، الأمر الذي لا & تحدد احتياجات سوق \\
\hline ويتم تحديثها باستمرار للاستفادة & يضر في المدرسة، بالإضافة & العمل من المهن \\
\hline منها وقت الحاجة إليها W1، & إلى توفير برامج تدربيية عن & والتخصصات \\
\hline .T6 ، T5 ،W6 & كيفية استخدام التكنولوجيا & المختلفة. \\
\hline 4. اهتمام الوزارة بعمل برامج توعية & الحديثة في الحفاظ على & 7.تدني المنظومة القيمية \\
\hline مستمرة للمعلمين والإداريين & المعلومات، مع الوضع في & في المجتمع؛ مما \\
\hline والمديرين والطلاب أيضًا؛ بحيث & الاعتبار ضرورة أن تكون & يمثل تهديدًا لأمن \\
\hline تهدف إلى تدعيم الجانب & تحت إشراف الوزارة، وفي & المعلومات بشكل \\
\hline الأخلاقي والقيمي لديهم، وتتمية & قاعات تدريبية مجهزة & 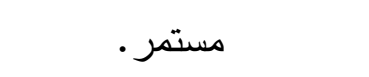 \\
\hline شعور الولاء والانتماء لمدرستهم، & بالتكنولوجيا الحديثة التي سيتم & 8.ضعف التخطيط لبناء \\
\hline الأمر الذي يمنعهم من تسريب & استخدامها بالفعل، وكذلك & برنامج متكامل لأمن \\
\hline المعلومات أو سرقتها، أو & استخدام قاعات وحدات & المعلومات بدءًا من \\
\hline إتلافها؛ مما يسهم في مساعدة & المعلومات والإحصاء، وغيرها & الوزارة وحتى المدرسة. \\
\hline المديرين والمسئولين على & من الوحدات المجهزة بالأجهزة & 9. عزوف القطاع \\
\hline التخطيط لإدارة الأمن المعلوماتي & التكنولوجية. وعليه، ثمة & الخاص عن تقديم \\
\hline قبل اختراق المعلومات، وقبل & ضرورة لإشراك القطاع & فرص كافية للدارسين \\
\hline حدوث الأزمات المترتبة عليها & الخاص في تمويل تلك & في المدارس الفنية \\
\hline .T8 ،W9 & البرامج، وتقديمها داخل & للتدربب العملي في \\
\hline 5. الاهتمام بتقديم المزيد من برامج & مؤسساته S1، S4، S5، & المصانع والثركات \\
\hline
\end{tabular}




\begin{tabular}{|c|c|c|}
\hline إجدارة عمليات الأمن المعلوماتى & 489 كتر ليجية مة & د/ ولاء السيد عبداله \\
\hline 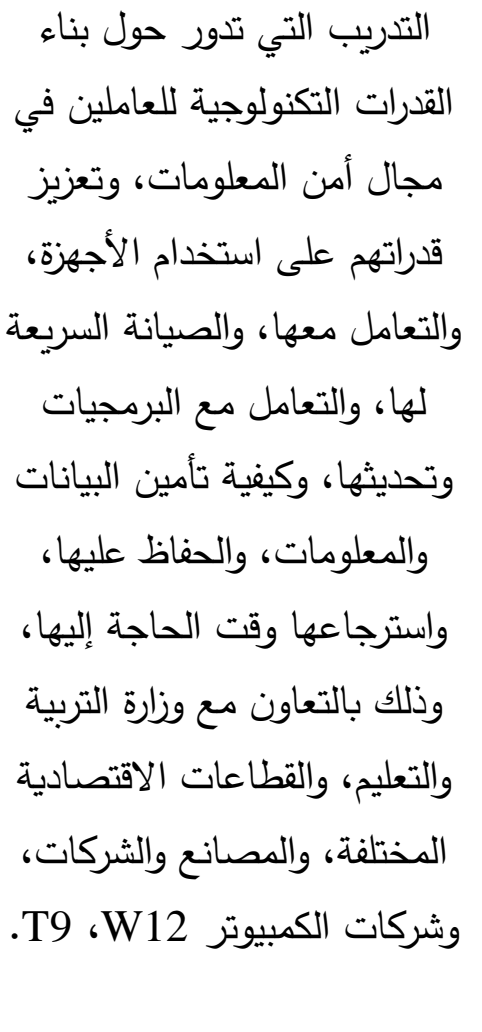 & 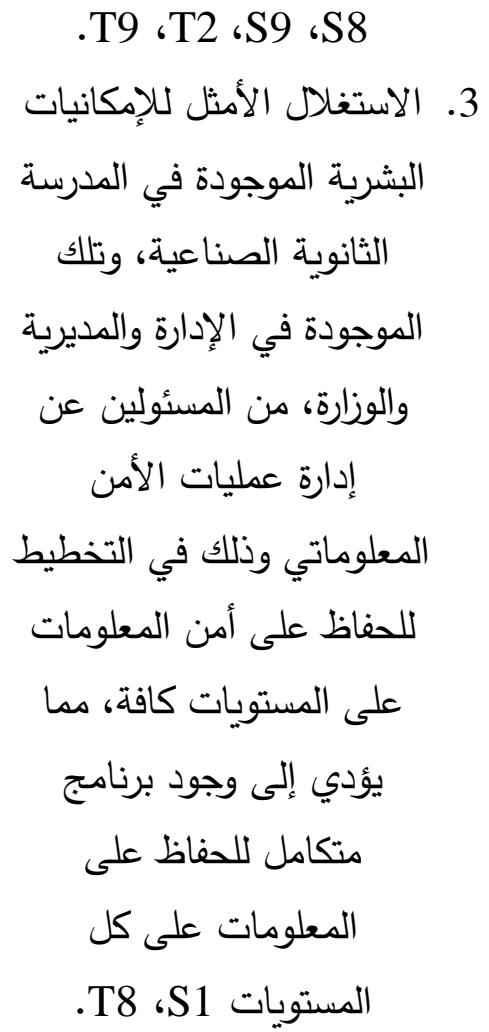 & والقطاعات الاقتصادية \\
\hline
\end{tabular}

ويتضح من الجدول السابق، أنه بالاستفادة من: نقاط القوة، والفرص،

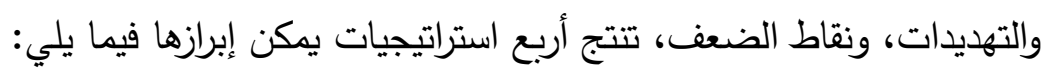
أ. إستراتيجية القوة/ الفرص (S/O) التوجه الريادي:

وفيها يتم استخدام مجالات القوة؛ لاقتتاص الفرص المتاحة، وتتضمن ما يلي:

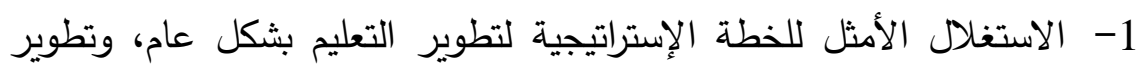

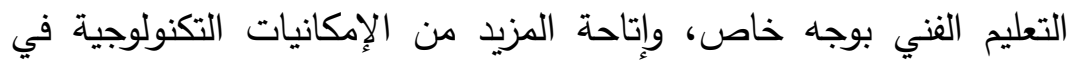
المدرسة الثانوية الصناعية بالثكل الذي يدعم البنية التحتية للأجهزة

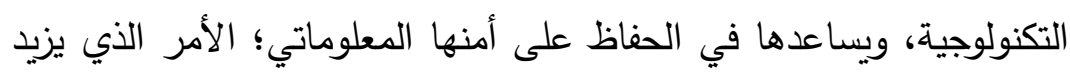
من عدد المدارس التي تم تتمية البنية التحتية فيها S2, S3, O4.

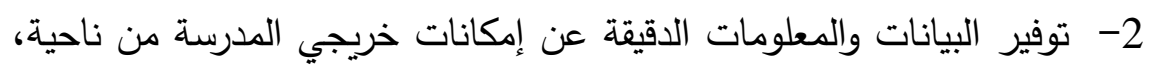
ومتطلبات سوق العمل من ناحية أخرى، وذلك من خلال الوحدات المدرسية المستحدثة، التي يتم تحديث بياناتها باستمرار وفقًا لآخر متطلبات السون السوق. .O1 ‘S9 ، S8 ،55 
3- تحديد التوصيف الوظيفي لمسئولي الوحدات المستحدثة في المدرسة الثانوية

الفنية، ومساعدتهم في تتمية ذاتهم مهنيًا من خلال تدريبهم على مهام وظائفهم الجديدة، وذلك تحت إشراف الجهاز القومي للرقابة على جميع

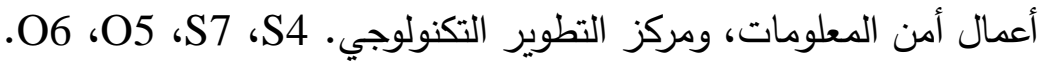
4- توافر الإمكانيات البشرية اللازمة للحفاظ على الأمن المعلوماتي في المدرسة الثانوية الصناعية بالتعاون بين: وزارة التربية والتعليم، والهيئات والوزارات الأخرى المعنية بتدريب العاملين في هذا المجال S1، O9. 5- عقد عدد من بروتكولات التعاون وعقود الشراكة بين الوزارة والشركات

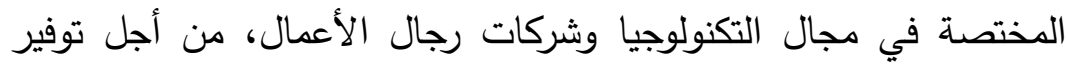

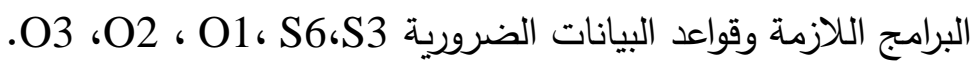
ب. إستراتيجية القوة / التهايدات (S/T) التوجه التكيفي: وفيها يتم تتمية مجموعة من الإستراتيجيات البديلة، التي تستخدم مجالات القوة للحد من التهديدات، وتتضمن ما يلي: 1. الاهتمام بتوفير التجهيزات المادية والبرمجية للمدرسة الثانوية الصناعية،

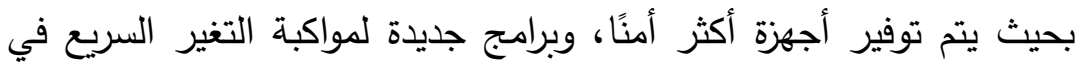
البرامج المستخدمة لاختراق المعلومات، وذلك بتكلفة تتلاءم والإمكانات المادية للمدرسة من خلال عقود شراكة، ومن ثم التغلب عليها ومواجهتها، وبناء قواعد البيانات في المدارس عن قدرات المدرسة واحتياجات السوق،

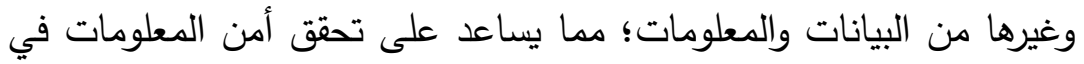

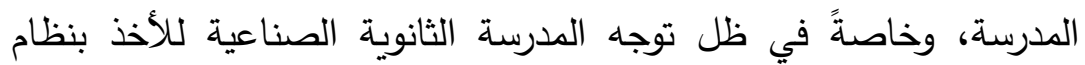

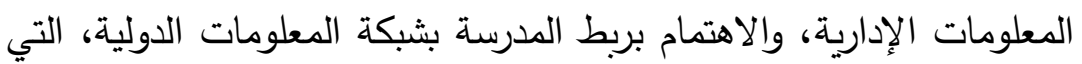
تمكنها من تحديث برامجها، والاتصال بغيرها من المدارس للاستفادة من

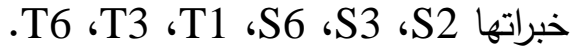

2. الاهتمام بتدريب العاملين في مجال تكنولوجيا المعلومات على الوعي بأهمية

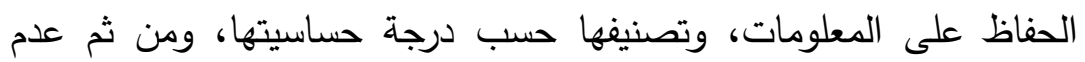

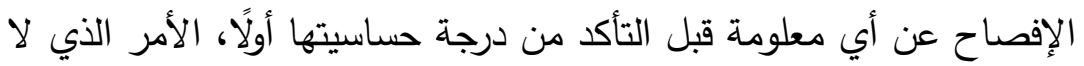
يضر في المدرسة، بالإضافة إلى توفير برامج تدريبية عن كيفية استخدام 
التكنولوجيا الحديثة في الحفاظ على المعلومات، مع الوضع في الاعتبار ضرورة أن تكون تحت إشراف الوزارة، وفي قاعات تدرببية مجهزة بالتكنولوجيا الحديثة التي سيتم استخدامها بالفعل، وكذلك استخدام قاعات وحدات المعلومات والإحصاء، وغيرها من الوحدات المجهزة بالأجهزة التكنولوجية. وعليه، فان ثمة ضرورة لإشراك القطاع الخاص في تمويل تلك البرامج،

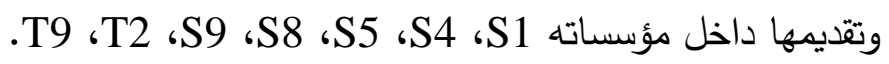
3. الاستثمار الأمثل للإمكانيات البشرية الموجودة في المدرسة الثانوية الصناعية، والموجودة في: الإدارة، والمديرية، والوزارة، من المسئولين عن إدارة عمليات الأمن المعلوماتي، وذلك في التخطيط للحفاظ على أمن المعلومات على المستويات كافة؛ مما يؤدي إلى وجود برنامج متكامل للحفاظ على المعلومات على كل المستويات S1، T8. ج. إستراتيجية الضعف والفرص (W/O) التوجه الافاعي ـ الإصلاحي: ويتم فيها تتمية مجموعة من الإستراتيجيات البديلة، من خلال التغلب على نقاط الضعف لاقتناص الفرص، وتتضمن ما يلي: 1. تدعيم قواعد البيانات الموجودة في المدارس الثانوية الصناعية وعنها، وعن المؤسسات التي من الممكن الاستفادة منها لإدارة عمليات الأمن المعلوماتي، وكذا المعلومات اللازمة لتسويق المنتجات المدرسية، واستخدام المعلومات وقت الحاجة، وذلك من خلال الاستفادة من شركات الكمبيوتر والمؤسسات المعنية W1،W13 ، 01 ،

2. تدريب الإدارين والمديرين على إعداد صف ثانٍ من القيادات يساعد في إدارة عمليات الأمن المعلوماتي في المدرسة، ويكون قادرًا على استخدام الأجهزة التكنولوجية في الحفاظ على الأمن المعلوماتي في المدرسة، من خلال برامج التدريب والمؤتمرات التي تعقد تحت إشراف الوزارة وغيرها من الجهات المعنية؛ مما يدعم الثقافة التظيمية الإيجابية عن إدارة عمليات الأمن المعلوماتي في المدرسة O8، O9 W2 W3 ، W12. 
3. الاهتمام بعمل قواعد بيانات عن المؤسسات التي من شأنها تقديم المساعدات

للمدرسة وقت حدوث الأزمات والمشكلات، وذلك بمساعدة شركات الكمبيوتر

المتخصصة في إعداد هذا النوع من قواعد البيانات W4. O2.

4. الاهتمام بصيانة الأجهزة التكنولوجية الموجودة في المدرسة، من خلال تدعيم

عقود الصيانة بين المدرسة والشركات المسئولة W10، O2.

5. تقديم المزيد من البرامج التدريبية للإدارينين والمديرين، التي تؤكد على

التعاونية والمشاركة في التخطيط لإدارة الأمن المعلوماتي في المدرسة

الثانوية الصناعية، وكذلك التخطيط للاستفادة من المعلومات قبل حدوث

الأزمات، بحيث تكون هنالك قواعد بيانات وافية عن القدرات الحالية للمديرين

والإداريين، والاحتياجات التي ما زالوا في حاجة للتدرب عليها في هذا

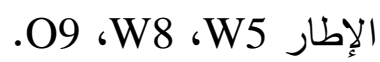

6. توفير الأماكن الملائمة والبنية التحتية والبرامج التكنولوجية اللازمة للمدارس

الثانوية الصناعية ـ خاصة تلك التي لم يتم تجهيزها بعد - تحقيقًا لبنود

الخطة الإستراتيجية، وبالتعاون مع مركز التطوير التكنولوجي ومنظمات

المجتمع المدني، والقطاع الخاص، وشركات الكمبيوتر، والوزارات المعنية

.O6 ، 04 ،O3 602 ،W11 ،W9 ،W7 ،W4

د. إستراتيجية الضعف والتهديدات (W/T) توجه المحافظة على البقاء:

يتم فيها تنمية مجموعة من الإستراتيجيات البديلة من خلال التغلب على نقاط الضعف للحد من التهديدات، وتتضمن ما يلي:

1. تعزيز قدرة المديرين في المدارس الثانوية الصناعية على إعداد صفٍ ثانٍ من

القيادات للتخطيط لإدارة الأمن المعلوماتي في المدرسة بشكل جماعي، على

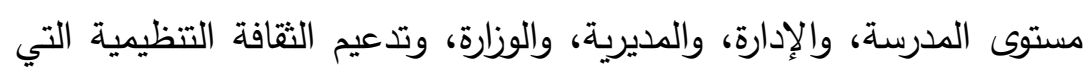

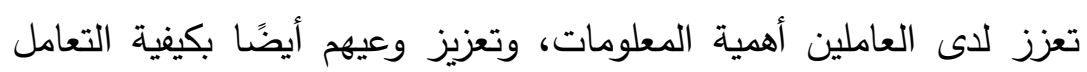
معها وتصنيفها وفقًا لدرجة حساسيتها لضمان عدم تسربها W3 ، . $\mathrm{T} 8$ ، $\mathrm{T} 2$ ،W5

2. تدعيم البنية التحتية والبرمجية للمدرسة الثانوية الصناعية؛ لمواكبة التغير المستمر والسريع في البرامج التي تستخدم في اختراق البيانات والمعلومات، 
ومن ثم تدعيم الحماية الأمنية للبيانات والمعلومات الخاصة في المدرسة، وذلك بالتعاون مع القطاع الخاص، ومنظمات المجتمع المدني، وشركات

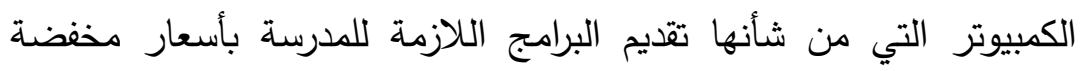

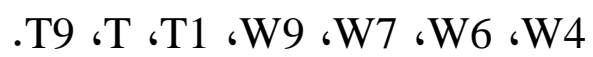

3. تصميم المزيد من قواعد البيانات التي تضم معلومات عن سوق العمل،

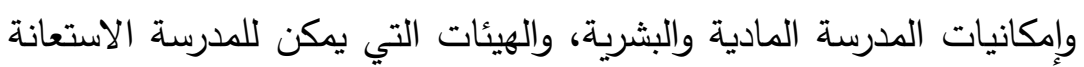

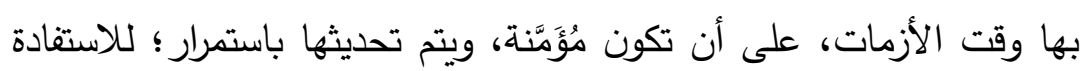

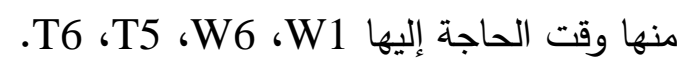

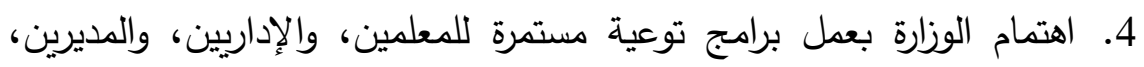

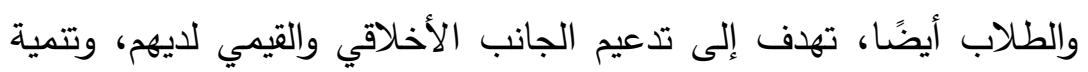

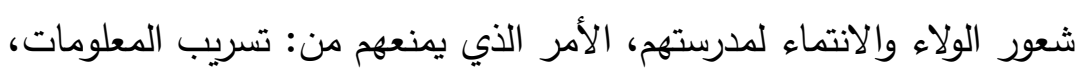

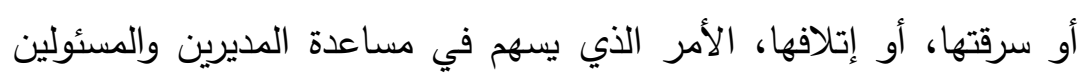

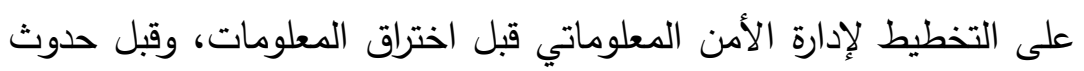

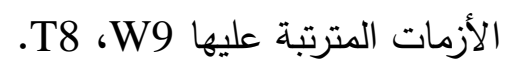
5. الاهتمام بتقديم المزيد من برامج التدريب التي تدور حول بناء القدرات التكنولوجية للعاملين في مجال أمن المعلومات، وتعزيز قدراتهج على استخدام

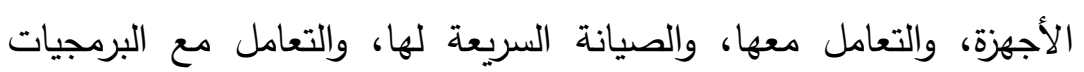

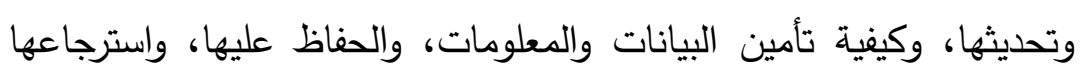

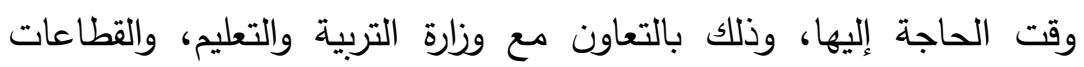

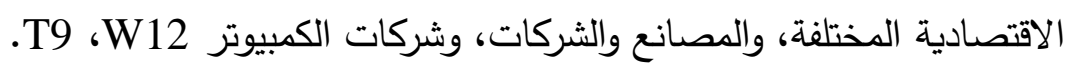

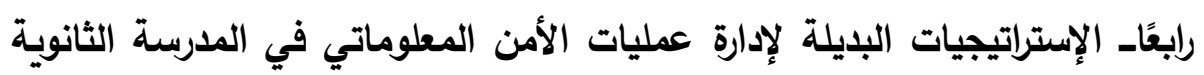
الصناعية في مصر (التداعيات والافتراضات): تتضمن الإستراتيجيات البديلة أربع إستراتيجيات تم التوصل إليها من نتائج

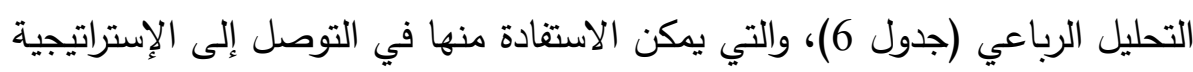

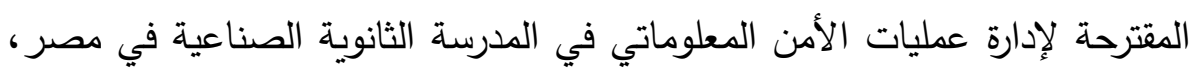
وفيما يلي عرض للافتراضات الأساسية التي يقوم عليها كل بديل، والتداعيات المحتملة عند تبنيه: 
البديل الأول - \}(التوجه الربادي: إستراتيجية تعظيم القوة، واستثمار الفرص

$\{(\mathbf{S} / \mathbf{O})$

يهدف هذا البديل إلى تتمية مجموعة من الإستراتيجيات لتحقيق الريادة والتميز

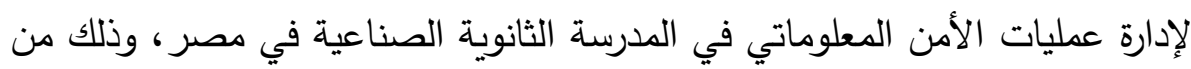
خلال الاستفادة من نقاط القوة، وتعظيمها في اقتتاص الفرص المتاحة، ويقوم هذات

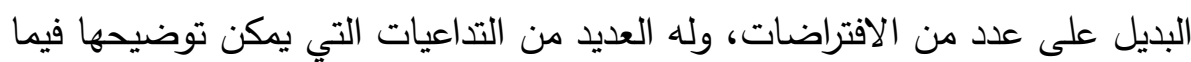

1 . الافتراضات التي يستتد إليها البديل الريادي:

توفير التمويل اللازم لتجهيز المدارس الثانوية الصناعية بالبنية التحتية

اللازمة للمدرسة الثانوية الصناعية؛ لحفظ معلوماتها إلكترونيًا.

الالتزام بتتفيذ بنود الخطة الإستراتيجية؛ لتطوير التعليم بشكل عام والتعليم

$$
\text { الفني على وجه الخصوص. }
$$

الاحتفاظ بالبيانات والمعلومات التي تمتلكها المدرسة الثانوية الصناعية داخل قواعد بيانات منظمة، تساعد المدرسة على استرجاع تلك البيانات

$$
\text { والمعلومات وقت الحاجة إليها. }
$$

الاستغلال الأمثل للوحدات الموجودة في المدرسة الثانوية الصناعية ـ كوحدة اليهات

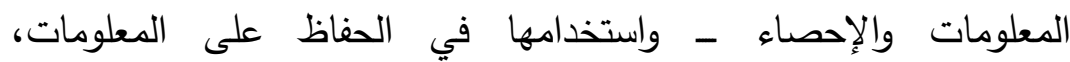

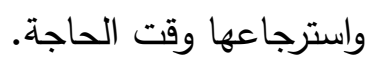

تحديث بطاقات الوصف الوظيفي للعاملين بشكل عام، والعاملين بالوحدات

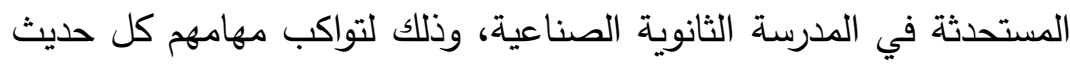
في مجال تكنولوجيا المعلومات، والتخزين الآمن للمعلومات. الاهتمام بالتتمية المهنية المستمرة للعاملين في مجال الحفاظ على المعلومات الددرسية، الأمر الذي يمكنهم من التعامل مع الأجهزة والبرمجيات المستحدثة التي تساعدهم على الحفاظ على تلك المعلومات من الضياع أو السرقة.

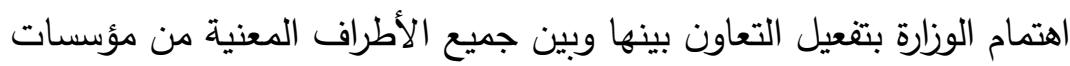

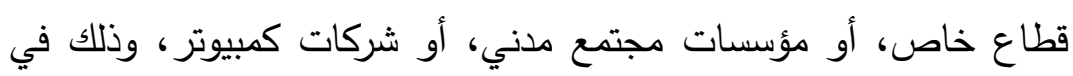


عمل برامج تدربيية للعاملين، أو في شراء البرمجيات، والأجهزة، أو في توفير أماكن للتدريب، والأجهزة اللازمة لإتمامه.

\section{2. التداعيات التي يستند إليها البديل الريادي:}

تتمثل التداعيات المتوقع حدوثها نتيجة تبني البديل الريادي لإدارة عمليات

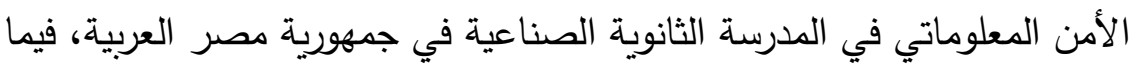

الاستعداد للأزمات والكوارث قبل حدوثها، ومن ثم قدرة المدرسة الثانوية الصناعية على تعافيها من الأزمات والكوارث بسرعة، واستمراريتها في تقديم خدماتها للعملاء.

توفير قواعد البيانات والمعلومات اللازمة للمدرسة الثانوية الصناعية، وبالتالي حفظها من التلف أو السرقة. رفع وعي العاملين في المدرسة بأهمية المعلومات والبيانات، وقدرتهم على تصنيف المعلومات وفقًا لحساسيتها. زيادة شعور العاملين بالانتماء للمدرسة، ومن ثم الحفاظ على المعلومات

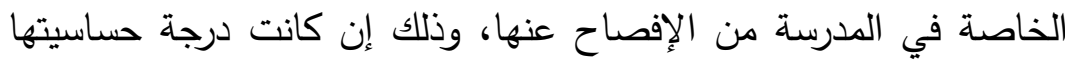
عالية، وذلك للحفاظ على المدرسة من الدخلاء، واستغلالهم السيئ للمعلومات التي تخص المدرسة في غير مصلحتها. إثراء قدرات العاملين في المدرسة الثانوية الصناعية، من خلال برامج التدريب المختلفة التي يلتحقون بها، ومن ثَمَ تمكنهم من استخدام الأجهزة التكنولوجية، واستخدام البرامج الحديثة التي تساعدهم على التخزين الآمن

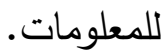
تفعيل دور الوحدات المدرسية المستحدثة، واستخدام ما بها من إمكانيات

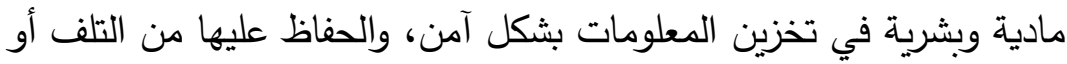

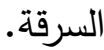

زيادة مشاركة العاملين في التخطيط لإدارة الأمن المعلوماتي، الأمر الذي يجعل التخطيط يتحول من عملية فردية إلى عملية جماعية، يشارك فيها 
جميع العاملين في المدرسة؛ مما يشعرهم بالمسئولية تجاه ما يقومون به من أعمال تصب في مصلحة المدرسة.

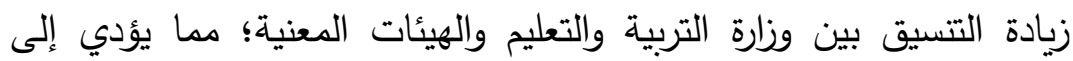

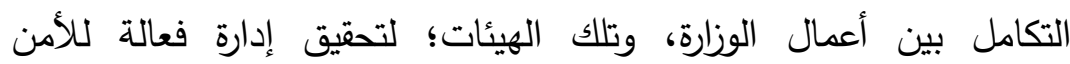
المعلوماتي في المدرسة الثانوية الصناعية. تحقيق المزيد من التزام العاملين بأداء المهام الموكلة إليهم بالوحدات الميهات المستحدثة، نتيجة لوجود توصيف دقيق وواضح لمهامهم في بطاقات

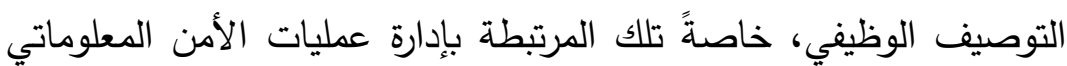
في المدرسة الثانوية الصناعية. البديل الثاني - التوجه التكيفي \}إستراتيجيات تعظيم القوة وتجنب التهايدات $:\{(\mathrm{S} / \mathrm{T})$

يهدف هذا البديل إلى تتمية مجموعة من الإستراتيجيات البديلة التي تستفيد من

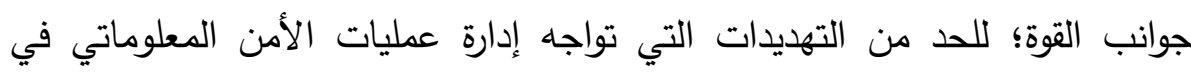
المدرسة الثانوية الصناعية في مصر ، وتتمثل افتراضات وتداعيات هذا البديل فيما

1. الافتراضات التي يستند إليها البديل التكيفي:

قلة مصادر التمويل المتاحة، التي تتعكس على صعوبة تجهيز المدارس لتهب الثانوية الصناعية بالبنية التحتية اللازمة؛ لحفظ المعلومات وتخزينها، وتوفير لهني البرمجيات اللازمة لإنشاء قواعد البيانات وتأمينها، وتوفير الأماكن الملائمة

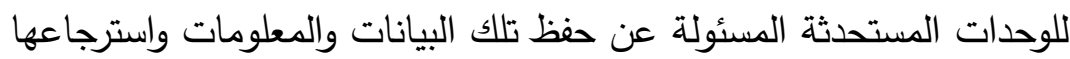
وقت الحاجة، وتوفير برامج التدريب للعاملين لمساعدتهم على القيام بالعمل

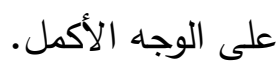
غموض التوصيفات الخاصة بالعاملين بالوحدات المستحدثة، وعدم الاهتمام بتحديثها وفقًا للمتطلبات الحديثة. غياب التسيق بين وزارة التربية والتعليم والهيئات والمؤسسات المعنية كالشركات والمصانع وشركات الكمبيوتر؛ ومن ثم ضعف فرصن ورلئ الاستفادة منهم لتحقيق إدارة جيدة للأمن المعلوماتي في المدرسة الثانوية الصناعية. 
ضعف الاهتمام بنشر الوعي بين العاملين بأهمية المعلومات ودرجة حساسيتها، وضرورة الحفاظ عليها من الاختراق والسرقة.

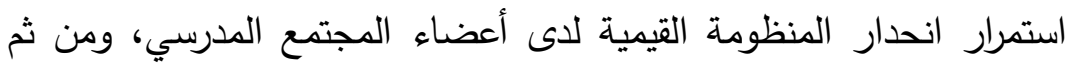
عدم الاهتمام بالحفاظ على البيانات والمعلومات الموجودة في المدرسة. الشعور بالانفصال والانعزال عن المدرسة، وعدم الانتماء لها، ومن ثم عدم

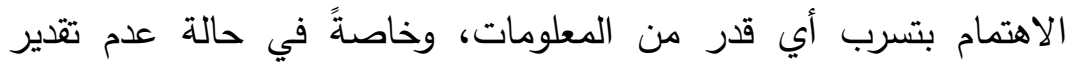

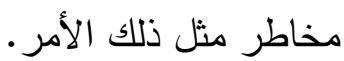
بدائية البرامج التدريبية الموجهة للعاملين، وقلة إمكانات القاعات التي يقدم بها التدريب؛ ومن ثم اقتصاره على الحقائق النظرية، دون الاهتمام بالتطبيق لهيق العملي لتلك الحقائق، ومن ثم محدودية الأثر الإيجابي للتدريب بعد انتهائه. انفراد وزارة التربية والتعليم بالتخطيط، ونظرتها للمستويات الأخرى (المديرية، والإدارة، والمدرسة) كافة على أنها مجرد جهات تتفيذية لتوجهات الوزارة، ومن ثم فقدان فرص الاستفادة من خبرة الجهات الأخرى في التخطيط لهذا الأمر .

\section{2. التداعيات التي يستند إليها البديل التكيفي:}

تتمثل التداعيات المتوقع حدوثها نتيجة تبني البديل التكيفي لإدارة عمليات الأمن المعلوماتي في المدرسة الثانوية الصناعية في مصر ، فيما يلي: النظر في المشكلات التي تتعرض لها المدرسة الثانوية الصناعية بعد في لهدية

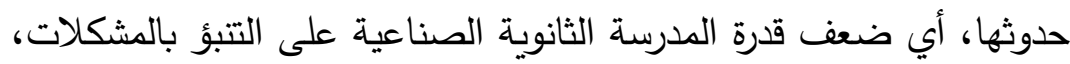

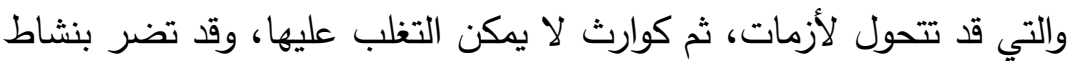

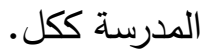

ضياع بعض البيانات والمعلومات التي تمتلكها المدرسة، ومن ثم ضعف قدرتها في الاعتماد على تلك المعلومات عند رغبتها في استعادة نشاطها مرة أخرى بعد انتهاء الأزمة. شعور القائمين على إدارة المدرسة والعاملين فيها بأنهم مجرد تروس في آلة،

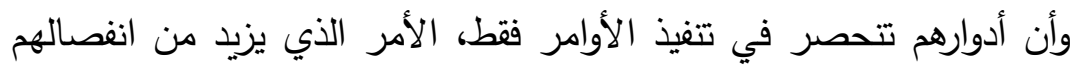

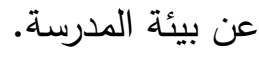


ضعف مردود البرامج التدربية المقدمة للقائمين في الوظائف الإدارية المرتبطة بالحفاظ على الأمن المعلوماتي، واستخدام التكنولوجيا الحديثة، والمديرين، ومن ثم عدم قدرتهم على إدارة عمليات الأمن المعلوماتي في المني المدرسة. استمرار عمل كل هيئة داخل المدرسة في معزل عن باقي الهيئات؛ مما

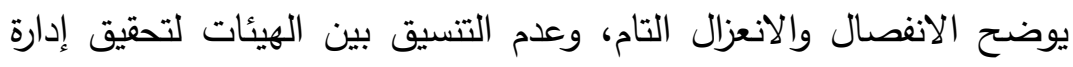

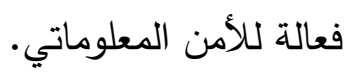
التركيز على الجانب النظري فقط في التدريب، ومن ثم إهمال التطبيق العملي. تهالك البنية التحتية الموجودة في المدارس الثانوية الصناعية، وصعوبة

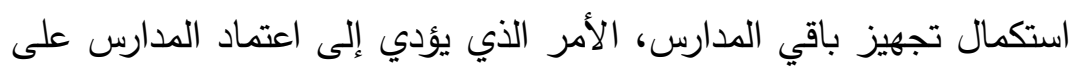

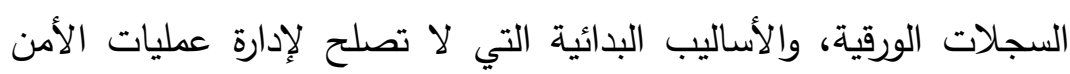
المعلوماتي. البديل الثالث ـ التوجه الدفاعي \}إستراتيجية معالجة الضعف واستثمار الفرص $\{(\mathbf{W} / \mathbf{O})$

يهذف هذا البديل إلى تتمية مجموعة من الإستراتيجيات البديلة التي تساعد

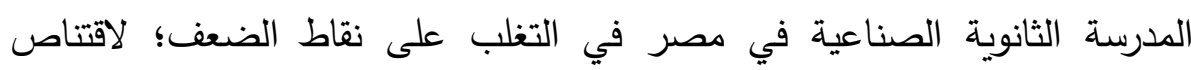

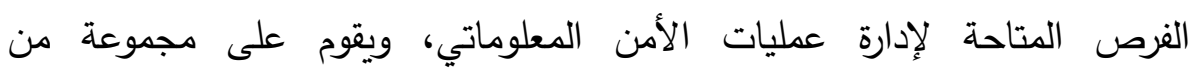
الافتراضات والتداعيات كالتالي: 1. الافتراضات التي يستند إليها البديل الدفاعي:

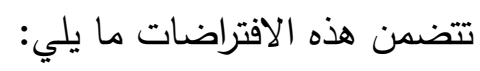
الاستفادة من عقود الثراكة وبروتوكولات التعاون المبرمة بين وزارة التربية

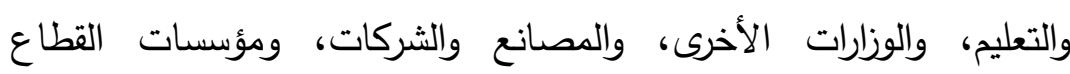

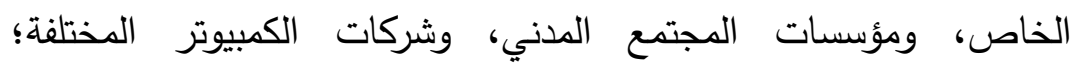
للمساهمة في تجهيز المدارس الثانوية الصناعية بوسائل التكنولوجيا الحديثة.

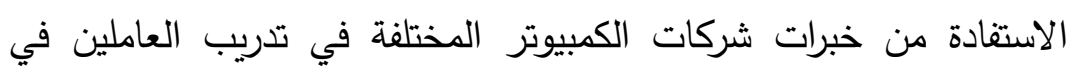

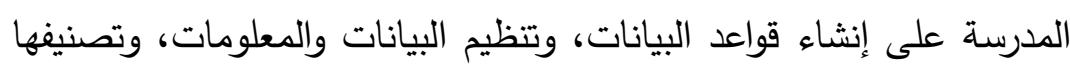


وفقًا لدرجة حساسيتها، مقابل تولي المدرسة الإعلان عن تلك الشركات

$$
\text { والبرامج التي تقدمها. }
$$

استخدام المديرين لبعض العمليات الإدارية التي تساعدهم على إنجاز العمل لهارل بشكل أسرع وأفضل، مثل التفويض الإداري، الذي يسهم في عمل صف ثانِ لثانٍ

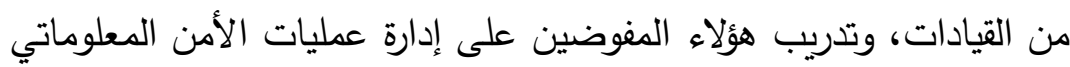

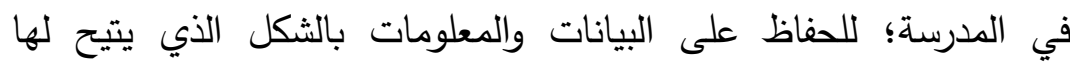
استعادة نشاطها بسهولة. توفير مصادر تمويل إضافية عن تلك المصادر التي توفرها وزارة التربية

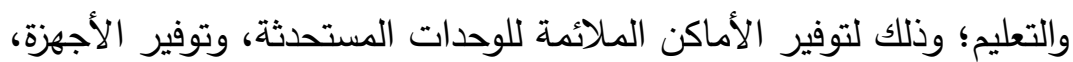
وبرامج التدريب الملائمة، وتوفير الأماكن الملائمة للتدريب، والمجهزة بالأدوات التي يجب أن تستخدم للحفاظ على أمن المعلومات في المدرسة الثانوية الصناعية. الاستفادة من العاملين المدربين على الأساليب التكنولوجية الحديثة، وإنشاء

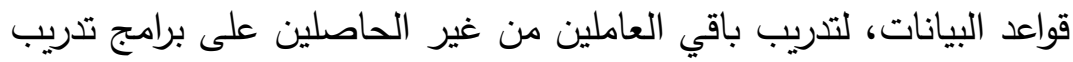
في هذا الإطار، وذلك بالاستعانة بوحدة التدريب والتقويم والجودة الموجودة في المدرسة. الاستفادة من قواعد البيانات الموجودة في المدرسة عن الإمكانات البشرية والمادية، والهيئات التي من شأنها تقديم مساعدات للددرسة وقت الحتوده الحاجة،

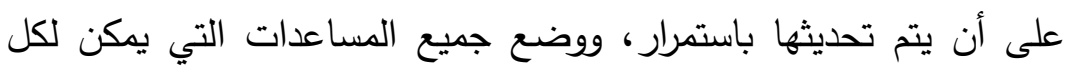

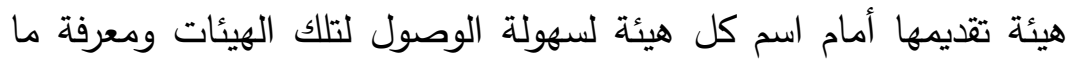

$$
\text { يمكن أن تقدمه من خدمات. }
$$

\section{2. التداعيات التي يستند إليها البديل الدفاعي:}

تتمثل التداعيات المتوقع حدوثها نتيجة تبني البديل الدفاعي لإدارة عمليات

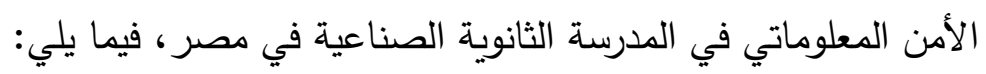
إشرالك الأطراف المعنية، مثل: الشركات، والمصانع، والقطاعات الاقتصادية فئهية المختلفة؛ للمساهمة في إدارة عمليات الأمن المعلوماتي في المدرسة الثانوية 
الصناعية، وذلك بتوفير البرامج التدريبية، والتجهيزات اللازمة، وغيرها من الأمور المرتبطة بهذا السياق.

الحاجة إلى إعطاء مديري مدارس التعليم الثانوي الصناعي المزيد من الحرية

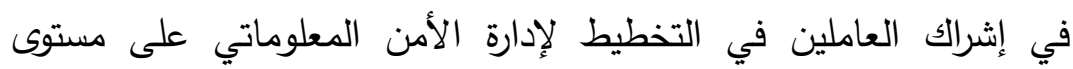

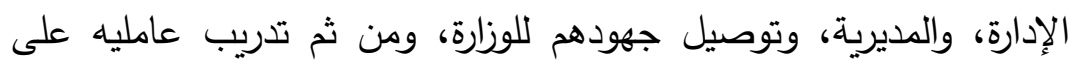
المشاركة في التخطيط للأمن المعلوماتي في المدرسة وعلى المستويات كافة.

الحد من تدهور البنية التحتية لبعض المدارس الثانوية الصناعية ــ خاصةً

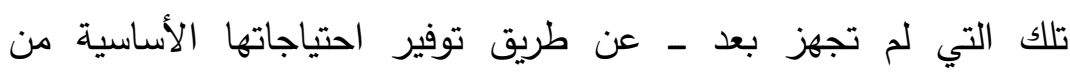
التكنولوجيا المتطورة.

الاهتمام بقياس المردود الإيجابي للبرامج التدريبية المقدمة للإداريين

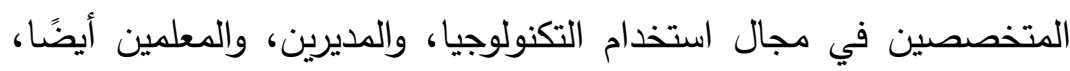

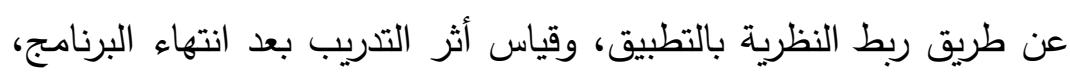

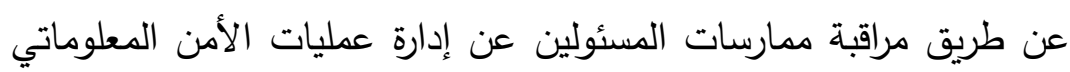
في المدرسة عند أداء مهامهم المرتبطة بالحفاظ على المعلومات وحمايتها.

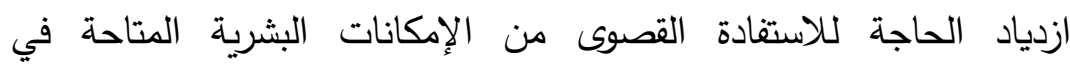
المدرسة، وتتمية شعورهم بالانتماء للددرسة الثانوية الصناعية.

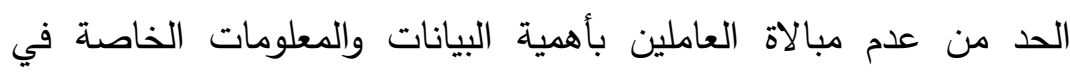
المدرسة، عن طريق نشر ثقافة تتظيمية تدعم ضرورة الاهتمام بالبيانات والمعلومات، وتدعم ضرورة وجودها للحفاظ على وضع المدرسة، وخاصة لهنة وقت الأزمات، لاسترجاع نشاط المدرسة بسهولة.

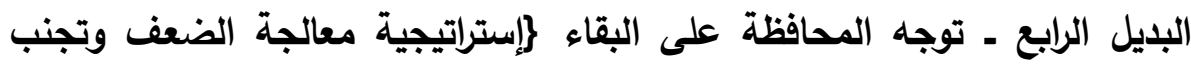

التهديدات (W/T)

يهدف هذا البديل إلى تنمية مجموعة من الإستراتيجيات البديلة التي تساعد

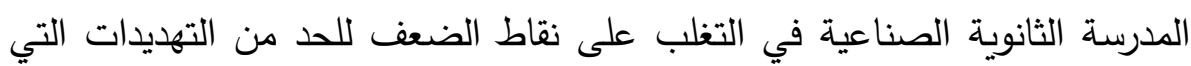

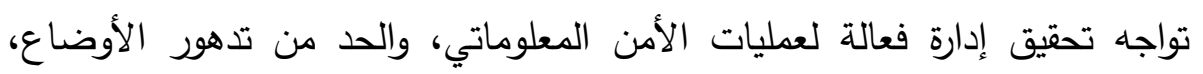

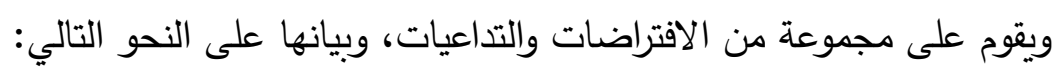


1. الافتراضات التي يستند إليها بديل المحافظة على البقاء، وتتضمن ما يلي:

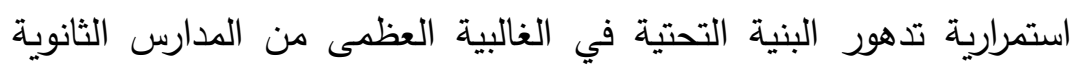
الصناعية، ومن ثم ضعف قدرة تلك المدارس على التخزين الآمن للبيانات والمعلومات، واستخدامها لاستعادة نشاط المدرسة وقت الحاجة لذلك.

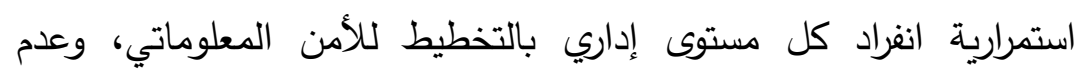

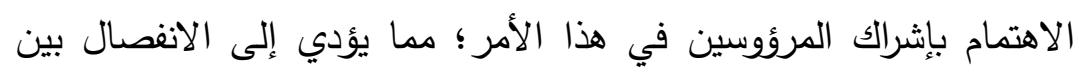
الفئات المختلفة، وفقدان فرصة الاستفادة من خبراتهم. لا تزال الثقافة التتظيمية الموجودة في المدرسة بعيدة عن النهان الاهتمام بالمعلومات ودورها في الحفاظ على استقرار المدرسة، واستمرارية العمل بها، الأمر الذي ينعكس على اللا مبالاة والاستهانة بها. تركيز البرامج التدريبية على الجانب النظري، وتدني قدرات وإمكانات قاعات

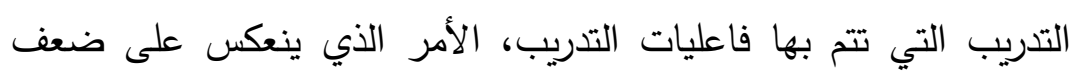
الاهتمام بالجانب العملي، وضعف ممارسة ما تم التدرب عليه في البرامج التدريبية في الواقع العملي. ضعف وغموض قواعد البيانات الموجودة في المدرسة، وعليه تعزر استخدامها وقت الحاجة. الاستمرارية في الانفصال وعدم التتسيق بين الوزارات والهيئات والجهات

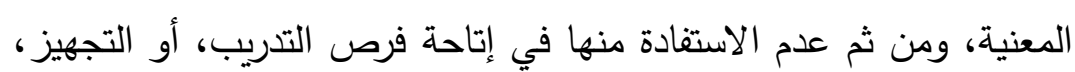
أو غيرها من الجهود التي يمكن القيام بها في هذا الإطار .

2. التداعيات التي يستند إليها بديل المحافظة على البقاء:

تتمثل التداعيات المتوقع حدوثها نتيجة تبني بديل المحافظة على البقاء لإدارة

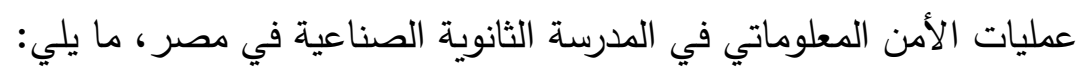

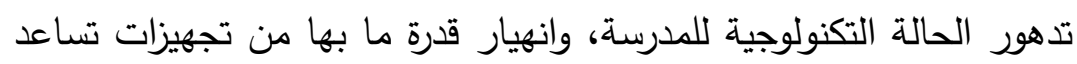
المدرسة على إنجاز مهامها الإدارية. 
استمرارية الاعتماد على السجلات الورقية في حفظ المعلومات؛ مما يعرضها

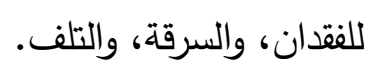

ضياع المردود الإيجابي للبرامج التدريبية المقدمة للعاملين، الأمر الذي في لدئي

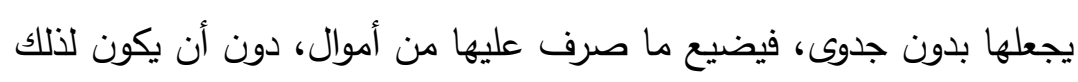
مردود إيجابي.

بدائية قواعد البيانات الموجودة في المدارس الثانوية الصناعية، ومن ثم ضعف القدرة على الاعتماد عليها عند اتخاذ القرارات الخاصة باستعادة نشاط المدرسة، أو حل مشكلاتها. ازدياد الانفصال بين المستويات الإدارية المختلفة بدايةً من الوزارة، وحتى دلى

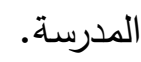

ازدياد تعرض المدارس الثانوية الصناعية للعديد من المشكلات، والأزمات،

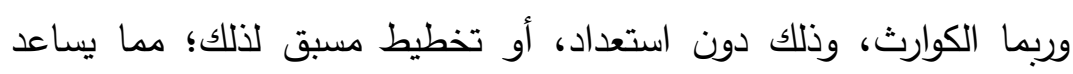
المدرسة على تدبير أمرها، الأمر الذي قد يؤدي إلى انهيار الخدمة.

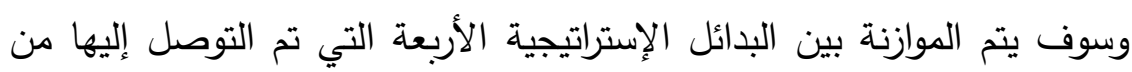

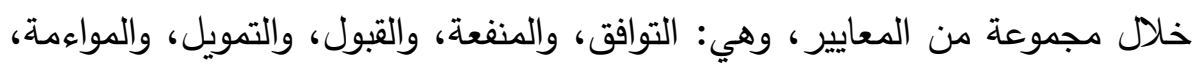
والتطابق، وذلك وفقًا للجدول التالي: 
جدول رقم (9) الموازنة بين البدائل الإستراتيجية وفق معايير الإستراتيجيات.

\begin{tabular}{|c|c|c|c|c|c|}
\hline 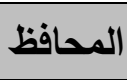 & الدفاعي & التكيفي & الريادي & الوصف & 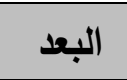 \\
\hline المرتبة & المرتبة & المرتبة & 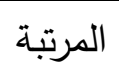 & أن يكون البديل متوافقًا مع الأهداف & 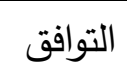 \\
\hline 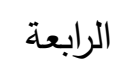 & 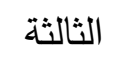 & 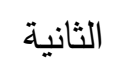 & 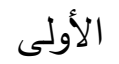 & العامة للمدرسة الثانوية الصناعية. & \\
\hline المرتبة & 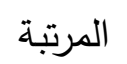 & 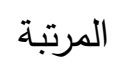 & 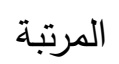 & قدرة البديل على المساهمة في تحقيق & 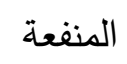 \\
\hline الرابعة & 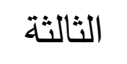 & 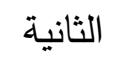 & 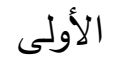 & إدارة فعالة للأمن المعلوماتي في & \\
\hline & & & & المدرسة الثانوية الصناعية. & \\
\hline المرتبة & 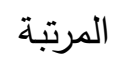 & 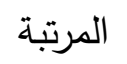 & 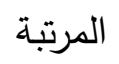 & قبول البديل من قبل الهيئات التربوية، & 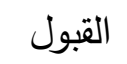 \\
\hline 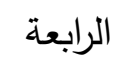 & 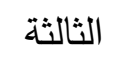 & 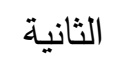 & 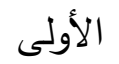 & ومؤسسات المجتمع وهيئاته. & \\
\hline 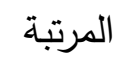 & 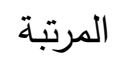 & 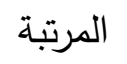 & 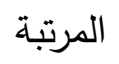 & قدرة البديل على توفير التمويل اللازم، & 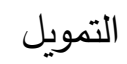 \\
\hline 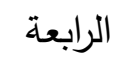 & 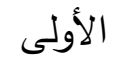 & 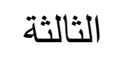 & 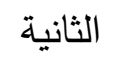 & والدائم لتتفيذه. & \\
\hline المرتبة & 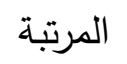 & 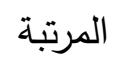 & 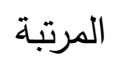 & يقصد بها مواءمته للقوانين & المواءمة \\
\hline 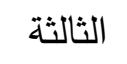 & 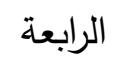 & 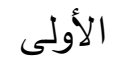 & 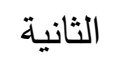 & والتشريعات، والثقافة السائدة لدى & \\
\hline & & & & المجتمع المحيط. & \\
\hline المرتبة & 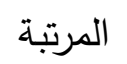 & 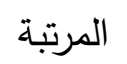 & 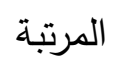 & يحقق البديل توافقًا بين الفرص & التطابق \\
\hline الرابعة & 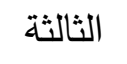 & 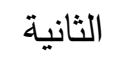 & 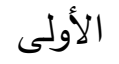 & والتهديدات في البيئة الخارجية، ونقاط & \\
\hline & & & & القوة والضعف في البيئة الداخلية. & \\
\hline
\end{tabular}

يتضح من الجدول السابق، أنه في ضوء أبعاد الموازنة بين البدائل المختلفة

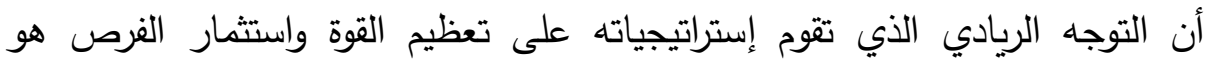
التوجه المثالي في ضوء نتائج التحليل، وأبعاد الموازنة بين البدائل، وذلك للحيثيات التالية:

التوافق: اتضح من خلال النظر لأهداف مدارس التعليم الفني الصناعي أن البديل

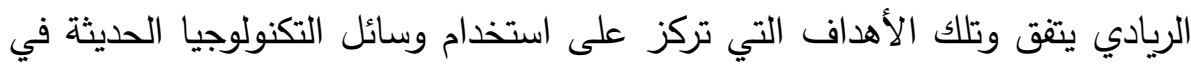
العمليات التي تتم في المدرسة كافة، استجابةً لمتطلبات عصر المعرفة.

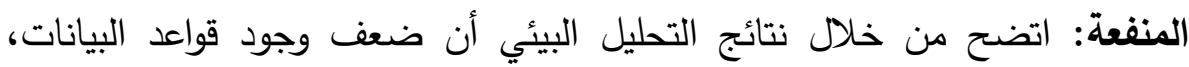
وضعف فرص التعامل معها، وعدم التخزين الآمن للبيانات، والمعلومات، يُصِيّب

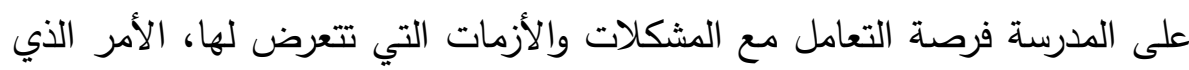


فرض تغييرًا جوهريًا في سبل التعامل مع البيانات والمعلومات التي تملكها المدرسة،

لمواكبة عصر المعلومات، ومساعدة المدرسة على سرعة التعافي من أزماتها. القبول: تبين من نتائج التحليل الرباعي رغبة الهيئات التربوية في تطوير التعليم الفني

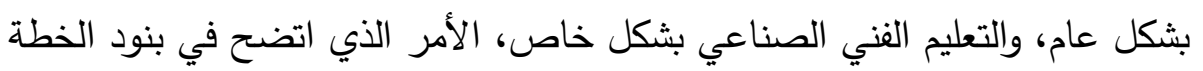

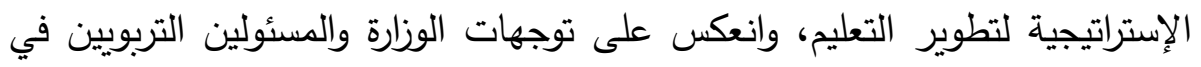
تجهيز المدارس الثانوية الصناعية بالبنية التحتية اللازمة؛ للمساهمة في تحقيق إدارة فعالة للأمن المعلوماتي. التمويل: تبين من نتائج التحليل البيئي ضعف التمويل الموجه لتجهيز مدارس التعليم الفني الصناعي باحتياجاتها، الأمر الذي يوضح ضعف لتئ فرصة البديل الريادي في هذا الأمر، إذ يعتمد على ضرورة تجهيز المدارس الثانوية الصناعية بالبنية التحتية

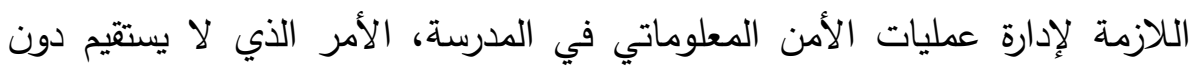

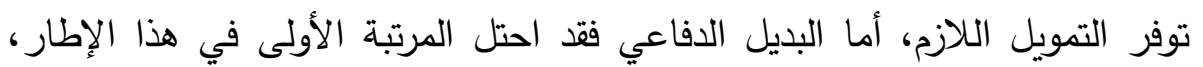
وذلك لأنه اعتمد على توفير مصادر تمويل بديلة تهيئ للمدرسة توفير احتياجاتها التكنولوجية. المواءمة: اتضح من نتائج التحليل البيئي استمرارية نمط الإدارة المركزية؛ حيث ما زال هناك انفراد بالتخطيط في المستويات العليا، دون الاهتمام بالمشاركة من قبل الجهات الدنيا، الأمر الذي يتعذر معه تطبيق البديل الريادي؛ حيث احتل البديل

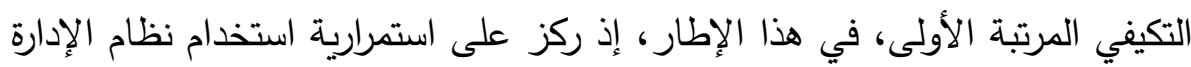

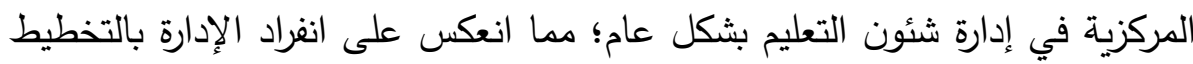

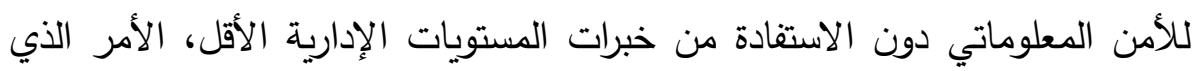
يتطلب تغييرًا في التشريعات والقوانين التي مازالت تتعامل وهذا النمط الذي لا لا يهتم بالتعامل مع أفكار العاملين والاستفادة من خبراتهم.

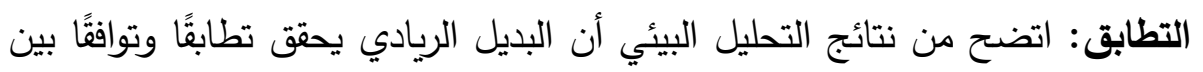

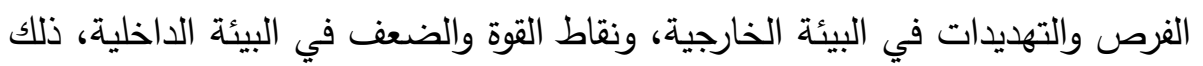
أن تحقيق الفرص ومقاومة التهديدات تتلاءم مع توجهات هذا البديل، وتدعم نقاط القوة، وتتخلص من نقاط الضعف، وتتلاعم أيضا مع توجهاته. 
وبناءً على ما سبق، وفي ضوء الموازنة بين البدائل الإستراتيجية، تم التوصل

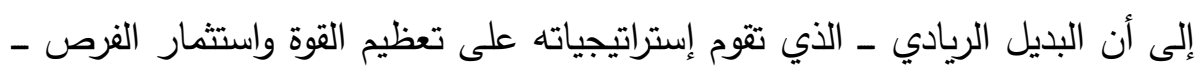
هو التوجه المثالي؛ وذلك لأنه احتل المركز الأول في أربعة أبعاد من أبعاد الموازنة.

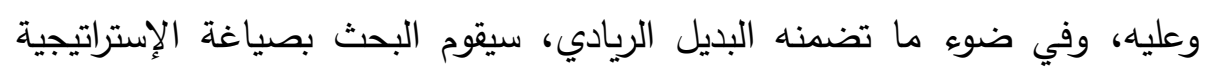

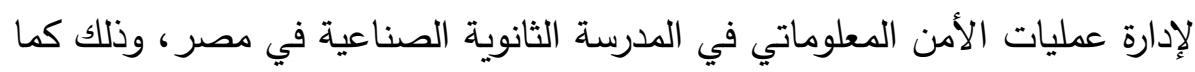
سيتضح في الخطوة التالية من البحث.

القسم الخامس ـ صياغة الإستراتيجية لإدارة عمليات الأمن المعلوماتي في المدرسة

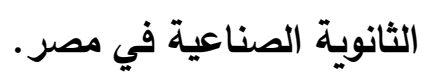
تهاف تلك الخطوة لصياغة الإستراتيجية المقترحة لإدارة عمليات الأمن فئن المعلوماتي في المدرسة الثانوية الصناعية في مصر ، وينقسم ذلك القسم إلى عدد من الإدهن المحاور ، بيانها على النحو التالي: 1. مرتكزات الإستراتيجية المقترحة. 2. 3. 4. الغايات والأهداف الإستراتيجية المقترحة. 5. ملامح الإستراتيجية المقترحة. 6. متطلبات تتفيذ الإستراتيجية المقترحة. 7. معوقات تتفيذ الإستراتيجية المقترحة وسبل مواجتها. وفيما يلي عرض لتلك المحاور بالتفصيل:

1. مرتكزات الإستراتيجية المقترحة لإدارة عمليات الأمن المعلوماتي في المدرسة الثانوية الصناعية في مصر. تقوم الإستراتيجية المقترحة على عدة مرتكزات، يمكن إبرازها فيما يلي:

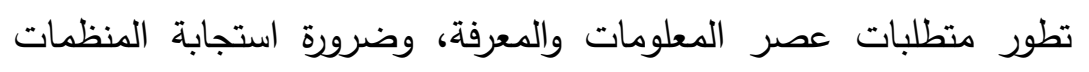

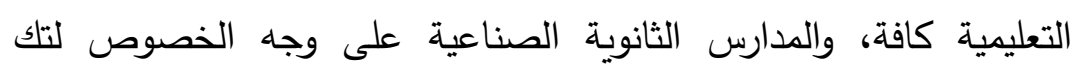
المتطلبات.

إن المعلومات أصبحت في الآونة الأخيرة الثروة الحقيقية التي تمتلكها المدرسة، وعليها حسن استخدامها؛ لضمان تحقيق أهدافها. 
توفير البنية التحتية والتكنولوجية اللازمة للحفاظ على المعلومات من الضياع

$$
\text { أو السرقة. - توفير. }
$$

أصبح للمدرسة القدرة على توقع ما يمكن أن يحدث لها من مشكلات أو أزمات قد تعترض تحقيقها لأهدافها، أو تقديم خدماتها لعملائها. وجود معايير ثابتة لتقويم قدرة المدرسة على إدارة عمليات الأمن المعلوماتي بها، وتحسين المسار باستمرار إذا كانت هناك مشكلات في الأداء.

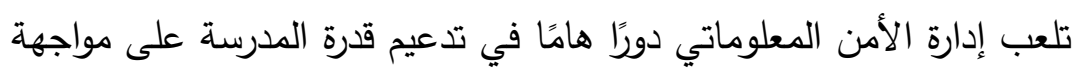

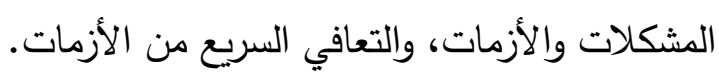
إن التدريب من العمليات الهامة لإدارة الأمن المعلوماتي، لما له من دالهات دور في

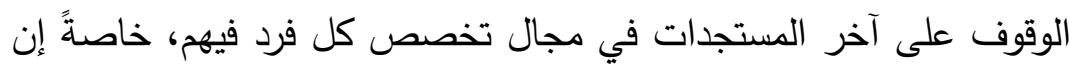

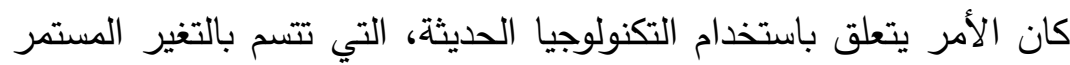
في فترات وجيزة جدًا.

أن هناك نوعان من المعلومات التي يتضمنها النظام المدرسي وهي

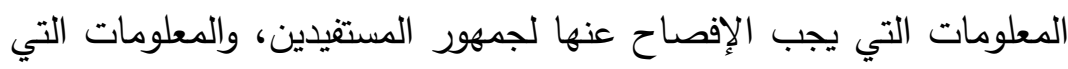
يجب على إدارة المدرسة الاحتفاظ بها لنفسها، لحساسيتها الثديدة، ولأنها تستخدم في استعادة نشاط المدرسة بعد تعرضها لإحدى الأزمات.

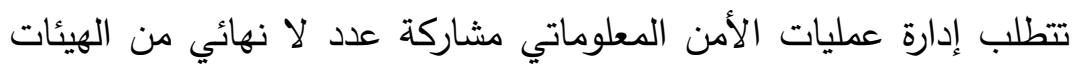

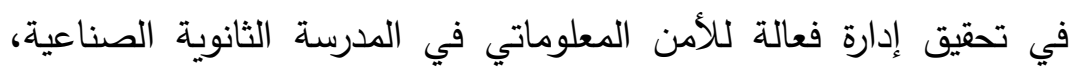

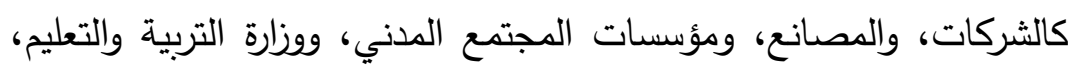

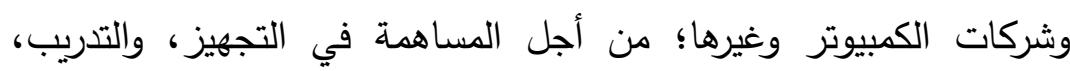
وغيرها من المهام اللازمة لتحقيق إدارة فعالة للأمن المعلوماتي.

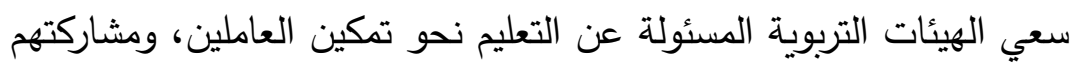

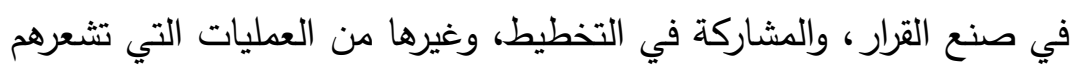
بانتمائهم للمدرسة، ومسئولياتهم عن كل ما يتم داخلها. 


\section{2.}

"تسعى المدرسة الثانوية الصناعية في مصر إلى وضع إستراتيجية لإدارة عمليات الأمن المعلوماتي استجابة لمتطلبات عصر التكنولوجيا والوصول إلى مركز

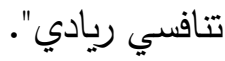

\section{3. رسالة الإستراتيجية المقترحة:}

تتمثل رسالة الإستراتيجية المقترحة في (تحسين قدرة المدرسة الثانوية الصناعية على إدارة عمليات الأمن المعلوماتي بها ولما تمتلكه من بيانات ومعلومات،

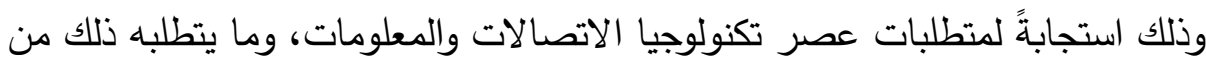

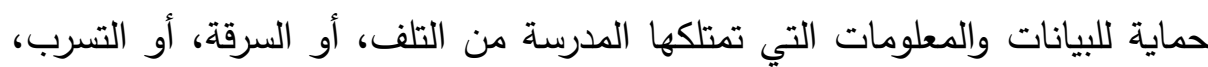
خاصةً تلك التي لا يجب الإفصاح عنها، الأمر الذي يساعد المدرسة على الاستعداد

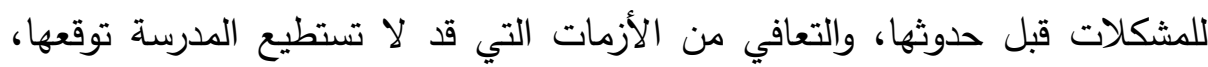
والاستعداد لها بسرعة تمكنها من استمرارية تقديم الخدمة، والتعافي السريع من الآثار السلبية للأزمة).

4. الغايات والأهداف الإستراتيجية المقترحة: تتحدد الغايات والأهداف الإستراتيجية فيما يلي:

الغاية الأولى - (دعم التوجه التلا مركزي في إدارة المدرسة الثانوية الصناعية في مصر، الأمر الذي يتيح للمدير والمرؤوسين وجميع المستويات الإدارية الأخرى المشاركة في التخطيط لإدارة عمليات الأمن المعلوماتي في المدرسة)، ويمكن تحقيق تلك الغاية من خلال الأهداف الإستراتيجية التالية:

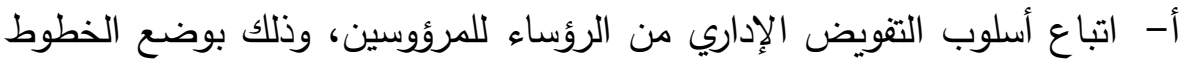
العريضة لإدارة عمليات الأمن المعلوماتي في المدرسة الثانوية الصناعية. ب-تشجيع المرؤوسين على المستويات كافة (المديرية، الإدارة، المدرسة) من لمن لمنية

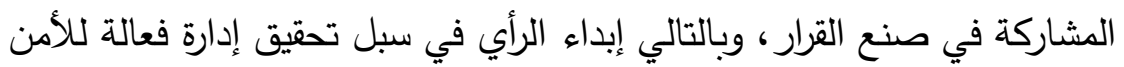

$$
\text { المعلوماتي في المدرسة. }
$$

ج- إكساب المسئولين عن حفظ المعلومات في المدرسة الثانوية الصناعية المهارات التي تمكنهم من تصنيف المعلومات، ومعرفة درجة حساسيتها، ومن ثم التخطيط لاستخدامها وتخزينها وفقًا لدرجة حساسيتها. 
الغاية الثانية ـ (العمل على تنمية قدرات الإمكانات البثرية في المدرسة الثانوية الصناعية، الأمر الذي يمكنه من الحفاظ على المعلومات التي تمتلكها المدرسة، واستخدامها وقت الحاجة إليها)، ويمكن تحقيق تلك الغاية من خلال الأهداف

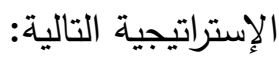

أ- تدريب العاملين في الددرسة الثانوية الصناعية على استخدام وسائل التكنولوجيا

الحديثة والحفاظ عليها، وذلك بناءً على احتياجاتهم التدريبية.

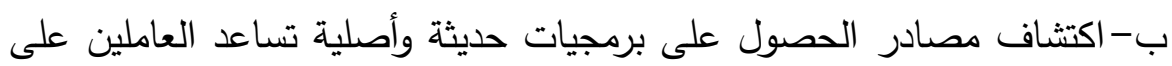

إدارة عمليات الأمن المعلوماتي في المدرسة الثانوية الصناعية.

ج- تدريب العاملين على استخدامها، وتثفيرها، واسترجاعها وقت الحاجة.

د- تشجيع العاملين الحاصلين على تدريب في مراكز التدريب الرسمية على تبادل

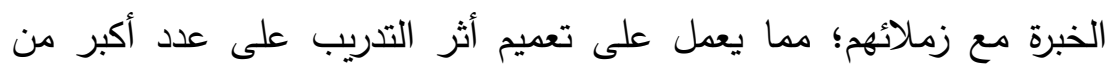

العاملين، وذلك داخل وحدة التدريب في المدرسة الثانوية الصناعية.

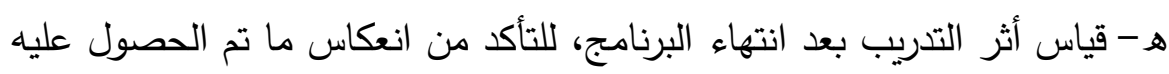

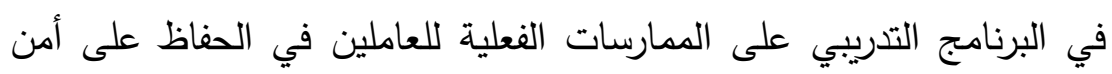

المعلومات.

و - تحديث قواعد البيانات الموجودة في المدرسة، والتدقيق فيما تحويه من بيانات،

وتحديثها باستمرار ؛ وذلك لضمان رشد القرار الذي سيتم اتخاذه بناء عليها.

الغاية الثالثة ـ (إعداد خطة شاملة تركز على التسيق الأئم بين وزارة التربية

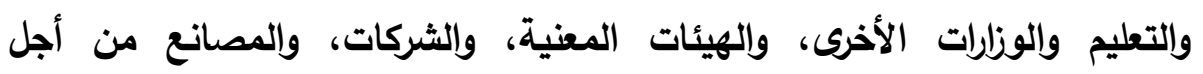

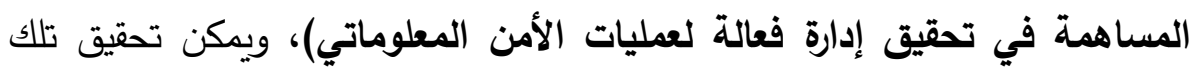
الغاية من خلال الهدف الإستراتيجي التالي:

أ. عقد شراكة وبرتوكولات تعاون بين وزارة التربية والتعليم والجهات المعنية

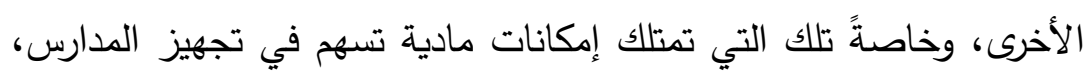
وتوفير عقود الصيانة، وبرامج التدريب، وتجهيز قاعات التدريب بما تحتاجه من إمكانات. 
الغاية الرابعة ـ (الاستغلال الأمثل لإمكانيات المدرسة الثانوية الصناعية؛ بما يسهح في إدارة عمليات الأمن المعلوماتي بها)، ويمكن تحقيق تلك الغاية من خلال الأهداف الإستراتيجية التالية: أ. التسيق بين الوحدات المدرسية المختلفة، مثل وحدة إدارة الأزمات في المدرسة الثانوية الصناعية، وذلك لما لها من دور في جمع البيانات

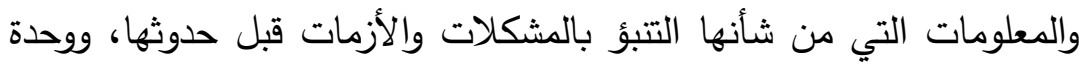
المعلومات والإحصاء باعتبارها المكان المسئول عن حفظ كل المعلومات التهات

$$
\text { التي تمتلكها المدرسة. }
$$

ب. استثمار الوحدات المدرسية الأخرى الموجودة في المدرسة، مثل: وحدة تيسير

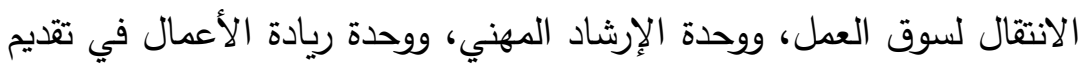
البرامج التدريبية الخاصة بتدريب العاملين على استخدام الأجهزة التكنولوجية

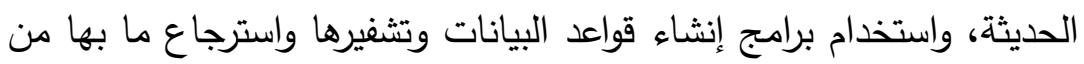
بيانات ومعلومات عند الحاجة.

الغاية الخامسة: (دعم الثقافة التظظيمية للعاملين في المدرسة الثانوية الصناعية عن أهمية المعلومات، للحفاظ على الأمن المعلوماتي)، ويمكن تحقيق تلك الغاية من خلال الأهداف الإستراتيجية التالية: أ. توعية العاملين بأهمية المعلومات للمدرسة الثانوية الصناعية، وخاصةً القائمين على اتخاذ القرارات. ب. دعم ولاء العاملين وانتمائهم للمدرسة الثانوية الصناعية، وذلك من خلال إشراكهم في صنع القرار، والأخذ بآرائهم المختلفة لحل مشكلات الددرسة، وبالتالي الشعور بمسئولياتهم تجاه ما يتم اتخاذه من قرارات تخص المدرسة.

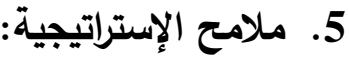

يعرض الجدول التالي ملامح الإستراتيجية المقترحة لإدارة عمليات الأمن المعلوماتي في المدارس الثانوية الصناعية في مصر ، من حيث: الغايات، والأهداف الإستراتيه الإستراتيجية، والأهداف الإجرائية، وكذلك أنشطة التنفيذ، ومؤشرات الإنجاز ، والمدى الزمني المقترح لتنفيذها: 


$$
\text { جدول رقم (10) }
$$

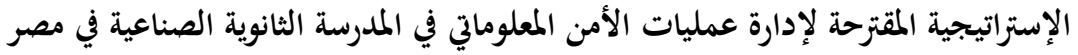

الغاية الأولى ـ (دعم التوجه اللا مركزي في إدارة المدرسة الثانوية الصناعية في مصر، الأمر الذي يتيح للمدير والمرؤوسين وكل المستويات الإدارية الأخرى المثاركة في التخطيط لإدارة عمليات الأمن المعلوماتي في المدرسة).

\begin{tabular}{|c|c|c|c|c|c|}
\hline الملمنى المدى & مسئولية التنفيذ & مؤشرات الإنجاز & أنشطة التنفيذ & الأهداف الإجرائية & الإستراتيجية \\
\hline مستمر & 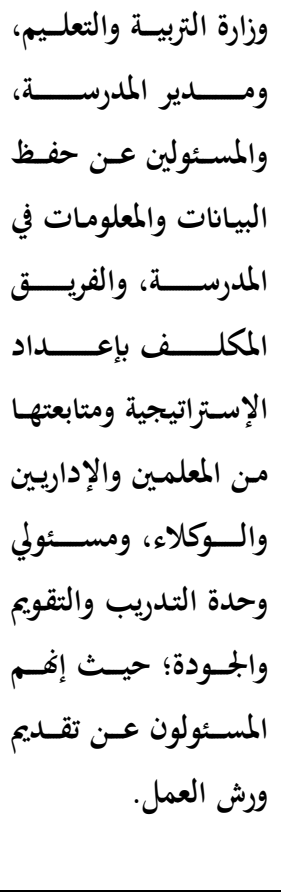 & 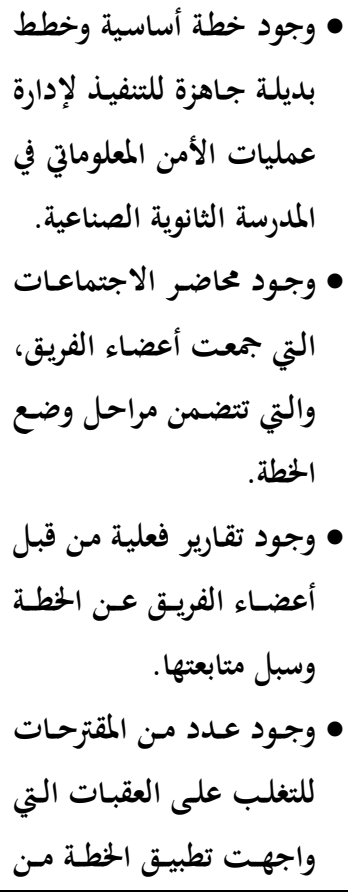 & 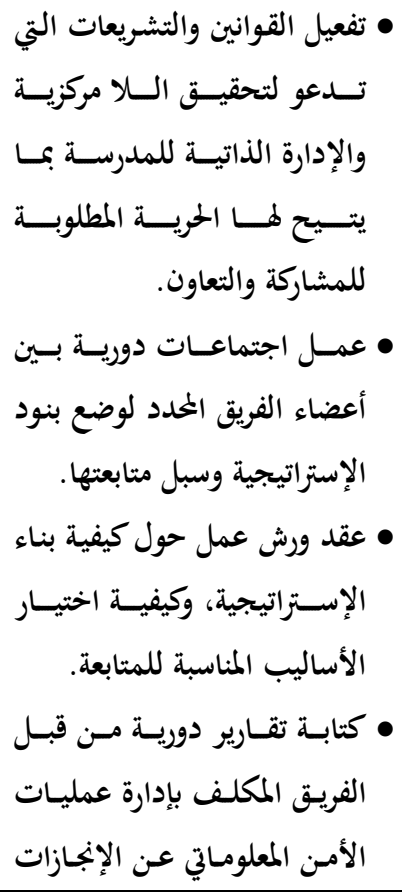 & 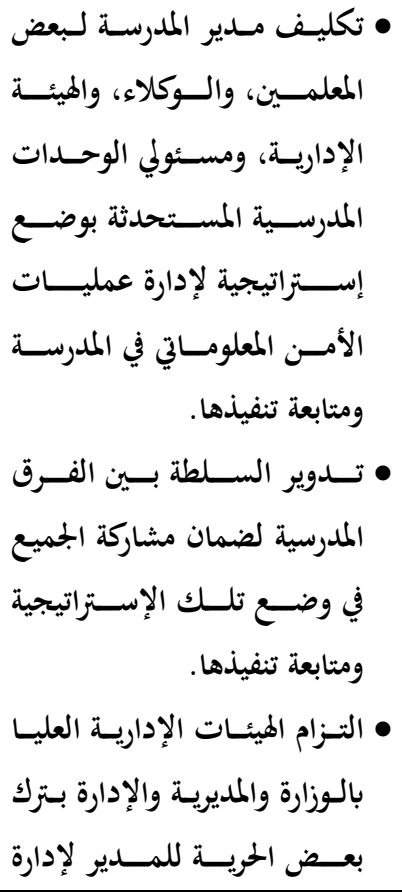 & 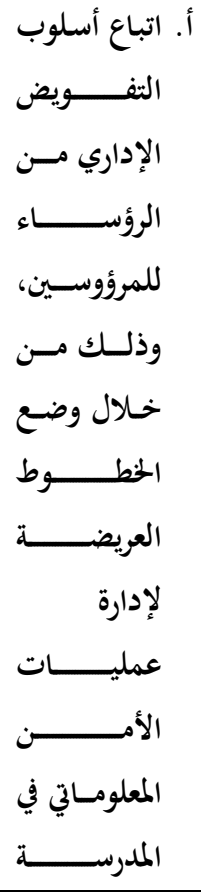 \\
\hline
\end{tabular}


استر ليجية مقترحة لإدارة عمليات الأمن المعلوماتى

\begin{tabular}{|c|c|c|c|c|c|}
\hline المقنى المنى & مسئولية التنفيذ & مؤشرات الإنجاز & أنشطة التنفيذ & الأهداف الإجرائية & الإستراتيجية \\
\hline & & 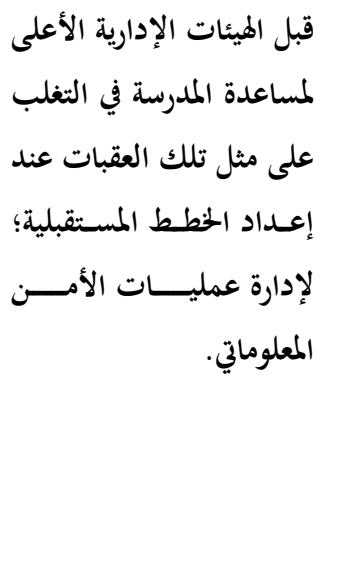 & 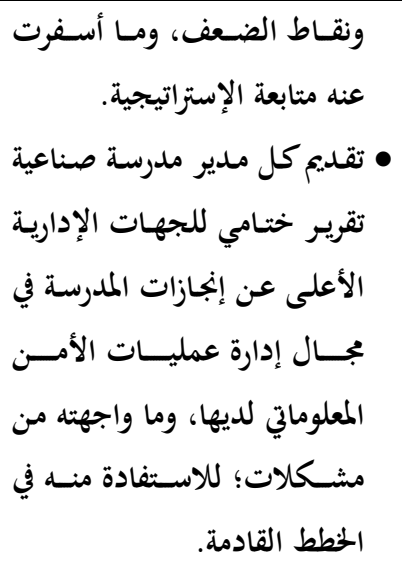 & 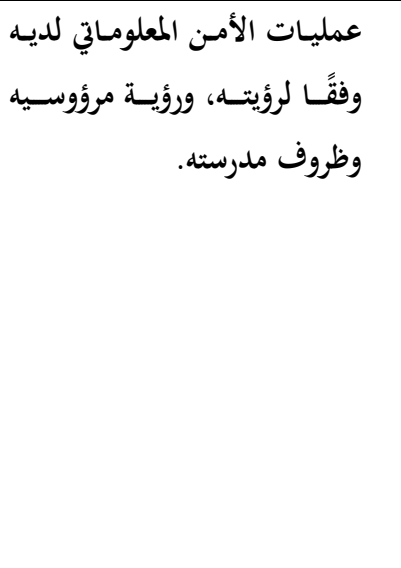 & 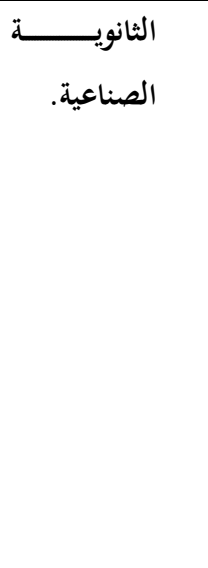 \\
\hline مستمر & 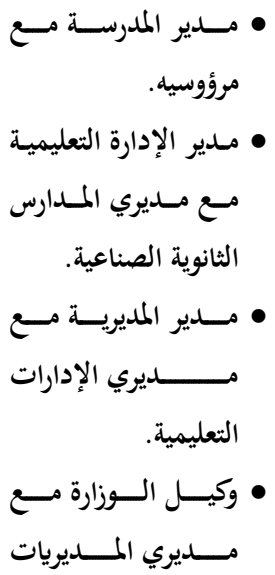 & • الأفكـار الجديـدة والمقتزحسات & 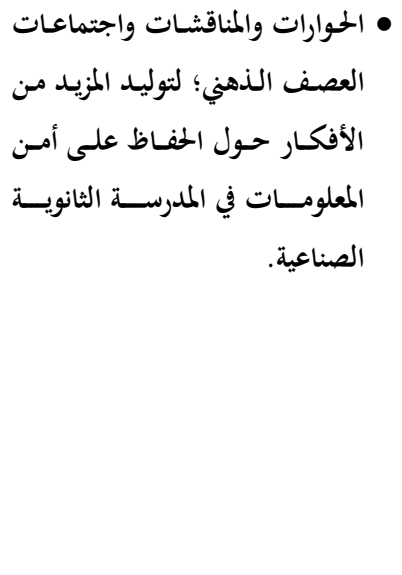 & 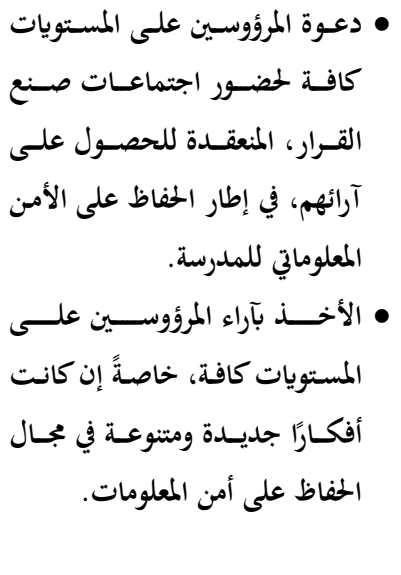 & 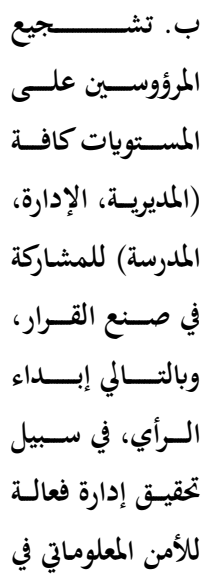 \\
\hline
\end{tabular}


استر ليجية مقترحة لإدارة عمليات الأمن المعلوماتي

\begin{tabular}{|c|c|c|c|c|c|}
\hline الملمدى المقنى & مسئولية التنفيذ & مؤشرات الإنجاز & أنشطة التنفيذ & الأهداف الإجرائية & الإستراتيجية \\
\hline & التعليمية. & & & & المدرسة. \\
\hline مستمر & 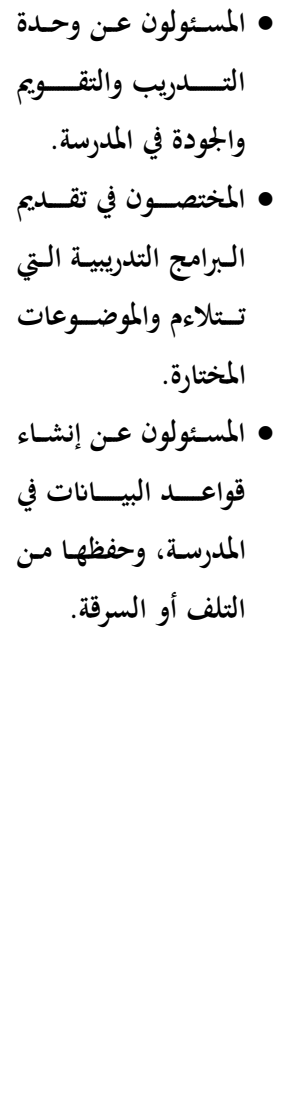 & 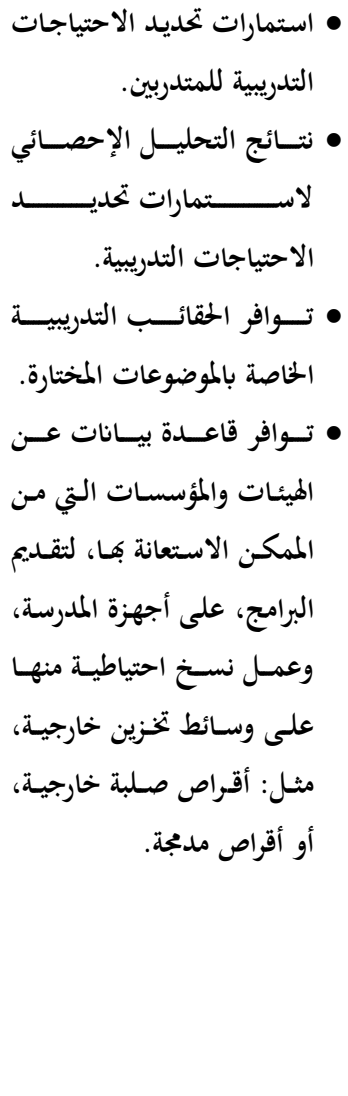 & 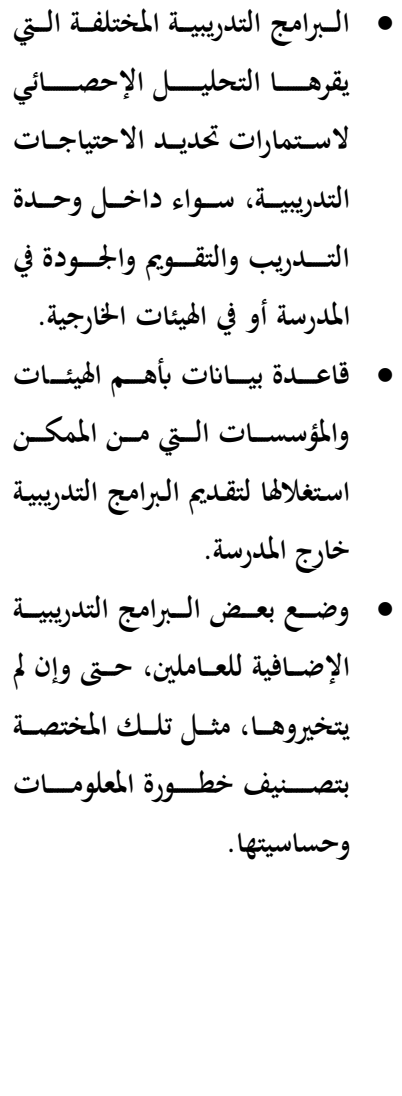 & 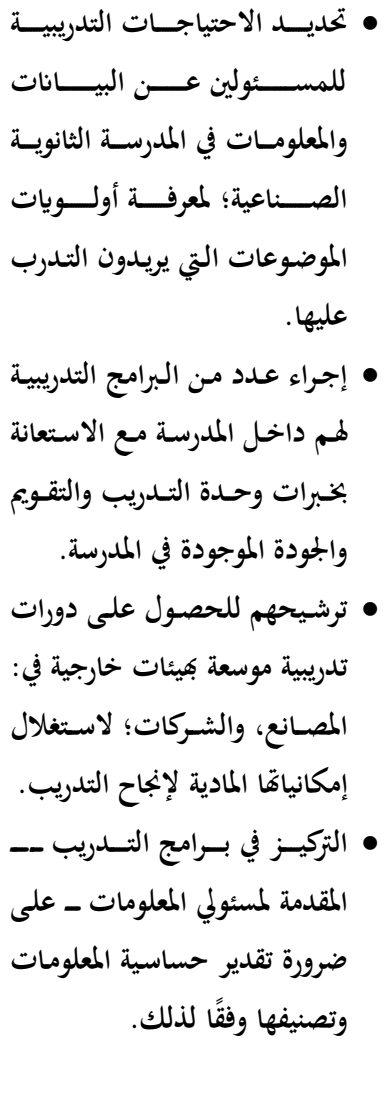 & 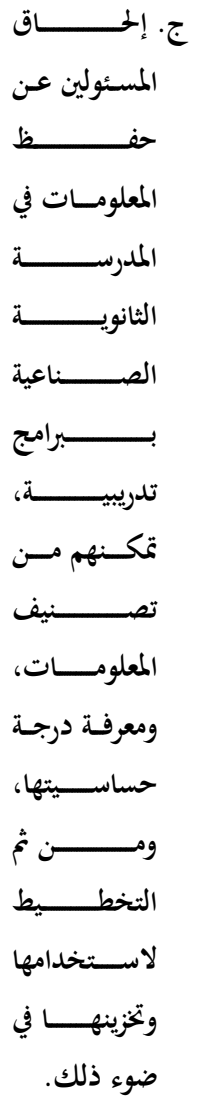 \\
\hline
\end{tabular}




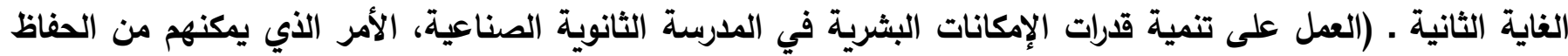

المعلومات التي تمتلكها المدرسة، واستخذامها وقت الحاجة إليها).

\begin{tabular}{|c|c|c|c|c|c|}
\hline المتمني & مسئولية التنفيذ & مؤشرات الإنجاز & أنشطة التنفيذ & الأهداف الإجرائية & الأأهداف \\
\hline مستمر & 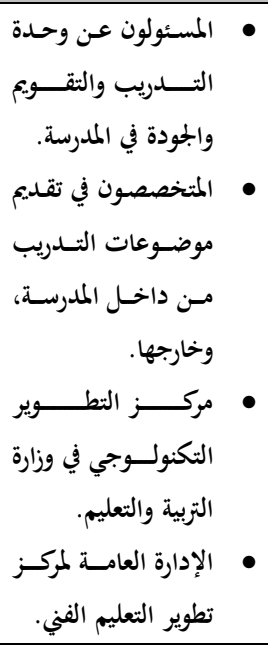 & 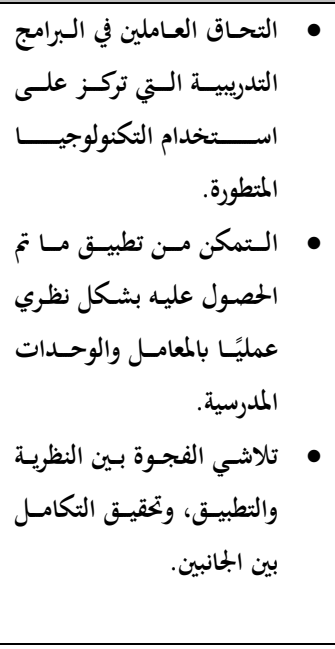 & 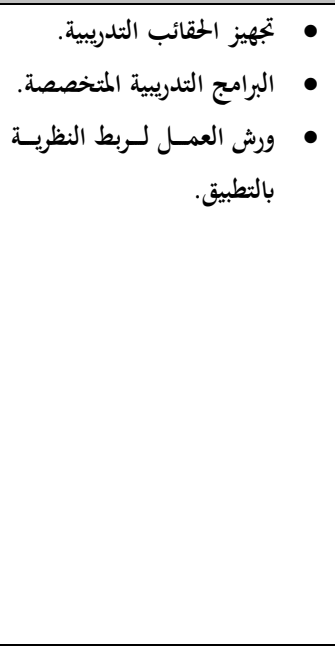 & 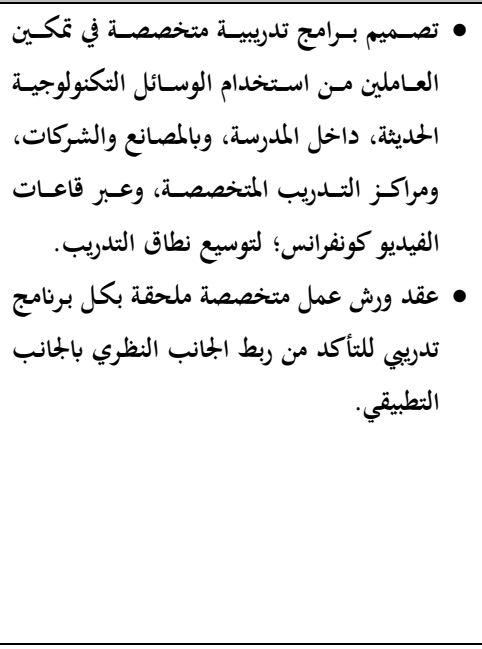 & 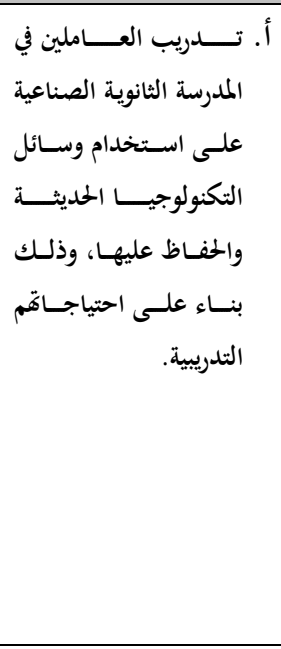 \\
\hline مستمر & 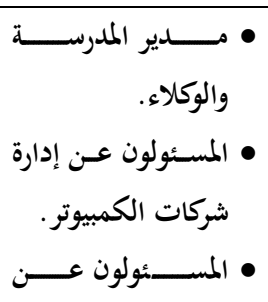 & 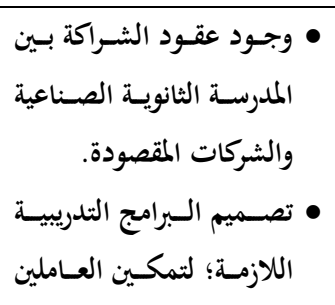 & 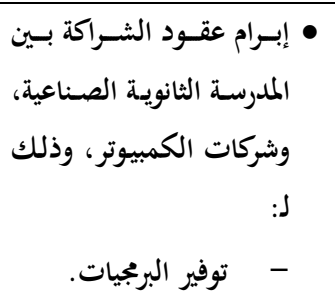 & 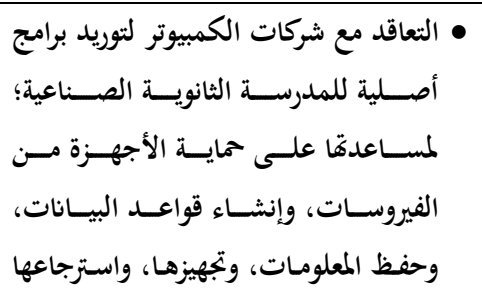 & 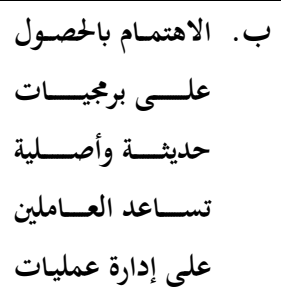 \\
\hline
\end{tabular}




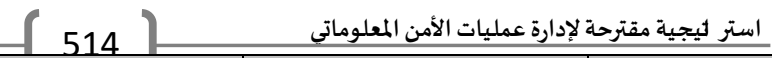

\begin{tabular}{|c|c|c|c|c|c|}
\hline المنمي & مسئولية التنفيذ & مؤشرات الإنجاز & أنشطة التنفيذ & الأهداف الإجرائية & الأأهداف \\
\hline & 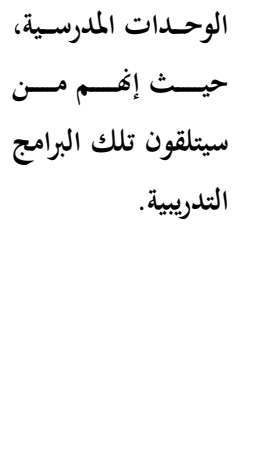 & 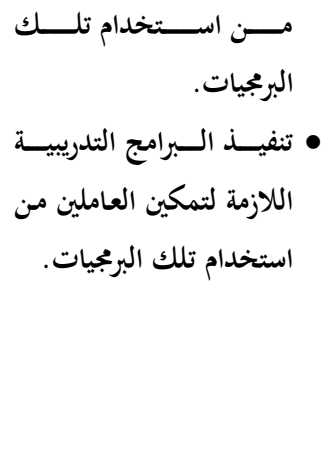 & 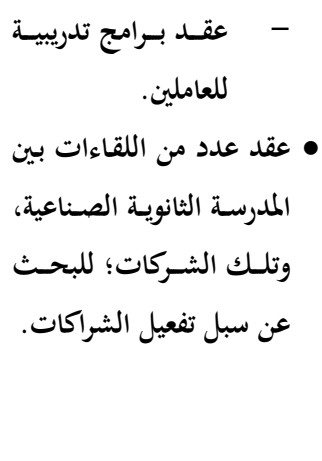 & 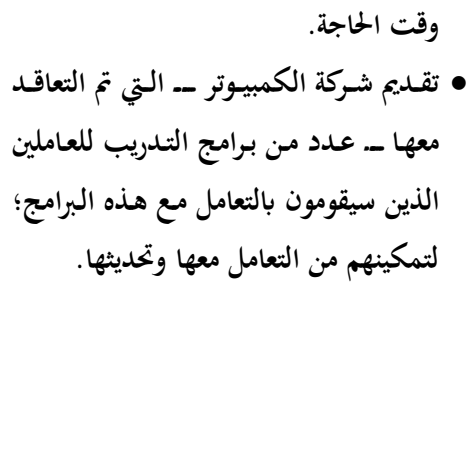 & 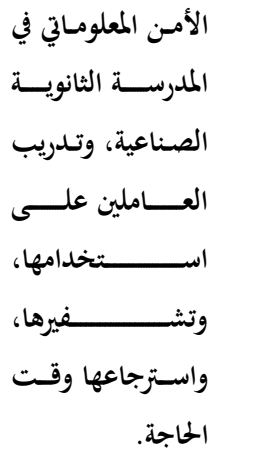 \\
\hline واحد & 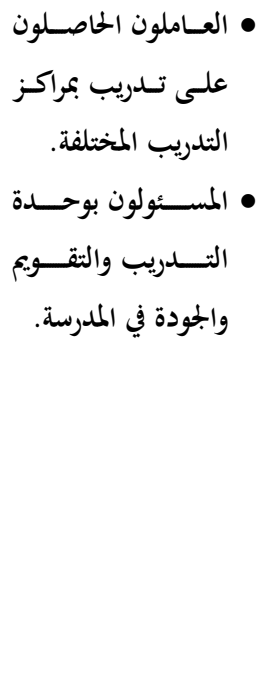 & 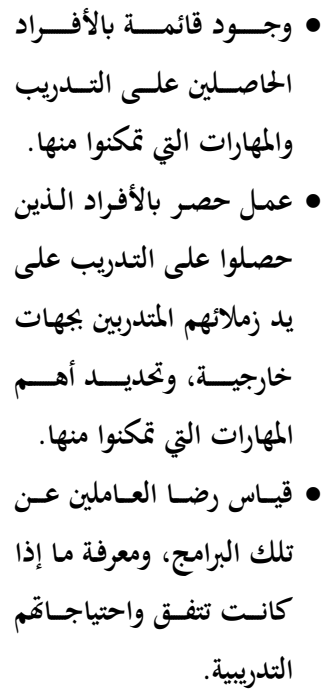 & 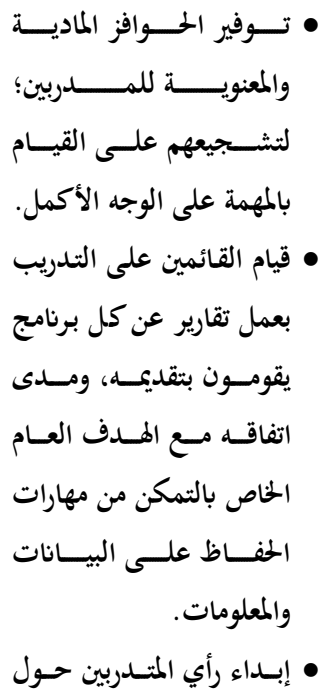 & 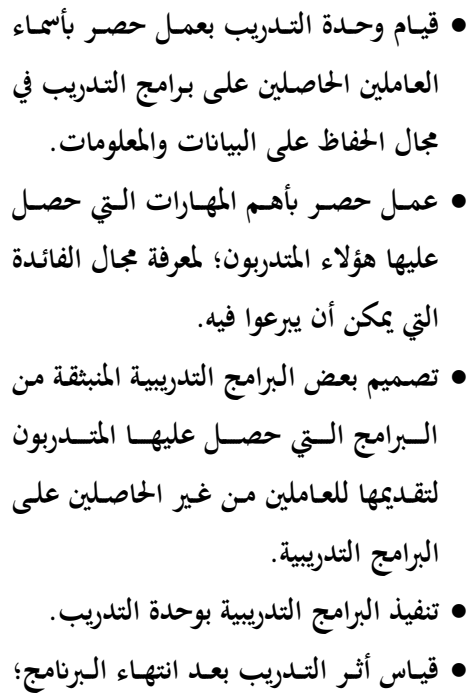 & 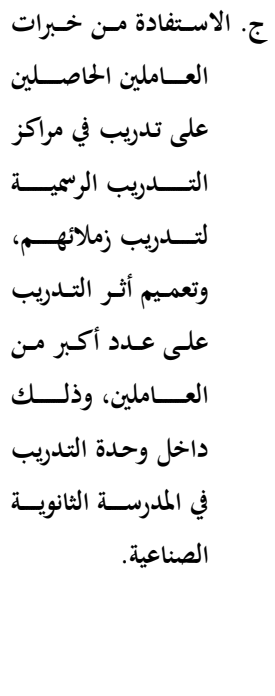 \\
\hline
\end{tabular}


لاستر ليجية مقترحة لإدارة عمليات الأمن المعلوماتى

\begin{tabular}{|c|c|c|c|c|c|}
\hline المقامي & مسئولية التنفيذ & مؤشرات الإنجاز & أنشطة التنفيذ & الأهداف الإجرائية & الأأهداف \\
\hline & & & 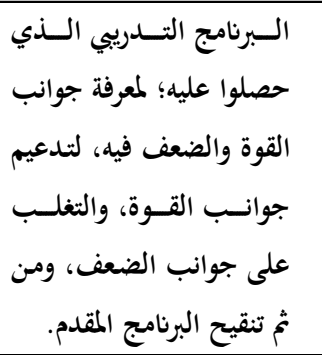 & 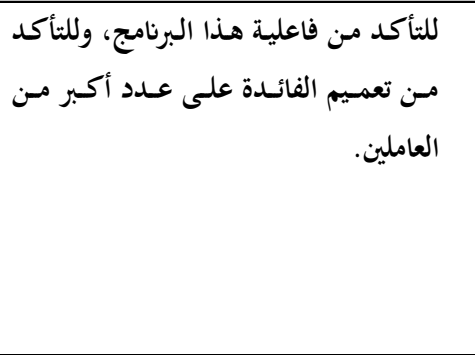 & \\
\hline شهر بعد & • المسـولون بوحسدة & • و وجـود مقـاييس مـن شـأفا & • عمـل مقـاييس مـن شـأفا & • • تقويم البرامج التدريبية المقدمة للعاملين. & د. الاهتمـام بقيـاس أثر \\
\hline 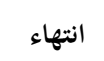 & التسدريب والتقـويم & الحككم على جودة البرامج & قياس أثر كل برنامج تدريبي & • تعديل البرامج التدريبيـة المقدمـة للعـاملين & التسـدريب بعـد انتهــاء \\
\hline 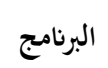 & والجودة. & التدريبية المقدمة. & 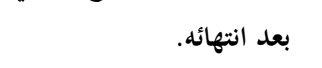 & وفقَـــ لأهــداف تلــك الــرامج، ووفقَــ & الـبرنامج للتأكسـد مــن \\
\hline 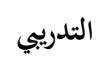 & & • وجـــود مقـــييس أخـــى & • ملاحظة أداء العـاملين بعـد & 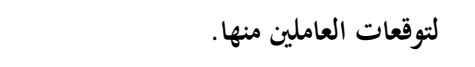 & انعكاس ما تم الحصول \\
\hline لتطبيق & & للحكــم علـى جــودة أداء & عــودةقم مـــن الــبرنامج & • وضع معايير ثابتة لتقويم البرامج التدريبية، & عليــــه في الــــرنامج \\
\hline 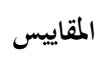 & & المتدربين بعد حصولم على & التسـدريبي؛ لمعرفــة مــدى & التي يـتم على أساسهها الحكـم على تلـك & التـــــدريبي علــــــى \\
\hline والحكم & & 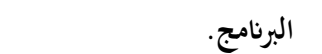 & قـــرقم على تطبيـق مـا تم & 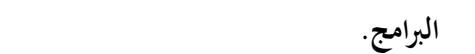 & الممارســـات الفعليــة \\
\hline على أداء & & & الحصـول عليسه في الـبرنامج & & للعساملين في الحفـــاظ \\
\hline 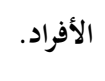 & & & التـــــديبي في ممارســــــم & & 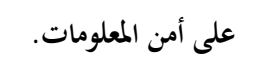 \\
\hline & & & اليومية. & & \\
\hline & & & • • اســتطلاع رأي المتـــدربين & & \\
\hline & & & حول البرنامج الذي حصلوا & & \\
\hline & & & 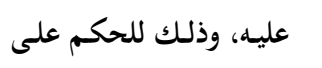 & & \\
\hline & & & مــدى جودتسه مـن وجهــة & & \\
\hline
\end{tabular}




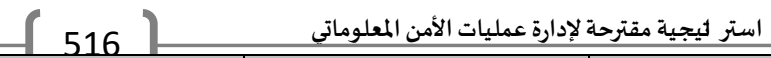

\begin{tabular}{|c|c|c|c|c|c|}
\hline المتمني & مسئولية التنفيذ & مؤشرات الإنجاز & أنشطة التنفيذ & الأهداف الإجرائية & الأأهداف \\
\hline & & & نظرهم. & & \\
\hline مستمر & 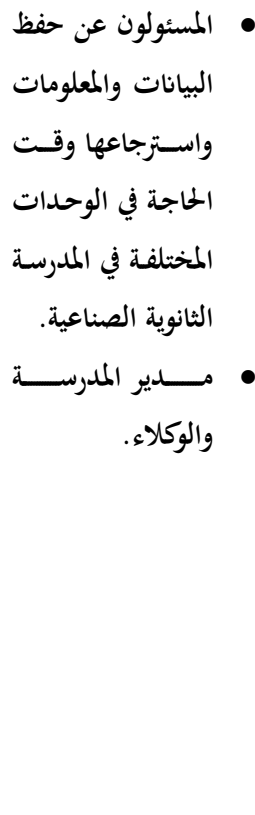 & 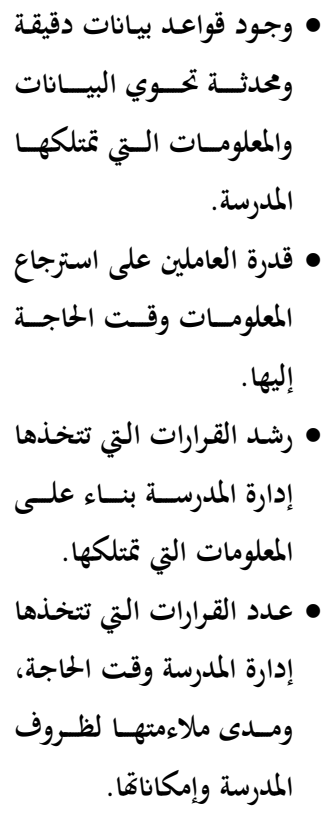 & 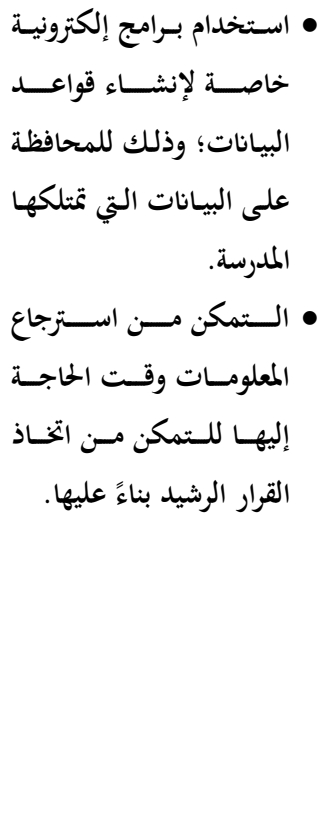 & 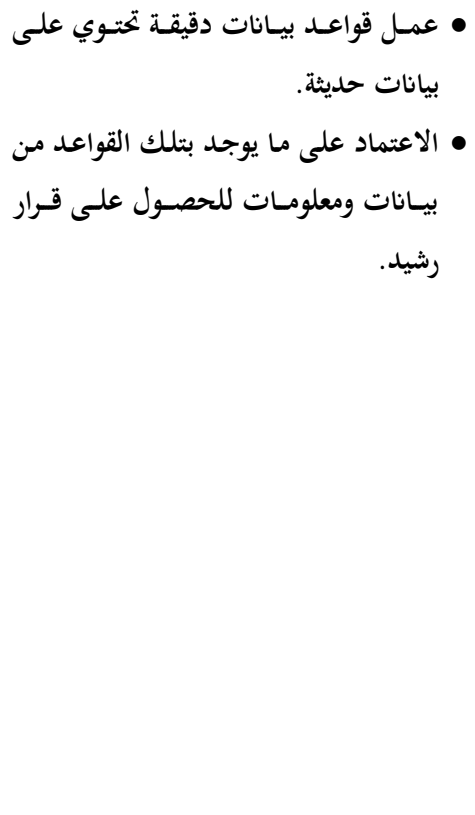 & 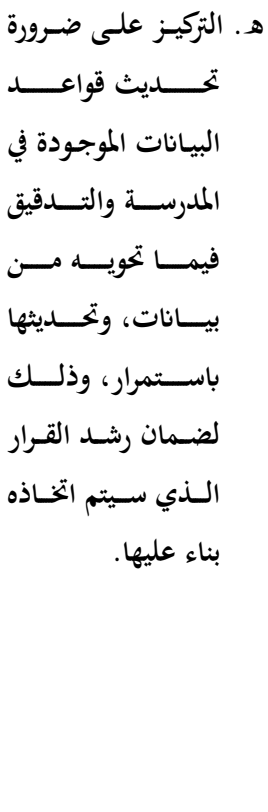 \\
\hline
\end{tabular}


الغاية الثالثة: (العمل على إعداد خطة شاملة، تركز على التنسيق الدائم بين وزارة التربية والتعليم والوزارات الأخرى، والههيئات المعنية، والثركات، والمصانع؛ من أجل المساهمة في تحقيق إدارة فعالة لعمليات الأمن المعلوماتي)

\begin{tabular}{|c|c|c|c|c|c|}
\hline الزمني المنتى & مسئولية التنفيذ & مؤشرات الإنجاز & أنشطة التنفيذ & الأهداف الإجرائية & الأهداف الإستراتيجية \\
\hline مستمر & • • • بـارة التزبية والتعليم. & 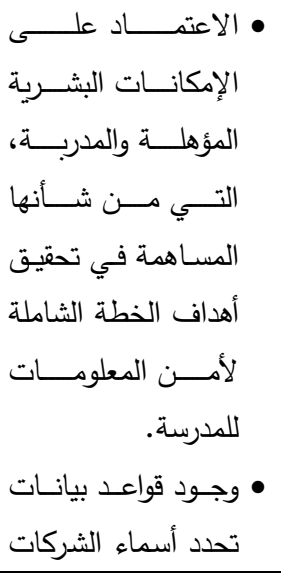 & 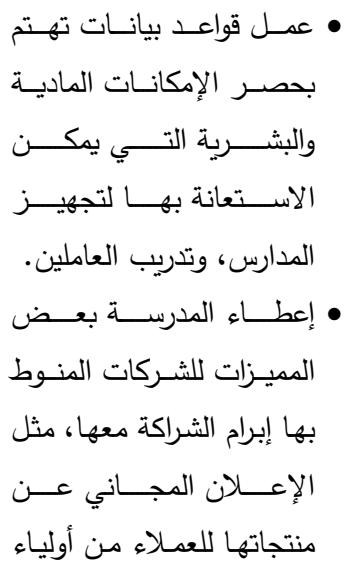 & • لـالإستتغلال الأمثنل & 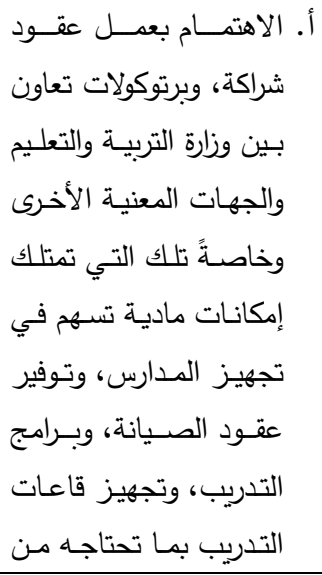 \\
\hline
\end{tabular}




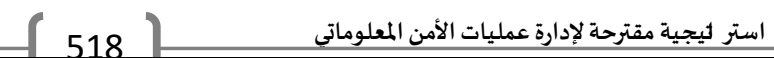

د/ولاء السيد عبدالله

\begin{tabular}{|c|c|c|c|c|c|}
\hline الزمني & مسئولية التنفيذ & مؤشرات الإنجاز & أنشطة التنفيذ & الأهداف الإجرائية & الأهداف الإستراتيجية \\
\hline & & 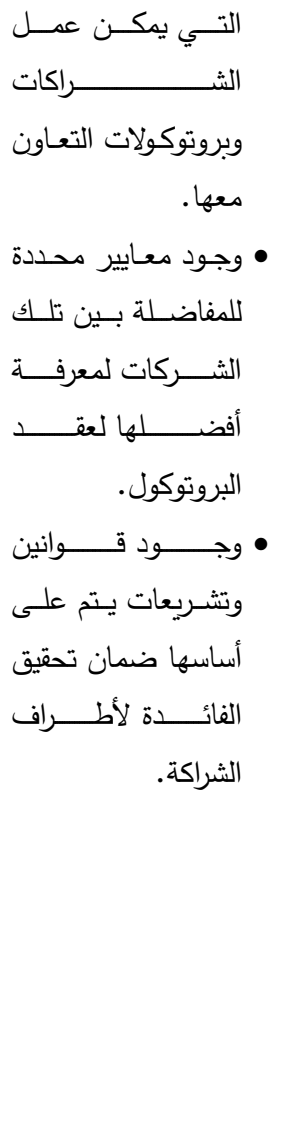 & 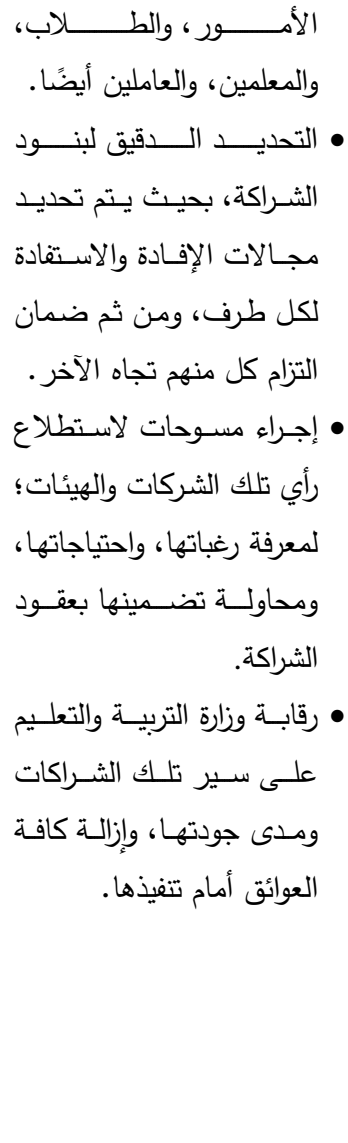 & 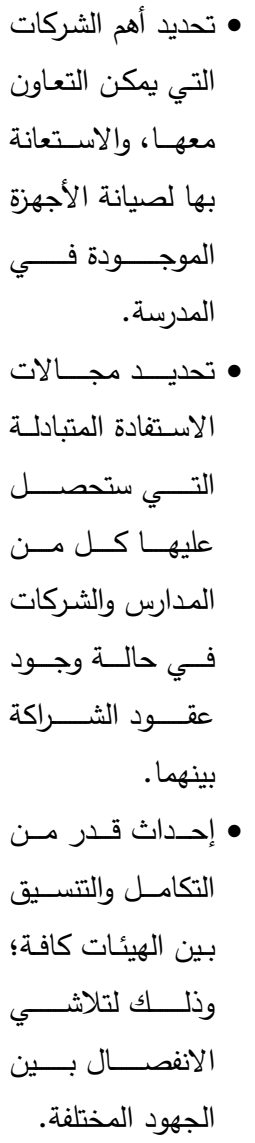 & إمكانيات. \\
\hline
\end{tabular}


الغاية الرابعة (الاستثمار الأمثل لإمكانيات الدرسة الثانوية الصناعية بما يسهم في إدارة عمليات الأمن المعلوماتي بها)

\begin{tabular}{|c|c|c|c|c|c|}
\hline المقترحي & مسنولية التنفيذ & مؤشرات الإنجاز & أنشطة التنفيذ & الأهداف الإجرائية & الأهداف الإستراتيجية \\
\hline مستمر & 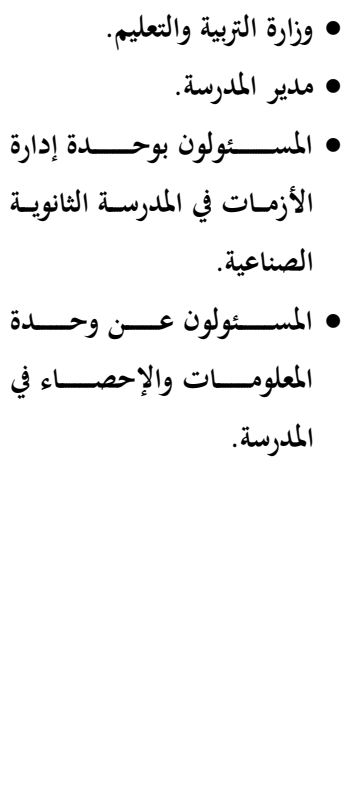 & 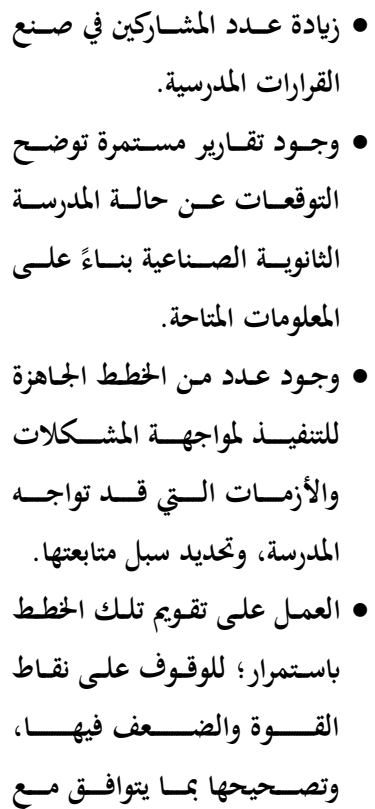 & 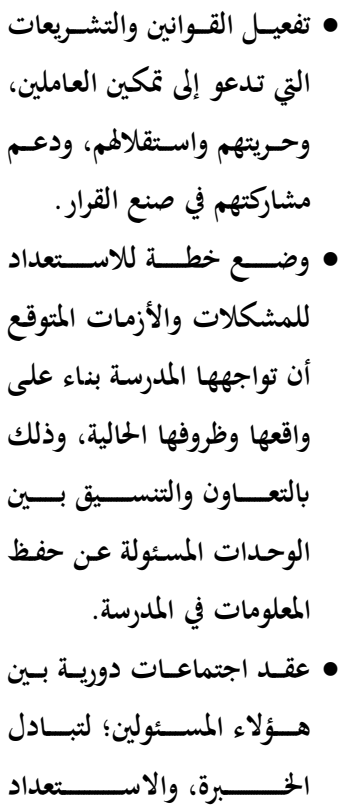 & 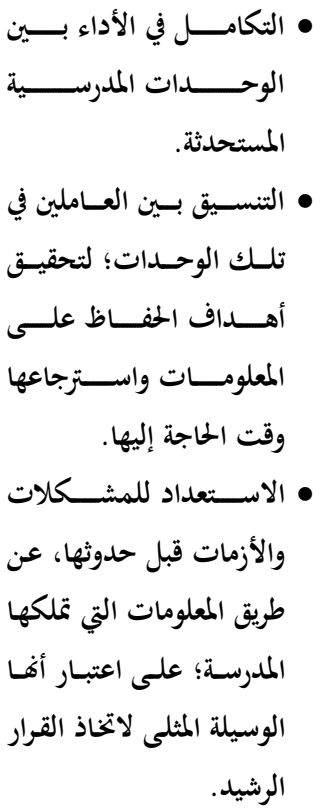 & 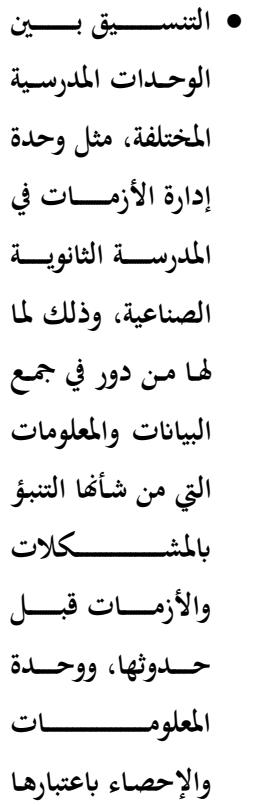 \\
\hline
\end{tabular}




\begin{tabular}{|c|c|c|c|c|c|}
\hline & & 520 & استر ليجية مقترحة لإدارة عمليات الأه & & د/ولاء السيد عبدالله \\
\hline الزمني & مسئولية التنفيذ & مؤشرات الإنجاز & أنشطة التنفيذ & الأهداف الإجرائية & الأهداف الإستراتيجية \\
\hline & & 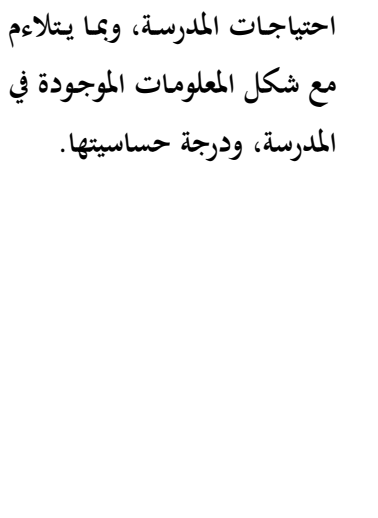 & 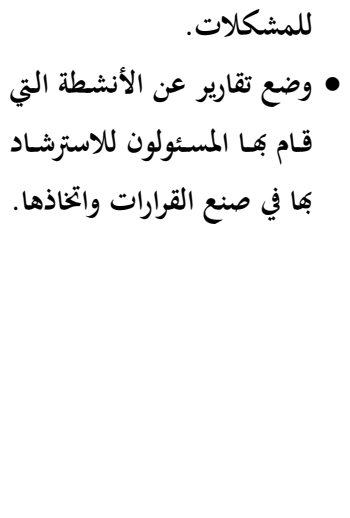 & 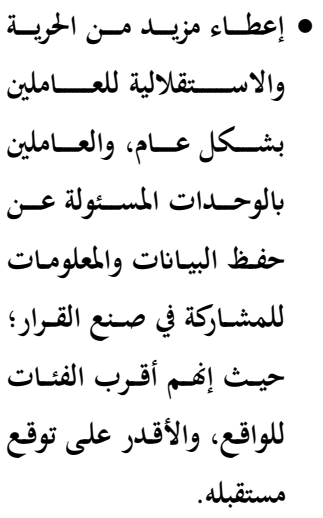 & 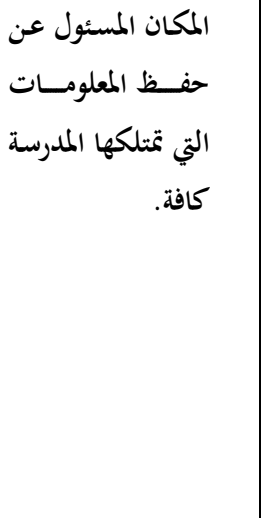 \\
\hline 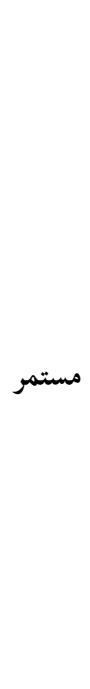 & 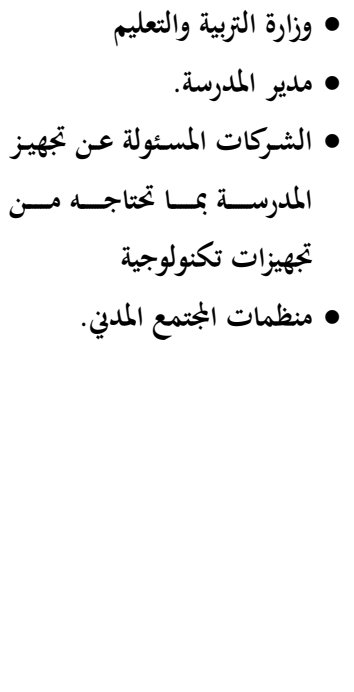 & 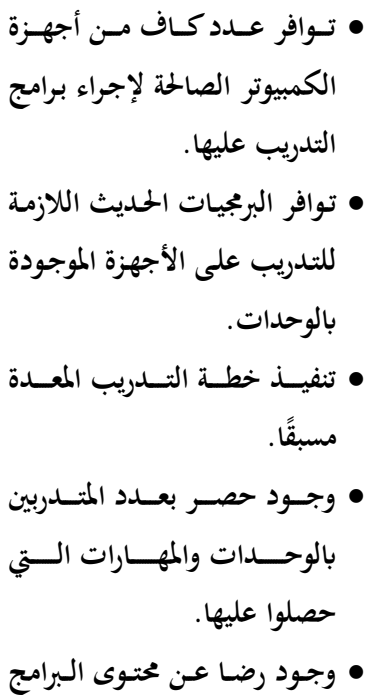 & 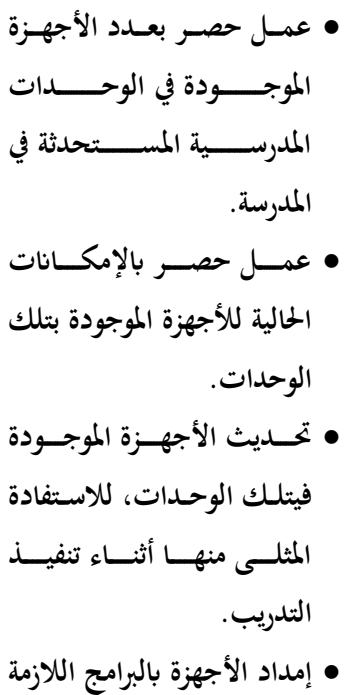 & 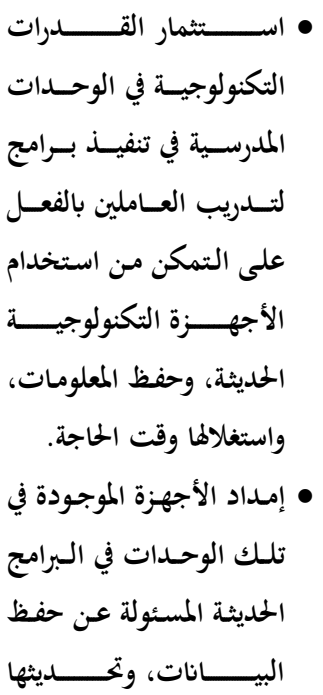 & 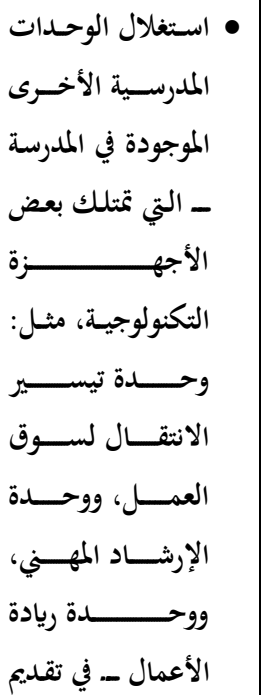 \\
\hline
\end{tabular}




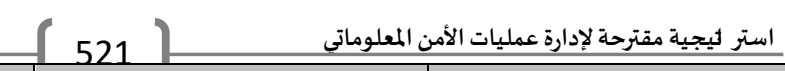

\begin{tabular}{|c|c|c|c|c|c|}
\hline المقندي & مسئولية التتفيذ & مؤشرات الإنجاز & أنثطة التنفيذ & الأهداف الإجرائية & الأهداف الإستراتيجية \\
\hline & & 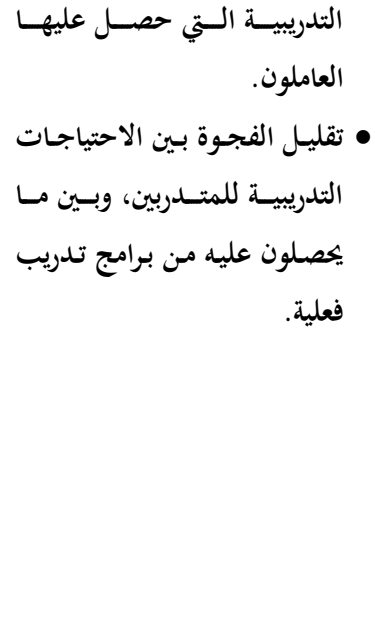 & 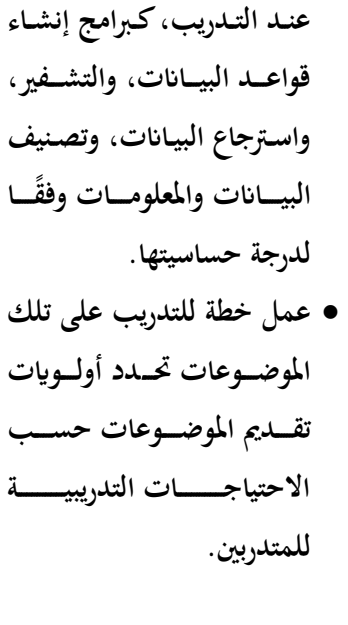 & 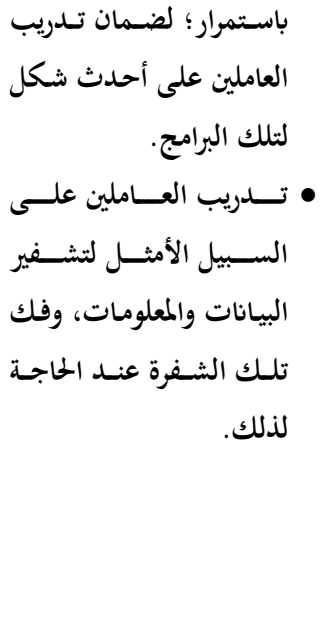 & 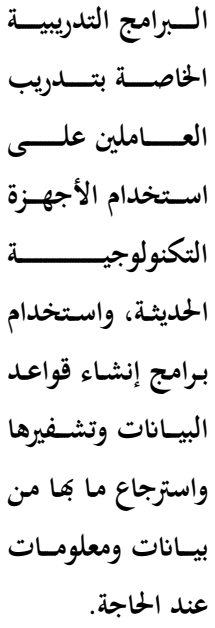 \\
\hline
\end{tabular}

الغاية الخامسة:(دعم الثقافة التنظيمية للعاملين في المدرسة الثانوية الصناعية عن أهية المعلومات، ومن ثم إدارة عمليات

الأمن المعلوماتي)

\begin{tabular}{|c|c|c|c|c|c|}
\hline المقلمتي & مسئولية التنفيذ & مؤشرات الإنجاز & أنشطة التنفيذ & الأهداف الإجرائية & الأهداف الإستراتيجية \\
\hline & • • • • • • & • تعامـــل العـــاملين في & 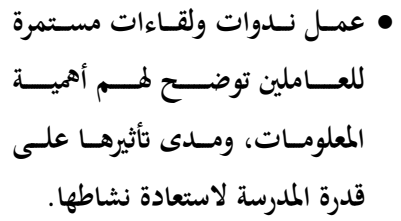 & • • توفير فرص للمناقشة والحوار بين مدير الملدرسة & 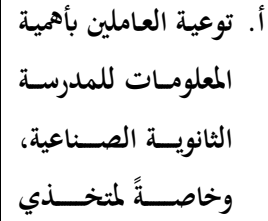 \\
\hline
\end{tabular}




\begin{tabular}{|c|c|c|c|c|c|}
\hline 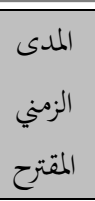 & مسئولية التنفيذ & مؤشرات الإنجاز & أنشطة التنفيذ & الأهداف الإجرائية & الأهداف الإستراتيجية \\
\hline مستمر & 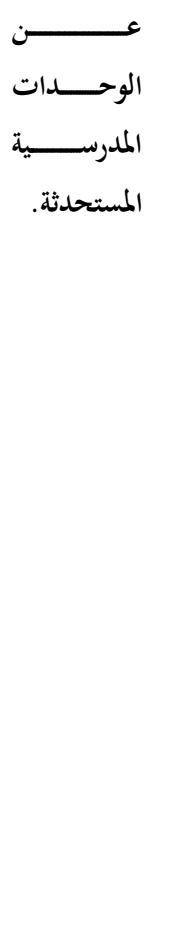 & 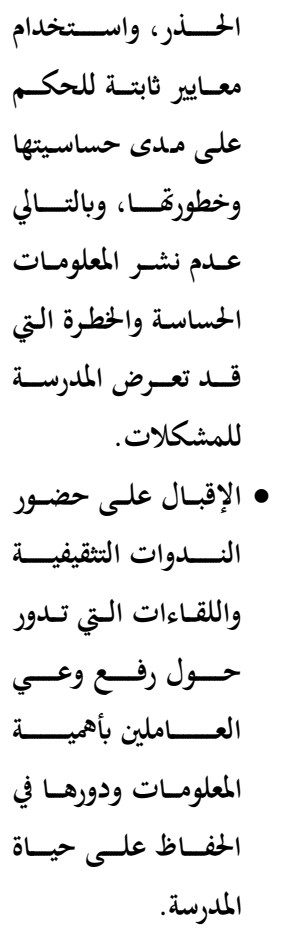 & 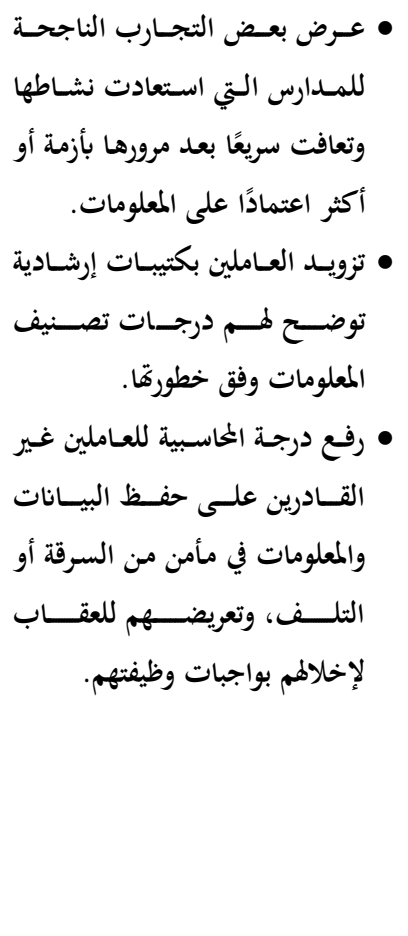 & 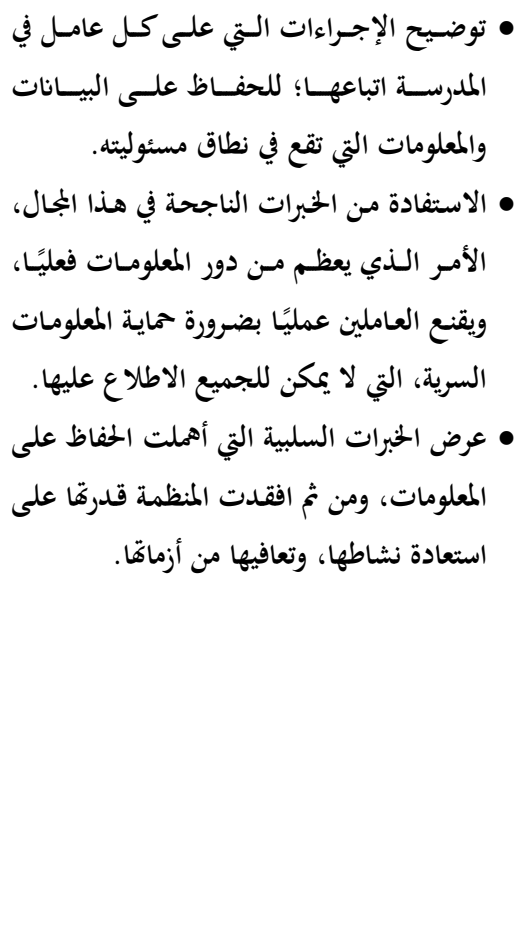 & 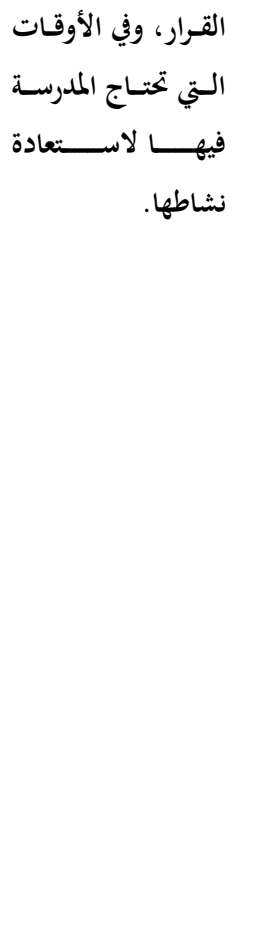 \\
\hline & • • • • • • وزارة التربيسة & • • زيادة مشـاركة العـاملين & • • • ــريع القوانين التي من شأفما تفعيل & 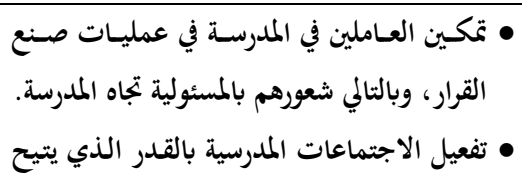 & بـ بـ ـ دعم ولاء العاملين \\
\hline
\end{tabular}




\begin{tabular}{|c|c|c|c|c|c|}
\hline المالمندى & مسئولية التنفيذ & مؤشرات الإنجاز & أنشطة التنفيذ & الأهداف الإجرائية & الأهداف الإستراتيجية \\
\hline مستمر & 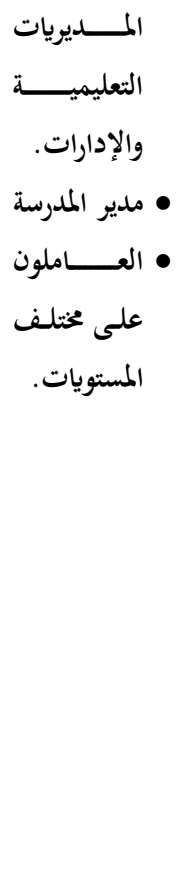 & 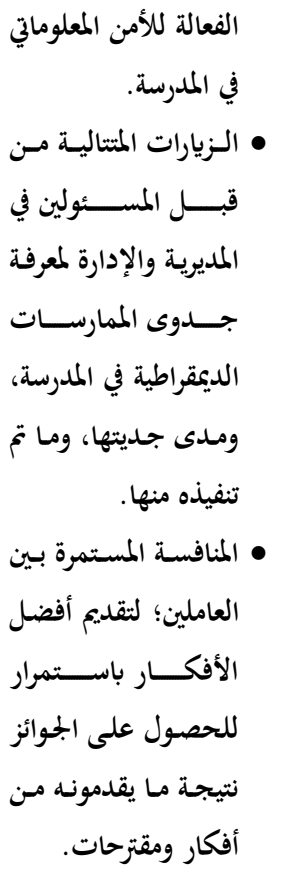 & 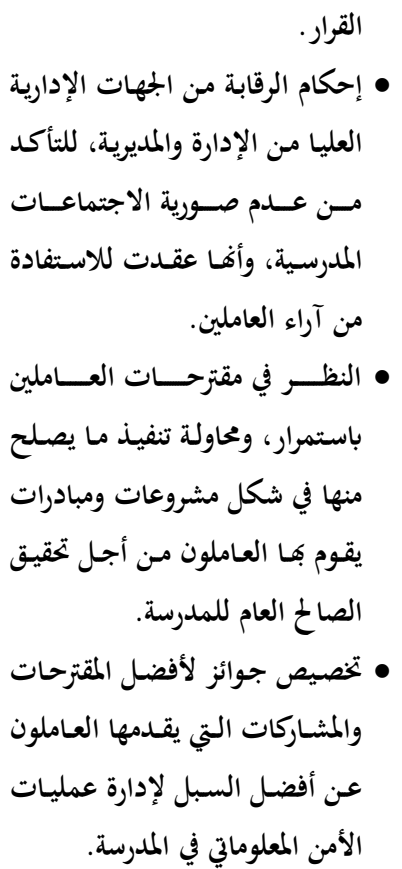 & 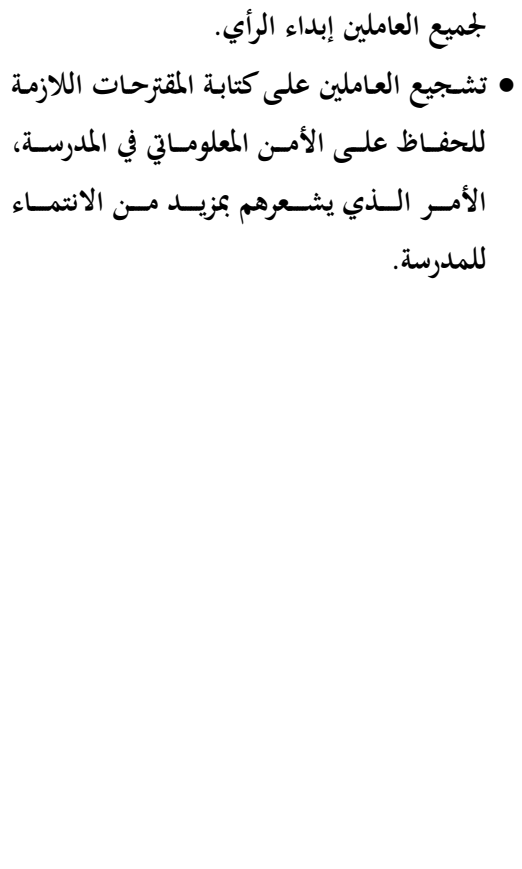 & 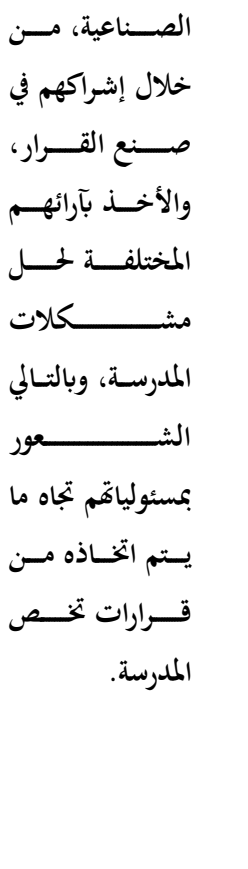 \\
\hline
\end{tabular}




\section{6. متطلبات تنفيذ الإستراتيجية المقترحة.}

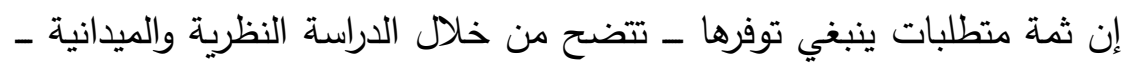
لتطبيق الإستراتيجية لإدارة عمليات الأمن المعلوماتي في المدرسة الثانوية الصناعية لتصنية

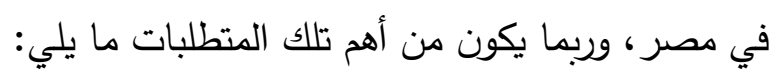
توفير التمويل اللازم لتجهيز مدارس التعليم الثانوي الصناعي بما تحتاج إليه لـانيه من تجهيزات، وأجهزة، وبرمجيات حديثة.

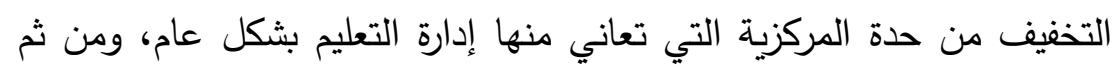

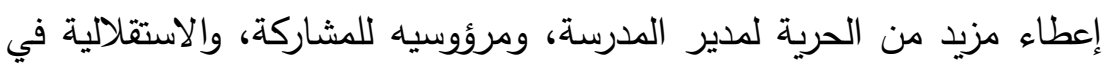
التخطيط، وصناعة القرارات التي تخص الحفاظ على المعلومات التي تمتلكها

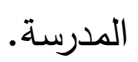

وعي مدير المدرسة الثانوية الصناعية، والمعلمين والإداريين بأهمية المعلومات، وأمنها، والحفاظ عليها، واستخدامها في استعادة نشاط المدرسة بعد تعرضها للمشكلات والأزمات. ضرورة توفير البنية التحتية اللازمة للحفاظ على المعلومات، والتنويع بين سياسات الحفاظ على أمن المعلومات لتوفير أكثر من فرصة وأكثر من طريقة للحفاظ على المعلومات واستخدامها وقت الحاجة.

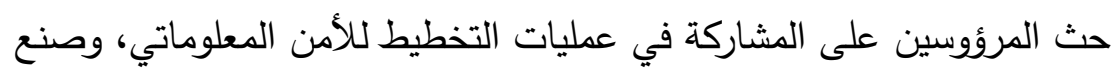

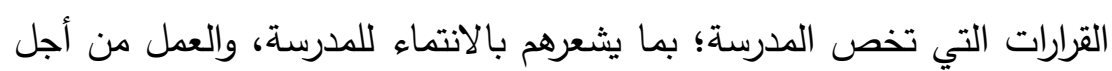

$$
\text { صالحها العام. }
$$

إعداد قاعدة بيانات شاملة عن أهم الجهات التي يمكن التواصل معها أثناء حدوث الأزمات؛ وذلك استعدادًا للأزمات قبل حدوثها، على أن يتم مراجعة تلك لكانك البيانات، والالتزام بتحديثها باستمرار •

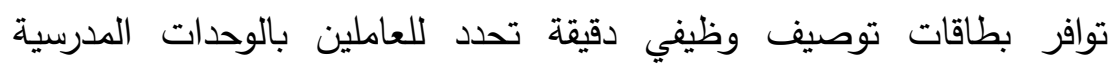

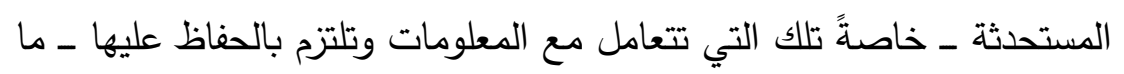
يجب عليهم القيام به عند القيام بحفظ البيانات والمعلومات وتخزينها تخزينًا آمنًا يحميها من السرقة أو التلف. بهان. 
التدريب المستمر للعاملين في قطاع المعلومات على تصنيف المعلومات وفقًا لخطورتها، ومعرفة أي المعلومات يمكن الإفصاح عنه، وأيها يجب تخدين تخلينه والاحتفاظ به لحين حاجة المدرسة إليه. تدريب العاملين في قطاع المعلومات على التعامل مع البرمجيات الحديثة التي تتعامل مع حفظ المعلومات، وتشفيرها، واستعادتها وقت الحاجة إليها.

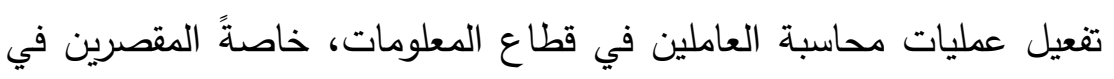
الحفاظ على أمن المعلومات، وفي حالة تسرب المعلومات التي تقع في نطاق مسئولياتهم.

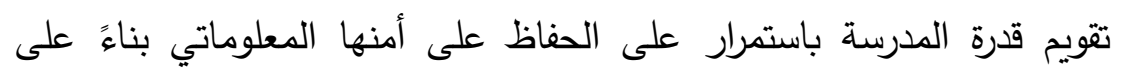

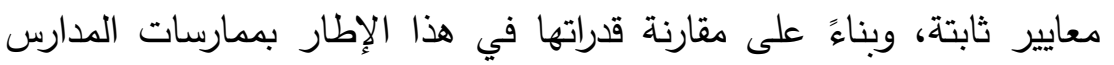
الأفضل التي استطاعت الحفاظ على أمنها المعلوماتي محليًا ودوليًا. الاهتمام بالتسيق المستمر بين وزارة التربية والتعليم وباقي الوزارات والقطاعات التعات التهاتي

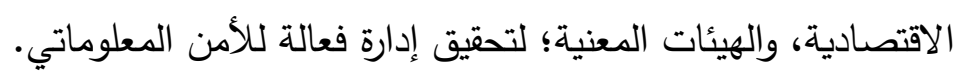
سابعًا معوقات تنفيذ الإستراتيجية المقترحة وسبل مواجهتها: توصلت الدراسة النظرية والميدانية لعدد من الصعوبات التي قد تعوق تتفيذ

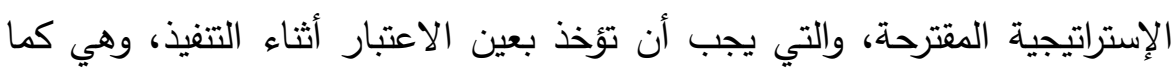

ضعف البنية التحتية والتجهيزات الموجودة في المدرسة الثانوية الصناعية، وللتغلب على ذلك يمكن الاستعانة بمصادر تمويل إضافية، مثل: المساعدات التي تقدمها القطاعات الاقتصادية كالشركات والمصانع، في هيئة برامج تدريبية

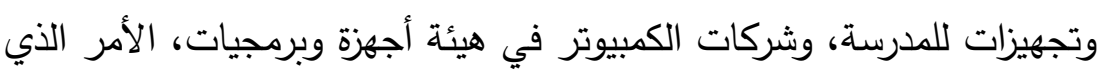
يتطلب مزيدًا من التنسيق بين تلك الجهات وبعضها.

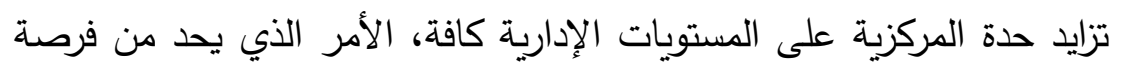

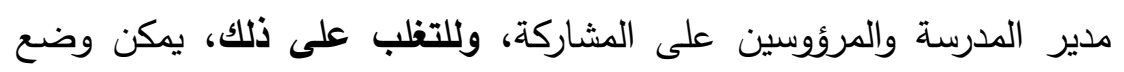
عدد من التشريعات التي تعطي لمدير المدرسة ومرؤوسيه فرصة لإدارة مدرستهم ذاتيًا، الأمر الذي يتيح لهم الفرصة على المشاركة وإشراك العاملين

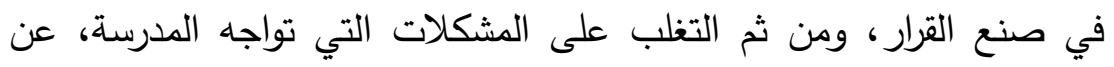
طريق الحفاظ على البيانات والمعلومات. 
ضعف دراية العاملين بأهية المعلومات وأهمية الحفاظ عليها؛ مما يجعلها عرضة للتلف أو السرقة، ويمكن التفلب على ذلك من خلال تقديم عدد من بن

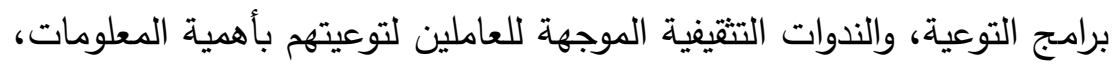
ومخاطر تسربها.

ضعف قدرة قواعد البيانات الموجودة في المدرسة عن أهم الهيئات وجهات

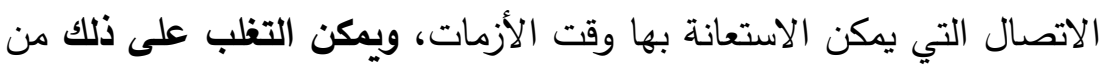
خلال الاهتمام بالحصول على برمجيات إنشاء قواعد البيانات، وتدريب الابل

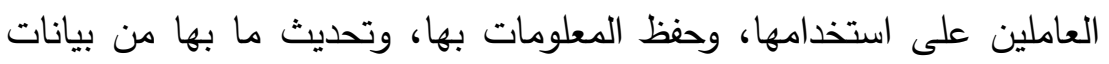

$$
\text { ومعلومات باستمرار - ولمان. }
$$

ضعف الحماية والتأمين اللازمين للبيانات والمعلومات الخاصة في المدرسة من ون السرقة، ويمكن التفلب على ذلك من خلال تأمين الحجرات التي تحوي الأجهزة

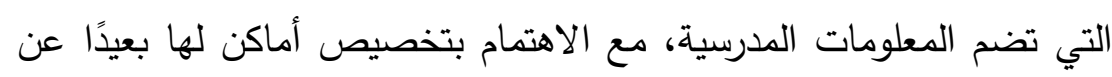

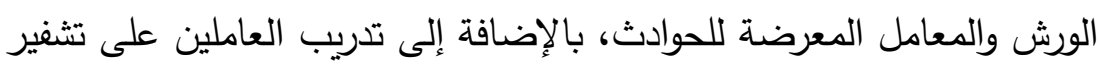

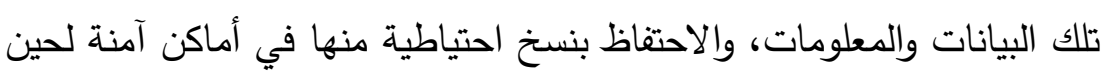

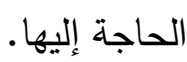

تركيز معظم برامج التدريب الموجهة للعاملين في المدرسة الثانوية الصناعية على الجوانب النظرية، دون الاهتمام بربط النظرية بالتطبيق، ويمكن التفلب

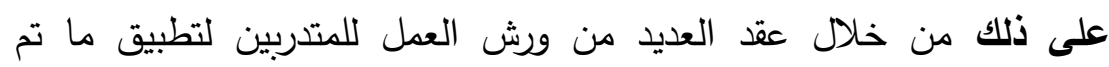
الحصول عليه بشكل نظري عمليًا؛ وذلك لتشجيعهم على التنفيذ الفعلي لما ورد في البرنامج التدريبي بعد العودة إلى المدرسة، لأداء مهامهم الوظيفية.

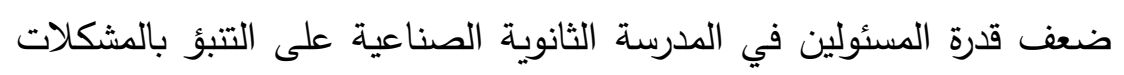

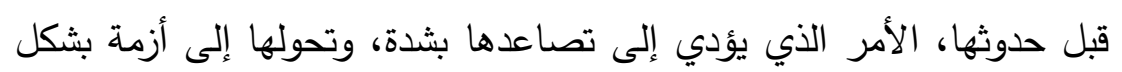

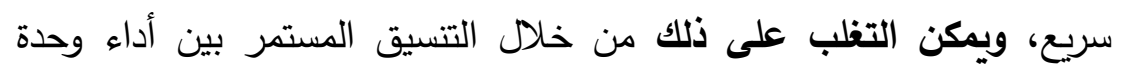
الأزمات من ناحية، ووحدة المعلومات والإحصاء من ناحية أخرى، لإحداث التكامل الذي يؤدي إلى توقع أفضل للمشكلات، وتلافي الأزمات التي قد تهدد قدرة المدرسة على تقديم خدماتها التعليمية. قلة عقود الصيانة الموجودة بين المدارس الثانوية الصناعية والثركات التي من

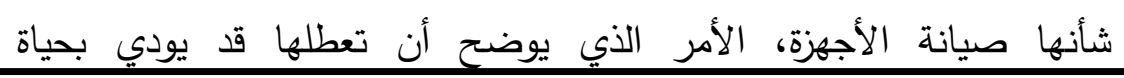
العدد الثاني عشر - مارس 2017 
المعلومات، ويؤدي إلى فسادها، ويمكن التغلب على ذلك من خلال عقد مزيد من عقود الشراكة بين المدارس الثانوية الصناعية، والشركات المنوط بها تقديم

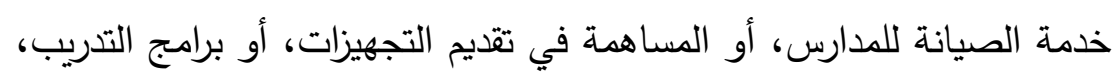

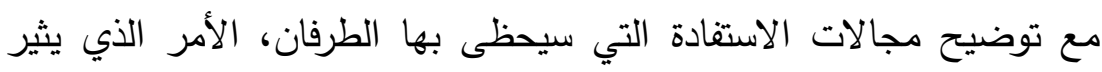
حماسة كل طرف في تنفيذ بنود الشراكة.

خلاصة:

في إطار البحث الحالي تم التوصل إلى إستراتيجية مقترحة لإدارة عمليات

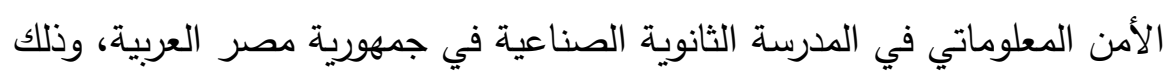
باستخدام أسلوب التحليل الرباعي، الذي اعتمد على تحليل البيئة الداخلية، ومعرفة نقاط القوة والضعف، وتحليل البيئة الخارجية من خلال معرفة الفرص والتهديدات؛ وذلك للتوصل لإدارة فعالة لعمليات الأمن المعلوماتي، والقدرة على استغلال المعلومات وقت الحاجة إليها، على اعتبار أنها المخزون الذي تستطيع الددرسة الإدية الاعتماد عليه، خاصةً وقت تعافيها من الأزمات التي قد تتعرض إلهات لها. 


\section{مراجح البحث}

( $\left.{ }^{1}\right)$ Ministry of Public Safety and Solicitor General, (2006), Disaster Recovery: Provincial Emergency Program, British Colombia, Ministry of Public Safety and Solicitor General, P. 1.1.

(2 ) Michael K.Lindell, (2013), Recovery and Reconstruction after Disaster, In, P.T. Bobrowsky, Encyclopedia of Natural Hazards, Vol., XLI England, Springer Publications, P.812.

وزارة التربية والتعليم، (2014) الخطة الإستراتيجية للتعليم قبل الجامعي

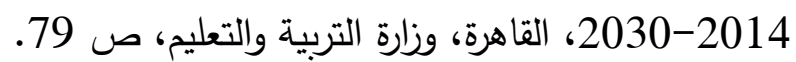

(4) وزارة التربية والتعليم، (2013)، برنامج تطوير التعليم الفني بالتعاون مع وزارة

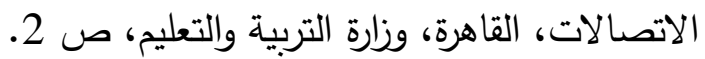

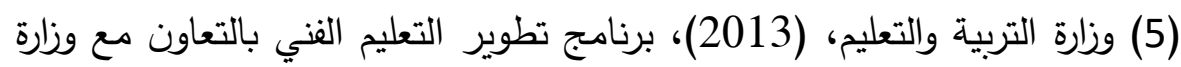

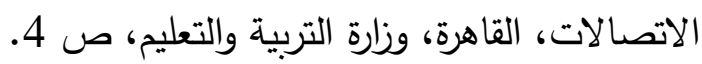

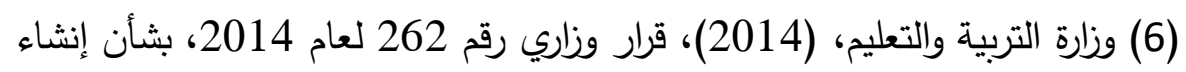

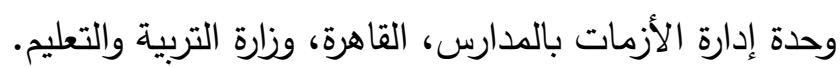

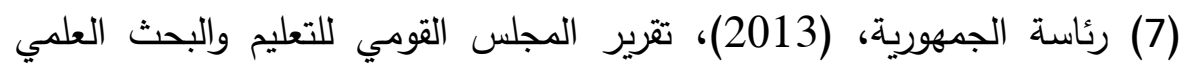

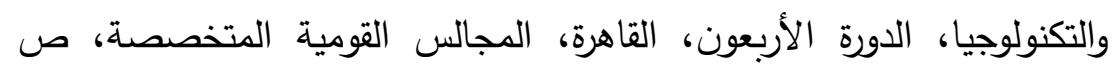

وزارة الاتصالات وتكنولوجيا المعلومات، (2012) الإستراتيجية القومية

للاتصالات وتكنولوجيا المعلومات 2012-2017: المجتمع المصري الرقمي الإنيات في ظل اقتصاد المعرفة، جمهورية مصر العربية، الإدارة المركزية للبحوث والسياسات والتخطيط الاستراتيجي، ص

(9) محمد جمال الدين درويش، (2009) مصر ومجتمع المعلومات، القاهرة،

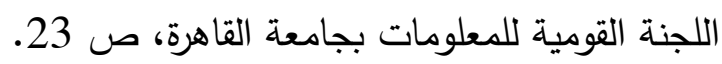

$$
\text { (10) (المرجع السابق، ص } 23
$$


(11) عماد ثروت محمد رضوان، (2009) السلوك القيادي لمديري المدارس

الثانوية الصناعية بمصر في التعامل مع الأزمات المدرسية: تصور مقترح،

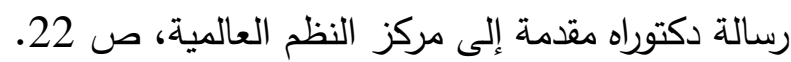

(12) نهلة عبد القادر هاشم، وإيمان زغلول راغب، (2007) "الإدارة المفتوحة

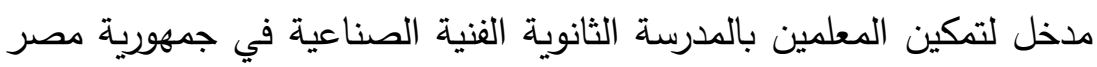

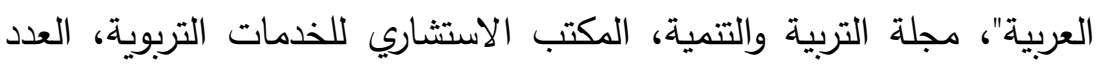

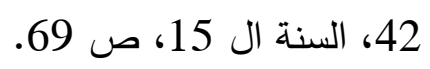

(13 ) RamziKamelHannaallah, Michael Takla, (1998) Dictionary of the Terms of Education, Beiruit, Librairie du Liban Publishers, P.211.

$\left({ }^{14}\right)$ Richard Kissel, (2013), Glossary of Key Information Security Terms, U.S.A, National Institute of Standards and Technology, P.94.

(15 ) Information Systems Audit and Control Association, (2015) ISACA Glossary of Terms, U.S.A, Information Systems Audit and Control Association, P.49.

(16) Tom Carlson, Information Security Management, (2002), USA, International Network Services Inc, P.9.

(17 ) Prasanna Ramakrishnan, (2003) Information Security Management Systems, North America, Federal Energy Regulatory commission, P.1.

(18 ) Gary R. Lomprey,(2008) Critical Elements of an Information Security Management Strategy, Presented to the Interdisciplinary Studies Program: Applied Information Management and the Graduate School of the University of Oregon in Partial Fulfillment of the Requirement for the 
Degree of Master of Science, Portland, University of

Oregon, Applied Information Management Program, P.18.

(19) RadhaBalamuralikrishna, and JhonC.Dugger,(2003) SWOT Analysis: A Managing Tool for Imitating New Programs in Vocational Schools, London, Person Education Limited, P.P. 185-187.

(20) Board of Studies, Industrial Technology, (2003), New South Wales, Board of Studies, P.11.

(21) Jethro Perkins, (2014) Information Security Policy, London: London School of Economics \& Political Science IT Services, P.2.

(22) Ibid, P.P.17-18

(23) Education Bureau, (2007) the Government of the HKSAR: Information Technology in Education Project, IT Security In Schools, (HK, Education Bureau P.P.23-26.

(24) Janet Reno and Others, (2008) The Appropriate and Effective Use of Security Technologies in U.S. Schools: A Guide for Schools and Law Enforcement Agencies, Washington, U.S. Department of Justice, P.26.

(25) John N. Stewart, (2013), School Information Security, New Jerrcy, Executive Thought Leadership Center, P.2.

(26) DanchoDanchev, (2003), Building and Implementing a Successful Information Security Policy, Windows Security Resource for IT Admins, London, Internet Software Marketing, P.P.12-15 
(27) Jethro Perkins, (2013) Policy Electronic Messaging Policy, London, London School of Economics \& Political Science IT Services, P.P.9-12.

(28) BundesamtfürSicherheit in der Information stechnik,(2008), Information Security Management System ,Version 1.5 Bonn, BundesamtfürSicherheit in der Informationstechnik, P.P.16-17.

(29) Ibid, P.P 18-19.

(30) Geoff Whitty, (2013), Information Security Management Policy, London, London Institute of Education, P.10.

(31) Moses Moyo, (2014), Information Security Risk Management in Small--Scale Organizations: A Case Study of Secondary Schools ${ }^{e e}$ Computerized Information System, submitted in Accordance with the Requirements for the Degree of MA, at University of South Africa, P.51.

(32) Malik Saleh, (2011), "The Three Dimensions of Security", In International Journal of Security, Volume 5, Issue 2, P.P.87-88.

(33 ) T Grobler, and Von Solms, (2005), Assessing the Policy Dimension, Johannesburg: Standard Bank Academy of Information Technology, P.6.

(34) Ibid, P.8.

(35) Ibid, P.6.

(36 ) Malik Saleh, Op.Cit, P.P.88, 90.

(37) At. Kearaney, (2015), Information Technology: It's all about Trust, Koera, At Kearaney Organization, P.P.5-6. 
(38) Ali Maqousi and Others, (2013), An Effective Method for Information Security Awareness Raising Initiatives, International Journal of Computer Science \& Information Technology (IJCSIT) Vol 5, No 2, P.65.

(39) Hussain A.H. Awad and Fadi M. Battah,(2011), Enhancing Information Systems Security in EducationalHl Organizations in KSA throughproposing security model, International Journal of ComputerScience Issues, Vol. 8, Issue 5, No 3, P.356.

(40) Jason Taule and Others, (2014), Building an Information Security Organization, Dave Summit, Chief Information Security Officer, University of Alabama at Birmingham Health System, Building Security Program, P.6.

(41) Kenneth Høstland and Others, (2010) Information Security Policy: Best Practice Document, Norway, UNINETT led Working Group, P.P 24-25.

(42) Alex Fagerström, (2013), Creating, Maintaining and Managing an Information Security Culture, Degree Thesis, Information and Media Technology Department, Arcada, P.14.

(43 ) Information Systems Audit and Control Association,(2005), Critical Elements of Information Security Program Success, United States of America, Information Systems Audit and Control Association, P. 8.

(44) Ibid, P. 9. 
(45) Information Security Policy Council, (2010), The First National Strategy on Information Security, Tokyo: Information Security Policy Council, P.P. 32-33.

(46) Information Security Board of Review Members,(2011), Information Security Plan, Michigan Technological University, Michigan, Michigan Technological University,P.P 23-25

(47) Virginia Department of Education, (2012), Model School Crisis Management Plan, Virginia: Division of Special Education and Student Services, P.71.

(48 ) Ibid, P. 74

(49) W. Timothy Coombs,(2007), Crisis Management and Communication, $\mathrm{PhD}$ Presented at Faculty of Education, Department of Education Foundation, Boston University, P.14.

(50) Massachusetts Department of Elementary and Secondary Education, Career/Vocational Technical Education,(2016), Massachusetts, Massachusetts Department of Elementary and Secondary Education, P.P 31-35

(51) AliMaqousi and Others, (2013), An Effective Method for Information Security Awareness Raising Initiative, International Journal of Computer Science \& Information Technology (IJCSIT) Vol.,5, No 2, P.67.

(52) Information System Security Association (ISSA), Available:www.issa.org, (Accessed: 14-2-2016) 
(53) The Information Systems Audit and Control Association (ISACA) Available: http://www.isaca.org (Accessed: 7-102016)

(54) The System Administration, Networking, and Security Institute (SANS), Available: http:// www.sans.org (Accessed: 7-10- 2016)

(55 ) Frost \& Sullivan, (2011), The 2011 Global Information Security Workforce Study, Geneva: A Frost\& Sullivan Market Survey, P.20.

(56 ) Security Awareness Program, (2014) Information Supplement: Best Practices for Implementing a Security Awareness Program, Special Interest Group PCI Security Standards Council, P.7.

(57 ) Joint Universities Computer Centre Limited ("JUCC"), (2009) Information Security-Perspective for Management Information Security Management Program -Concept and Implementation, Information Security Awareness TrainingSession One, Hong Kong, P.8.

(58) Gary R. Lomprey,(2008), Critical Elements of an Information Security Management Strategy, Presented to the Interdisciplinary Studies Program: Applied Information Management and the Graduate School of the University of Oregon in partial fulfillment of the requirement for the degree of Master of Science, P.66. 
(59) Benjamin Wright, (2009)," Employment, Trends, and Training in Information Security", Occupational Outlook Quarterly, P.P. 37-38

(60) Eric Henault, (2016), Master Class Cycle on Information Security Management, EU: European Technical School Union, P.P.2-3.

(61) Kathryn Parsons and Others, (2013), Human Factors and Information Security: Individual, Culture and Security Environment, Australia, Defense Science Technology Organization, P.35.

(62 ) Alex Fagerström, Creating, Maintaining and Managing an Information Security Culture, Op.Cit, p.20

(63) Tom Carlson, (2001), Information Security Management: Understanding ISO 17799, London, International Network Services,P.P.8-10

(64) Tom Carlson, (2002) Information Security Management: Understanding ISO 17799, Washington: International Network Services, P.P.7-9

(65 ) Ohio Department of Education, (2013), Information Technology Career Field Technical Content Standard, Ohio, Department of Education, P.P. 20-25.

(66) وزارة التربية والتعليم، الرؤية المستقبلية لسياسة التعليم قبل الجامعي Available: $\quad$ http://knowledge.moe.gov.eg/arabic/

(Accessed: 13-8-2016)

(67) وزارة التربية والتعليم، قطاع التعليم الفني، الأهداف العامة للتعليم الفني، Available: 
http://portal.moe.gov.eg/Aboutministery/Departments/tech nical/pages/aims.aspsx (Accessed: 13-8-2016) (68) هناء شحتة السيد مندور، (2010) " تطوير النمط القيادي لمديري المدارس

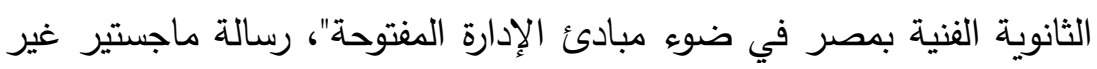

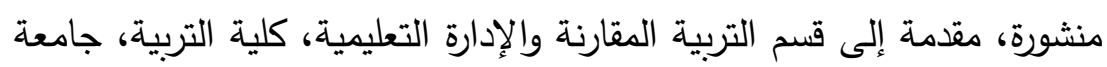

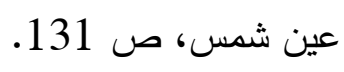

(69) وزارة التربية والتعليم، الخطة الاستراتيجية للتعليم قبل الجامعي 2014-

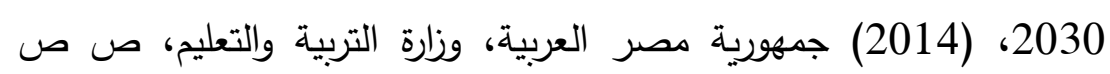
$.78-77$

(70) البوابة المصرية للتعليم الفني، مشروع تطوير التعليم الفني باستخدام تكنولوجيا Available: المعلومات والاتصالات http:fany.moe.gov.eg/forums Accessed (13-7-2016) (71) وزارة التربية والتعليم، (2002)، قرار وزاري رقم 99 بتاريخ 6/8/ 2002،

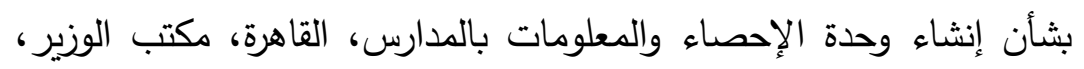
مادة 1. (72) (المرجع السابق، مادة 2. (73) المرجع السابق، مادة 3.

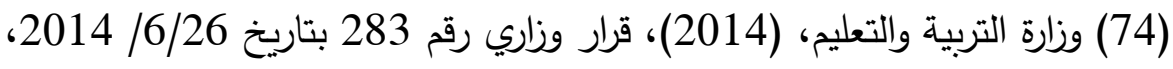

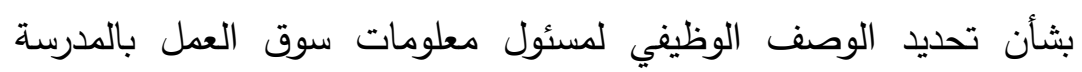
الثانوية الفنية، القاهرة، مكتب الوزير، مادة 1، 2

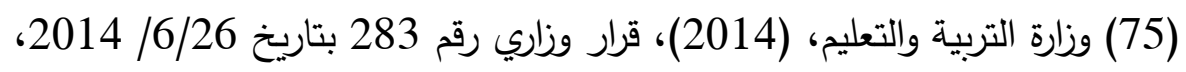
بثأن تحديد الوصف الوظيفي لمسئول التوظيف بالمدرسة الثانوية الفنية، ولردا،

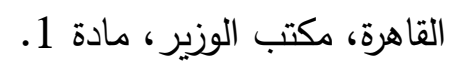

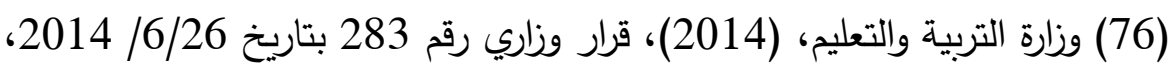

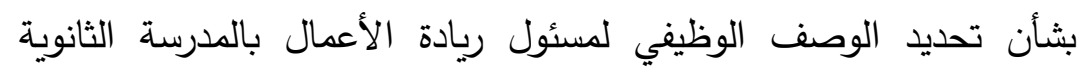
الفنية، القاهرة، مكتب الوزير، مادة 1، 2. 
(77) وزارة التربية والتعليم، (2014)، قرار وزاري رقم 283 بتاريخ 20/26/ 2014، بثأن تحديد الوصف الوظيفي لمسئول الإرشاد والتوجيه المهني بالمدرسة ولتها الثانوية الفنية، القاهرة، مكتب الوزير ، مادة 1، 2. (78) يسري طه دنيور، (2015)، آليات التوسع في التعليم الفني في ضوده احتياجات سوق العمل (تصور مقترح)، القاهرة، المركز القومي للبحوث التربوية والتنمية، ص 16.

(79) يسرى طه دنيور ، (2014)، تقويم البرامج التدريبية لمعلمي التعليم الفني في

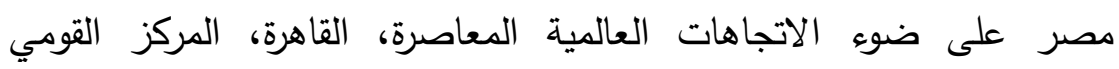

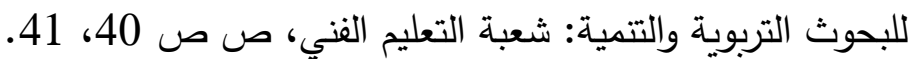
(80) يسري طه دنيور، (2014)، مشكلات بعض المدارس الثانوية الفنية في مصر ومقترحات حلها، القاهرة، المركز القومي للبحوث التربوية والتتمية: شعبة

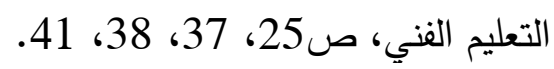
(81) ناجي شنودة نخلة، (2013) تفعيل جهود الجهات الداعمة للتعليم الفني " دراسة ميدانية"، القاهرة، المركز القومي للبحوث التربوية والتتمية: شعبة

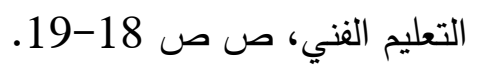

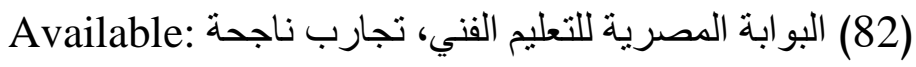
http:fany.moe.gov.eg/sucessfulExperiments Accessed (13-7-2016)

(83) وزارة الاتصالات وتكنولوجيا المعلومات، مرجع سابق، ص 19.

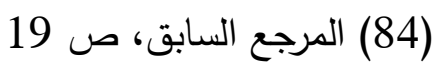
(85) رئاسة مجلس الوزراء قانون جهاز أمن المعلومات ومكافحة جرائم الاتصالات، (2015)، جمهورية مصر العربية، وزارة الاتصالات، المادة السادسة.

(86) معهد اليونسكو للإحصاء، منظمة الأمم المتحدة للتربية والثقافة والعلوم، دئ

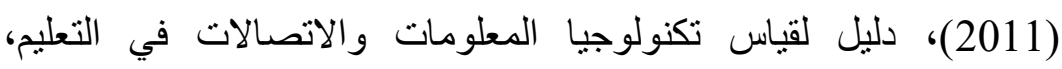

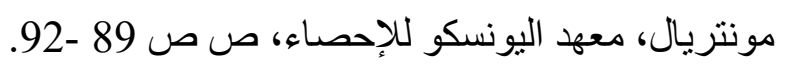

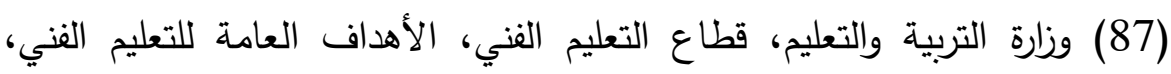
Available: 
http://portal.moe.gov.eg/Aboutministery/Departments/tec hnical/pages/conferences.aspsx (Accessed: 13-8-2016) (88) وزارة التربية والتعليم، قطاع التعليم الفني، الأهداف العامة للتعليم الفني،

Available:

http://portal.moe.gov.eg/Aboutministery/Departments/technical/ pages/techconf2.aspsx (Accessed: 13-8-2016) (89) اليونسكو، تقرير التعليم للجميع في مصر (2000-2015)، (2014)،

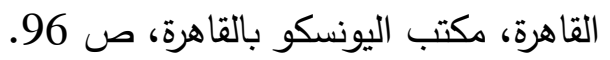

$$
\text { (90) المرجع السابق، ص ص صن 106-107) }
$$

(92) عبدالخالق يوسف سعد، (2009)، استخدام تكنولوجيا المعلومات

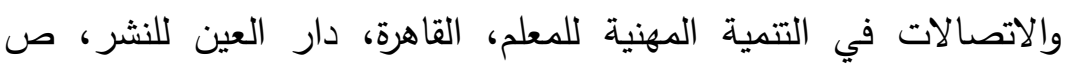
.101

(93) يسري طه دنيور، تقويم البرامج التدريبية لمعلمي التعليم الفني في مصر على

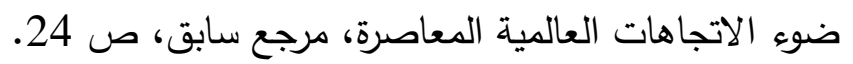

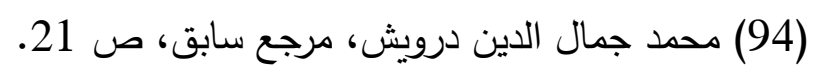

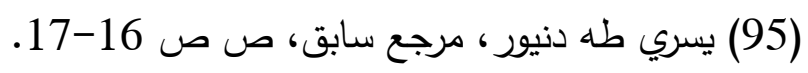
(96) السيد أحمد عبد الغفار، (2010)، دور التعليم الثانوي الفني في مواجهة تحديات بناء الاقتصاد المعرفي، القاهرة، المركز القومي للبحوث التربوية لتعاية والتتمية: شعبة التعليم الفني، ص 28. (100) محمود محمد الهادي (1995)، أساليب إعداد وتوثيق البحوث العلمية،

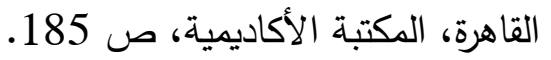

(101) Milorad M. Novicevic et al (2004): Dual Perspective SWOT: a Synthesis of Marketing Intelligence and Planning. Marketing Intelligence and Planning, Vol. 22, No. 1, p. 89. 
